\title{
Trophic Interactions of Marine Sponges
}

\section{Charlotte Lucy Mortimer}

\author{
A thesis submitted to the Victoria University of Wellington \\ in fulfilment of the requirements for the degree of
}

Doctor of Philosophy

\section{VICTORIA \\ UNIVERSITY \\ WELLINGTON}

TE WHARE WĀNANGA

O TE ÜPOKO O TE IKA A MĀUI

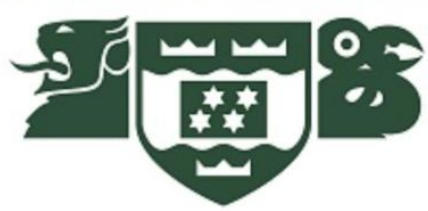





\section{Thesis abstract}

Marine communities in the Anthropocene are changing rapidly with potentially severe consequences for ecosystem functioning. Recently, there has been increased interest in the ecological role of sponges, particularly on coral reefs, driven by evidence that sponges may be less affected by this period of environmental change than other benthic organisms. The Sampela reef system in the Wakatobi Marine National Park, Indonesia, is an example of a reef that has shifted to sponge dominance following a decline in hard corals and an increase in sponge density. Previous research suggests that the Sampela reef system may support a greater abundance of spongivorous fishes relative to surrounding reefs, however, uncertainties remain regarding spongivore identity and predated sponges. In addition, little is known about how shifts towards sponge dominance affect the trophic structure of reefs. The primary aim of my thesis was to investigate sponge trophic interactions to gain insight into the way spongedominated reefs of the future might function. This information is essential to predict the broader functional consequences of increasing sponge dominance on reefs in the Anthropocene.

In my first data chapter, I measured the functional impact of spongivorous fishes by quantifying sponge biomass consumption on Wakatobi reefs. Video analysis identified 33 species from 10 families of reef fish grazing on Xestospongia spp., although $95 \%$ of bites were taken by only 11 species. Gut content analysis indicated that Pygoplites diacanthus and Pomacanthus imperator were obligate spongivores and Pomacanthus xanthometopon, Zanclus cornutus and Siganus punctatus regularly consumed sponges. In situ feeding observations revealed that sponges from the family Petrosiidae are preferred by $P$. diacanthus and $Z$. cornutus. Spongivores were estimated to consume $46.6 \pm 18.3 \mathrm{~g}$ sponge $1000 \mathrm{~m}^{-2}$ of reef day ${ }^{-1}$ and $P$. diacanthus had the greatest predatory impact on sponges. While estimates provided here are conservative and likely underestimate the true magnitude of spongivory on IndoPacific coral reefs, this chapter provides the first known estimate of reef wide sponge biomass consumption. Comparisons with published data estimating coral consumption by Chaetodontids in the Pacific suggests that biomass transferred through both pathways is similar in magnitude. Hence spongivory is an important, yet overlooked, trophic pathway on Indo-Pacific reefs.

In my second data chapter, I developed genetic methods to identify sponges from the stomach contents of spongivorous angelfishes sampled in my first chapter. A range of primers and associated predatorblocking primers targeting the 18S rDNA gene were designed and tested on extracts of sponge and spongivore DNA. Sequences were successfully amplified from 14 sponges spanning 6 orders of Porifera, with the majority of samples identified belonging to the order Haplosclerida. This study is the first to successfully sequence sponges from the gut contents of spongivorous fishes. Sequence data indicated that Pygoplites diacanthus consumed sponges with considerable chemical defences and 
exhibited significant dietary plasticity within the Porifera phylum, similar to observations of angelfishes in the Caribbean and the eastern Pacific.

In my third data chapter, I used stable isotope analysis to investigate differences in consumer niche widths and trophic diversity on the sponge-dominated Sampela reef system in comparison to an adjacent, higher quality reef. I measured the stable isotope ratios of coral reef fish representing different functional feeding groups, prey items and basal carbon sources at both sites. I used isotope data to calculate the trophic position and isotopic niches of each species and performed interspecific and intersite comparisons. The fish assemblage had a significantly lower mean trophic position at the spongedominated site and the majority of species had wider isotopic niches, in accordance with optimal foraging theory which supports expansion in niche widths when per capita prey is low. The fish assemblage sampled at the sponge-dominated site used a significantly lower range of resources, had lower trophic diversity and obtained more carbon from benthic production than fish from the higher quality reef site. Results indicate a simpler trophic structure at the sponge-dominated site characterised by fish with more similar diets. Whilst trophic niche expansion may facilitate population survival in the short term, it can be expected to lead to intensified competition for increasingly scarce resources.

In my final data chapter, I investigated niche partitioning and organic matter contributions to cooccurring temperate sponges. I sampled the stable isotope ratios of five abundant sponge species at $10 \mathrm{~m}$ and $30 \mathrm{~m}$ at two sites at opposing ends of Doubtful Sound, Fiordland. I also used an ROV to opportunistically sample sponges at depths $>50 \mathrm{~m}$ and measured stable isotope ratios of picoplankton ( $<2 \mu \mathrm{m}$ size phytoplankton), the 2-200 $\mu \mathrm{m}$ fraction of the water column, macroalgae and terrestrial organic matter (TOM), and used isotope mixing models to estimate the contribution of carbon sources to sponge species. Sponges displayed a wide range of $\delta^{15} \mathrm{~N}$ values spanning two trophic levels and spatial variation in sponge stable isotope ratios was not reflected by water column resources. There was a high degree of interspecific resource partitioning and comparisons of isotopic niche size suggested more diverse resource use at the Outer Fiord site for Axinella richardsoni, Cymbastela tricalyciformis and Raspailia topsenti. Surprisingly, isotopic mixing models indicated that picoplankton was not a significant carbon source for sponges, which could not be easily explained but may relate to the degradation of dissolved TOM by heterotrophic bacteria. This study found that differential use of the 2-200 $\mu \mathrm{m}$ fraction of the water column and macroalgal derived OM supports the majority of sponges in Fiordland. However, terrestrial production may support some sponges via microbial pathways where marine production is limited.

In summary, species identity and angelfish foraging strategies in the Wakatobi Marine National Park were consistent with known global patterns of spongivory. Observations of feeding behaviour suggested that alternative trophic pathways involving sponge mucus or sponge detritus may also be important for 
upper trophic levels. Low densities of spongivores at the Sampela reef system indicate that spongivores may not necessarily benefit from shifts to sponge-dominance that result in low diversity sponge assemblages dominated by one or two competitive species. Whilst sponge consumption may be an important and overlooked trophic pathway on Indo-Pacific reefs, observations from the Sampela reef system demonstrate that the range of trophic pathways originating from the base of the food web is important for maintaining trophic complexity. Hence, sponge-dominated reefs resulting from a decline in corals relative to sponges are less productive and ultimately less stable than coral-dominated reefs. 


\section{Acknowledgements}

I would like to thank my primary academic supervisor Professor James Bell for his guidance, for keeping me on track during challenging times and for putting up with me for a year longer than anticipated. Being one of James' students has taken me to some wonderful places and I have treasured our research group field trips, which allowed me to learn new skills alongside some fantastic people. I would also like to thank my secondary academic supervisor Dr Matt Dunn for constructive feedback on my thesis and some great chats in the early stages of my PhD. Thanks also go to Sarah Bury for her invaluable technical expertise, emotional support and extensive and constructive feedback on my writing.

I am very thankful for the Commonwealth Scholarship and the Victoria Doctoral Submission Scholarship which have funded me during my thesis. Thanks also go to the PADI Foundation for supporting the stable isotope research in Indonesia and to Prof. Jamal Jompa and Prof. Abdul Haris at Hasanuddin University for facilitating this research. Thanks to Operation Wallacea for their funding associated with my fieldwork in Indonesia, covering travel expenses, diving, food and accommodation. I would particularly like to thank Pippa and Ro for their hard work and effective management of the Hoga Island Research station, and to the Indonesian staff for being truly instrumental in the running of Hoga Island.

I am indebted to the team at NIWA: Josette, Julie and Anna, who took me on as one of the team and spent their valuable time teaching me how to process stable isotope samples. Also, to the Department of Conservation team on the MV Southern Winds: Rich, Chris, Ross and Chloe, I cannot thank you enough for the diving, water sampling and the wonderful food that helped me to complete my final chapter. I owe a big debt of gratitude to Irina and Meg for their patience in teaching me molecular techniques and to Maren for helping me to troubleshoot PCR problems. To my sponge club compadres: Emily, Meg, Albi, Joe, Andy, Irina and Holly; some of the best memories I have from the past four years involve you. I could not have done it without your support, both in the field and in the pub.

Finally, to my friends and family, without whom I would not have made it this far. To my parents, who gifted me with a love of the natural world and constantly surprise me with their continuing desire to learn. To my sister, who is an unshakeable powerhouse, completely dedicated to working towards a sustainable future for all living things. To my partner Tony, who has endured endless conversations about sponges and science with good humour for four long years. You kept me going. Thank you for your love and support, but most of all, thank you for the laughter. 


\section{Chapter contributions and publications}

Field surveys, laboratory analyses, statistical analyses and writing were all performed by Charli Mortimer with guidance from Professor James Bell and Dr Matt Dunn (National Institute of Water and Atmospheric Research - NIWA). Additional guidance on stable isotope analysis was provided by Dr Sarah Bury (NIWA) for Chapters 4 and 5. All chapters are being written into manuscripts. 


\section{Table of Contents}

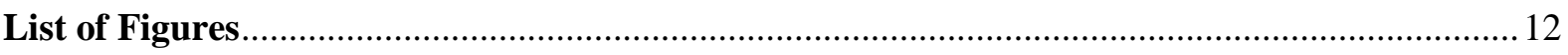

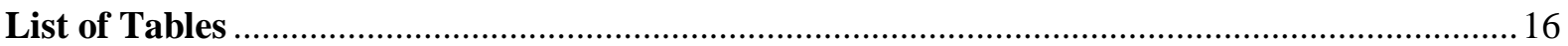

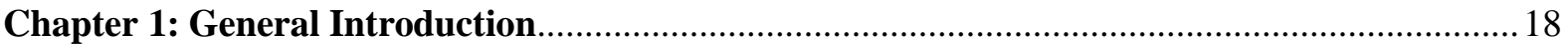

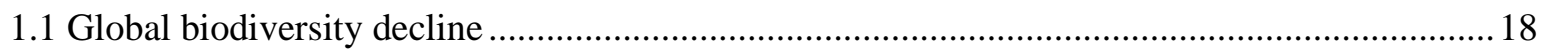

1.2 Rapid changes in community composition: Regime shifts ..................................................... 19

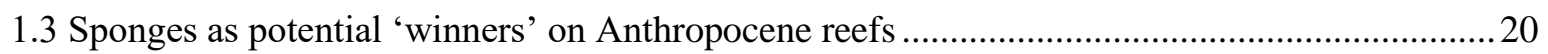

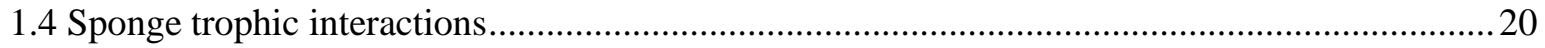

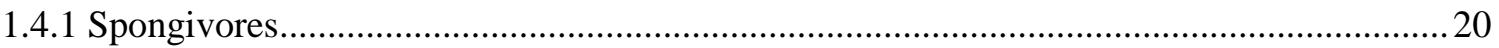

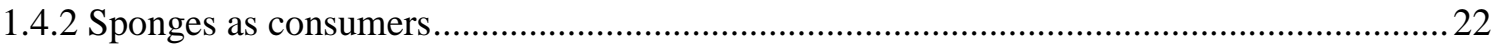

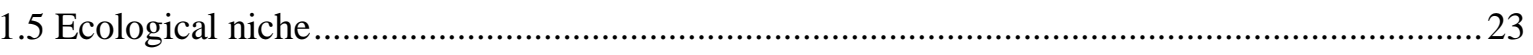

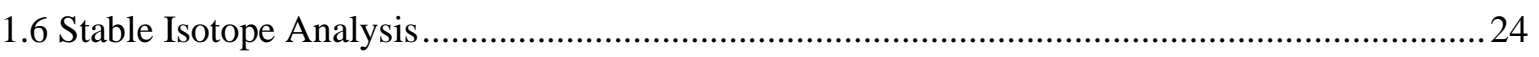

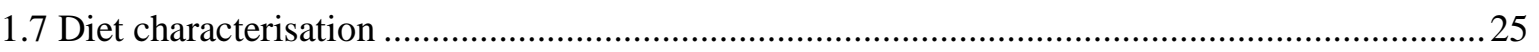

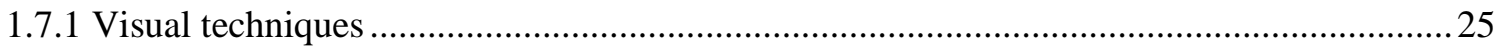

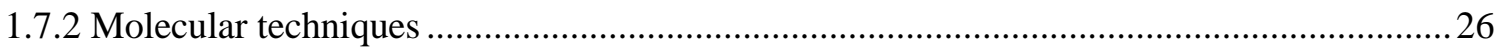

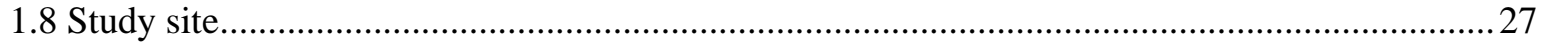

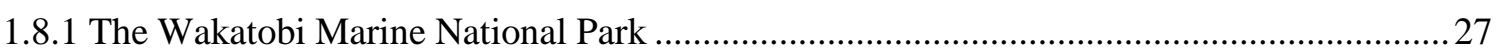

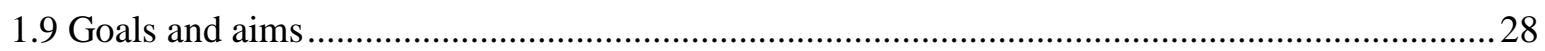

Chapter 2. Biomass transferred from sponges to spongivores equates to the coral-corallivore pathway .30

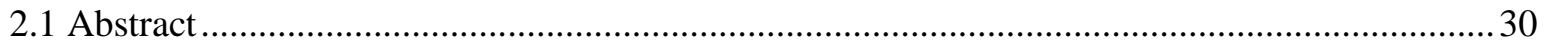

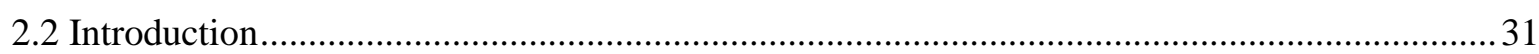

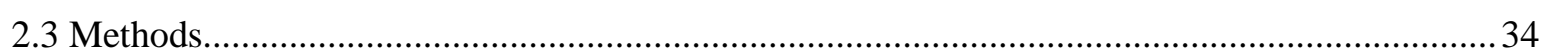

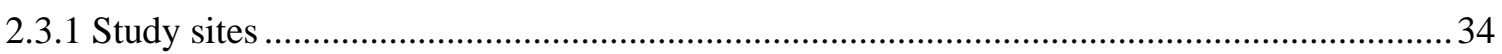

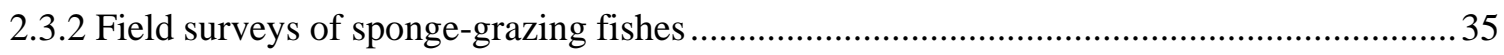

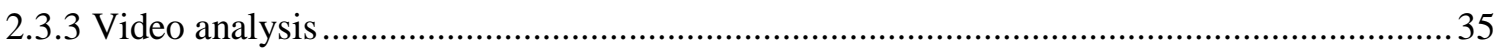

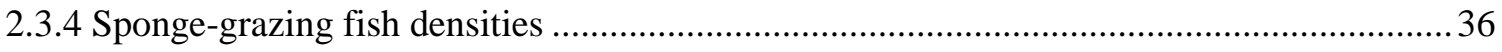

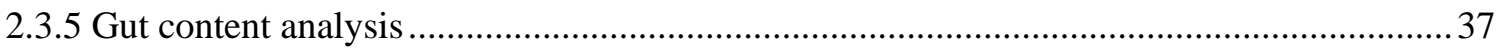

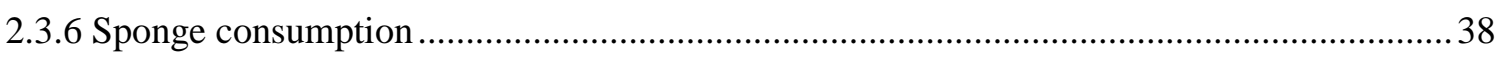

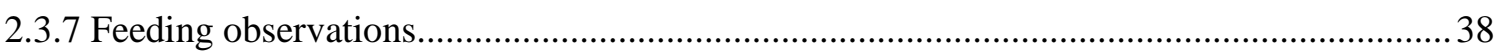

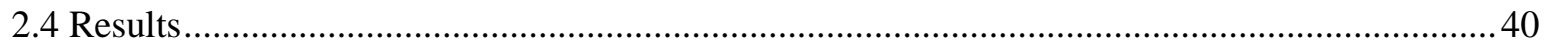

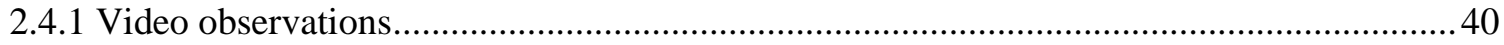

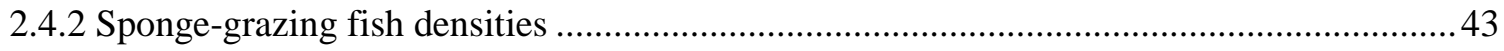

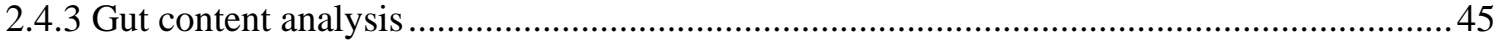

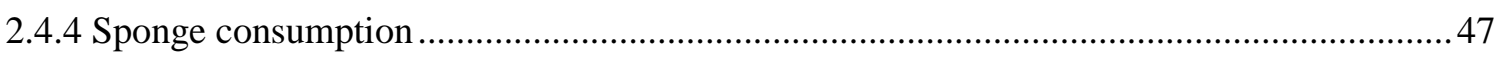


2.4.5 Feeding selectivity of Pygoplites diacanthus, Zanclus cornutus and Coradion melanopus 48

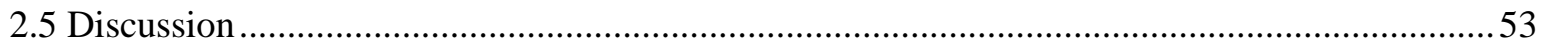

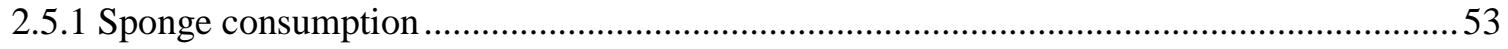

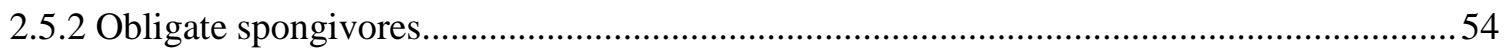

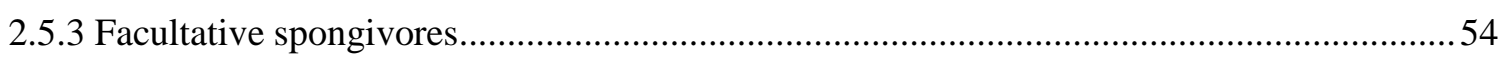

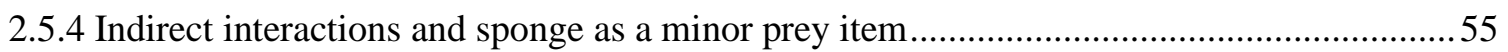

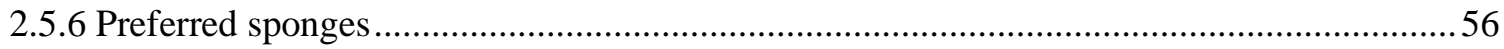

2.5.7 Limitations of sponge consumption estimates ...................................................................57

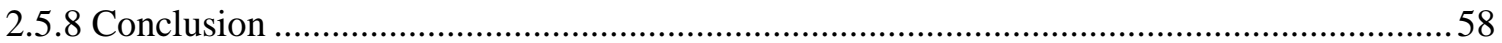

Chapter 3. DNA analysis of angelfish stomach contents reveals the diversity of predated sponges .59

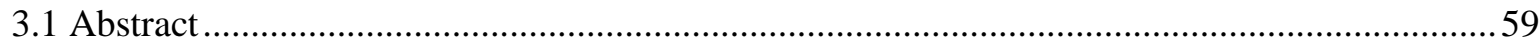

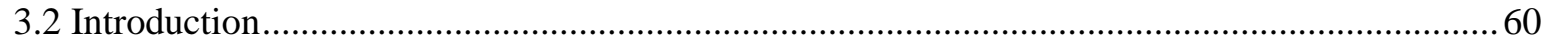

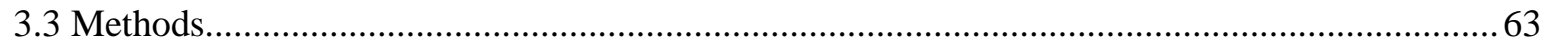

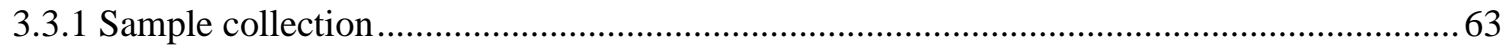

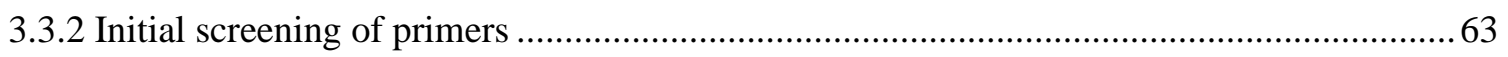

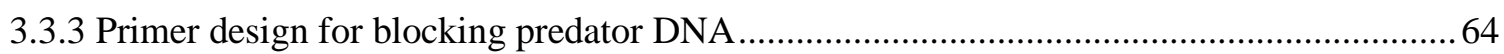

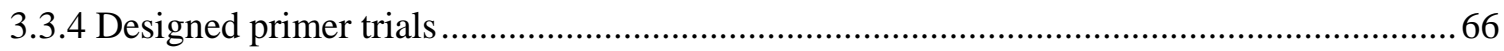

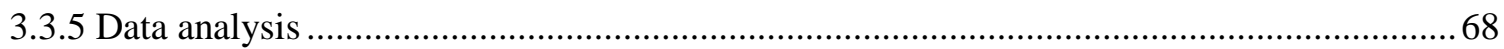

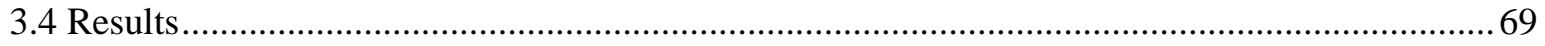

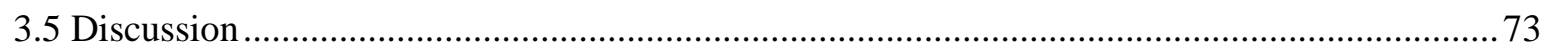

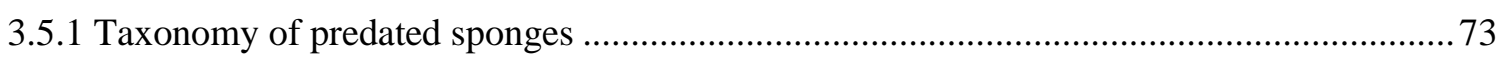

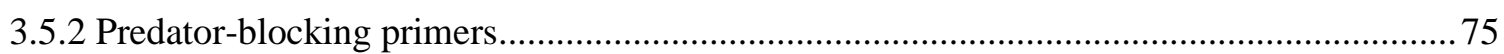

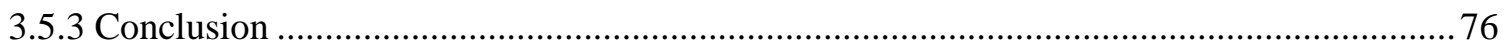

Chapter 4. Niche width expansion and a loss of trophic diversity on a sponge-dominated reef in

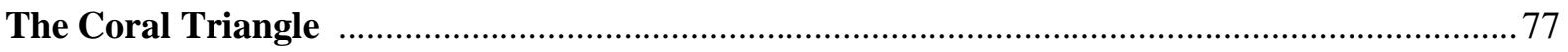

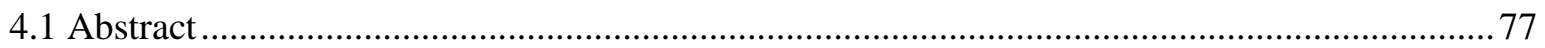

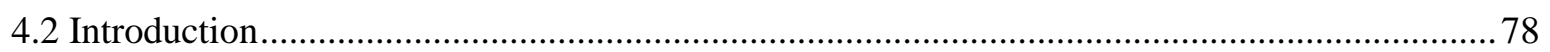

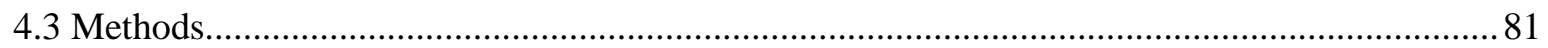

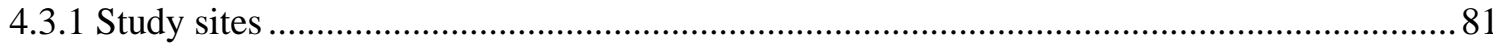

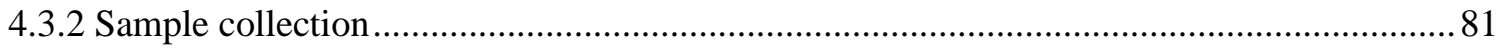

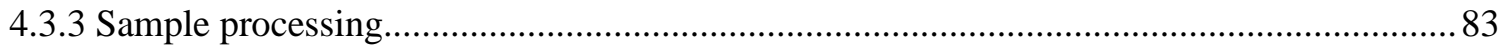

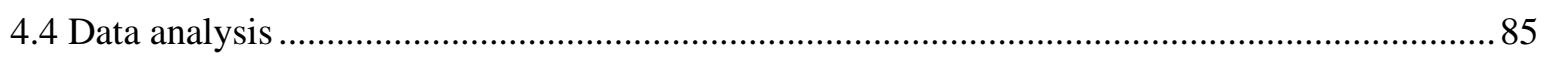

4.4.1 Spatial and interspecific variation in trophic position and $\delta^{13} \mathrm{C}$ values............................... 85

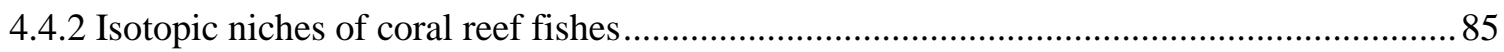

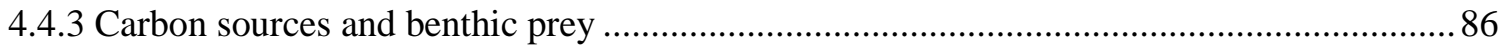

4.4.4 Pelagic and benthic carbon contributions to coral reef fish diets......................................... 87 
4.4.5 Quantitative comparison of trophic structure

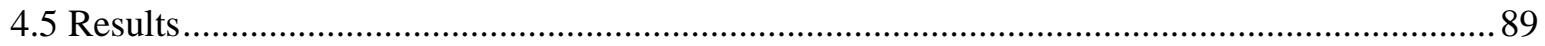

4.5.1 Spatial and interspecific variation in trophic position and $\delta^{13} \mathrm{C}$ values............................... 89

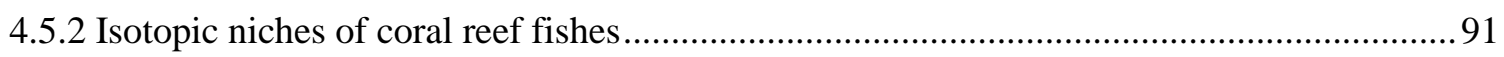

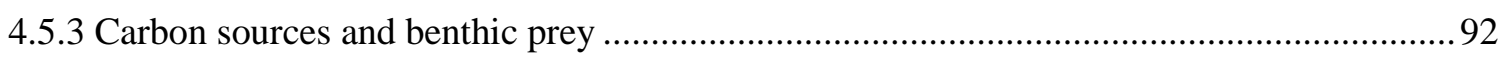

4.5.4 Pelagic and benthic carbon contributions to coral reef fish diets......................................... 94

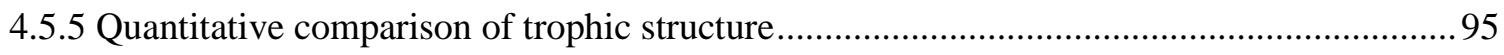

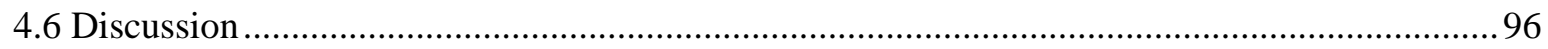

4.6.1 Spatial and interspecific variation in trophic position and $\delta^{13} \mathrm{C}$ values............................... 96

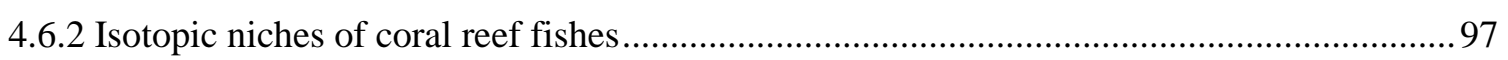

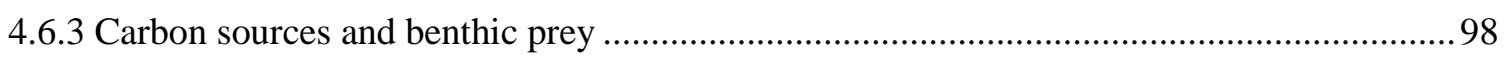

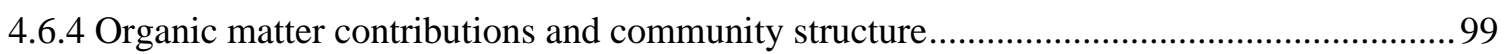

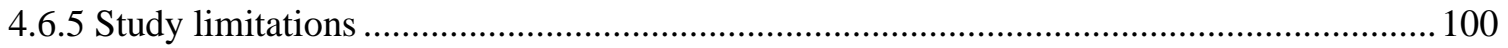

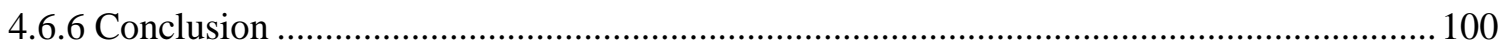

Chapter 5. Resource partitioning by temperate sponges is driven by differential use of pelagic

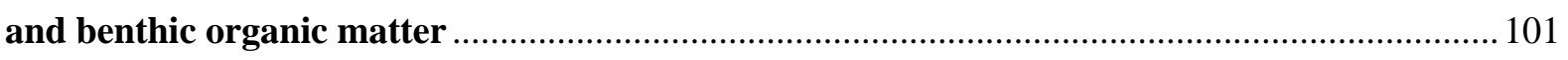

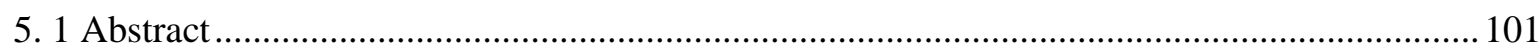

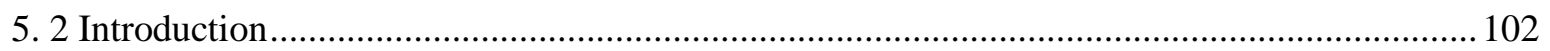

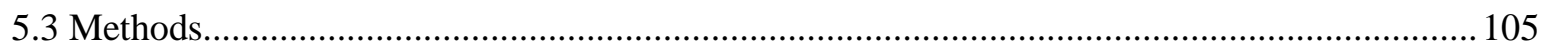

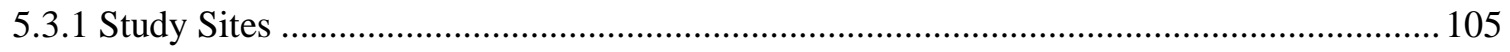

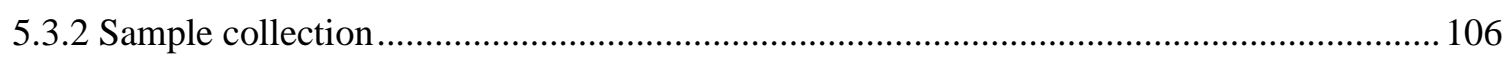

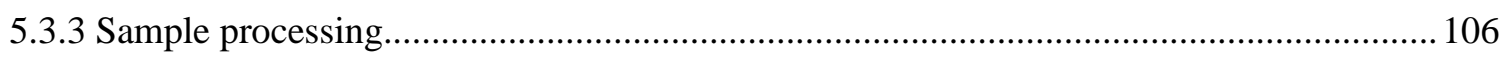

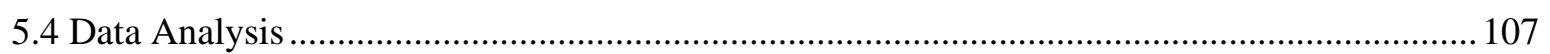

5.4.1 Spatial variation in the stable isotope ratios of sponges and water column resources ........ 107

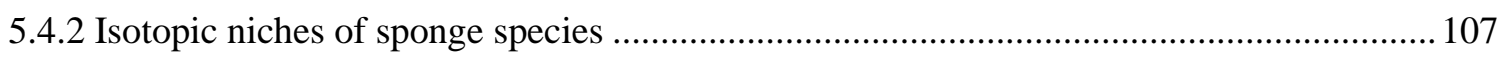

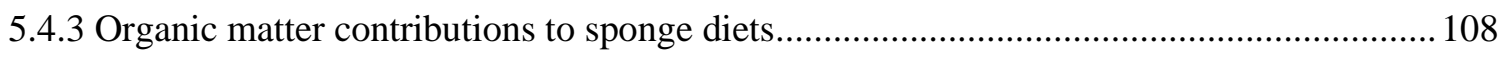

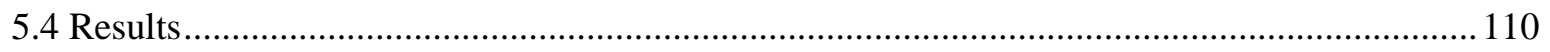

5.4.1 Spatial variation in the stable isotope ratios of sponges and water column resources ........ 110

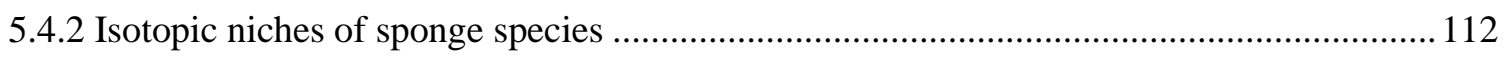

5.4.3 Organic matter contributions to sponge diets................................................................. 113

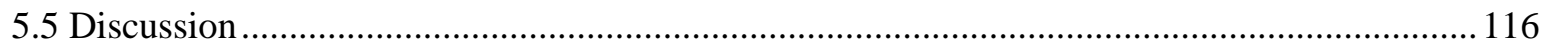

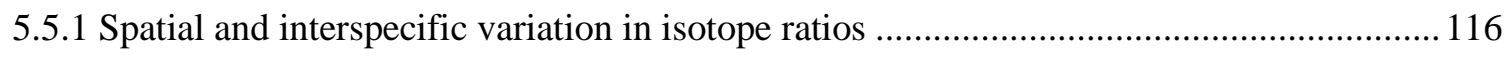

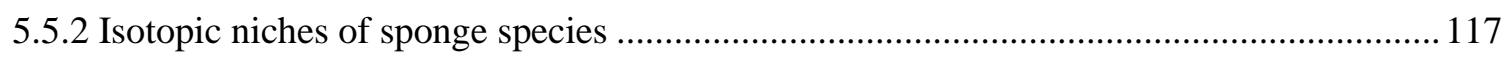

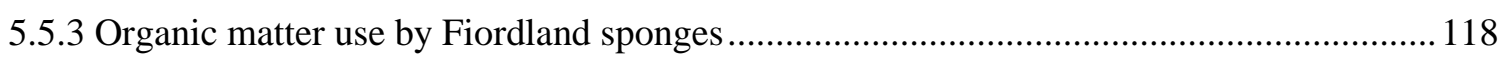

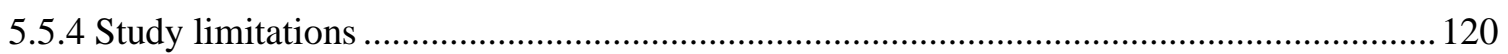

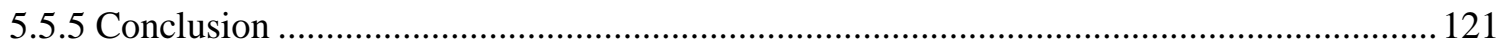

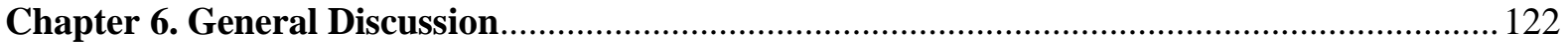




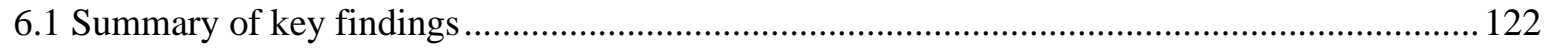

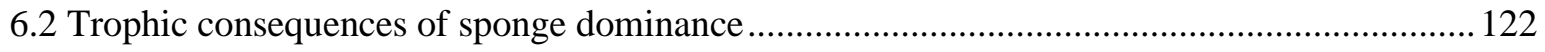

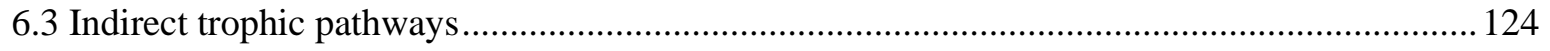

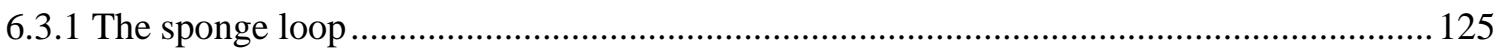

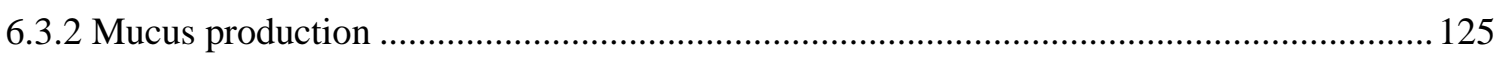

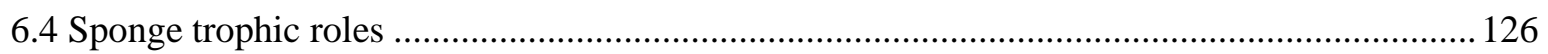

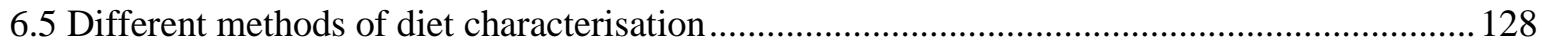

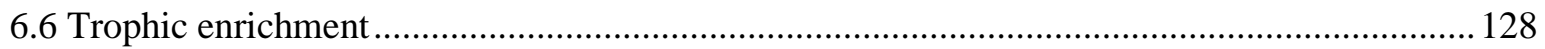

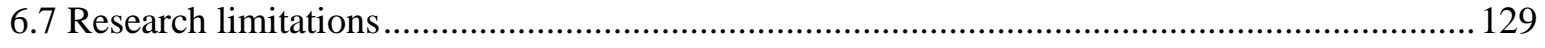

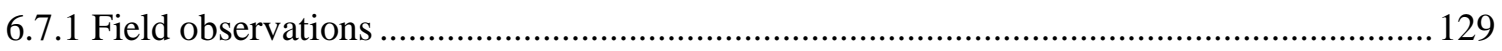

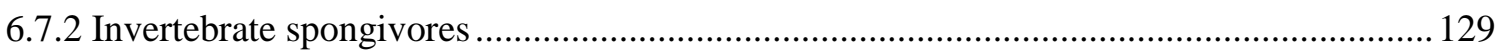

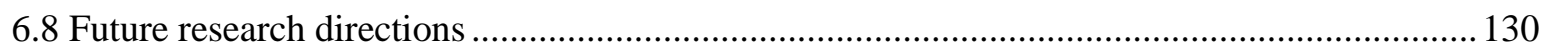

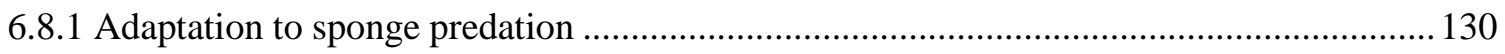

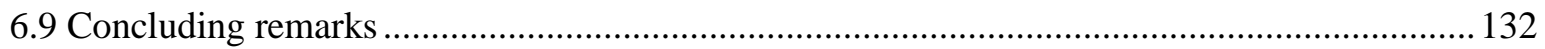

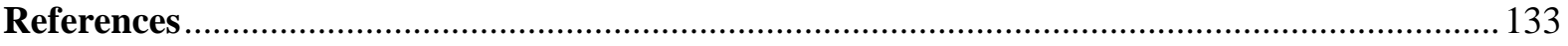

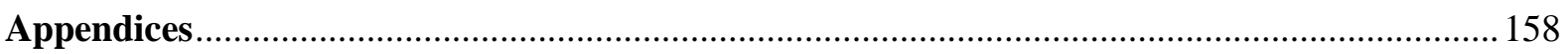




\section{List of Figures}

Figure 1. 1 Location of the study area within the Wakatobi Marine National Park, and its position within The Coral Triangle (purple boundary).

Figure 2. 1 Map of the four study sites and the position of the Hoga/ Kaledupa channel within the Wakatobi Marine National Park and Indonesia.

Figure 2. 2 Grazing intensity of fishes (measured as bites $\min ^{-1} \mathrm{~m}^{-2}$ [mean $\left.\pm \mathrm{SE}\right]$ ) on Xestospongia spp. filmed at four sites in the Wakatobi MNP. Number in parentheses is the number of Xestospongia spp. filmed at each site.

Figure 2. 3 The percentage of total bites on Xestospongia spp. taken by 11 species of sponge-grazing fishes filmed at four sites in the Wakatobi MNP.

Figure 2. 4 The percentage of total abundance of sponge-grazing fishes surveyed by UVC at each of the four study sites in the Wakatobi MNP.

Figure 2.5 The percentage cover of 16 benthic categories assessed by ten $1 \mathrm{~m}^{2}$ divided quadrats at three sites (Sampela, B1 and The Ridge) in the Wakatobi MNP.

Figure 2. 6 A. Spheciospongia sp. at Sampela. B. Close up of bites on Spheciospongia sp. made by $P$. diacanthus. C. Clathria sp. at Sampela. D. Close up of bites on Clathria sp. made by P. diacanthus. E. Xestospongia spp. at Sampela predated by P. diacanthus and Z. cornutus. F. Clathria reinwardtii at B1 predated by $P$. diacanthus. G. Exposed inner tissue of Petrosia corticata at the Ridge, predated by $P$. diacanthus and Z. cornutus. H. Petrosia sp. at the Ridge, predated by P. diacanthus and Z. cornutus.

Figure 3. 1 A 255 bp region of Pygoplites diacanthus $18 \mathrm{~S}$ sequence showing the location of primer Set 3 (Table 3.2) designed and trialled in this study. C3 denotes C3 spacer modification that prevents elongation during PCR.

Figure 3. 2 Gel electrophoresis of four primer sets (Table 3.2) designed to block predator DNA from amplification. Predator-blocking primers were tested at $5 \mathrm{X}$ and $10 \mathrm{X}$ concentration (see the top of 
diagram) on DNA extracts from sponges (S) and the predator (P). Set 2 successfully blocked the amplification of predator DNA at 10 times concentration.

Figure 3. 3 Cladogram showing the placement of 13 sponges within six orders of Porifera dissected from the stomach contents of the angelfishes Pygoplites diacanthus (RA) and Pomacanthus xanthometopon (PX) caught at two sites in the Wakatobi MNP and based on 18S sequence data. The outgroup is the glass sponge Rhabdocalyptus dawsoni (AF100949). Branch supports reported as SHaLRT support (\%) / ultrafast bootstrap support (\%).

Figure 3. 4 Cladogram showing the placement within the order Haplosclerida of six sponges sampled from the stomach contents of the angelfish Pygoplites diacanthus (RA) caught at two sites in the Wakatobi MNP and based on $18 \mathrm{~S}$ sequence data. Branch supports are reported as SH-aLRT support (\%) / ultrafast bootstrap support (\%).

Figure 3. 5 Cladogram showing the placement of seven sponge sequences amplified from the stomach contents of the angelfishes Pygoplites diacanthus (RA) and Pomacanthus xanthometopon (PX) caught at two sites in the Wakatobi MNR. Branch supports are reported as SH-aLRT support (\%) / ultrafast bootstrap support $(\%)$.

Figure 4. 1 Example standard ellipse from Batschelet, (1981) and reproduced in Jackson et al. (2011). Black circles are sample data, the black ellipse is the standard ellipse containing $40 \%$ of the sample data. Semi-major axis (a) and semi-minor axis (b) are shown on the diagram.

Figure 4. 2 Boxplots of trophic position and $\delta^{13} \mathrm{C}$ values of seven species of reef fish compared between two reef systems of contrasting quality in the Wakatobi MNP, Indonesia. ZC = Zanclus cornutus, PD $=$ Pygoplites diacanthus, $\mathrm{FF}=$ Forcipiger flavissimus, $\mathrm{CB}=$ Ctenochaetus binotatus, $\mathrm{CK}=$ Chaetodon kleinii, $\mathrm{CL}=$ Chaetodon lunulatus, $\mathrm{NN}=$ Neoglyphidodon nigroris .

Figure 4. 3 Isotopic niches (standard ellipse area - SEAc) of seven species of reef fish each representing a different functional feeding group sampled at two sites in the Wakatobi MNP, Indonesia. SEAc represented by solid ellipses and dashed polygon is the isotopic total area (TA). ZC = Zanclus cornutus, $\mathrm{PD}=$ Pygoplites diacanthus, $\mathrm{FF}=$ Forcipiger flavissimus, $\mathrm{CB}=$ Ctenochaetus binotatus, $\mathrm{CK}=$ Chaetodon kleinii, $\mathrm{CL}=$ Chaetodon lunulatus, $\mathrm{NN}=$ Neoglyphidodon nigroris. 
Figure 4. 4 Isotopic niches (standard ellipse area - SEAc) of carbon sources and potential prey collected at two sites in the Wakatobi MNP, Indonesia. Insert is Figure 4.3.

Figure 4. 5 Isotopic niches (standard ellipse area $-\mathrm{SEA}_{\mathrm{C}}$ ) of sponges, corals and detritus $+1 \mathrm{TP}$ collected at two sites in the Wakatobi MNP, Indonesia.

Figure 4. 6 Relative contributions of pelagic and benthic carbon to the diet of seven coral reef fish species representing functional feeding groups sampled at two sites in the Wakatobi MNP, Indonesia. Boxes represent the credible interval of 50\% and error bars the credible interval of $95 \% . \mathrm{ZC}=$ Zanclus cornutus, $\mathrm{PD}=$ Pygoplites diacanthus, $\mathrm{FF}=$ Forcipiger flavissimus, $\mathrm{CB}=$ Ctenochaetus binotatus, $\mathrm{CK}$ $=$ Chaetodon kleinii, $\mathrm{CL}=$ Chaetodon lunulatus, $\mathrm{NN}=$ Neoglyphidodon nigroris .

Figure 4. 7 Bayesian results of the Layman community metrics for two sites (higher-quality and spongedominated) sampled in the Wakatobi MNP Indonesia. Black circles represent the mode and boxes correspond to the $50 \%, 75 \%$ and $95 \%$ credible intervals. $\delta^{15} \mathrm{~N}$ Range $=$ Range of $\delta^{15} \mathrm{~N}$ values. $\delta^{13} \mathrm{C}$ Range $=$ Range of $\delta^{13} \mathrm{C}$ values. $\mathrm{CD}=$ Mean distance to the centroid. NND $=$ Mean nearest neighbour distance. SDNND = Standard deviation of nearest neighbour distance.

Figure 5. 1 Map showing locations of sample sites in Doubtful Sound, Fiordland visited during February 2019 on the MV Southern Winds. Sponges were collected the Inner Fiord and Outer Fiord at opposing ends of Doubtful Sound, with three additional deep sponges collected by ROV at Fergusson Island. Organic matter samples were collected at the Inner Fiord and Outer Fiord, and an intermediate site in Bradshaw Sound.

Figure 5. 2 The isotopic niches (standard ellipse area - SEAc) of sponges (all species combined) grouped by site (Inner Fiord and Outer Fiord) and depth $(10$ and $30 \mathrm{~m})$ collected from Doubtful Sound in Fiordland in February 2019.

Figure 5. 3 Isotopic niches (standard ellipse area - SEAc) of sponge species, picoplankton and the 2$200 \mu \mathrm{m}$ size fraction of the water column collected from Doubtful Sound in Fiordland grouped by site (Inner Fiord and Outer Fiord) and depth (10 and $30 \mathrm{~m})$.

Figure 5. 4 Isotope biplots of carbon sources (mean \pm SD) and isotopic niches (standard ellipse area SEAc) of sponge species (samples pooled between depths) collected from Doubtful Sound in Fiordland 
at the Inner Fiord and Outer Fiord. NB: Fergusson sponges (three individual unknown species collected from $55 \mathrm{~m}$ at Fergusson Island) and $60 \mathrm{~m}$ sponges (Inner Fiord) were collected by ROV.

Figure 5. 5 Isotope mixing model posterior estimates of the proportional contribution of each carbon source to the diet of five sponge species at two different sites in Doubtful Sound, Fiordland. Boxes represent the credible interval of $50 \%$ and error bars the credible interval of $95 \%$. 


\section{List of Tables}

Table 2. 1 Total number of bites taken by 33 reef fish species filmed grazing on Xestospongia spp. at four sites in the Wakatobi MNP. Frequency of occurrence in videos (FO \%) calculated from the total number of Xestospongia spp. pooled across all sites $(\mathrm{n}=30)$. X indicates fish was observed biting Xestospongia spp. at a particular site and * indicates species sampled for gut contents.

Table 2. 2 Sponge-grazing fish densities (mean \pm SE) per $250 \mathrm{~m}^{2}$ surveyed by UVC $(\mathrm{n}=6)$ at 4 sites in the Wakatobi MNP.

Table 2. 3 Relative gut content (\%) of 8 species of sponge-grazing reef fish caught in the Wakatobi MNP in 2017. P. diacanthus - S. punctatus are percent weight $(\% \mathrm{~W})$ and C. kleinii - C. binotatus are relative volumetric quantity $(\% \mathrm{~V})$ due to low volume of stomach/gut contents.

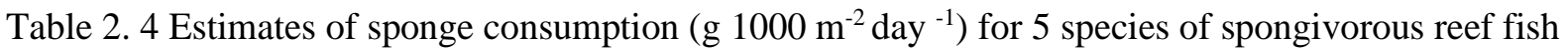
calculated from mean sponge weight in gut contents and fish densities. NB. Siganus punctatus was not included in the UVC of sponge-grazing fishes, therefore density was conservatively estimated from video observations.

Table 2. 5 Benthic categories percentage cover (mean \pm SE) estimated from ten $1 \mathrm{~m}^{2}$ divided quadrats placed randomly along a $100 \mathrm{~m}$ stretch of reef slope (10-14m) at three sites in the Wakatobi MNP. 49

Table 2. 6 Relative abundance (\% cover) of sponge species and percent bites taken by 3 species of sponge-grazing fishes at three sites (B1, Sampela and The Ridge) in the Wakatobi MNP. Sponges were considered preferred if the percentage of bites > percentage abundance $+5 \%$ and avoided if the percentage of bites < percentage abundance $-5 \%$.

Table 3. 1 18S primers designed during this study. 3 denotes C3 spacer modification added to the 3'end of blocking primers.

Table 3. 2 Four 18S primer sets trialled during this study.

Table 4. 1 Seven coral reef fish species targeted by this study and major recorded prey items ( $>10 \%$ gut contents) from this study (Chapter 2) and literature references (all images licenced under Creative Commons BY-C 3.0). 


\section{Chapter 1: General Introduction}

\subsection{Global biodiversity decline}

The Earth is experiencing species and population losses at such severe rates scientists have declared the beginning of Earth's sixth mass extinction event (Barnosky et al. 2011; Ceballos et al. 2017). The rate of population loss in terrestrial vertebrates is particularly high, with a recent study finding that one-third of the $>27,000$ terrestrial vertebrate species examined were in decline (Ceballos et al. 2017). Flying insects that perform vitally important functional roles including pollination, nutrient cycling and detritivory are also declining globally (Conrad et al. 2006; Goulson et al. 2008; Hallmann et al. 2017). The biomass of aerial insects in protected areas in Germany has reduced by $76 \%$ in 27 years, partly due to agricultural intensification and the associated use of pesticides (Hallmann et al. 2017). Biodiversity, commonly measured as species richness, evenness and heterogeneity (Cardinale et al. 2012) increases ecosystem stability, productivity and directly influences a number of ecosystem services (Cardinale et al. 2012) that are vital to human civilisation (Ceballos et al. 2017). Thus, the loss of biodiversity can be considered a direct threat to the future of mankind (IPBES, 2019).

Historically, pressure on marine environments has been lower than terrestrial environments due to the relative inaccessibility of marine resources (McCauley et al. 2015). However, coastal development and commercial fishing have increased the rate at which marine environments are changing (Jackson et al. 2001; McCauley et al. 2015). In a 2008 assessment of the human impact on marine ecosystems, coastal wildlife habitats were considered most at risk due to the cumulative impacts from land- and oceanbased anthropogenic drivers (Halpern et al. 2008). Land-based drivers include processes that remove vegetation and increase nutrient input into coastal systems, whereas ocean-based drivers include processes that extract resources and alter community composition (Halpern et al. 2008). Species' sensitivity to climate change is thought to be greater in marine than terrestrial systems (Pinsky et al. 2019). Marine ectotherms have narrower thermal safety margins than terrestrial ectotherms and local extirpations resulting from increasing temperatures are twice as common in the ocean than in terrestrial environments (Pinsky et al. 2019). In addition, the rapid reorganisation of communities via changes to species identity and abundance is more prevalent in marine systems as opposed to terrestrial systems (Blowes et al. 2019). Using an extensive database of assemblage time series and independent studies, Blowes et al. (2019) compiled time-series data from >50,000 local assemblages to identify hotspots of biodiversity change. Marine biomes including the tropics, temperate west Atlantic and northwest Australia were all identified as areas that should be prioritised for targeted conservation action based on having the highest rates of species turnover and community restructuring (Blowes et al. 2019). Coral reefs in particular cover $<1 \%$ of the global marine environment (Olivotto et al. 2011) but are critical to the survival of approximately a quarter of all marine life and an estimated 450 million people (Wilkinson, 2004; Reaser et al. 2008). Significant community restructuring will shift the functional landscape of these critical habitats and affect their capacity to provide essential goods (e.g. food, wood) 
and other services (e.g. coastal protection, climate regulation) (Salm, 1983; Hoegh-Guldberg, 1999; Cardinale et al. 2012).

\subsection{Rapid changes in community composition: Regime shifts}

One of the best-known examples of significant community restructuring on coral reefs is the regime shifts from coral- to algal-dominated reef states in the Caribbean. This process was identified nearly 40 years ago when a species-specific pathogen led to mass mortality of the grazing urchin Diadema antillarum on Jamaican reefs (Lessios, 1988; Hughes, 1994). Diadema antillarum mortality, coupled with chronic overfishing of herbivorous fishes, reduced grazing pressure leading to a proliferation of fleshy algae after only 1-2 years (Hughes, 1994). Decades of intense research on herbivorous reef fish assemblages followed (Bellwood et al. 2004) making herbivory the most widely studied functional role on coral reefs (Bellwood et al. 2004). The homogeneous functional group 'herbivores' was subdivided based on feeding behaviour, morphology and targeted substrate (Bellwood \& Choat, 1990; Bellwood et al. 2004). For example, parrotfishes (family Scaridae) were divided into scrapers (Scarus), excavators (Chlorurus) and grazers (Sparisoma) due to their different impacts on reef substrate (Bellwood \& Choat, 1990; Bellwood et al. 2004). More recently, parrotfishes on Caribbean reefs have been delineated into four functional groups (scrapers, excavators, croppers and browsers) based on observations of feeding behaviour, descriptions of individual bites and videos of bite mechanics (Adam et al. 2018). Similarly, detritivorous surgeonfishes (genus Ctenochaetus) were originally grouped with other surgeonfishes (Tebbett et al. 2017) until grazing experiments clarified that they were ineffective at removing algal turfs and gut contents were found to be dominated by sediments and detritus (Tebbett et al. 2017). Recognising these differences enables scientists to better predict how changes in assemblage structure may affect ecosystem processes (Bellwood et al. 2019).

Of the benthic invertebrate feeders, corallivores are the best-studied group (Pratchett et al. 2005; Cole et al. 2011) because their reliance on living corals makes them good indicators of habitat degradation (Cole et al. 2008). Corallivores are classified based on their reliance on corals as a resource, with the majority belonging to the Chaetodontidae family (Cole et al. 2008). Obligate corallivores are defined as species that depend on corals for $\geq 80 \%$ of their diet (Cole et al. 2008), whereas facultative corallivores may also consume substantial amounts of other organisms including motile invertebrates, sponges, algae and sedentary polychaetes (Harmelin-Vivien \& Bouchon-Navaro, 1983; Sano, 1989; Nagelkerken et al. 2009). Obligate corallivores are considered the functional group most threatened by climate-driven habitat loss (Graham et al. 2011), as resource specialisation is key to determining a species' response to habitat degradation (Layman et al. 2007). Localised extinctions following dramatic declines in coral abundance have already been reported for obligate corallivores and coral-dwelling specialists (Munday, 2004; Brooker et al. 2014). With the exception of herbivores and corallivores, numerous species on coral reefs play relatively unknown and unquantified functional roles (Bellwood 
et al. 2019). These significant knowledge gaps need to be addressed and translated into effective management approaches to preserve ecosystem functions on transitioning coral reefs (Bellwood et al. 2019).

\subsection{Sponges as potential 'winners' on Anthropocene reefs}

Heightened interest in the role of sponges on coral reefs has been driven by evidence that sponges may, at least initially, be less affected by this period of unprecedented environmental change (Bell et al. 2013; Bell et al. 2018a; Bell et al. 2018b; Pawlik et al. 2018). Several studies have reported increasing sponge abundance (Ruzicka et al. 2013; McMurray et al. 2015; de Bakker et al. 2017) and transitions to spongedominated states have been reported in the Caribbean, Atlantic, Indo-Pacific and the Pacific (reviewed in Bell et al. 2013). In addition to reports of increasing abundance, experimental studies indicate that some sponges may have a greater tolerance for environmental shifts than calcifying fauna (Vicente et al. 2015; Bennett et al. 2017). For example, four Great Barrier Reef (GBR) sponge species exhibited tolerance to ocean warming and acidification predicted under the intermediate Representative Concentration Pathway (RPC) climate change scenario (Bennett et al. 2017). However, under the elevated RPC pathway, significant sponge mortality occurred (Bennett et al. 2017). Interestingly, the interactive effects of ocean acidification (OA) and ocean warming (OW) varied depending on trophic mechanisms (Bennett et al. 2017). Elevated $\mathrm{pCO}_{2}$ mitigated the effects of temperature stress in phototrophic sponges but exacerbated the effects in heterotrophic sponges (Bennett et al. 2017). It has also been suggested that reefs in the Anthropocene more closely resemble reefs in the geological past (Bellwood et al. 2019). As one of the worlds' oldest living organisms, sponges have been dominant frame-building organisms in various geological periods (reviewed in Bell et al. 2013) and proliferated after the decimation of bio-calcifying communities at the end of the Triassic period (Delecat et al. 2011). Increasing sponge abundance may have profound impacts on ecosystem functioning (Bell, 2008; Bell et al. 2013; Bell et al. 2018b), yet they remain under-represented in most monitoring programmes and much-needed time-series census studies are lacking for many reef locations (Bell, 2008; Bell et al. 2013; Wulff, 2017). Addressing knowledge gaps regarding sponge functional roles will better enable scientists to predict the broader functional consequences of changing sponge abundance (Bell et al. 2018b).

\subsection{Sponge trophic interactions}

\subsubsection{Spongivores}

The majority of sponge predation in temperate waters is carried out by invertebrate feeders (but see Ayling, 1981 for the description of a temperate spongivorous filefish). However, in tropical regions, vertebrate predators (fish and turtles) have the largest predatory impact on sponge assemblages (Meylan, 1988; Randall \& Hartman, 1968). The most charismatic sponge specialist is the Hawksbill turtle, Eretmochelys imbricata. They have a taxonomically narrow diet, consisting of a few highly siliceous sponge species from the orders Astrophorida, Chondrosida and Hadromerida (Meylan, 1988; 
Leon \& Bjorndal, 2002; Wulff, 2012; Stringell et al. 2016). Severe Caribbean-wide depletion of $E$. imbricata to $<1 \%$ former population sizes (McClenachan et al. 2006) has been implicated in increasing sponge abundance on Caribbean reefs (Pawlik et al. 2018), although it is unclear whether sponges predated by spongivorous turtles have increased in abundance. Aside from E. imbricata, only a few families of reef fish eat sponges (Randall \& Hartman, 1968; Wulff, 2006) and those that do typically only consume part of the sponge; hence mortality is only partial (Wulff, 1994). In addition, many sponges regenerate quickly after predation events, which may have contributed to the assumption that predation has little impact on tropical sponge assemblages (Pawlik, 2011). Randall \& Hartman (1968) examined the gut contents of 212 fish species and found sponge remains in only 21 of those species. Sponges made up a substantial percentage of the gut contents of angelfishes of the genus Holacanthus (>95\%), Pomacanthus (>70\%), the filefish Cantherhines macrocerus (>85\%) and the spadefish Chaetodipterus faber (>30\%). Other spongivorous fishes have been identified from the families Tetraodontidae, Ostraciidae and Scaridae (Randall \& Hartman, 1968; Clements \& Livingstone, 1983; Wulff, 1994; Dunlap \& Pawlik, 1996; Wulff, 1997). Unlike Hawksbill turtles, spongivorous fishes consume a wide range of sponge species in a rotational fashion (Wulff, 1994; Lesser \& Slattery, 2013). This feeding behaviour was first noted by Randall \& Hartman (1968) who referred to it as the 'smorgasbord feeding' approach. They recorded $>40$ sponge species in the gut contents of 24 Holacanthus ciliaris specimens (Randall \& Hartman, 1968). Similarly, in Brazil, 34 sponge species were found in the gut contents of three angelfish predators (Andrea et al. 2007) and in the Pacific, spongivorous angelfish consumed $46 \%$ of available sponge species (Verdín Padilla et al. 2010). This behaviour was explained by the need to rotate exposed, chemically defended sponge species, thus reducing the effects of secondary metabolites (Wulff, 1994; Wulff, 2006).

Consuming a wide range of sponge species does not necessarily indicate that spongivores select their prey at random. Frequency of occurrence and relative volume of sponge species in the gut contents of spongivorous angelfishes in Randall and Hartman's 1968 study indicated that Callyspongia vaginalis, Chondrilla nucula, Spirastrella coccinea, Xestospongia sp. and Niphates erecta are heavily predated by angelfishes. However, preference for particular species cannot be determined without knowledge of relative abundance, as heavily predated species could simply reflect availability in the field (Wulff, 2006). For instance, the most heavily predated species documented by Randall \& Hartman (1968), Callyspongia vaginalis, is also one of the most abundant species on Caribbean coral reefs (Pawlik et al. 1995; Wulff, 2006).

Gut content analysis is considered by many researchers to be the best method of estimating the feeding preferences of spongivores (Pawlik et al. 2018) however, the destructive sampling of large numbers of reef fishes (e.g. Randall \& Hartman 1968) has ethical implications that need to be carefully considered (Pawlik et al. 2018). Instead, palatability assays conducted using a generalist wrasse and pelletised extractions of sponge secondary metabolites have been used to identify sponges with significant 
deterrent properties (Pawlik et al. 1995). For example, sponges from the orders Hadromerida, Poecilosclerida and Haplosclerida were palatable to the generalist wrasse Thalassoma bifasciatum, whereas sponges from the aspiculate orders Verongiida and Dictyoceratida possessed highly deterrent extracts (Pawlik et al. 1995). Many sponges commonly found in open reef environments (e.g. Callyspongia, Niphates and Iotrochota) were chemically undefended (Pawlik, 2011). These undefended, open reef sponges were also the dominant sponge species recorded in the gut contents of angelfishes sampled by Randall \& Hartman (1968) (Pawlik, 1997). This challenged the theory that spongivores are 'smorgasbord' feeders, suggesting that instead, they target chemically undefended species to circumvent sponge chemistry (Pawlik, 1997). Open reef, chemically undefended species that incur predation were found to have higher rates of growth and regeneration than chemically defended species (Walters \& Pawlik, 2005; Leong \& Pawlik, 2010) suggesting a trade-off between investing energy in chemical defences or growth and regeneration (Pawlik, 2011). These observations led to the theory that Caribbean sponges could be partitioned into three ecologically meaningful groups: (1) defended, open reef sponges; (2) undefended but tolerant, palatable sponges; and (3) palatable species that are restricted to cryptic habitats (Pawlik, 2011).

\subsubsection{Sponges as consumers}

Despite being commonly viewed as simple filter feeders (Maldonado et al. 2012), sponges have a wide range of nutritional strategies (Yahel et al. 2006) that facilitate survival in a range of habitats (Maldonado et al. 2012; Maldonado et al. 2017). Sponges pump large volumes of water, linking benthic and pelagic systems, which can have a profound effect on the overlying water column (Reiswig, 1971; Lesser, 2006). For instance, populations of the giant barrel sponge Xestospongia muta can filter a water column 30 m deep every 2.3 to 18 days (McMurray et al. 2014) and some sponges can filter 60 to 900 times their volume per hour (Yahel et al. 2003). Sponges consume both living and non-living (detrital) particles, although the role of detritus in the diets of sponges is relatively unknown (Hadas et al. 2009). Detritus made up approximately half of the particulate organic carbon (POC) consumed by the sponges Xestospongia muta and Negombata magnifica (Hadas et al. 2009; McMurray et al. 2016) but in other studies, the consumption of detritus was negligible (Yahel et al. 2003). Generally, sponges are limited to feeding on particles $<50 \mu \mathrm{m}$ due to the structure of their aquiferous system (Reiswig, 1971; Pile at al. 1996) and have higher retention efficiencies for picoplankton $(0.2-2 \mu \mathrm{m})$ (Pile, 1997; Ribes et al. 2006), although larger particles may be taken up by surface epithelial cells (Maldonado et al. 2012). Once considered non-selective, several studies have now demonstrated processes of particle selection in marine sponges (Yahel et al. 2006; Hanson et al. 2009; Topçu et al. 2010). For example, Yahel et al. (2006) demonstrated size-independent selective feeding by two species of hexactinellid sponges and suggested that selective feeding likely involves processes of recognition, sorting and transport. Large rare eukaryotic algae and small non-photosynthetic bacteria were efficiently removed but intermediate- 
sized Synechococcus was less preferred and there were seasonal differences in preferences between species (Yahel et al. 2006).

The recognition that sponges take up dissolved organic carbon (DOC) (Yahel et al. 2003; de Goeij et al. 2008), operationally defined as the fraction of the water column that passes through a GF/F filter with $\pm 0.7 \mu \mathrm{m}$ pore size (Maldonado et al. 2012; de Goeij et al. 2017), has shed light on carbon balance discrepancies (de Goeij et al. 2008). It also led to the recognition of the 'sponge-loop' pathway whereby DOC is taken up by sponges, transformed into sponge biomass and eventually shed as cellular detritus, and consumed by detritivores (de Goeij et al. 2008; Rix et al. 2018). Net DOC uptake has been estimated for a number of sponges from tropical, temperate and deep reef systems, and for some sponges, DOC has been estimated to contribute $>90 \%$ of TOC intake (see de Goeij et al. 2017 for review). On coral reefs, DOC taken up by sponges is released from benthic primary producers eg. corals and macroalgae, representing an additional trophic link between benthic organisms (van Duyl et al. 2011; Rix et al. 2016; Rix et al. 2017). It has also recently been demonstrated that coral- and algal- derived dissolved organic matter are differentially incorporated into the host sponge and its symbionts (Rix et al. 2017), adding another layer of complexity to sponge trophic pathways.

The majority of sponge-hosted symbiotic associations involve microbes but associations with dinoflagellate zooxanthellae are also found among sponges of the genus Cliona (Weisz et al. 2010). Some sponges have symbiont densities amounting to $40 \%$ sponge tissue volume (Vacelet, 1975; Taylor et al. 2007). Pulse-chase experiments demonstrated that symbiotic zooxanthellae transfer carbon to Cliona varians but there was no evidence of nitrogen transfer (Weisz et al. 2010). Similarly, Freeman $\&$ Thacker (2011) reported symbiont derived nutrients being transferred into host cells for three tropical sponges with cyanobacterial symbionts, however stable isotope values suggested interspecific differences in carbon and nitrogen integration between host and symbiont community. Symbiotic associations are common in oligotrophic ecosystems such as coral reefs as they allow host species access to additional nutritional pathways that facilitate survival (Freeman et al. 2014).

\subsection{Ecological niche}

The term 'ecological niche' has been central to ecological theory for over a century (Grinnell, 1917; Schoener, 1986). The term was first conceptualised by Grinnell (1917) who described it as the habitat and accompanying behavioural adaptations of a species. In Grinnell's concept, the ecological niche was a set of behavioural, morphological and physiological adaptations that were represented in all habitat types and filled by ecologically equivalent species (Grinnell 1917; Schoener, 2009). Hutchinson (1957) expanded on the niche concept with a focus on the species rather than the environment. In Hutchinson's concept, the range of potential environments available to an organism could be visualised as an ' $n$ dimensional hypervolume' with axes that quantitatively describe environmental factors that affect an organism's performance (Hutchinson, 1957; Hutchinson, 1978; Holt, 2009). The recognition that 
species' distributions are also constrained by competition led to the understanding that the fundamental niche is not fully exploited, and species are restricted to a realised niche (Hutchinson, 1978).

Interest in quantifying an organism's ecological niche has grown substantially in the last decade, fuelled by the need to predict ecological responses to environmental change (Holt, 2009). Experimental niche models expose a species to a range of environmental conditions and monitor mortality and fecundity to delineate niche boundaries at which intrinsic growth rate (per capita birth rate minus death rate) is $\geq 0$ (Holt, 2009). However, experimental niche models are often limited to small organisms that can be conveniently manipulated at small spatial scales (Holt et al. 2009). Statistical niche models use geographic distribution and environmental variables to produce predictive habitat models that delineate realised niche. For example, Howell et al. (2016) used presence-only data for two types of deep sea sponge aggregations alongside 16 environmental variables to highlight high suitability habitat and inform conservation initiatives. This approach relies upon robust estimates of a species' distribution, which are not always available (Holt et al. 2009), particularly on coral reefs where traditional UVC methods tend to overlook cryptobenthic species (Brandl et al. 2018).

\subsection{Stable Isotope Analysis}

Over the past decade, stable isotope analysis (SIA) has been proposed as a method to quantify the ecological niche of an organism because it captures both environmental and trophic components of a species' existence, which are represented in multidimensional space (Newsome et al. 2007; Jackson et al. 2011). Carbon isotopes $\left({ }^{13} \mathrm{C} /{ }^{12} \mathrm{C}\right.$ ratios) vary among primary carbon sources (primary producers) within a food web due to different inorganic substrate and pathways used in photosynthesis (Smith \& Epstein, 1970). Predictable patterns in carbon isotope values (e.g. marine versus terrestrial, inshore versus offshore, benthic versus pelagic), can be used to illustrate reliance on different carbon pathways because of minimal isotopic fractionation (0-1\%) (De Niro \& Epstein, 1978) between source and consumer (but see Caut et al. 2009; Busst \& Britton, 2016). Nitrogen isotopes $\left({ }^{15} \mathrm{~N} /{ }^{14} \mathrm{~N}\right.$ ratios) indicate the trophic position of a consumer (Post, 2002) because of the predictable stepwise enrichment in ${ }^{15} \mathrm{~N}$ per trophic level transfer, generally estimated as 3.5\% (Post, 2002) but can be as high as 5\%o for some marine herbivores (Mill et al. 2007). In practice, nitrogen enrichment has been shown to decrease with successive trophic levels (Hussey et al. 2014) and sponge $\delta^{15} \mathrm{~N}$ values have been shown to vary between co-occurring species by $>3.5 \%$ in polar (Thurber, 2007), temperate (Freeman et al. 2016) and tropical habitats (Freeman et al. 2014; Freeman et al. 2016). Both carbon and nitrogen isotope values of an individual or a population are commonly represented on an isotope biplot, which is useful for depicting relative positions of species within a community (Newsome et al. 2007). Furthermore, intraspecific variation in isotope values can be used as a measure of niche width (Bearhop et al. 2004) provided that isotopic variation in food sources is considered (Newsome et al. 2007). For example, Layman et al. (2007) used intraspecific variation in isotope values to demonstrate the effects of habitat fragmentation 
on the trophic ecology of the grey snapper Lutjanus griseus. Snapper from fragmented tidal creeks had smaller niche widths than snapper from unfragmented creeks due to a collapse in prey diversity and the disruption of hydrological connectivity (Layman et al. 2007). To quantify niche width, Layman et al. (2007) used the total area of the convex hull (TA), which is the smallest polygon that can be drawn around all individual data points. However, TA is sensitive to sample size, preventing robust comparisons amongst data sets with different sample sizes, as is common in ecological studies (Jackson et al. 2011). To address these methodological issues, Jackson et al. (2011) suggested that niche width be quantified using standard ellipse areas (SEA). A standard ellipse can be understood as a measure of deviation for bivariate $\left(\delta^{15} \mathrm{~N}\right.$ and $\left.\delta^{13} \mathrm{C}\right)$ data that is comparable to standard deviation for univariate data (Jackson et al. 2011). It contains approximately $40 \%$ of the sample data of a group/ species and is less sensitive to sample size than the TA (Jackson et al. 2011). Furthermore, the application of Bayesian inference techniques generates probability distributions of the standard ellipse area allowing for statistical comparisons between different groups (Jackson et al. 2011). In addition, an overlap of SEA among different species indicates similar resource use and can be used as an indicator of interspecific competition (Frisch et al. 2016; Eurich et al. 2019). On coral reefs, these methods have been used to investigate the trophic diversity and tropic position of reef sharks which were found to occupy a similar position in the food chain to mesopredators such as snappers and grouper (Frisch et al. 2016). These findings question the functional role of reef sharks which are frequently assumed to be apex predators even though they have similar diets to teleost fishes (Frisch et al. 2016). Eurich et al (2019) used the isotopic niche (SEA) to illustrate trophic diversity and niche overlap between seven different species of territorial damselfish. Despite generally being classified in the same functional group (territorial algalturf herbivores) none of the species examined were strict herbivores and some relied mainly on pelagic carbon (Eurich et al. 2019). Both of these studies highlight how SIA can be applied to studies that seek to address functional processes on reef systems.

\subsection{Diet characterisation}

\subsubsection{Visual techniques}

Characterising the diet of a predator is key to determining its ecological function (Leray et al. 2015). One of the disadvantages of stable isotope analysis is that it cannot easily be used to identify specific dietary components (Nielsen et al. 2018), particularly in high diversity systems such as coral reefs. Visual techniques (in situ observations and gut content analysis) remain some of the best methods of characterising trophic interactions (Nielsen et al. 2018). In the context of sponge predators, long-term observational studies were key to revealing the impact of predation on sponge assemblages in the Antarctic (Dayton et al. 1974; Wulff, 2006) and gut contents have highlighted previously unknown feeding behaviours (Santos et al. 2002). Providing sponge assemblages have been catalogued and characterised (Wulff, 2006) in situ observations can lead to species level resolution whereas digestion 
can limit identification of stomach contents (Nielsen et al. 2018). Conversely, gut contents provide an unambiguous record of sponges being ingested (Wulff, 2006) where visual observations often fail to distinguish targeted prey (Nagelkerken et al. 2009; Pawlik et al. 2018). Visual observations can also reveal other interesting details about feeding behaviours and provide quantitative estimates of diet (Cole et al. 2011). They are, however, limited by a number of factors. In situ observations are complicated in marine systems (Nielsen et al. 2018) often requiring time-intensive approaches (Wulff, 2006) and fish behaviour can be altered by diver presence (Emslie et al. 2018). Gut content that can't be obtained by gastric lavage requires destructive sampling, which is not ethically appropriate for rare species. Gut content samples cannot capture liquid feeding (Nielsen et al. 2018) and are biased towards items that retain structural integrity, thus underestimating soft-bodied prey (Nielsen et al. 2018). Despite these drawbacks, using in situ observations and gut content analysis in tandem can provide more detail on the specific diets of reef fish (Nagelkerken et al. 2009) and assist with the categorisation of functional roles.

\subsubsection{Molecular techniques}

Over the past decade, molecular methods of diet characterisation have been favoured by aquatic and terrestrial researchers (Nielsen et al. 2018) due to their ability to overcome some of the problems associated with visual techniques (Vestheim \& Jarman, 2008). Polymerase chain reaction (PCR) is a sensitive technique that can target even small amounts of DNA (Symondson, 2002) providing resolution to highly degraded or rare prey items (Vestheim \& Jarman, 2008; Nielsen et al. 2018). DNA extraction and amplification can be used on whole samples when species consume relatively large prey. For example, Dunn et al (2010) used DNA barcoding techniques on muscle tissue retrieved from deepwater sharks improving the rate of data accumulation. DNA barcoding techniques can also be used on gut content homogenates or faecal matter (Deagle et al. 2009; Leray et al. 2015). For example, Deagle et al. (2009) used DNA analysis of faeces to reveal the importance of redbait, jack mackerel and blue mackerel to the diets of Australian fur seals. Visual gut content analysis conducted in tandem with DNA analysis confirmed the same main prey species but yielded much lower species diversity and some groups were unrepresented (eg. cartilaginous fish) (Deagle et al. 2009). Similarly, Leray et al. (2015) used DNA analysis of gut contents of coral-dwelling hawkfishes to demonstrate a high degree of diet partitioning. They identified approximately 300 unique DNA sequences in hawkfish gut contents, significantly increasing knowledge of the number of taxa consumed by this family of reef fishes. Thus, DNA gut content analysis has the potential to vastly improve our understanding of trophic links in marine systems. However, working with degraded DNA also presents a host of methodological challenges including predator DNA swamping, PCR inhibitors eg. bile, faeces and co-amplification of non-target sequences (O’Rorke et al. 2012). 


\subsection{Study site}

\subsubsection{The Wakatobi Marine National Park}

The first three data chapters of this thesis (Chapters 2-4) were focused in the Wakatobi Marine National Park (MNP), located in The Coral Triangle, Indonesia (Figure 1.1). The Coral Triangle is recognised as the global centre for marine biodiversity and home to over 500 species of coral (Allen \& Adrim, 2003). The trajectory of this area reflects the global trajectory of reef systems, with coral cover nearly halving from $42.5 \%$ in the 1980 s to $22.1 \%$ by 2003 (Bruno \& Selig, 2007), although not in all areas (e.g. Moritz et al. 2018).

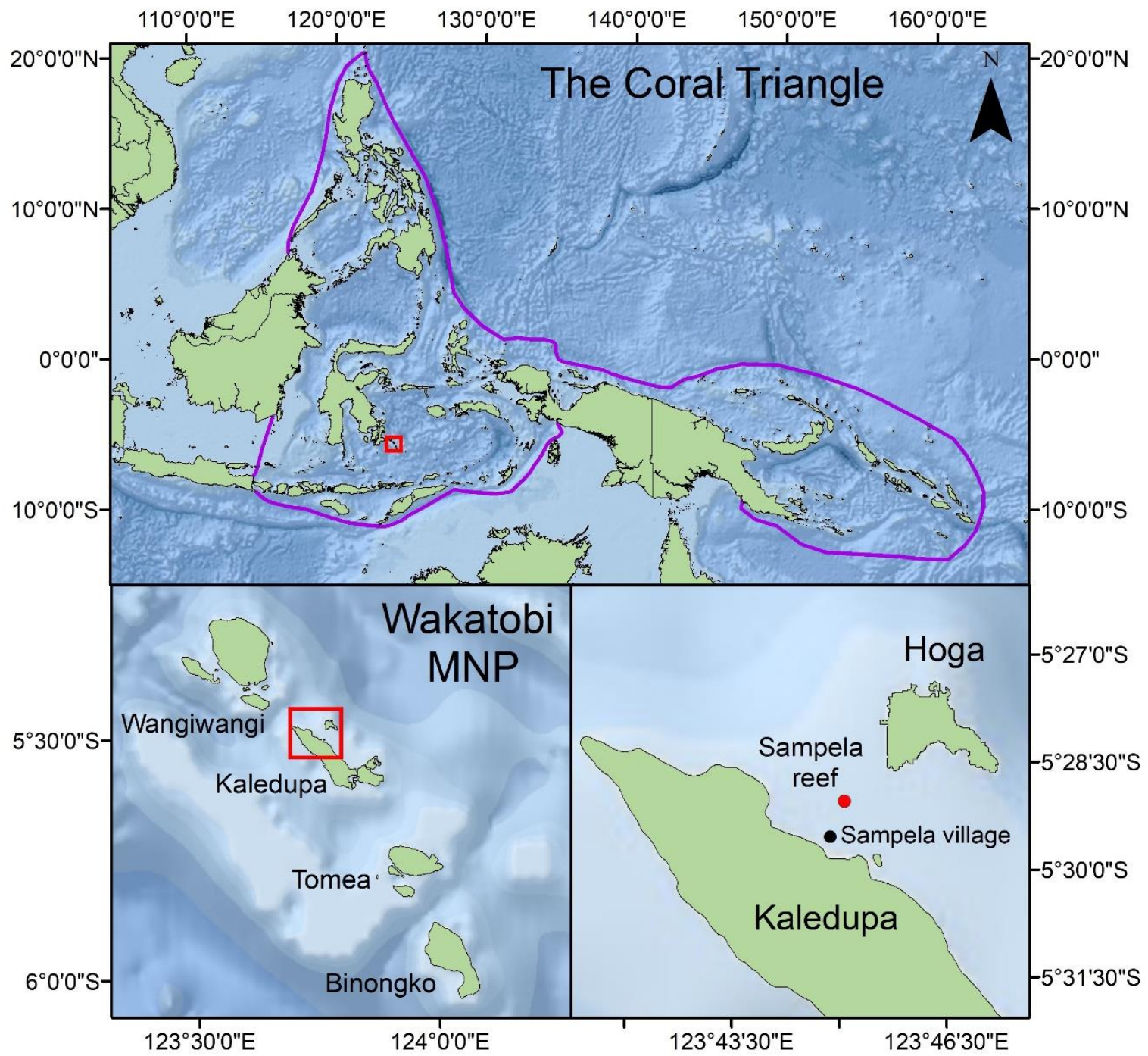

Figure 1. 1 Location of the study area within the Wakatobi Marine National Park, and its position within The Coral Triangle (purple boundary).

The Wakatobi MNP is a World Biosphere Reserve and the third largest, most populated marine national park in Indonesia with approximately 100,000 people residing within the park boundary (Cullen, 2007). 
Reefs in the Wakatobi MNP are considered most threatened by destructive fishing practices (e.g. bomb and cyanide fishing) (Allen, 2008; Clifton \& Unsworth, 2013), which affects 60\% of reefs in the region (Burke et al 2011). A history of poor resource management and high resource pressure has already caused an estimated 50\% decline in hard coral cover from 2000-2007 (McMellor \& Smith, 2010). The Sampela reef system provides an example for shallow coral reefs in the Anthropocene that shift towards sponge dominance. Sampela reef is impacted by high levels of sedimentation (Crabbe \& Smith, 2005; Curtis-Quick, 2013) and its proximity to the Bajo intertidal settlement of Sampela Village means that pressure on the reef system historically has been high. During 2000-2007, hard coral cover declined from $\sim 33 \%$ to $\sim 12 \%$ (McMellor \& Smith, 2010) however sponge density increased (Bell \& Smith, 2004), and this site has now transitioned from a coral- to a sponge-dominated reef (Bell \& Smith, 2004; Powell et al. 2014). This regime shift has been driven almost exclusively by increases in the abundance of an encrusting phototrophic sponge Lamellodysedia herbacea, which accounts for over $40 \%$ of sponge abundance (Powell et al. 2014). Lamellodysedia herbacea shows tolerance for the poor environmental conditions at Sampela through effective sediment clearance mechanisms and rapid photoacclimation (Biggerstaff et al. 2015; Biggerstaff et al. 2017). Previous work on this reef has indicated a higher abundance of spongivorous fishes relative to surrounding less-degraded reefs (Powell, 2013) indicating that it may support more spongivorous species (Bell et al. 2013). However, uncertainties remain regarding the functional role of some species previously categorised as spongivores (Powell et al. 2014; Bell et al. 2017) and accurate quantification of a species' functional impact is essential to preserve ecosystem processes in the Anthropocene (Bellwood et al. 2019). Research to date has been focused on identifying the drivers of the regime shift (Powell et al. 2014; Biggerstaff et al. 2017). However, considering that sponge-dominated reefs may be a realistic scenario for some future reefs (Bell et al. 2013) it is essential to examine how shifts to sponge dominance affect the trophic structure of reefs.

\subsection{Goals and aims}

The main aim of this thesis was to investigate sponge trophic interactions to gain insight into how sponge-reefs of the future might function.

The aims of my thesis were:

1. To estimate sponge consumption by spongivorous fishes on Wakatobi reefs and identify predated sponges. I used a combination of video observations and gut content analysis to correctly identify spongivorous fishes, then combined density data with quantitative data on sponge consumption by spongivorous species. This allowed me to address previous functional misclassifications and to compare sponge-spongivore pathways with the coral-corallivore pathways, whilst highlighting predation intensity by different species of reef fish. In situ observations of species with the highest predatory impact on sponge assemblages also highlighted any diet preferences for particular sponge species. 
2. To develop molecular methods to identify predated sponges from the gut contents of spongivorous angelfishes. This improved the taxonomic resolution for predated sponges by overcoming some of the problems associated with visual observations of sponge predation in a species-rich environment. It also allowed me to compare diet preferences on Indo-Pacific angelfishes with angelfishes from other reef locations.

3. To investigate how habitat quality affects niche widths and trophic diversity in a coral reef fish assemblage. I measured the carbon and nitrogen stable isotope ratios of seven species of reef fish, carbon sources and other benthic prey. This allowed me to examine differences in the trophic position and niche width of individual fish species, and to quantitively compare trophic structure between sites.

4. To investigate niche partitioning and resource use among co-occurring temperate sponges. In this chapter, I used stable isotope analysis to calculate the isotopic niches of five sponge species at two sites (Outer Fiord and Inner Fiord) at two different depths (10 m and $30 \mathrm{~m}$ ) in Doubtful Sound, Fiordland. I used isotope data to investigate shifts in resource use over depths and between species. I also used isotope mixing models to estimate the contribution of carbon sources to the diets of each sponge species. 


\section{Chapter 2. Biomass transferred from sponges to spongivores equates to the coral- corallivore pathway}

\subsection{Abstract}

Accurate knowledge of the diets of individual species is essential to understand the range of functional roles played by coral reef fishes. Sponges are key members of benthic communities, however, in the Indo-Pacific, an area of exceptionally high sponge diversity, spongivorous fish and predated sponges are relatively unknown. In this chapter, I studied sponge-grazing fishes in the Wakatobi Marine National Park (MNP) using a combination of observational approaches and gut content analysis to quantify sponge consumption. Video analysis identified 33 species from 10 families of reef fish grazing on Xestospongia spp. although $95 \%$ of bites were taken by only 11 species. Gut content analysis indicated that Pygoplites diacanthus and Pomacanthus imperator were obligate spongivores and Pomacanthus xanthometopon, Zanclus cornutus and Siganus punctatus regularly consumed sponges. Species-specific data on the mean weight (wet weight $-0.01 \mathrm{~g}$ ) of sponge in stomachs combined with spongivore densities provided a reef-wide estimate of sponge consumption for these five spongivorous fishes of $46.6 \pm 18.3 \mathrm{~g}$ sponge $1000 \mathrm{~m}^{-2} \mathrm{day}^{-1}$. In situ observations of feeding behaviour indicated that sponges from the genus Clathria and the family Petrosiidae were preferred by P. diacanthus and Z. cornutus. Despite numerous observations of sponge-grazing, gut contents indicated that Chaetodon kleinii and Forcipiger flavissimus targeted sponge-associated macrofauna. Similarly, sponge-grazing behaviour exhibited by the detritivore Ctenochaetus binotatus could not be explained by gut contents but may indicate a preference for sponge bi-products such as mucus or cellular detritus. This study provides the first known estimate of reef-wide sponge consumption and suggests that in the Wakatobi MNP, biomass transferred between sponges and spongivores may be similar to biomass transferred between corals and corallivores. Hence, spongivory is potentially an important yet overlooked trophic link on Indo-Pacific reefs. 


\subsection{Introduction}

Accurate quantification of a species' functional impact is essential to provide accurate estimates of ecosystem function (Bellwood et al. 2019). Yet, aside from well-studied groups on coral reefs e.g. herbivores and corallivores (Bellwood \& Choat, 1990; Bellwood et al. 2004; Pratchett et al. 2005; Cole et al. 2011) our understanding of the range of functional roles performed by individual marine species remains limited. This impacts our ability to make informed recommendations on the preservation of ecosystem functions and services on transitioning coral reefs (Bellwood et al. 2019). Spongivores as a functional group have been relatively overlooked outside of the Caribbean (but see Powell et al. 2015), where sponge biomass is thought to exceed that of corals (Diaz \& Rützler, 2001). Reports of increasing sponge abundance from many global locations (Bell et al. 2013; McMurray et al. 2015; Ruzicka et al. 2013; de Bakker et al. 2017) has led to increased interest in the interactions of sponges with other organisms (Wulff, 2012; Pawlik et al. 2018). However, our understanding of the ecological significance of spongivory is restricted by limited data on the taxonomic breadth of spongivores and their preferred prey (Wulff, 2017). Similarly, the predatory impact of spongivores will be influenced by their density and dependence on sponges. Although obligate spongivores have not been explicitly defined in the literature, obligate corallivores are defined as species that rely on corals for $\geq 80 \%$ of their diet (Cole et al. 2008), hence a similar definition appears appropriate for spongivores. One of the best-known obligate spongivores is the hawksbill turtle Eretmochelys imbricata, which feeds almost exclusively on a narrow range of highly silicified, toxic sponges (Meylan, 1988). Predation pressure from Hawksbill turtles has greatly reduced over the past few decades as turtle populations have been decimated by hunting, habitat loss and poaching (McClenachan et al. 2006; Miller et al. 2019). Reduced predation pressure on sponges from Hawksbill turtles coupled with an increase in space for sponge recruitment due to coral mortality has been linked to an increase in sponge abundance on Caribbean reefs (Pawlik et al. 2018).

Of the vertebrate spongivores still sufficiently abundant on Caribbean reefs, angelfishes (family Pomacanthidae) are somewhat synonymous with spongivory, with at least five species considered obligate spongivores (Randall \& Hartman, 1968; Hourigan, et al 1989; Dunlap \& Pawlik, 1996; Wulff, 1994; Slattery et al. 2016). Angelfishes are thought to reduce the harmful effects of sponge defensive compounds by foraging on a wide range of sponge species (Randall \& Hartman, 1968; Hourigan et al. 1989; Wulff, 1994), a so-called 'smorgasbord' approach (Randall \& Hartman, 1968; Wulff, 2006). This is not thought to lead to significant sponge morality because only part of the sponge is consumed (Wulff, 2006) and those that do experience significant grazing regenerate quickly (Pawlik, 2011). In addition to angelfishes, boxfishes (family Ostraciidae), filefishes (family Monacanthidae) and pufferfishes (family Tetraodontidae) regularly consume sponges as part of an omnivorous diet (Randall \& Hartman, 1968; Wulff, 1994). Parrotfishes (family Scaridae) have also been recorded consuming sponges (Dunlap \& Pawlik, 1996; Loh \& Pawlik, 2009), however, their potential impact on sponge assemblages on reef 
systems remains contentious because they are not considered to be regular spongivores (Wulff, 2017). Outside the Caribbean, some butterflyfishes (family Chaetodontidae) have been documented with sponge tissue in their guts in the Central and Indo-Pacific (Hobson, 1974; Sano, 1989; Nagelkerken et al. 2009). However, the volume of sponge found in all species was $<20 \%$ indicating that sponges were a minor prey item or, for those with $<5 \%$ volume, potentially ingested incidentally in the pursuit of other prey (Randall \& Hartman, 1968; Nagelkerken et al. 2009). The only member of the family Zanclidae, the Moorish Idol Zanclus cornutus, had gut contents dominated by sponges in Hawaii (>80\%: Hobson, 1974). however, in the Gilbert Islands, it consumed mainly algae (Randall, 1955), hence the diets of some species can vary among substantially among geographic locations and habitats. Rabbitfishes (family Siganidae) are generally considered to be grazing or browsing herbivores (Green \& Bellwood, 2009; Hoey et al. 2013) however, Siganus puellus and Siganus punctatus have both been reported to consume substantial quantities of sponge (Sano, 1989; Pitt, 1997; Hoey et al. 2013). This highlights the variation that can exist within a family frequently viewed as a uniform functional group e.g. herbivores (Green \& Bellwood, 2009; Hoey et al. 2013).

Indo-Pacific reefs exhibit some of the highest sponge diversity in the world (Bell \& Smith, 2004; de Goeij et al. 2017; Rovellini et al. 2019) however, few studies have considered the role of spongivory (but see Powell et al. 2014; Powell et al. 2015). Powell et al. (2014) listed 21 species of spongivorous reef fishes reported from seven studies covering the Indian Ocean, the Indo- and Central Pacific. The abundance of these 21 species was subsequently used as a factor explaining variation in sponge abundance in the Wakatobi Marine National Park (Powell et al. 2014). However, only 11 of the 21 species listed by Powell et al. (2014) had gut content data verifying sponge as ingested prey. Fish may bite at sponges but have no predatory impact (Bell et al. 2017; Pawlik et al. 2018), which seems likely for two surgeonfishes (Ctenochaetus binotatus and Acanthurus pyroferus) included in the list of spongivores (Powell et al. 2014). C. binotatus and A. pyroferus are generally considered grazers/detritivores (Green \& Bellwood, 2009) that lack the necessary dental morphology to remove sponge tissue (Bellwood et al. 2014). Combining species which likely fulfil different functional roles on reef systems into the category of spongivore could inadvertently bias results (Wulff, 2017). When the functional role of a species remains ambiguous, direct methods of quantification that characterise true diet can prevent functional misclassifications and provide more detail on a specific diet (Nagelkerken et al. 2009; Bell et al. 2017; Nielsen et al. 2018).

Detailed quantitative analysis of stomach contents combined with fish densities can be used to estimate biomass consumption of individual species and functional groups (Harmelin-Vivien \& BouchonNavarro, 1982; Harmelin-Vivien \& Bouchon-Navarro, 1983) and provide direct estimates of the magnitude of a functional process e.g. material consumption per unit area (Bellwood et al. 2019). Estimates of reef wide coral consumption by corallivorous butterflyfish have been calculated using these methods in the Central Pacific (Harmelin-Vivien \& Bouchon-Navarro, 1983) and the Red Sea 
(Harmelin-Vivien \& Bouchon-Navarro, 1982) however there are no published estimates of reef-wide sponge biomass removal by spongivorous fishes. Corallivorous fishes are extremely vulnerable to environmental disturbance due to their heavy reliance on corals (Graham et al. 2011) and localised extinctions have already been reported for some coral specialists (Kokita \& Nakazono 2001; Munday, 2004; Brooker et al. 2014) as corals continue to decline (Hughes et al. 2017). By contrast, transitions towards sponge-dominance have been reported from several reefs worldwide (see Bell et al. 2013 for review) and spongivores may benefit from increasing sponge abundance at the expense of corallivores (Bell et al. 2013; Bell et al. 2018b).

In this chapter, I used the same methods as Harmelin-Vivien \& Bouchon-Navarro $(1982,1983)$ with the primary aim of quantifying sponge biomass removed by spongivorous fishes. My aims were: i) to identify sponge-grazing fishes; ii) to measure sponge-grazing fish densities, and iii) to quantify the amount of sponge consumed by sponge-grazing fishes. Considering that the impact of sponge biomass removal will depend on the sponges targeted, I also carried out in situ feeding observations with the secondary aim of identifying predated sponges. 


\subsection{Methods}

\subsubsection{Study sites}

The present study was conducted at four sites within the Wakatobi Marine National Park, the thirdlargest marine national park in Indonesia (Clifton \& Unsworth, 2013) (Figure 2.1). Reefs in the IndoPacific region are considered the most threatened in the world (Burke et al 2011), particularly by unsustainable fishing practices (Allen, 2008), which affects $60 \%$ of reefs in the region (Burke et al 2011). Four sites were chosen that were separated by at least $3 \mathrm{~km}$, aside from Sampela and B1, that are separated by a channel that is $1.5 \mathrm{~km}$ wide and extends to a depth of $40 \mathrm{~m}$, thus limiting the movement of coral reef fish between the Hoga and Kaledupa reef systems.

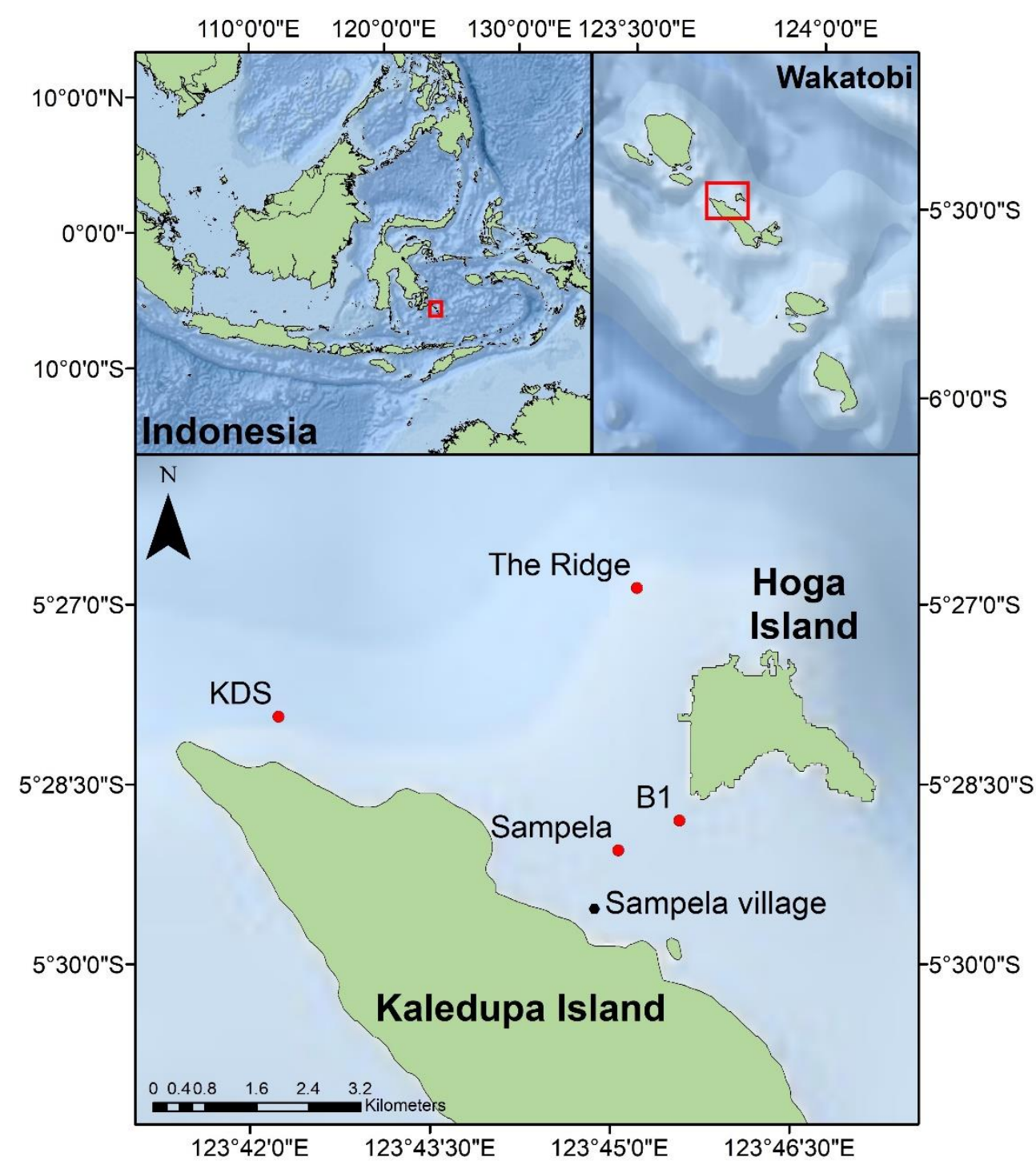

Figure 2. 1 Map of the four study sites and the position of the Hoga/ Kaledupa channel within the Wakatobi Marine National Park and Indonesia. 
Both Sampela and Kaledupa Double Spur (KDS) are located on the fringing reef surrounding Kaledupa Island. Sampela is approximately $500 \mathrm{~m}$ from the intertidal Bajo settlement of Sampela village at the narrowest part of the channel separating the two islands, whereas KDS is located at the northeast side of Kaledupa Island. B1 is located opposite the Sampela reef site on the west side of Hoga Island and The Ridge is located on a ridge approximately $1 \mathrm{~km}$ offshore from Hoga Island. The Sampela reef system is the most degraded of the four sites, experiencing sedimentation rates that are four times higher than the other three reef sites (Crabbe \& Smith, 2005) with the lowest abundance of live coral cover $\sim 10 \%$ (unpublished monitoring data, Operation Wallacea, 2016). This site has experienced a coralsponge regime shift (Powell et al. 2014) and has a high abundance of the phototrophic encrusting sponge Lamellodysedia herbacea (Powell et al. 2014; Biggerstaff et al. 2015). B1 has moderate coral cover $\sim 20 \%$ and both The Ridge and KDS have higher coral cover $\sim 35 \%$ (unpublished monitoring data, Operation Wallacea, 2016).

\subsubsection{Field surveys of sponge-grazing fishes}

To identify sponge-grazing fishes, videos of the giant barrel sponge Xestospongia spp. were conducted at all four sites from June to August 2016. Barrel sponges in the Wakatobi MNP are comprised of a species complex including X. testudinaria, X. bergquistia and an undescribed species (Bell et al. 2014). Xestospongia spp. was chosen because an initial trial suggested this genus incurs significant grazing activity (Appendix A) and was present in sufficient densities across the four study sites. Additionally, the Caribbean congener X. muta was used by Dunlap \& Pawlik (1998) to monitor predation by parrotfishes, suggesting that members of this genus attract predators in a variety of reef locations. A GoPro camera was deployed approximately $1 \mathrm{~m}$ away from the sponge and set to record at the end of diving activities to maximise the amount of footage in which diving activities did not disrupt fish behaviour (Emslie et al. 2018). To avoid any effect of depth or microhabitat on fish assemblages (Depczynski \& Bellwood, 2004; Stefanoudis et al. 2019), sponges were filmed on the open reef slope (10 - 14 m depending on the site). At the beginning of the video, a measuring stick was placed next to the sponge to generate screenshots from which $2 \mathrm{D}$ area of sponge captured in the frame was estimated. All cameras were deployed during the morning ( $0800-1100)$ and collected on a subsequent dive in the afternoon, often yielding $>2$ hours of uninterrupted footage.

\subsubsection{Video analysis}

The first five minutes of video footage were discarded to account for disturbance from divers leaving the site. The remaining footage was analysed by counting all bites made by fish on Xestospongia spp. with bites determined as individual 'strikes' on the sponge surface. Fish were identified to species level except for Ctenochaetus spp. where it was not always possible to distinguish between C. binotatus or C. striatus due to poor visibility. However, of the fish that could be identified, $>95 \%$ of bites were attributed to $C$. binotatus. Distinguishing individual fish that may have fed repeatedly from the same 
sponge was not possible using these methods, however, the aim was to measure the grazing intensity of each species rather than individual bite rates. To calculate the area of sponge captured in video footage, screenshots generated from footage containing the scaling device were imported into Image $\mathbf{J}$ (Abramoff et al. 2004). The difference in overall grazing intensity (count of bites - all species combined) between sites was tested using negative binomial regression using the MASS package (Venables \& Ripley, 2002) for R studio (RStudio Team, 2015) with footage length (minutes) and area of sponge $\left(\mathrm{m}^{2}\right)$ included as offsets in the model. Fitting both footage length and area as offsets allowed both of these predictors to vary, which was preferable to discarding data by standardising to the shortest video. To determine any differences in fish species contributing to grazing intensity (total bites) at each site, I used PERMANOVA+ add-in to PRIMER version 6.1 (PRIMER-E Ltd, Plymouth, UK). This was done using Type III sums of squares and based on a Bray-Curtis similarity matrix with the unrestricted permutation of raw data and subsequent pair-wise comparisons. Data were checked for multivariate homogeneity of group dispersions using PERMDISP. Data were standardised and square root transformed prior to analysis to reduce the influence of frequent grazers (Clarke and Warwick 2001). The Similarity Percentages routine (SIMPER) was performed to calculate the contribution of each species (\%) to the dissimilarity between sites. The more consistently abundant a species is within a site, the more it contributes to intra-site similarity, whereas a species that is consistently abundant at one site but not another is a good discriminating species (Clarke \& Warwick 2001).

\subsubsection{Sponge-grazing fish densities}

Sponge-grazing fish densities were quantified at all sites by underwater visual census (UVC) using six replicate $50 \mathrm{~m} \times 5 \mathrm{~m}$ belt transects deployed on the reef slope $(8-10 \mathrm{~m})$ with each transect separated by $15 \mathrm{~m}$. For each transect, the lead diver recorded fish data and a second diver followed behind deploying the transect tape to ensure the area covered was undisturbed by diver presence (Emslie et al. 2018). Fourteen species of sponge-grazing fishes were recorded by UVC (Table 2.2). This included nine out of 11 species recording $>95 \%$ of all bites on Xestospongia spp. (Table 2.1). The other two species (Heniochus singularius and Scarus flavipectoralis) were not recorded because they had not yet been identified as sponge-grazers (not all of the video footage had been analysed at the time of the UVC). Four additional species of Pomacanthidae (Centropyge vroliki, Pomacanthus imperator, Pomacanthus xanthometopon and Pomacanthus sexstriatus) were also recorded because they were observed in initial videos of sponge-grazing activity (Appendix A) and previously observed grazing on sponges (Powell et al. 2015). A difference in the density of sponge-grazing fishes between sites was analysed using a one-factor ANOVA, with test assumptions verified by Shapiro-Wilk test of normality and Levene's test of the equality of variances. To determine any differences in the community structure of sponge-grazing fishes between sites, I used PERMANOVA+ (as above) using Type III sums of squares and based on a Bray-Curtis similarity matrix with the unrestricted permutation of raw data and subsequent pair-wise comparisons. Data were checked for multivariate homogeneity of group dispersions using PERMDISP. 
Data were square root transformed prior to analysis and SIMPER was carried out to identify species responsible for the differences in assemblage structure between sites.

\subsubsection{Gut content analysis}

To quantify the amount of sponge consumed by sponge-grazing fishes, five species (Ctenochaetus binotatus, Chaetodon kleinii, Pygoplites diacanthus, Zanclus cornutus, Forcipiger flavissimus) identified from the Xestospongia spp. video footage as frequent sponge grazers were spear-fished at The Ridge and Sampela over two weeks in July 2017 by local spearfishers (see Table 2.3 for sample sizes). Fish were collected at both sites, but data were combined due to small sample sizes. One Pomacanthus imperator was purchased from fishers at Sampela, and Pomacanthus xanthometopon $(\mathrm{n}=3)$ and Siganus punctatus $(\mathrm{n}=5)$ were purchased from fishers at the Ridge. These species were not observed in videos of Xestospongia spp., but they were observed feeding on other sponges in an initial trial (Appendix A). Fish were placed on ice immediately after spearing and kept at $-20^{\circ} \mathrm{C}$ until dissection. During dissection, fish were weighed $(0.1 \mathrm{~g})$ and total length $(\mathrm{mm})$, standard length $(\mathrm{mm})$ and gape size $(\mathrm{mm})$ were recorded. The entire digestive tract was removed, preserved at $-20^{\circ} \mathrm{C}$ in $96 \%$ ethanol to prevent further digestion. Preserved digestive tracts were returned to Wellington and dissected at the Victoria University Coastal Ecology Laboratory (VUCEL). During dissection, contents from the stomach (or entire digestive tract for C. binotatus and S. punctatus) were examined under a dissecting microscope and separated into identifiable and unidentifiable portions. For $P$. diacanthus, Pomacanthus spp., S. punctatus and Z. cornutus, food items in the identifiable portion were separated into 13 major categories (Table 2.3), blotted to remove gastric juices and weighed (wet weight- $0.01 \mathrm{~g}$ ) to estimate diet proportions. Due to low stomach/ digestive tract volumes, the diet composition of $C$. kleinii, F. flavissimus and $C$. binotatus, was estimated visually via relative volumetric quantity using a stereomicroscope (after Nielsen \& Johnson, 1992). Samples of sponges recovered from gut contents were stored in separate microcentrifuge tubes at $-20^{\circ} \mathrm{C}$ in $96 \%$ ethanol for subsequent DNA extraction (Chapter 3). All dissecting instruments were ethanol cleaned and rinsed three times with double distilled water (DDW) between stomachs to prevent cross-contamination.

Levin's standardised diet breadth (Levin, 1968) was calculated by first estimating niche breadth according to the equation:

$\mathrm{B}=\frac{1}{\sum \mathrm{p}_{\mathrm{j}}^{2}}$

where B is diet breadth and $p$ is the proportion of overall diet made up by the food category ( $\mathrm{j}$ ). This can then be standardised and expressed on a scale of $0-1$ according to the following:

$\mathrm{BA}=\frac{\mathrm{B}-1}{\mathrm{n}-1}$ 
where BA is the standardised niche breadth, B is the measure of niche breadth and $\mathrm{n}$ is the number of food categories. Low values indicate a specialised diet based on few dietary items.

\subsubsection{Sponge consumption}

To estimate sponge consumption, I used the mean weight (wet weight $-0.01 \mathrm{~g}$ ) of sponge in the gut contents of each species and assumed that stomachs are filled at least twice daily (Harmelin \& Vivien, 1983). This amount was multiplied by the total number of fish of each species observed at each site and scaled to $1000 \mathrm{~m}^{-2}$.

\subsubsection{Feeding observations}

\subsubsection{Food availability}

To determine the proportion of available food resources, ten $1 \mathrm{~m}^{2}$ divided quadrats were placed randomly along a $100 \mathrm{~m}$ stretch of reef slope at B1, Sampela and The Ridge. Pictures were taken of each $25 \mathrm{~cm}^{2}$ divided section to determine benthic cover. Photo quadrats were analysed using CPCe (Kohler \& Gill, 2006) with 60 points randomly assigned per divided picture yielding 960 points per $1 \mathrm{~m}^{2}$ quadrat. The number of points was determined following repeated measures analysis conducted on a subset of quadrats which showed that 60 points recorded significantly more benthic categories than 5, 10, 20 and 30 points, but not significantly fewer than 120 points (Appendix B, Table 4). Points were assigned to the following major categories: hard coral, sponge, soft coral, macroalgae, turf algae, CCA, rock covered with sand, rock covered with algae, dead coral, sand, detritus (detrital macroalgae or seagrass), rubble, other (e.g. starfish, urchins) and undetermined. To determine differences in benthic community structure between sites, quadrat data were analysed using the same PERMANOVA+ design as described above (see 2.3.4). A difference in sponge abundance between sites was analysed using a one-factor ANOVA, with test assumptions checked using the Shapiro-Wilk test of normality and Levene's test of the equality of variances.

\subsubsection{Observations}

The sponge grazers Pygoplites diacanthus, Zanclus cornutus and Coradion melanopus were chosen for an in situ study to identify predated sponges. Feeding observations were conducted throughout the day from 07:00 to 16:00 at Sampela, B1, and the Ridge, during 2016 and 2017. Replicate 3-minute observations were carried out based on the methodology outlined by Berumen et al. (2005). Briefly, data collection commenced after a 3-minute acclimation period, or after the fish took its first bite, and were aborted if the fish fled or sought refuge from the diver (Berumen et al. 2005). The total number of bites was recorded on the following benthic categories: sponge, hard coral, soft coral, macroalgae, detritus (detrital macroalgae or seagrass), other invertebrates and rock (rock with algae, rock with sand, turf algae, CCA and rubble). Subcategories of rock were recorded during observations, but these were combined into the major category 'rock' for selectivity analyses because targeted organism could not be accurately determined. Sponges were identified to the lowest taxonomic level in situ and samples 
were taken to aid with identification. A minimum of 25 observations was made for each species, except for C. melanopus, which was found in low densities (Table 2.2) and was only observed at B1 $(\mathrm{n}=6)$.

Selectivity for each benthic category was assessed by calculating Manly selection functions $\left(w_{i}\right)$ using the package adehabitatHS (Manly et al. 2002) for R studio, which compares the proportional use of each benthic category $\left(u_{i}\right)$ with the proportional availability of that benthic category $\left(p_{i}\right)$ (Manly et al. 1993) according to the following:

$w_{i}=u_{i} / p_{i}$

Data were based on a Type II design where resources are equally available for all individuals observed and use of each substrate type is measured for each fish (Manly et al. 2002). For fish feeding studies, use relates to the number of bites on each substrate type in a given period (Berumen et al. 2005). Bonferroni-corrected 95\% confidence intervals were calculated around each selection function with positive selectivity determined by selection functions with confidence intervals that were $>1$. Positive selection functions indicate that a prey item was being used significantly more than would be expected given availability whereas selection ratios that are $<1$ indicate avoidance (Manly et al. 2002).

To highlight selectivity of specific sponge species, sponges in benthic quadrats were identified to the lowest taxonomic level and ranked in order of percentage contribution to overall sponge abundance to determine preference/avoidance of spongivores. Sponges were considered preferred if the percentage of bites $>$ percentage abundance $+5 \%$ and avoided if the percentage of bites < percentage abundance + $5 \%$. The total number of species present in each quadrat was also recorded and a one-factor ANOVA was used to test for a difference in total species recorded between sites. 


\subsection{Results}

\subsubsection{Video observations}

In approximately 50 hours of video footage, 28,477 bites were recorded on Xestospongia spp. across four sites. In total, 33 species from 10 families of coral reef fish were identified grazing on Xestospongia spp. (Table 2.1). Grazing intensity (total bites) was significantly different between sites with barrel sponges at Sampela experiencing fewer bites than barrel sponges at The Ridge $(Z=2.85, p=0.004)$ and barrel sponges at B1 $(\mathrm{Z}=2.59, \mathrm{p}=0.009)$, but not barrel sponges at KDS. Xestospongia spp. at Sampela experienced $12.2 \pm 2.6$ bites $\mathrm{min}^{-1} \mathrm{~m}^{-2}$ whilst Xestospongia spp. at the Ridge experienced 34.9 \pm 10.8 bites $\min ^{-1} \mathrm{~m}^{-2}$ (mean $\pm \mathrm{SE}$ ) (Figure 2.2).

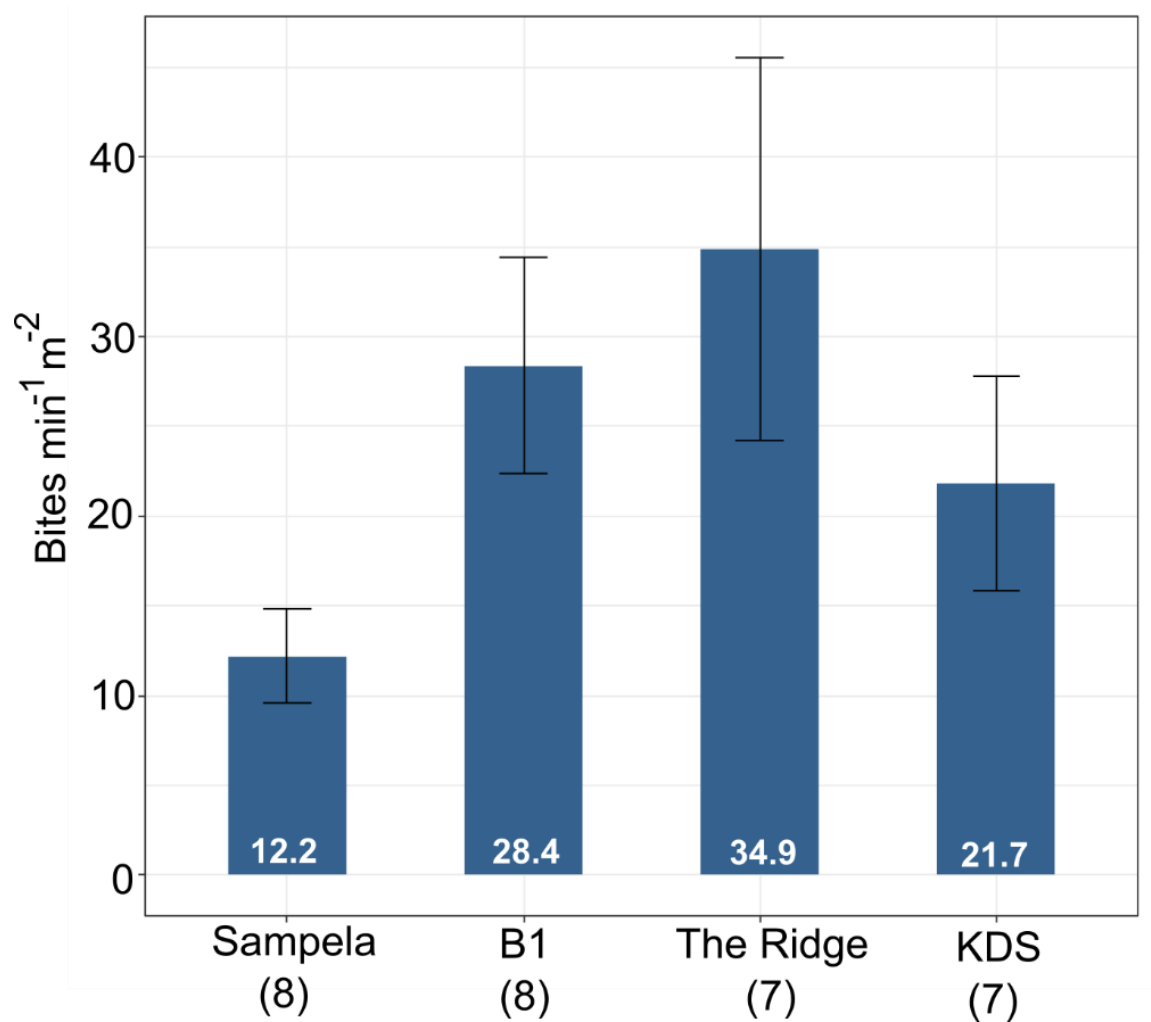

Figure 2. 2 Grazing intensity of fishes (measured as bites $\min ^{-1} \mathrm{~m}^{-2}$ [mean $\left.\pm \mathrm{SE}\right]$ ) on Xestospongia spp. filmed at four sites in the Wakatobi MNP. Number in parentheses is the number of Xestospongia spp. filmed at each site.

Despite the large number of species observed grazing on Xestospongia spp., over half of the total bites recorded were taken by Ctenochaetus spp. and Chaetodon kleinii and 95\% were taken by 11 of the 33 species recorded (Table 2.1). 
Table 2. 1 Total number of bites taken by 33 reef fish species filmed grazing on Xestospongia spp. at four sites in the Wakatobi MNP. Frequency of occurrence in videos (FO \%) calculated from the total number of Xestospongia spp. pooled across all sites $(n=30)$. X indicates fish was observed biting Xestospongia spp. at a particular site and * indicates species sampled for gut contents.

\begin{tabular}{|c|c|c|c|c|c|c|c|c|}
\hline Species & Family & $\begin{array}{l}\text { Total } \\
\text { Bites } \\
\end{array}$ & $\begin{array}{c}\text { Cumulative } \\
(\%)\end{array}$ & $\begin{array}{l}\text { FO } \\
(\%)\end{array}$ & Sampela & B1 & $\begin{array}{l}\text { The } \\
\text { Ridge }\end{array}$ & KDS \\
\hline Ctenochaetus spp.* & Acanthuridae & 10,771 & 37.8 & 80 & $\mathrm{X}$ & $\mathrm{X}$ & $\mathrm{X}$ & $\mathrm{X}$ \\
\hline Chaetodon kleinii* & Chaetodontidae & 7,829 & 65.3 & 86.7 & $X$ & $\mathrm{X}$ & $\mathrm{X}$ & $X$ \\
\hline Zanclus cornutus* & Zanclidae & 1,835 & 71.8 & 36.7 & $\mathrm{X}$ & $\mathrm{X}$ & $\mathrm{X}$ & $\mathrm{X}$ \\
\hline Coradion melanopus & Chaetodontidae & 1,687 & 77.7 & 26.7 & & $\mathrm{X}$ & $\mathrm{X}$ & $\mathrm{X}$ \\
\hline Forcipiger flavissimus* & Chaetodontidae & 1,545 & 83.1 & 40 & & $\mathrm{X}$ & $\mathrm{X}$ & $X$ \\
\hline Centropyge tibicen & Pomacanthidae & 1,167 & 87.2 & 13.3 & $\mathrm{X}$ & $\mathrm{X}$ & & $X$ \\
\hline Scarus flavipectoralis & Scaridae & 996 & 90.7 & 26.7 & $\mathrm{X}$ & $\mathrm{X}$ & & $\mathrm{X}$ \\
\hline Pygoplites diacanthus* & Pomacanthidae & 595 & 92.8 & 20 & $X$ & $\mathrm{X}$ & $\mathrm{X}$ & $X$ \\
\hline Heniochus singularius & Chaetodontidae & 282 & 93.8 & 16.7 & & $\mathrm{X}$ & $\mathrm{X}$ & \\
\hline Centropyge bicolor & Pomacanthidae & 259 & 94.7 & 10 & $\mathrm{X}$ & & & $\mathrm{X}$ \\
\hline Centropyge nox & Pomacanthidae & 225 & 95.5 & 10 & $\mathrm{X}$ & $\mathrm{X}$ & $\mathrm{X}$ & \\
\hline Zebrasoma scopas & Acanthuridae & 163 & 96.1 & 13.3 & & $\mathrm{X}$ & $\mathrm{X}$ & $\mathrm{X}$ \\
\hline $\begin{array}{l}\text { Thalassoma lunare } \\
\text { Chaetodon }\end{array}$ & Labridae & 156 & 96.6 & 23.3 & $\mathrm{X}$ & $\mathrm{X}$ & & $\mathrm{X}$ \\
\hline punctatofasciatus & Chaetodontidae & 138 & 97.1 & 10 & & $\mathrm{X}$ & & $\mathrm{X}$ \\
\hline Balistapus undulatus & Balistidae & 105 & 97.5 & 33.3 & $\mathrm{X}$ & $\mathrm{X}$ & $\mathrm{X}$ & $X$ \\
\hline Centropyge vroliki & Pomacanthidae & 102 & 98.2 & 10 & $\mathrm{X}$ & & & $X$ \\
\hline Chromis xanthochira & Pomacentridae & 102 & 97.8 & 10 & $\mathrm{X}$ & & $\mathrm{X}$ & \\
\hline Anampses meleagrides & Labridae & 89 & 98.5 & 13.3 & $\mathrm{X}$ & $\mathrm{X}$ & & $\mathrm{X}$ \\
\hline $\begin{array}{l}\text { Scarus niger } \\
\text { Halichoeres }\end{array}$ & Scaridae & 83 & 98.8 & 13.3 & & $\mathrm{X}$ & $\mathrm{X}$ & $\mathrm{X}$ \\
\hline prosopeion & Labridae & 69 & 99.0 & 26.7 & & $\mathrm{X}$ & $\mathrm{X}$ & $\mathrm{X}$ \\
\hline $\begin{array}{l}\text { Neoglyphidodon melas } \\
\text { Diproctacanthus }\end{array}$ & Pomacentridae & 65 & 99.2 & 13.3 & & $\mathrm{X}$ & $\mathrm{X}$ & \\
\hline xanthurus & Labridae & 51 & 99.4 & 6.7 & & $\mathrm{X}$ & $\mathrm{X}$ & \\
\hline $\begin{array}{l}\text { Canthigaster valentini } \\
\text { Heniochus }\end{array}$ & Tetraodontidae & 38 & 99.6 & 3.3 & & & & $\mathrm{X}$ \\
\hline pleurotaenia & Chaetodontidae & 37 & 99.7 & 3.3 & & $\mathrm{X}$ & & \\
\hline Scarus dimidiatus & Scaridae & 22 & 99.8 & 6.7 & $\mathrm{X}$ & $\mathrm{X}$ & & \\
\hline Pomacentrus adelus & Pomacentridae & 13 & 99.8 & 3.3 & $X$ & & & \\
\hline $\begin{array}{l}\text { Scarus ghobban } \\
\text { Paracentropvge }\end{array}$ & Scaridae & 11 & 99.9 & 3.3 & & & & $\mathrm{X}$ \\
\hline multifasciata & Pomacanthidae & 10 & 99.9 & 3.3 & & $\mathrm{X}$ & & \\
\hline Siganus vulpinus & Siganidae & 9 & 99.9 & 3.3 & & & & $\mathrm{X}$ \\
\hline Chaetodon ulietensis & Chaetodontidae & 8 & 99.9 & 3.3 & & & $\mathrm{X}$ & \\
\hline Sufflamen bursa & Balistidae & 6 & 99.9 & 10 & $\mathrm{X}$ & & $\mathrm{X}$ & \\
\hline Melichthys vidua & Balistidae & 6 & 99.9 & 3.3 & & & & $\mathrm{X}$ \\
\hline Odonus niger & Balistidae & 3 & 100.0 & 3.3 & & $\mathrm{X}$ & & \\
\hline \multicolumn{9}{|c|}{ Other species grazing on sponges where bites could not be accurately determined: } \\
\hline $\begin{array}{l}\text { Acanthurus pyroferus } \\
\text { Acanthurus }\end{array}$ & Acanthuridae & & & 63.7 & $\mathrm{X}$ & $\mathrm{X}$ & $\mathrm{X}$ & $\mathrm{X}$ \\
\hline auranticavus & Acanthuridae & & & 10 & $\mathrm{X}$ & & & \\
\hline Acanthurus nigricauda & Acanthuridae & & & 3.3 & $\mathrm{X}$ & & & \\
\hline Acanthurus thompsoni & Acanthuridae & & & 3.3 & $\mathrm{X}$ & & & \\
\hline
\end{tabular}


Species contributing to grazing intensity were significantly different between sites ( $\mathrm{pseudoF}_{3,26}=1.73$, $\mathrm{p}=0.012)$ with pairwise tests indicating significant differences between B1 and Sampela $(\mathrm{p}=0.001)$ and $\mathrm{B} 1$ and The Ridge $(\mathrm{p}=0.038)$ (Figure 2.3), all other pairwise comparisons showed no significant differences ( $p>0.05$ ). The highest average within group similarity was recorded at B1 (49.0\%) followed by The Ridge (36.6\%), KDS (34.8\%) and Sampela (30.7\%).

SIMPER showed that the top three species driving the differences in predation between B1 and Sampela (average dissimilarity 68.7\%), and B1 and The Ridge (average dissimilarity 63.4\%) were Coradion melanopus, Ctenochaetus spp., and Chaetodon kleinii. At B1, C. melanopus took $18.8 \%$ of bites, opposed to $1 \%$ at The Ridge and none were observed at Sampela. At B1, Ctenochaetus spp. took 50.4\% of bites, opposed to $18.4 \%$ at Sampela and $19 \%$ at The Ridge. At B1, C. kleinii took $7.4 \%$ of bites, as opposed to $49.1 \%$ at Sampela, $33.7 \%$ at The Ridge (Figure 2.3).

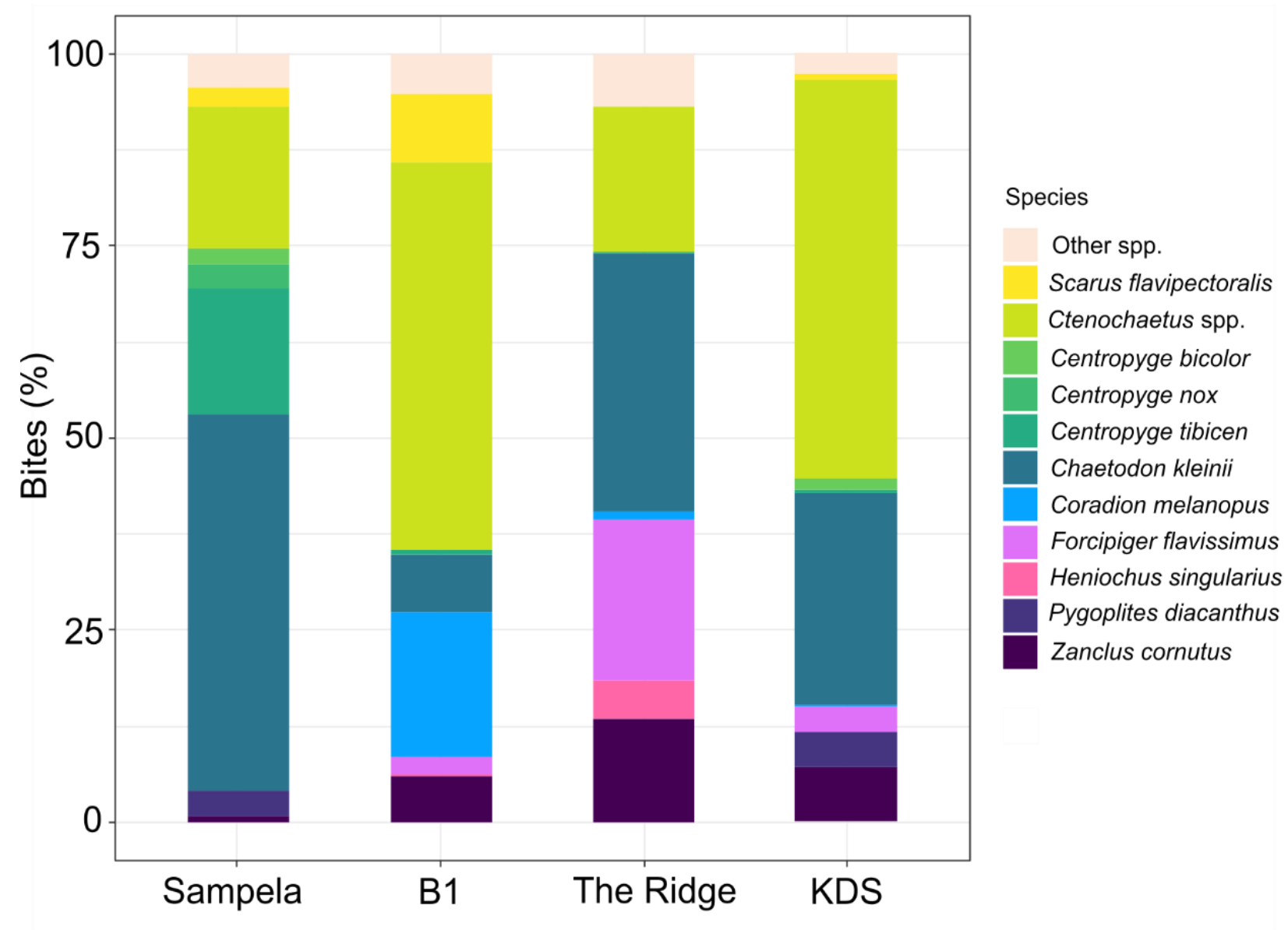

Figure 2. 3 The percentage of total bites on Xestospongia spp. taken by 11 species of sponge-grazing fishes filmed at four sites in the Wakatobi MNP. 


\subsubsection{Sponge-grazing fish densities}

Sponge-grazing fish densities were not statistically different between sites with $24 \pm 1$ (mean \pm SE) fish observed per $250 \mathrm{~m}^{2}$. There was also no difference in the densities of the top two species observed grazing on Xestospongia spp. (Table 2.1), Ctenochaetus binotatus and Chaetodon kleinii (Table 2.2). However, there was a difference in sponge-grazing fish assemblage structure between sites (pseudoF $\mathrm{F}_{3}$, $20=3.95, p=0.001$ ). Pairwise comparisons revealed that the sponge-grazing fish assemblage at Sampela was significantly different to the assemblage at $\mathrm{B} 1(\mathrm{t}=2.38, \mathrm{p}=0.003)$, the assemblage at The Ridge $(\mathrm{t}=2.93, \mathrm{p}=0.003)$ and assemblage at $\operatorname{KDS}(\mathrm{t}=2.19, \mathrm{p}=0.001)$ and there was also a significant difference in the sponge-grazing fish assemblage between The Ridge and $\mathrm{B} 1(\mathrm{t}=1.55, \mathrm{p}=0.033)$ (Figure 2.4).

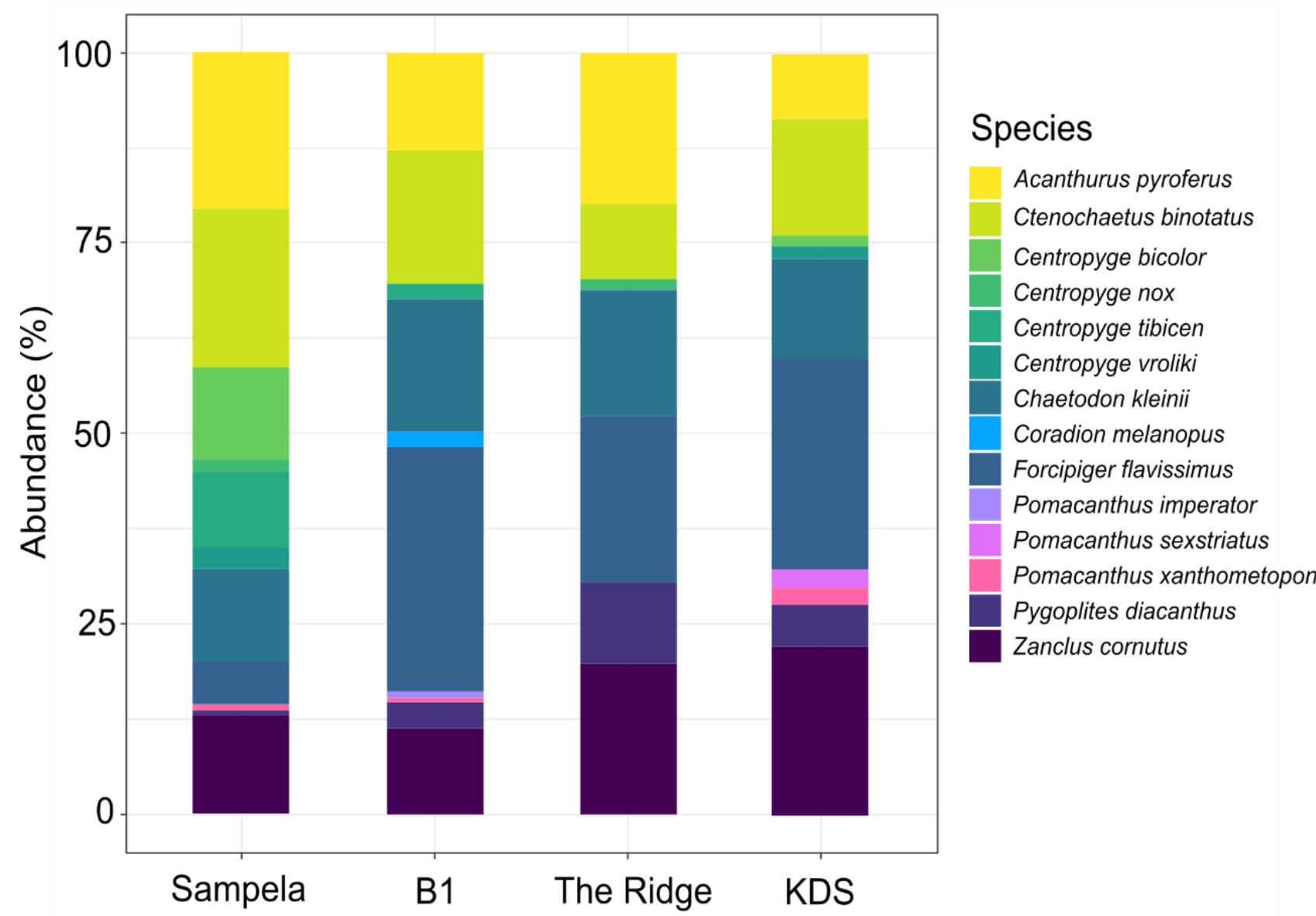

Figure 2. 4 The percentage of total abundance of sponge-grazing fishes surveyed by UVC at each of the four study sites in the Wakatobi MNP.

SIMPER indicated that spatial variation in sponge-grazing fish assemblages was mainly driven by variations in the abundance of Forcipiger flavissimus, Centropyge bicolor and Centropyge tibicen (Table 2.2). At Sampela, densities of C. bicolor were $2.8 \pm 0.9$ fish per $250 \mathrm{~m}^{2}$ but $C$. bicolor densities were only $0.3 \pm 0.3$ fish per $250 \mathrm{~m}^{2}$ at KDS and C. bicolor was not recorded at The Ridge or B1. Similarly, $C$. tibicen densities were $2.3 \pm 0.9$ per $250 \mathrm{~m}^{2}$ at Sampela, but $C$. tibicen densities were only 
$0.5 \pm 0.3$ per $250 \mathrm{~m}^{2}$ at $\mathrm{B} 1$, and $C$. tibicen was not recorded at The Ridge or KDS. Densities of $F$. flavissimus were much lower at Sampela $\left(1.3 \pm 0.5\right.$ per $\left.250 \mathrm{~m}^{2}\right)$ than $F$. flavissimus densities at B1 $(8 \pm$ 0.9 per $\left.250 \mathrm{~m}^{2}\right)$, The Ridge $\left(5.5 \pm 0.6\right.$ per $\left.250 \mathrm{~m}^{2}\right)$ and $\mathrm{KDS}\left(6.0 \pm 1.4\right.$ per $\left.250 \mathrm{~m}^{2}\right)$.

Table 2. 2 Sponge-grazing fish densities (mean \pm SE) per $250 \mathrm{~m}^{2}$ surveyed by UVC $(\mathrm{n}=6)$ at 4 sites in the Wakatobi MNP.

\begin{tabular}{llllll}
\hline Family & Species & Sampela & B1 & Ridge & KDS \\
\hline Acanthuridae & Acanthurus pyroferus & $4.8 \pm 1.1$ & $3.2 \pm 0.4$ & $5.0 \pm 0.7$ & $1.8 \pm 0.7$ \\
& Ctenochaetus binotatus & $4.8 \pm 1.0$ & $4.3 \pm 1.0$ & $2.5 \pm 0.5$ & $3.3 \pm 0.7$ \\
Chaetodontidae & Chaetodon kleinii & $2.8 \pm 0.8$ & $4.3 \pm 1.0$ & $4.2 \pm 1.5$ & $2.8 \pm 0.7$ \\
& Coradion melanopus & $0.0 \pm 0.0$ & $0.5 \pm 0.5$ & $0.0 \pm 0.0$ & $0.0 \pm 0.0$ \\
& Forcipiger flavissimus & $1.3 \pm 0.5$ & $8.0 \pm 0.9$ & $5.5 \pm 0.6$ & $6.0 \pm 1.4$ \\
Pomacanthidae & Centropyge bicolor & $2.8 \pm 0.9$ & $0.0 \pm 0.0$ & $0.0 \pm 0.0$ & $0.3 \pm 0.3$ \\
& Centropyge nox & $0.3 \pm 0.2$ & $0.0 \pm 0.0$ & $0.3 \pm 0.3$ & $0.0 \pm 0.0$ \\
& Centropyge tibicen & $2.3 \pm 0.9$ & $0.5 \pm 0.3$ & $0.0 \pm 0.0$ & $0.0 \pm 0.0$ \\
& Centropyge vroliki & $0.7 \pm 0.4$ & $0.0 \pm 0.0$ & $0.0 \pm 0.0$ & $0.3 \pm 0.3$ \\
& Pomacanthus imperator & $0.0 \pm 0.0$ & $0.2 \pm 0.2$ & $0.0 \pm 0.0$ & $0.0 \pm 0.0$ \\
& Pomacanthus sexstriatus & $0.0 \pm 0.0$ & $0.0 \pm 0.0$ & $0.0 \pm 0.0$ & $0.5 \pm 0.5$ \\
& Pomacanthus xanthometopon & $0.2 \pm 0.2$ & $0.2 \pm 0.2$ & $0.0 \pm 0.0$ & $0.5 \pm 0.3$ \\
Zanclidae & Pygoplites diacanthus & $0.2 \pm 0.2$ & $0.8 \pm 0.4$ & $2.7 \pm 0.6$ & $1.2 \pm 0.4$ \\
& Zanclus cornutus & $3.0 \pm 0.5$ & $2.8 \pm 0.5$ & $5.0 \pm 0.8$ & $4.8 \pm 0.5$ \\
\hline
\end{tabular}




\subsubsection{Gut content analysis}

\section{Obligate spongivores}

Pygoplites diacanthus had stomach contents containing $>90 \%$ sponge (\% wet weight), it was also the most specialised species identified by gut content analysis (diet breadth $=0.005$ ) (Table 2.3). Soft coral was found in the stomach of one individual and small amounts of tunicates, and mobile invertebrates including polychaetes and small bivalves were also observed. The one Pomacanthus imperator stomach examined had a similarly specialised diet to $P$. diacanthus containing $>90 \%$ sponge ( $\%$ wet weight).

\section{Facultative spongivores}

Sponge made up approximately half of the contents (\% wet weight) of Pomacanthus xanthometopon stomachs, but soft coral, primarily Dendronephthya, was consumed in equal quantities (Table 2.3). Minor order prey items included gastropods, polychaetes and one stomach contained several juvenile starfish. Sponges were also found to be a major prey item of $Z$. cornutus making up approximately $70 \%$ of total weighed contents. Other items observed included macroalgae and calcareous sediments. Siganus punctatus contained approximately $1 / 3$ sponge (\% wet weight), with the most dominant dietary item identified as the red alga Laurencia sp. Seagrass was present in all S. punctatus stomachs analysed, as were other types of algae and small mobile invertebrates were occasionally observed.

\section{Indirect interactions and sponge as a minor prey item}

Chaetodon kleinii had one of the widest diets observed of all the fish observed (Table 2.3). Although observations reported here suggested this species was spongivorous, sponge tissue was not observed, but sponge spicules were seen in 9/12 stomachs. Most of the organic matter in C. kleinii appeared to be of soft coral origin and a variety of crustacea were observed. Small volumes of green filamentous algae were also present in the majority of stomachs. Forcipiger flavissimus appeared to have a much more specialised diet than $C$. kleinii with the majority of stomachs containing tentacles of Serpulidae worms, possibly Spirobranchus as distinctive toothed opercula were visible in many samples. Sponge tissue remains were sighted in two stomachs, visually estimated to be $<5 \%$ of the total volume. Other minor prey items recorded in F. flavissimus stomachs included amphipods, isopods, and decapod shrimps. The gut contents of Ctenochaetus binotatus were dominated by calcareous sediments and unidentifiable organic matter. Sponge spicules were sighted in 9/12 gut contents but in very low numbers (one or two per gut). 
Table 2. 3 Relative gut content (\%) of eight species of sponge-grazing reef fish caught in the Wakatobi MNP in 2017. P. diacanthus - S. punctatus are percent weight $(\% \mathrm{~W})$ and $C$. kleinii - C. binotatus are relative volumetric quantity $(\% \mathrm{~V})$ due to low volume of stomach/gut contents.

\begin{tabular}{|c|c|c|c|c|c|c|c|c|c|c|c|c|c|c|c|c|}
\hline & \multirow{4}{*}{$\begin{array}{l}\text { Gut samples }(\mathrm{n}) \\
\mathrm{TL} \text { range }(\mathrm{mm}) \\
\text { Levin's diet breadth }\end{array}$} & \multicolumn{2}{|c|}{ P. diacanthus } & \multirow{2}{*}{$\begin{array}{r}\text { P. imperator } \\
1\end{array}$} & \multicolumn{2}{|c|}{ P. xanthometopon } & \multicolumn{2}{|c|}{ Z. cornutus } & \multicolumn{2}{|c|}{ S. punctatus } & \multicolumn{2}{|c|}{ C. kleinii } & \multicolumn{2}{|c|}{ F. flavissimus } & \multicolumn{2}{|c|}{ C. binotatus } \\
\hline & & & 13 & & \multicolumn{2}{|c|}{3} & \multicolumn{2}{|c|}{15} & \multicolumn{2}{|c|}{5} & \multicolumn{2}{|c|}{11} & \multicolumn{2}{|c|}{11} & \multicolumn{2}{|c|}{10} \\
\hline & & & -188 & 102 & & 272 & \multicolumn{2}{|c|}{$82-150$} & \multicolumn{2}{|c|}{$236-285$} & \multicolumn{2}{|c|}{$82-104$} & \multicolumn{2}{|c|}{$122-158$} & \multicolumn{2}{|c|}{$122-136$} \\
\hline & & & 0.005 & 0.004 & & .046 & & 0.036 & & 0.095 & & .097 & \multicolumn{2}{|c|}{0.032} & \multicolumn{2}{|c|}{ N/A } \\
\hline & & $\% \mathrm{~W}$ & $\% \mathrm{~F}$ & $\% \mathrm{~W}$ & $\% \mathrm{~W}$ & $\% \mathrm{~F}$ & $\% \mathrm{~W}$ & $\% \mathrm{~F}$ & $\% \mathrm{~W}$ & $\% \mathrm{~F}$ & $\% \mathrm{~V}$ & $\% \mathrm{~F}$ & $\% \mathrm{~V}$ & $\% \mathrm{~F}$ & $\% \mathrm{~V}$ & $\% \mathrm{~F}$ \\
\hline Annelida & Polychaete & $<1$ & 69 & $<1$ & $<1$ & 33 & 1 & 53 & $<1$ & 60 & 15 & 92 & 75 & 100 & & \\
\hline \multirow[t]{4}{*}{ Crustacea } & Amphipod & & & $<1$ & & & $<1$ & 13 & $<1$ & 60 & 14 & 58 & 7 & 27 & & \\
\hline & Copepod & & & & & & & & & 20 & 4 & 50 & & & & \\
\hline & Decapod & & & & & & $<1$ & 7 & $<1$ & 20 & $<1$ & 17 & 9 & 18 & & \\
\hline & Isopod & & & & & & $<1$ & 7 & & & 4 & 33 & 2 & 9 & & \\
\hline Bryozoa & Bryozoan & & & & & & 1 & 20 & & & & & & & & \\
\hline Porifera & Sponge & 94 & 100 & 96 & 53 & 100 & 73 & 100 & 32 & 100 & $<1$ & 75 & 2 & 18 & $<1$ & 70 \\
\hline Chordata & Ascidian & $<1$ & 38 & 1 & $<1$ & 33 & 3 & 73 & 17 & 100 & & & & & & \\
\hline \multirow[t]{2}{*}{ Echinodermata } & Asteroidea & & & & $<1$ & 33 & & & & & & & & & & \\
\hline & Ophiuroidea & & & & & & & & $<1$ & 20 & & & & & & \\
\hline \multirow[t]{3}{*}{ Cnidaria } & Hydrozoa & & & & & & & & & & 2 & 42 & & & & \\
\hline & Anthozoa - Hard coral & & & & $<1$ & 100 & $<1$ & 13 & & & 2 & 33 & & & & \\
\hline & Anthozoa - Soft coral & 5 & 8 & 3 & 46 & 100 & 10 & 7 & $<1$ & 20 & 51 & 83 & $<1$ & 9 & $<1$ & 50 \\
\hline Mollusc & Gastropod & & & & $<1$ & 33 & $<1$ & 20 & & & $<1$ & 17 & & & & \\
\hline & Bivalve & $<1$ & 46 & & & & 1 & 60 & $<1$ & 60 & $<1$ & 17 & 1 & 18 & & \\
\hline Algae & Calcareous algae & & & & $<1$ & 33 & 1 & 73 & 1 & 20 & & & & & & \\
\hline & Red macroalgae & & & & & & & & 42 & 100 & & & & & & \\
\hline & Green filamentous & $<1$ & 46 & & & & & & & & 4 & 58 & & & 5 & 80 \\
\hline & Green turfing & & & & & & & & $<1$ & 20 & & & & & & \\
\hline & Brown macroalgae & & & & & & 2 & 60 & $<1$ & 40 & & & & & & \\
\hline Seagrass & Seagrass & & & & & & & & 6 & 80 & & & & & 4 & 90 \\
\hline Eggs & Eggs & & & & & & $<1$ & 6 & & & 3 & 50 & $<1$ & 9 & & \\
\hline Sediments & Calcareous deposits & $<1$ & 15 & & & & 6 & 67 & 1 & 60 & & & & & 90 & 100 \\
\hline Fluid & Fluid/ mucus & & & & & & & & & & & & 2 & 9 & & \\
\hline
\end{tabular}




\subsubsection{Sponge consumption}

Estimates of sponge consumption were highest at the two outer reef sites, with $73.3 \pm 21.5 \mathrm{~g}$ sponge $1000 \mathrm{~m}^{-2}$ day $^{-1}$ (mean $\pm 95 \% \mathrm{CI}$ ) consumed at The Ridge and $52.9 \pm 25.6 \mathrm{~g}$ sponge $1000 \mathrm{~m}^{-2} \mathrm{day}^{-1}$ consumed at KDS (Table 2.4). The lowest estimate was at Sampela with $27.6 \pm 15.3 \mathrm{~g}$ sponge $1000 \mathrm{~m}^{-2}$ day ${ }^{-1}$ and $32.5 \pm 10.9 \mathrm{~g}$ sponge $1000 \mathrm{~m}^{-2}$ was consumed at B1. The reef-wide estimate of sponge consumption by five species of spongivorous reef fish was $46.6 \pm 18.3 \mathrm{~g}$ sponge $1000 \mathrm{~m}^{-2} \mathrm{day}^{-1}$ (mean $\pm 95 \% \mathrm{CI})$.

Table 2. 4 Estimates of sponge consumption $\left({\mathrm{g} 1000 \mathrm{~m}^{-2} \text { day }}^{-1}\right)$ for five species of spongivorous reef fish calculated from mean sponge weight in gut contents and fish densities. NB. Siganus punctatus was not included in the UVC of sponge-grazing fishes, therefore density was conservatively estimated from video observations.

\begin{tabular}{|c|c|c|c|c|}
\hline Site & Spongivore & $\begin{array}{l}\text { Total Fish in } \\
1500 \mathrm{~m}^{2}\end{array}$ & $\begin{array}{l}\text { Sponge weight }(\mathrm{g}) \\
\text { mean } \pm 95 \% \text { CI }\end{array}$ & $\begin{array}{l}\text { Sponge consumption (g } \\
\left.1000 \mathrm{~m}^{-2} \text { day }^{-1}\right) \text { mean } \pm \\
95 \% \mathrm{CI}\end{array}$ \\
\hline \multirow[t]{5}{*}{ Sampela } & P. diacanthus & 1 & $2.05 \pm 0.38$ & $2.7 \pm 0.5$ \\
\hline & P. imperator & 0 & 2.83 & $0.0 \pm 0.0$ \\
\hline & P. xanthometopon & 1 & $4.68 \pm 4.54$ & $6.2 \pm 6.1$ \\
\hline & Z. cornutus & 18 & $0.39 \pm 0.10$ & $9.4 \pm 2.4$ \\
\hline & S. punctatus & 2 & $3.49 \pm 2.35$ & $9.3 \pm 6.3$ \\
\hline \multirow[t]{5}{*}{ B1 } & P. diacanthus & 5 & $2.05 \pm 0.38$ & $13.7 \pm 2.5$ \\
\hline & P. imperator & 1 & 2.83 & 3.8 \\
\hline & P. xanthometopon & 1 & $4.68 \pm 4.54$ & $6.2 \pm 6.1$ \\
\hline & Z. cornutus & 17 & $0.39 \pm 0.10$ & $8.8 \pm 2.3$ \\
\hline & S. punctatus & 0 & $3.49 \pm 2.35$ & $0.0 \pm 0.0$ \\
\hline \multirow[t]{5}{*}{ The Ridge } & P. diacanthus & 16 & $2.05 \pm 0.38$ & $43.7 \pm 8.1$ \\
\hline & P. imperator & 0 & 2.83 & $0.0 \pm 0.0$ \\
\hline & P. xanthometopon & 0 & $4.68 \pm 4.54$ & $0.0 \pm 0.0$ \\
\hline & Z. cornutus & 30 & $0.39 \pm 0.10$ & $15.6 \pm 4.0$ \\
\hline & S. punctatus & 3 & $3.49 \pm 2.35$ & $14.0 \pm 9.4$ \\
\hline \multirow[t]{5}{*}{ KDS } & P. diacanthus & 7 & $2.05 \pm 0.38$ & $19.1 \pm 3.5$ \\
\hline & P. imperator & 0 & 2.83 & $0.0 \pm 0.0$ \\
\hline & P. xanthometopon & 3 & $4.68 \pm 4.54$ & $18.7 \pm 18.2$ \\
\hline & Z. cornutus & 29 & $0.39 \pm 0.10$ & $15.1 \pm 3.9$ \\
\hline & S. punctatus & 0 & $3.49 \pm 2.35$ & $0.0 \pm 0.0$ \\
\hline
\end{tabular}




\subsubsection{Feeding selectivity of Pygoplites diacanthus, Zanclus cornutus and Coradion melanopus}

\subsubsection{Food availability}

There were significant differences in benthic community structure between sites $\left(\mathrm{pseudoF}_{2,29}=7.34, \mathrm{p}\right.$ $=0.001$ ) with pairwise tests indicating that all sites were significantly different to one another (all pairwise comparisons, $\mathrm{p}=0.001$ ) (Figure 2.5). The two benthic categories contributing the most to the dissimilarity between Sampela and the other two sites were rock with sand and sand, both of which were greater at Sampela (Table 2.5). The two benthic categories contributing the most to the dissimilarity between The Ridge and B1 were soft coral, which was higher at The Ridge than B1, and rubble, which was higher at B1 than The Ridge.

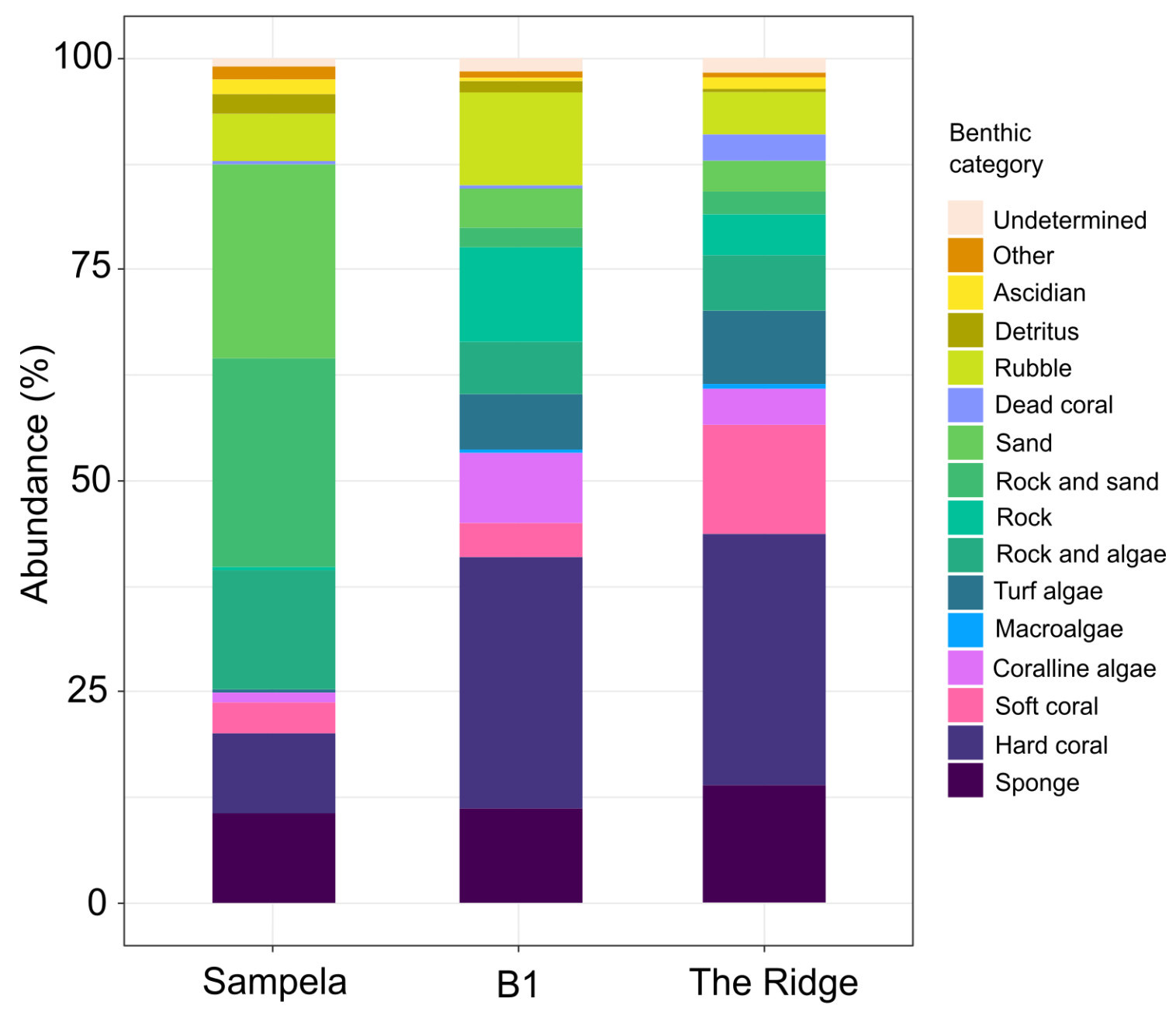

Figure 2. 5 The percentage cover of 16 benthic categories assessed by ten $1 \mathrm{~m}^{2}$ divided quadrats at three sites (Sampela, B1 and The Ridge) in the Wakatobi MNP. 
Table 2. 5 Benthic categories percentage cover (mean $\pm \mathrm{SE}$ ) estimated from ten $1 \mathrm{~m}^{2}$ divided quadrats placed randomly along a $100 \mathrm{~m}$ stretch of reef slope (10-14m) at three sites in the Wakatobi MNP.

\begin{tabular}{llll}
\hline Benthic category & Sampela & B1 & The Ridge \\
\hline Sponge & $10.6 \pm 2.9$ & $11.3 \pm 2.3$ & $13.8 \pm 2.4$ \\
Hard coral & $9.5 \pm 1.8$ & $29.7 \pm 4.0$ & $29.7 \pm 6.0$ \\
Soft coral & $3.8 \pm 1.5$ & $3.9 \pm 1.7$ & $13.0 \pm 4.4$ \\
Coralline algae & $1.3 \pm 0.7$ & $8.4 \pm 1.0$ & $4.1 \pm 0.9$ \\
Dead coral & $0.3 \pm 0.2$ & $0.4 \pm 0.2$ & $3.2 \pm 2.9$ \\
Rock & $0.5 \pm 0.2$ & $11.1 \pm 2.5$ & $4.7 \pm 1.8$ \\
Rock and sand & $24.7 \pm 4.4$ & $2.2 \pm 0.5$ & $2.7 \pm 0.8$ \\
Rock and algae & $14.1 \pm 2.8$ & $6.2 \pm 2.3$ & $6.6 \pm 1.9$ \\
Macroalgae & $0.0 \pm 0.0$ & $0.4 \pm 0.3$ & $0.6 \pm 0.3$ \\
Turf algae & $0.4 \pm 0.3$ & $6.5 \pm 1.5$ & $8.7 \pm 1.9$ \\
Sand & $22.8 \pm 4.2$ & $4.8 \pm 1.1$ & $3.6 \pm 1.6$ \\
Detritus & $2.3 \pm 0.9$ & $1.2 \pm 0.4$ & $0.2 \pm 0.1$ \\
Rubble & $5.6 \pm 2.2$ & $11.0 \pm 4.7$ & $5.1 \pm 2.1$ \\
Ascidian & $1.7 \pm 1.0$ & $0.5 \pm 0.2$ & $1.5 \pm 0.4$ \\
Undetermined & $1.5 \pm 0.1$ & $0.8 \pm 0.2$ & $0.6 \pm 0.2$ \\
Other & $0.9 \pm 0.2$ & $1.7 \pm 0.5$ & $1.8 \pm 1.0$ \\
\hline
\end{tabular}

There was no difference in the overall percentage cover of sponges amongst sites $\left(F_{2,27}=0.43, p=0.66\right)$ (Table 2.5), which covered on average $11.9 \% \pm 1.4 \%$ of the substrate. There was a significant difference in the number of species recorded at each site $\left(\mathrm{F}_{2,29}=5.08, \mathrm{p}=0.013\right)$. The number of species recorded was highest at The Ridge $\left(9.2 \pm 1.3 \mathrm{~m}^{-2}\right)$ and it was significantly higher than Sampela $\left(5.3 \pm 0.5 \mathrm{~m}^{-2}\right)(\mathrm{p}$ $=0.14)$ but not significantly higher than B1 $\left(6.2 \pm 0.8 \mathrm{~m}^{-2}\right)$. There was no difference in the number of species observed at Sampela and B1. When sponges were ranked by abundance, different species were dominant at each site (Table 2.6, A-C). The sponge assemblage at Sampela was dominated by the encrusting phototrophic sponge Lamellodysedia herbacea (39.9\%), the giant barrel sponge Xestospongia spp. (24.0\%) and the encrusting orange sponge Protosuberites sp. (10.5\%) (Table 2.6, B). At B1, the sponge assemblage was dominated by the massive sponge Agelas clathrodes (30\%), the giant barrel sponge Xestospongia spp. (14.4\%) and the tubular sponge Theonella swinhoei (13.9\%) (Table 2.6, A). The sponge assemblage at The Ridge was dominated by the encrusting sponge Chalinula milnei (37.5\%), the tubular Callyspongia aerizusa (14.4\%) and Verongula sp. (9.6\%) (Table 2.6, C).

\subsubsection{Feeding observations}

Pygoplites diacanthus positively selected sponges at Sampela $\left(w_{i}=5.15, \mathrm{CI}=2.57-7.73\right)$ and the Ridge $\left(w_{i}=5.51, \mathrm{CI}=2.63-8.4\right)$ but not at $\mathrm{B} 1(\mathrm{CI}<1)$. A preference for Xestospongia spp. was indicated by P. diacanthus at all sites (Table 2.6, A-C). It also appeared to prefer some species of Clathria (Figure 2.6, D\&F), Petrosia (Figure 2.6, G\&H) and Spheciospongia sp. (Figure 2.6B). Zanclus cornutus positively selected sponges at the Ridge $\left(w_{i}=5.42, \mathrm{CI}=1.85-8.99\right)$ but not at Sampela or B1 $(\mathrm{CI}<1)$. 
At B1, Z. cornutus spent the majority of time grazing on rock surfaces under overhangs where it was difficult to determine substrate type. At Sampela, most of the fish observed took only a few bites from a substrate type before moving to another area however, two were engaged in focused feeding on Xestospongia spp. with one individual recording 83 bites in the three-minute observation period. At The Ridge, Z. cornutus demonstrated a preference for sponges from the genus Petrosia and Xestospongia spp. (Figure 2.6, E) (Table 2.6, A-C). C. melanopus exhibited significant dietary selectivity for sponges at $\mathrm{B} 1\left(w_{i}=7.60, \mathrm{CI}=7.39-7.81\right)$. The six individuals observed fed almost exclusively from Xestospongia spp. (Table 2.6, A) and only two bites recorded on rock and one on hard coral.

Table 2. 6 Relative abundance (\% cover) of sponge species and percent bites taken by three species of sponge-grazing fishes at three sites (B1, Sampela and The Ridge) in the Wakatobi MNP. Sponges were considered preferred if the percentage of bites > percentage abundance $+5 \%$ and avoided if the percentage of bites $<$ percentage abundance $-5 \%$.

\begin{tabular}{|c|c|c|c|c|c|c|}
\hline \multicolumn{2}{|c|}{ A) $\mathbf{B 1}$} & \multicolumn{3}{|c|}{ Bites (\%) } & \multirow[b]{2}{*}{$\begin{array}{c}C . \\
\text { melanopus }\end{array}$} & \multirow[b]{3}{*}{$\begin{array}{l}\text { Avoided by } \\
\text { all }\end{array}$} \\
\hline Rank & Species & $\begin{array}{c}\text { Abundance } \\
(\%)\end{array}$ & $\begin{array}{c}P . \\
\text { diacanthus }\end{array}$ & $\begin{array}{c}Z . \\
\text { cornutus }\end{array}$ & & \\
\hline 1 & $\begin{array}{l}\text { Agelas } \\
\text { clathrodes }\end{array}$ & 30.0 & 12.7 & 0 & 0 & \\
\hline 2 & $\begin{array}{l}\text { Xestospongia } \\
\text { spp. }\end{array}$ & 14.4 & 32.4 & 0 & 100 & $\begin{array}{l}\text { Preferred by } \\
C . \text { melanopus } \\
\text { and } P \text {. } \\
\text { diacanthus }\end{array}$ \\
\hline 3 & $\begin{array}{l}\text { Theonella } \\
\text { swinhoei }\end{array}$ & 13.9 & 1.4 & 0 & 0 & $\begin{array}{l}\text { Avoided by } \\
\text { all }\end{array}$ \\
\hline 4 & $\begin{array}{l}\text { Aaptos } \\
\text { suberitoides }\end{array}$ & 10.7 & 0 & 0 & 0 & $\begin{array}{l}\text { Avoided by } \\
\text { all }\end{array}$ \\
\hline 5 & $\begin{array}{l}\text { Protosuberites } \\
\text { sp. }\end{array}$ & 6.2 & 0 & 0 & 0 & $\begin{array}{l}\text { Avoided by } \\
\text { all }\end{array}$ \\
\hline 6 & Chalinula milnei & 5.9 & 0 & 0 & 0 & $\begin{array}{l}\text { Avoided by } \\
\text { all }\end{array}$ \\
\hline 7 & $\begin{array}{l}\text { Lamellodysedia } \\
\text { herbacea }\end{array}$ & 5.1 & 0 & 0 & 0 & $\begin{array}{l}\text { Avoided by } \\
\text { all }\end{array}$ \\
\hline 8 & Niphates sp. & 3.5 & 0 & 0 & 0 & \\
\hline 9 & Clathria sp.1 & 2.8 & 0 & 6.7 & 0 & \\
\hline 10 & Aaptos sp. & 1.7 & 0 & 0 & 0 & $\begin{array}{l}\text { Avoided by } \\
\text { all }\end{array}$ \\
\hline 23 & $\begin{array}{l}\text { Callyspongia } \\
\text { aerizusa }\end{array}$ & NR & 2.8 & 0 & 0 & \\
\hline 24 & $\begin{array}{l}\text { Petrosia } \\
\text { corticata }\end{array}$ & NR & 1.4 & 0 & 0 & \\
\hline 25 & $\begin{array}{l}\text { Clathria } \\
\text { reinwardtii }\end{array}$ & NR & 43.7 & 0 & 0 & $\begin{array}{l}\text { Preferred by } \\
P \text {. diacanthus }\end{array}$ \\
\hline \multicolumn{3}{|c|}{ Total bites } & 71 & 15 & 280 & \\
\hline \multicolumn{3}{|c|}{$\begin{array}{l}\text { Fish biting sponges/total observed } \\
\text { Percentage of bites on unidentified } \\
\text { sponges }\end{array}$} & $5 / 9$ & $5 / 9$ & $6 / 6$ & \\
\hline
\end{tabular}




\begin{tabular}{|c|c|c|c|c|c|}
\hline \multirow{2}{*}{$\begin{array}{r}\text { B) } \\
\text { Rank }\end{array}$} & \multirow{2}{*}{$\begin{array}{l}\text { Sampela } \\
\text { Sponge species }\end{array}$} & \multicolumn{3}{|c|}{ Bites $(\%)$} & \\
\hline & & $\begin{array}{c}\text { Abundance } \\
(\%)\end{array}$ & $\begin{array}{c}P . \\
\text { diacanthus }\end{array}$ & $\begin{array}{c}Z . \\
\text { cornutus }\end{array}$ & \\
\hline 1 & $\begin{array}{l}\text { Lamellodysedia } \\
\text { herbacea }\end{array}$ & 39.9 & 0 & 1 & Avoided by both \\
\hline 2 & Xestospongia spp. & 24.0 & 59 & 75.1 & Preferred by both \\
\hline 3 & Protosuberites sp. & 10.5 & 0 & 0 & Avoided by both \\
\hline 4 & Hyrtios erecta & 6.9 & 5.0 & 0 & Avoided by Z. cornutus \\
\hline 5 & Axinyssa sp. & 3.5 & 0 & 0 & \\
\hline 6 & $\begin{array}{l}\text { Myrmekioderma } \\
\text { granulatum }\end{array}$ & 2.9 & 0 & 0 & \\
\hline 7 & Clathria sp.1 & 2.5 & 9 & 3.6 & Preferred by $P$. diacanthus \\
\hline 8 & $\begin{array}{l}\text { Unknown massive } \\
\text { sponge }\end{array}$ & 1.9 & 0 & 0 & \\
\hline 9 & $\begin{array}{l}\text { Orange encrusting } \\
\text { sp.2 }\end{array}$ & 1.5 & 0 & 0 & \\
\hline 10 & Pink branching sp.2 & 1.3 & 0 & 0 & \\
\hline 19 & $\begin{array}{l}\text { Acanthella } \\
\text { cavernosa }\end{array}$ & 0.2 & 0 & 2.1 & \\
\hline 22 & Spheciospongia sp. & NR & 8 & 0 & Preferred by P. diacanthus \\
\hline \multicolumn{2}{|c|}{ Total bites } & & 200 & 193 & \\
\hline \multicolumn{3}{|c|}{$\begin{array}{l}\text { Fish biting sponges/total observed } \\
\text { Percentage of bites on unidentified } \\
\text { sponges }\end{array}$} & $13 / 17$ & $8 / 20$ & \\
\hline
\end{tabular}

C) The Ridge

\begin{tabular}{|c|c|c|c|c|c|}
\hline Rank & Species & $(\%)$ & diacanthus & cornutus & \\
\hline 1 & Chalinula milnei & 37.5 & 0 & 0 & Avoided by both \\
\hline 2 & Callyspongia & 14.4 & 2.9 & 2.7 & \\
\hline & aerizusa & & & & Avoided by both \\
\hline 3 & Verongula sp. & 9.6 & 0 & 0 & Avoided by both \\
\hline 4 & Clathria sp. 1 & 7.8 & 0 & 0 & Avoided by both \\
\hline 5 & Black encrusting sp. 2 & 6.0 & 0 & 0 & Avoided by both \\
\hline 6 & Hyrtios erecta & 3.3 & 0 & 0 & \\
\hline 7 & $\begin{array}{l}\text { Melophlus } \\
\text { sarasinorum }\end{array}$ & 2.7 & 5.7 & 0 & \\
\hline 8 & $\begin{array}{l}\text { White spikey } \\
\text { branching }\end{array}$ & 2.0 & 0 & 0 & \\
\hline 9 & Brown unknown & 1.6 & 0 & 0 & \\
\hline 10 & $\begin{array}{l}\text { Lamellodysedia } \\
\text { herbacea }\end{array}$ & 1.5 & 0 & 0 & \\
\hline 48 & Xestospongia spp. & NR & 7.6 & 62.2 & Preferred by both \\
\hline 49 & Petrosia corticata & NR & 31.4 & 13.5 & Preferred by both \\
\hline 50 & Petrosia sp. & NR & 26.7 & 21.6 & Preferred by both \\
\hline \multicolumn{3}{|c|}{ Total bites } & 105 & 74 & \\
\hline \multicolumn{3}{|c|}{ Fish biting sponges/total observed } & $6 / 6$ & $4 / 4$ & \\
\hline \multicolumn{3}{|c|}{ Percentage of bites on unidentified sponges } & 25.7 & 0 & \\
\hline
\end{tabular}



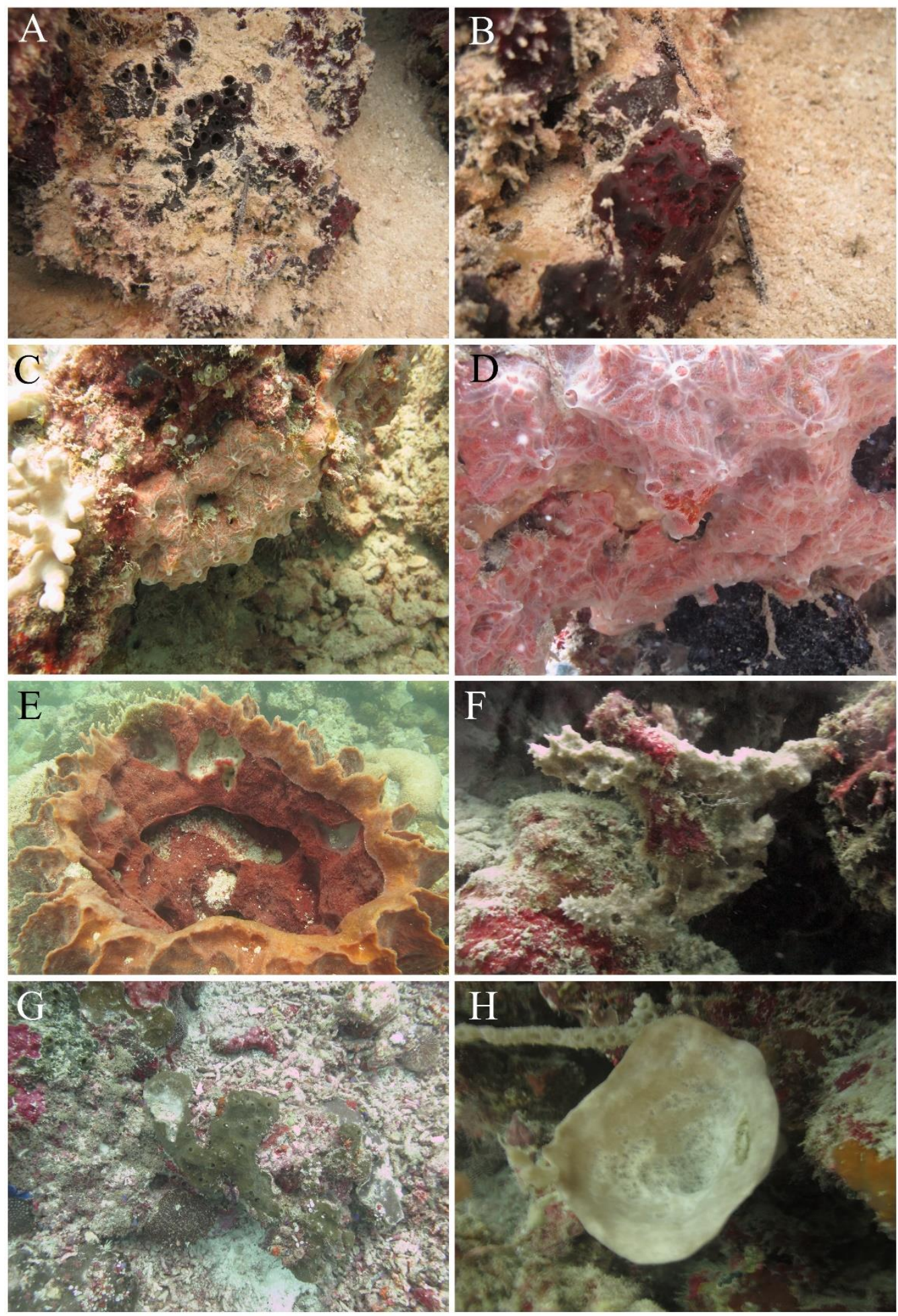

Figure 2. 6 A. Spheciospongia sp. at Sampela. B. Close up of bites on Spheciospongia sp. made by $P$. diacanthus. C. Clathria sp. at Sampela. D. Close up of bites on Clathria sp. made by P. diacanthus. E. Xestospongia spp. at Sampela predated by P. diacanthus and Z. cornutus. F. Clathria reinwardtii at B1 predated by P. diacanthus. G. Exposed inner tissue of Petrosia corticata at the Ridge, predated by $P$. diacanthus and Z. cornutus. H. Petrosia sp. at the Ridge, predated by P. diacanthus and Z. cornutus. 


\subsection{Discussion}

Diet characterisation is fundamental to understand the range of functional roles played by reef fishes (Leray et al. 2015) and this information is essential to preserve key ecosystem functions on transitioning coral reefs (Bellwood et al. 2019). The present study provides the first reef-wide estimate of sponge biomass consumption on coral reefs. Five spongivorous fishes were identified through a combination of video observations and gut content analysis and were estimated to consume $46.6 \pm 18.3 \mathrm{~g}$ sponge $1000 \mathrm{~m}^{-2}$ day ${ }^{-1}$. Sponges dominated the diet of the angelfish Pygoplites diacanthus which had the greatest predatory impact on sponges. Estimates provided here are conservative. Nevertheless, predation of this magnitude may have sublethal indirect impacts on sponges such as reduced fecundity and physiological condition.

\subsubsection{Sponge consumption}

Quantitative data on the role of sponges in the diets of sponge-grazing fishes combined with density data made it possible to estimate sponge consumption at each location and provide reef-wide estimates of sponge biomass consumption. Considering that these are the first known estimates of reef-wide sponge consumption, comparisons with studies from other regions are not possible. However, following the same methodology as Harmelin-Vivien \& Bouchon-Navarro (1983) allows for a comparison with coral consumption in the Central Pacific. The maximum coral consumption reported was $62.5 \mathrm{~g}$ coral $1000 \mathrm{~m}^{-2}$ day $^{-1}$ at the outer barrier reef slope (Harmelin-Vivien \& Bouchon-Navarro, 1983), which is similar to the estimates of daily sponge consumption reported for the outer reef sites in this study (mean $52.9 \mathrm{~g}-73.3 \mathrm{~g}$ sponge $1000 \mathrm{~m}^{-2}$ ). This suggests that in the Indo-Pacific, biomass transferred from sponges to spongivores is of a similar magnitude to biomass transferred through the coral - corallivore pathway, although this comparison is limited by large geographic differences. Nevertheless, data presented in this chapter suggests that spongivory may be an important but relatively overlooked trophic link on Wakatobi reefs.

Although biomass transferred from the benthos to upper trophic levels via the processes of corallivory and spongivory appears to be similar, there appear to be many more species of corallivorous fishes than there are spongivorous fishes. Cole et al (2008) compiled the literature on corallivorous fishes, documenting 128 corallivores, 41 of which were considered obligates. By contrast, approximately 50 species have been documented as spongivores (Hiatt \& Strasbourg, 1960; Randall \& Hartman, 1968; Hobson, 1974; Clements \& Livingstone, 1983; Sano, 1989; Wulff, 1994; Dunlap \& Pawlik, 1996; Wulff, 1997; Pitt, 1997; Dunlap \& Pawlik, 1998; Eagle \& Jones, 2004; Nagelkerken et al. 2009; Verdín Padilla et al. 2010; Hoey et al. 2013) with only 13 of these considered obligates (Hiatt \& Strasbourg 1960; Randall \& Hartman, 1968; Hobson, 1974; Hourigan, 1989; Dunlap \& Pawlik 1996; Verdín Padilla et al. 2010). Whilst these differences are undoubtedly exacerbated by the more extensive research that has taken place regarding the functional process of corallivory (Pratchett et al. 2005; Cole 
et al. 2008; Cole et al. 2011), the family associated with sponge feeding (Pomacanthidae) has fewer species than the Chaetodontidae family associated with coral feeding (86 species and 128 species respectively (Konow \& Ferry-Graham, 2013). Additionally, the most voracious sponge predator recorded during this study, Pygoplites diacanthus, is monotypic (Coleman et al. 2016). Hence, it seems likely that the coral-corallivore pathway supports a higher diversity of fish species than the spongespongivore pathway.

\subsubsection{Obligate spongivores}

Angelfishes are well-known spongivores in the Caribbean and the Pacific (Randall \& Hartman, 1968; Hobson, 1974; Verdín Padilla et al. 2010), with at least five species thought to rely on sponges for the majority of their diet (Randall \& Hartman, 1968; Hobson, 1974). The present study confirms that Pygoplites diacanthus is also reliant on sponges as stomach contents contained $>80 \%$ sponge. These findings are consistent with previous observations of feeding behaviour (Powell et al. 2015). Diet breadth was very low for this species, indicating a high degree of trophic specialisation. Scaling up from the individual to the reef-wide level, $P$. diacanthus has the largest predatory impact, accounting for almost half of the total sponge consumption. The one Pomacanthus imperator stomach dissected contained $>90 \%$ sponge suggesting a similar reliance on sponges to $P$. diacanthus. However, the small sample size means that some uncertainty still surrounds the extent of sponge predation by $P$. imperator.

\subsubsection{Facultative spongivores}

Sponges were the dominant dietary item for Zanclus cornutus, although its diet also consisted of algae and other sessile invertebrates, including bryozoans and ascidians. This species had a slightly lower predatory impact than $P$. diacanthus, consuming an estimated $12.2 \pm 3.1 \mathrm{~g}$ sponge $1000 \mathrm{~m}^{-2}$ day $^{-1}$ (mean

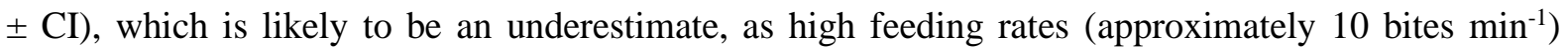
suggests that they likely fill their stomach more than twice daily. Z. cornutus is found in a substantial range of habitats, from intertidal mangroves (pers. obs) to mesophotic depths (Wagner et al. 2014). There is also evidence that $Z$. cornutus is expanding into temperate waters, possibly as a result of warming (Seo \& Lee 2009; Fernández-Rivera Melo et al. 2018). An expansive range coupled with generalist foraging indicates that $Z$. cornutus could be relatively resilient to habitat disturbances.

Gut content data also confirmed Pomacanthus xanthometopon was a spongivore, but it appeared to have a lower reliance on sponges than $P$. diacanthus, consuming an equal amount of predominantly Dendronephthya soft corals with one stomach containing three juvenile starfish. The rabbitfish Siganus punctatus also regularly consumed sponges, which were found in the gut contents of all sampled individuals, although in widely varying amounts (2-76\%). Similar feeding behaviour has been recorded in the GBR where sponges were the dominant category in juvenile S. punctatus and represented $20 \%$ of the diets of adults (Pitt, 1997). It was also noted by Sano (1989) in Japan where sponge was found to constitute $72 \%$ of $S$. punctatus gut contents (Sano, 1989). Data presented here indicate that sponges and 
the red algae Laurencia spp. made up the majority of the diet of adult S. punctatus on Wakatobi reefs. A study looking at the diet and distribution of rabbitfishes on the Great Barrier Reef also found that the stomach contents of the rabbitfish Siganus puellus was dominated by sponges, suggesting that the diet of some Siganids is more varied than previously recognised (Hoey et al. 2013).

\subsubsection{Indirect interactions and sponge as a minor prey item}

Butterflyfishes are generally associated with coral feeding, although only 69 out of 128 species are known to directly consume Scleractinian corals (Cole et al. 2008; Konow \& Ferry-Graham, 2013) with numerous other prey items reported (Sano, 1989; Nagelkerken et al. 2009). Despite recording $>7500$ bites on Xestospongia spp. sponge tissue remains were not found in Chaetodon kleinii stomach contents, although spicules were sighted in 9/12 stomachs. Similarly, Forcipiger flavissimus recorded $>1500$ bites on Xestospongia spp. but out of 11 stomachs analysed, only two contained sponge tissue remains both amounting to $\sim 2 \%$ of total contents. Coradion melanopus was one of the top sponge-grazing fishes identified in video footage despite being found in extremely low densities on Wakatobi reefs. In situ feeding observations pointed towards extremely selective feeding on barrel sponges however gut content samples were not collected due to small population size. Other studies in the Indo-Pacific have found small volumes of sponge $(<10 \%$ volume) in both C. kleinii and F. flavissimus (Sano, 1989; Nagelkerken et al. 2009) and $18 \%$ sponge in the C. melanopus congener C. altivelis suggesting that sponges are either a minor prey item or incidentally ingested in the pursuit of sponge-associated macrofauna (Nagelkerken et al. 2009). Observations of the internal tissue of Xestospongia spp. in the Wakatobi MNP have shown that they are infested with an unidentified white polychaete (family Syllidae) (mean $579 \pm 44$ g-1 [DW]) (C.M, unpublished data). The digestive tracts of polychaetes found in the cyanobacterial layer of Xestospongia spp. were brown/red whilst those retrieved from the inner tissue were white (pers. obs) suggesting that these polychaetes consume host tissue. Spongivorous polychaetes (e.g. Haplosyllis spongicola and Branchiosyllis oculata) can directly penetrate sponge tissues where canals are small (Martin \& Britayev, 1998) and have been found in extremely high densities on both the surface and inside sponges (Pawlik, 1983). This may explain the high grazing rates by Chaetodontids and other invertivores recorded in video footage of Xestospongia spp.

Ctenochaetus binotatus likely lacks the necessary dental morphology to remove sponge biomass and appears to 'brush' the surface of the sponge with comb-like teeth (Purcell \& Bellwood, 1993). Members of this genus are generally considered detritivores (Choat, 2002) however, other studies have indicated that Ctenochaetus striatus can also remove large quantities of algal turf (Marshell \& Mumby, 2012). Gut content data presented in this chapter support the conclusion that $C$. binotatus is a detritivore as gut contents were dominated by sediments and detritus (defined as opaque flocculent material) (Wilson et al. 2003). Sponge-grazing detritivores may target mucus-bound sediment on sponge surfaces, as some sponges including Xestospongia spp. produce mucus as a sediment clearing mechanism (McGrath et al. 
2017). Although there have been no published studies regarding the energy content of sponge mucus, coral mucus is known to be energy and nutrient-rich (Wild et al. 2004) hence it is likely that sponge mucus provides similar nutritional benefits. In the only published study of the trophic role of sponge mucus, the sponge-associated holothuroid Synaptula lamperti were found to ingest mucus directly from the sponge Ianthella basta and incorporate metabolised compounds into body wall tissues (Hammond \& Wilkinson, 1985). Hammond \& Wilkinson (1985) concluded that sponge mucus represents a new trophic pathway involving sponges not previously identified. The feeding behaviour of detritivorous fishes could also be explained by the 'sponge loop' whereby sponges assimilate DOC and return it to the reef as cellular detritus that is readily ingested by sponge-associated detritivorous invertebrates (de Goeij et al. 2013; Rix et al. 2018). Both pathways suggest that sponges mediate a variety of trophic interactions beyond biomass removal via predation by spongivores.

\subsubsection{Preferred sponges}

To infer preference, relative abundance needs to be quantified to distinguish between being preferred by spongivores or the most abundant in the field (Wulff, 2012). I used percentage cover to quantify sponge abundance and hence infer preference from visual observations of feeding behaviour. However, methods that estimate abundance using different metrics such as volume or biomass are known to give different results (Wilkinson, 1987). Where sponge assemblages are dominated by tubular or erect sponges, volume may be the most appropriate metric as percentage cover would underestimate their contribution (Wulff, 2001). However, estimating sponge volume is time-intensive, particularly on reefs like those in the Wakatobi MNP that host sponge assemblages with diverse morphologies (Bell et al. 2017). Hence, the divided quadrat was chosen to capture larger morphologies that would be missed using smaller quadrats but also with the resolution necessary to capture encrusting species.

Feeding observations indicated that Clathria spp. and Spheciospongia sp. are preferred by Pygoplites diacanthus and sponges from the Petrosiidae family including Xestospongia spp., Petrosia sp. and Petrosia corticata are preferred by both $P$. diacanthus and Zanclus cornutus. Clathria spp. were considered unpalatable to spongivorous starfishes in Caribbean (Wulff, 1995) and Antarctic waters (Peters et al. 2009) however small volumes $(<2 \%)$ were found in the stomach contents of spongivorous angelfishes (Randall \& Hartman, 1968). Similarly, angelfishes have been recorded with Spheciospongia vesparium in gut contents (Randall \& Hartman, 1968) and it was also predated by starfish in feeding choice experiments (Wulff, 1995). Petrosiidae sponges have also been recorded in spongivorous fish gut contents (Randall \& Hartman, 1968), although only in one Caribbean study. During in situ data collection, $Z$. cornutus and $P$. diacanthus were often seen predating the same sponge and exhibit competitive behaviours. Often, one would chase the other away from the sponge and take numerous bites (frequently $>15$ ) before the other would return and exhibit the same behaviour. This is somewhat contrary to the 'smorgasbord' feeding behaviour described from the Caribbean where angelfishes take 
relatively few bites from the same open reef species before moving on to another food item (Randall \& Hartman, 1968; Wulff, 1994). It could be explained by the densities of cyanobacteria in the outer tissues of Xestospongia spp. and Petrosia corticata, as repetitive feeding on exposed inner tissue (Appendix A), could be nutritionally beneficial (Duffy \& Paul, 1992) and contain a lower concentration of chemical defences than the outer tissue layer. Some studies have supported the optimal defence theory (Becerro et al. 1998; Schupp et al. 1999), which suggests that chemical defences are concentrated to high-value areas eg. reproductive tissues or regions most at risk of predation (Rhoades \& Cates, 1976; Swearingen \& Pawlik, 1988). However, not all studies support this hypothesis, with some finding no difference in deterrent properties between extracts from the inner and outer tissue layers of sponges (Swearingen \& Pawlik, 1998; Burns et al. 2003).

\subsubsection{Limitations of sponge consumption estimates}

Estimates provided in this thesis are conservatively based on stomach contents rather than total gut contents and on the assumption that fish fill their stomachs twice daily. Coral material has been estimated to pass through the intestinal tract of the butterflyfish Chaetodon unimaculatus between $1 \frac{1 / 2}{1}$ and 2 hours, indicating that stomach may be filled at least six times daily (Cox, 1986; Cole et al. 2011). Considering that reported gut length to body length ratios for Chaetodon unimaculatus (Berumen et al. 2011) and Pomacanthus spp. (Pérez-España \& Abitia-Cárdenas, 1995) are similar, it seems likely that spongivores may also fill their stomachs up to six times daily. Additionally, there are likely other spongivorous fishes who were not included in the estimates of sponge consumption (e.g. triggerfishes, filefishes and pufferfishes), and the functional roles of some prevalent sponge-grazing fishes remain ambiguous due to lack of gut content data. Four species of Centropyge (bicolor, nox, tibicen, vroliki) were recorded taking numerous bites from Xestospongia spp. and Powell et al. (2015) also recorded similar feeding behaviour in the Wakatobi MNP. Sponge was recorded as the dominant dietary item (>40\% by volume) in the stomach of C. vroliki (Eagle \& Jones, 2004) and morphological studies indicate that Centropyge spp. are adapted to feed on attached colonial invertebrates (Konow \& Bellwood, 2011). However, other studies list Centropyge as epilithic algal grazers that are important and numerous herbivores (Green \& Bellwood, 2008). Considering the high abundances of Centropyge spp. at the sponge-dominated site, future studies should prioritise the gut content analysis of these species to resolve their potential impact on sponge assemblages. Similarly, hawksbill turtles were not considered by this study due to low abundances on Wakatobi reefs (only one hawksbill turtle was sighted during the three-month study period). Hence their predatory impact on sponges in the Hoga/Kaledupa channel was likely negligible. 


\subsubsection{Conclusion}

The study provides the first known estimate of sponge consumption by spongivorous fishes on coral reefs. Results presented here suggest that sponge consumption in the Wakatobi, particularly by the angelfish Pygoplites diacanthus and the Moorish Idol Zanclus cornutus, was considerable and comparable to estimates of coral consumption in the Central Pacific. By combining visual techniques and gut content analysis, I have addressed previous functional misclassifications and shown that both methods used in tandem provide more detail on the specific diets of sponge-grazing fishes. 


\section{Chapter 3. DNA analysis of angelfish stomach contents reveals the diversity of predated sponges}

\subsection{Abstract}

Accurately defining predator-prey relationships is essential to understand the strength of predation as a top-down force in ecosystems. Angelfishes are one of only a few families of spongivorous fishes found on coral reefs. Whilst extensive work on spongivore feeding preference has been conducted in the Caribbean, where angelfishes have a taxonomically wide diet and consume mainly chemically undefended sponges, little is known about sponges predated by angelfishes in the Indo-Pacific. This information is essential to understand the functional role of spongivory on Indo-Pacific reefs. In Chapter 2, sponges were quantified from the stomach contents of three species of Indo-Pacific angelfish (Pygoplites diacanthus, Pomacanthus imperator and Pomacanthus xanthometopon) but could not be visually identified beyond the phylum level. In studies where visual prey identification is problematic, molecular methods of diet tracing can improve the taxonomic resolution of prey. In this chapter, I developed genetic methods that allowed the identification of predated sponges from the stomach contents of spongivorous angelfishes. A range of primers and associated predator-blocking primers targeting the 18S rDNA gene were designed and tested on extracts of sponge and spongivore DNA. One primer set was the most effective at blocking the amplification of spongivore DNA, and sequences were successfully obtained from 14 sponges extracted from stomach contents. Phylogenetic analysis indicated that these sponges spanned six orders of Porifera, with the majority identified in the Order Haplosclerida. There was strong support for the placement of one sponge within a clade containing the Indo-Pacific species Chalinula hooperi and another within a clade with sponges from the genus Petrosia. Three sponges were categorised as the order Verongiida due to their placement within a clade containing Pseudoceratina and Verongula sponges. One sponge belonged to a clade made up of Clionaidae and Spirastrellidae sponges, and others were placed into clades containing sponges from the genera Aaptos and Guitarra, and the family Agelasidae. Results indicated that Pygoplites diacanthus had a wide diet within the Porifera phylum and consumed sponges with substantial chemical defences. This study is the first to successfully sequence sponges from the stomach contents of spongivorous angelfishes and has identified several sponges previously unknown to be predated in the Indo-Pacific. 


\subsection{Introduction}

Predators are vitally important in ecosystems as they generate top-down forces that enhance ecosystem stability (Paine, 1966; Paine, 1969). Yet not all predators are functionally equivalent, and in-depth knowledge of a predator's diet can elucidate its ecological function (Leray et al. 2015). In marine systems, visual approaches to diet characterisation, such as diver led surveys, present practical difficulties (e.g. time and depth limits), and the presence of divers can alter fish behaviour (Emslie et al. 2018). By contrast, gut content analysis provides an unambiguous record of ingested prey (Wulff, 2006) but it is biased towards structural components and taxonomic resolution can be hindered by digestion (Nielsen et al. 2018). Over the past decade, molecular methods have emerged as a valuable tool to overcome some of the challenges associated with diet identification (Nielsen et al. 2018). Polymerase chain reaction (PCR) can detect small amounts of DNA, providing greater resolution to diets that are hard to visually characterise because they lack hard parts, are heavily degraded, or are liquid remains (Symondson, 2002; Vestheim \& Jarman, 2008; Nielsen et al. 2018). However, using molecular methods to identify predated items from gut content samples also presents a range of complications due to digestive processes (Vestheim \& Jarman, 2008).

Gut content DNA can be degraded and fragmented by digestion (Deagle et al. 2009), which may constrain the study to target only short sequence lengths (Vestheim \& Jarman, 2008). Short sequence lengths often have fewer appropriate binding sites and can impact taxonomic resolution, which also depends on the sequence coverage of reference databases (O'Rorke et al. 2012). DNA extraction and PCR can also be inhibited by substances found in digestive tracts (Schrader et al. 2012). Gut contents contain a mixed profile of samples and universal primers that target a broad range of organisms may also amplify predator DNA, which is often found in excess and preferentially amplified over degraded prey DNA (Vestheim \& Jarman, 2008). Group-specific primers can overcome the problem of predator amplification and have been successfully applied in many studies (Hoss et al. 1992; Jarman et al. 2004), particularly in cases where the group-specific primer is exclusive to an entire kingdom (e.g. plants used to characterise the diet of a herbivore; Jarman et al. 2004). When group-specific primers are not an option, methods that block predator DNA from amplification, including the use of restriction enzymes (Dunshea et al. 2009), PNA clamps (Chow et al. 2010), and predator-blocking primers (Vestheim \& Jarman, 2008; Leray et al. 2013; Leray et al. 2015), have all been used successfully, resolving the diets of marine animals including Australian fur seals (Deagle et al. 2009), corallivorous fishes (Leray et al. 2013; Leray et al. 2015) and the spiny lobster (Chow et al. 2010).

Tropical reefs experience greater predation pressure than other marine ecosystems (Paine, 1966) and tropical sponges differ from their temperate counterparts because they encounter significant predation from vertebrate predators (turtles and fish) in addition to invertebrates (Randall \& Hartman, 1968; Meylan, 1988; Wulff, 2006). Sponges exhibit life-history strategies, and structural and chemical 
defences to deter predation (Hay, 1996; McClintock et al. 2005; Hill et al. 2005), but they are thought to rely mainly on secondary chemistry (Chanas \& Pawlik, 1995; Pawlik, 2011). Obligate spongivores can be defined as species that depend on sponges for $\geq 80 \%$ of their diet (Cole et al. 2008; Chapter 2), with the majority belonging to the Pomacanthidae family (Randall \& Hartman, 1968). Obligate spongivores are thought to reduce the impact of chemical substances by adopting a 'smorgasbord' approach to foraging (Randall \& Hartman, 1968), as using a wide variety of prey items may reduce the effect of secondary compounds (Wulff, 1994). Evidence for generalist foraging on sponges was reported in early studies of sponge predation in the Caribbean, which cited $>40$ species of sponge in the gut contents of 24 Holacanthus ciliaris specimens and $>20$ species from other spongivorous angelfishes (Randall \& Hartman, 1968). Similarly, in the Mexican Pacific, angelfishes were reported to feed on $46 \%$ of the available sponge species (Verdín Padilla et al. 2010) and in Brazil, 34 species were found in the gut contents of three angelfish predators (Andrea et al. 2007). This foraging strategy is not thought to lead to significant sponge mortality as typically only part of the sponge is consumed (Wulff, 1994), and targeted sponges are often found in abundance on reefs (Wulff, 2006; Pawlik, 2018).

To identify palatable sponges and those with significant deterrent properties, some researchers have conducted feeding choice experiments using pelletised extractions of secondary metabolites (Pawlik et al. 1995; Becerro et al. 2003; Peters et al. 2009). Secondary metabolites are extracted from sponges and added to artificial diet cubes, which are then offered to generalist fishes alongside control pellets to determine predator deterrence (Pawlik et al. 1995). Feeding choice experiments conducted in the Caribbean revealed that species of Agelas, Amphimedon, Aplysina and Ectyoplasia had highly deterrent properties whereas species of Callyspongia, Niphates and Iotrochota were palatable to generalist fishes (Pawlik et al. 1995; Pawlik, 1997). Results of the feeding choice experiments were applied to data on sponges consumed by spongivorous angelfishes in a study by Randall and Hartman (1968), indicating that the majority of sponges consumed by Caribbean angelfishes were chemically undefended (Pawlik, 2011). These observations and others (see Pawlik, 2011 for review) led to the theory that sponges could be partitioned into three ecologically meaningful groups: (1) defended, open reef sponges; (2) undefended but tolerant, palatable sponges; and (3) palatable species that are restricted to cryptic habitats (Pawlik, 2011). However, assessing palatability using pellet assays is not always reflective of ecological reality (Lesser \& Slattery 2013; Wulff, 2017), as there can be extreme differences in palatability between spongivores (Wulff, 2006). For instance, Hawksbill turtles and angelfishes have different diet preferences (Wulff, 2012). Similarly, using a generalist wrasse to infer the broad effectiveness of defensive compounds ignores the fact that specialist spongivores (e.g. angelfishes) can exhibit a higher tolerance for chemical defences (Schupp et al. 1999). For example, crude organic extracts from the Micronesian sponge Oceanapia sp. deterred feeding by the spongivore Pomacanthus imperator but the deterrent effect was less pronounced than that observed from generalist reef fishes (Schupp et al. 1999). In addition, defences are not always 'static'; for example, Slattery et al. (2016) 
showed that the Caribbean reef sponge Plakortis angulospiculatus could increase defensive compounds when transplanted to an area of higher predation.

Only one published study has explicitly considered the role of sponge predators on Indo-Pacific reefs (Powell et al. 2015), revealing that Hyrtios erectus (Keller, 1889), Jaspis splendens (de Laubenfels, 1954) and Xestospongia testudinaria (Lamarck, 1815) were predated by the spongivores Pygoplites diacanthus, Pomacanthus sexstriatus and Zanclus cornutus, respectively (Powell et al. 2015). Other studies have identified sponges as a dietary item for reef fishes using visual observations of feeding behaviour and gut content analysis (Sano, 1989; Eagle \& Jones, 2004; Nagelkerken et al. 2009), but no information on sponge species identity was provided. In Chapter 2, in situ observations identified an additional 12 sponges that were predated by the spongivores $P$. diacanthus and $Z$. cornutus, with Clathria, Spheciospongia and Petrosiidae sponges preferred by P. diacanthus. However, the full dietary range was difficult to characterise visually because spongivorous fishes are often found at depths exceeding safe diving limits, forage in cryptic habitats and change their behaviour in the presence of divers (pers. obs). In Chapter 2, sponges from the gut contents of three angelfish predators $(P$. diacanthus, Pomacanthus imperator and Pomacanthus xanthometopon) were quantified, but taxonomic resolution beyond the phylum level was limited by the lack of reliable field guides and species-rich environment (Bell \& Smith, 2004; Rovellini et al. 2019). Additionally, homogenisation of sponges within the digestive tract hampered visual identification using spicule morphology. To address these problems, and improve the taxonomic resolution of predated sponges, I developed molecular methods to identify predated sponges from the gut contents of spongivorous angelfish from the Indo-Pacific. My specific aims for this chapter were: (i) to test 6 primer sets using DNA extractions from gut content sponges; and (ii) to identify generated sequences to the lowest possible taxonomic level using phylogenetic analysis. 


\subsection{Methods}

\subsubsection{Sample collection}

Gut content analysis of the Indo-Pacific angelfishes Pygoplites diacanthus, Pomacanthus imperator and Pomacanthus xanthometopon was performed in Chapter 2 as part of a wider study of spongegrazing fishes. $P$. imperator $(\mathrm{n}=1)$ was bought opportunistically from local fishers at Sampela reef and P. xanthometopon was bought opportunistically from local fishers at a site known locally as The Ridge (see Chapter 2, Figure 2.1). P. diacanthus was caught by local spearfishers at both Sampela $(\mathrm{n}=7)$ and The Ridge $(n=6)$. Fish were dissected and stomachs stored in $96 \%$ ethanol at $-20^{\circ} \mathrm{C}$ and returned to Wellington for dissection (see Chapter 2 for detail). During gut content analysis, sponges present in the stomachs of spongivorous fishes were visually separated by colour and location in the stomach. Samples of each sponge were retained and stored in $96 \%$ ethanol at $-20^{\circ} \mathrm{C}$ in sterile microcentrifuge tubes. All instruments and dissecting tools were ethanol cleaned and rinsed three times with double distilled water (DDW) between stomachs to prevent cross-contamination.

\subsubsection{Initial screening of primers}

Six primer sets were tested on a subset of 18 sponge samples recovered from six individual Pygoplites diacanthus stomachs, with success determined by visualisation on $1 \%$ agarose gels. Total genomic DNA was extracted using a DNeasy Blood and Tissue Kit (Qiagen) following the protocol of the manufacturer. PCR was conducted in $20 \mu \mathrm{l}$ reactions consisting of $10 \mu \mathrm{l}$ MyTaq Red Mix (Bioline), 0.4 $\mu \mathrm{l}$ of each primer $(10 \mu \mathrm{m}), \sim 25 \mathrm{ng}$ of template DNA and a volume of distilled water to reach $20 \mu \mathrm{l}$. PCR cycling conditions were: $94^{\circ} \mathrm{C}$ for 5 minutes; then 35 cycles of $94^{\circ} \mathrm{C}$ for 30 seconds, $58^{\circ} \mathrm{C}$ for 55 seconds (COI, COI ext, rnl, ITS2) or $50^{\circ} \mathrm{C}$ for 55 seconds $(18 \mathrm{~S}, 28 \mathrm{~S}), 72^{\circ} \mathrm{C}$ for 45 seconds and a final extension step of $72^{\circ} \mathrm{C}$ for 7 minutes. The $18 \mathrm{~S}$ primer set (Knapp et al. 2015) was the most successful, producing a single clear band of expected length for $13 / 18$ samples. PCR using primers to amplify $28 \mathrm{~S}$ (Baroin et al. 1988) produced single faint bands for 6/13 samples; no results could be visualised using the primers for COI (Folmer et al. 1994) or COI-ext (Rot et al. 2006); and multiple bands were present when amplifying ITS2 (Adlard \& Lester, 1995) and rnl (Lavrov et al. 2008). Successful amplifications using the $18 \mathrm{~S}$ primer set were sent for purification and sequencing on an ABI 3730 capillary sequencer (Macrogen, South Korea). Generated sequences were run through BLAST (http://blast.ncbi.nlm.nih.gov/Blast.cgi), which verified three samples as $>97 \%$ similar to sponge sequences held in the database and two samples that were verified as Poriferan, but with considerable uncertainty in identity. Two further samples were identified as crinoid and the remaining six samples were identified as the predator, $P$. diacanthus. $18 \mathrm{~S}$ is a popular gene used in the amplification and identification of metazoans because it is highly conserved among taxa (O'Rorke et al. 2012). Closer inspection of the $18 \mathrm{~S}$ primer set revealed that the forward primer was conserved between fish and sponges and the reverse primer had only two mismatches near the end of the primer sequence. Due to 
the lack of specificity between fish and sponge, the $18 \mathrm{~S}$ primers used here were not effective in preventing the amplification of predator DNA, which is often preferentially targeted over degraded prey DNA (Vestheim \& Jarman, 2008).

\subsubsection{Primer design for blocking predator DNA}

All available 18S sequence data for marine sponges were downloaded from the NCBI database using the search terms "18S ribosomal RNA gene", "Demospongiae" and "Marine". This yielded >100 sequences that were at least 1725 base pairs (bp) long, which were compiled alongside $18 \mathrm{~S}$ sequence data that were available for three spongivorous angelfishes, $P$. diacanthus, $P$. imperator and $P$. xanthometopon (Shen \& Hsiao, 2016). Sequences were aligned using the ClustalW function in BioEdit version 7.0.5.3 (Hall et al. 1999) and the alignment was searched for sponge-specific primer binding sites that would prevent the amplification of predator DNA. No variable regions of appropriate length (e.g. $20 \mathrm{bp}$ ) for primer design were found. Subsequently, I explored the use of predator-blocking primers which are modified so that they will not prime amplification and can be an effective method for inhibiting the amplification of undesired DNA (Vestheim \& Jarman, 2008; O'Rorke et al. 2012). Aligned sequence data and entropy plots were used to identify (1) primer binding sites that contained a conserved region across both sponge and predator DNA (hereafter the universal primer binding site) that flanked a (2) variable region with at least 4 or 5 mismatches between fish and sponge sequences (hereafter the blocking primer binding site) (Figure 3.1). This allowed for a predator-specific blocking primer to overlap with the 3 ' end of the universal primer binding site but extend into a predator specific sequence (Vestheim \& Jarman, 2008). The predator-blocking primer is then modified with a C3 spacer attached to the terminal 3' hydroxyl group of the oligonucleotide that prevents elongation during PCR (Vestheim \& Jarman, 2008; O’Rorke et al. 2012).

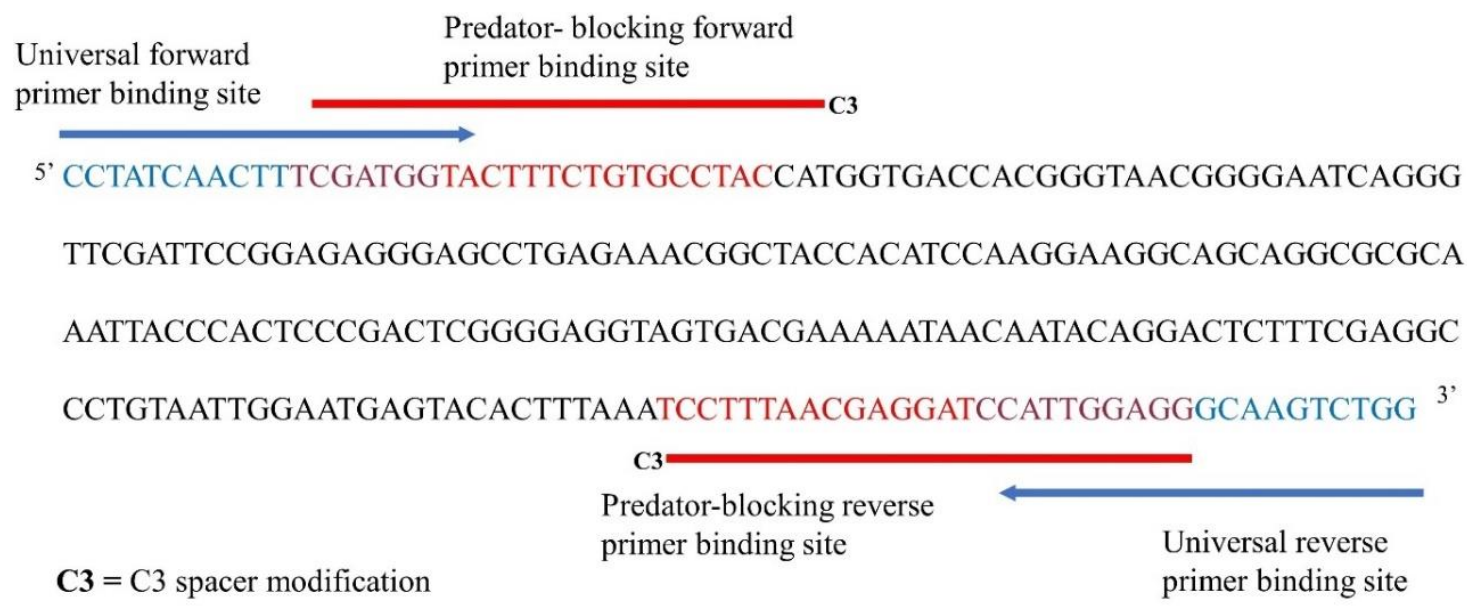

Figure 3. 1 A 255 bp region of Pygoplites diacanthus $18 \mathrm{~S}$ sequence showing the location of primer set 3 (Table 3.2) designed and trialled in this study. C3 denotes C3 spacer modification that prevents elongation during PCR. 
Primers that target short sequences of multi-copy DNA are likely to be effective in amplification of DNA degraded by digestion (Vestheim \& Jarman, 2008), however short sequences limit the taxonomic resolution of the output, particularly with the $18 \mathrm{~S}$ target gene, which is highly conserved amongst Eukaryotes and sometimes fails to resolve to the species level (O'Rorke et al. 2012). A range of universal primers and associated predator-blocking primers were designed to target different sequence lengths and tested using the initially screened samples using both sponge and predator controls. Primers had to be between 18-25 bp with an overlap of at least 8 bp between the universal and the blocking primer sets and 4-5 mismatches between predator and prey at the blocking primer site (Vestheim \& Jarman, 2008) (Figure 3.1). Blocking primers also had to have a higher melting temperature (Tm) so they will anneal before the universal primers during PCR, fortunately, an increase in Tm is usually achieved by the addition of the C3 spacer (O'Rorke et al. 2012). Two forward and two reverse binding sites were identified on the $18 \mathrm{~S}$ gene that met most of these conditions (Table 3.1).

Table 3. 1 18S primers designed during this study. 3 denotes C3 spacer modification added to the 3'end of blocking primers.

\begin{tabular}{|c|c|c|c|c|c|}
\hline Primer name & Position & Sequence $\left(5^{\prime}-3^{\prime}\right)$ & $\mathrm{BP}$ & $\mathrm{GC} \%$ & $\operatorname{Tm}(\mathrm{C})$ \\
\hline 18S_2A_F & Forward universal & $\begin{array}{l}\text { GGC TCA TTA AAT CAG TTA } \\
\mathrm{T}\end{array}$ & 19 & 31.6 & 48.7 \\
\hline 18S_2A_F_Block & Forward blocking & $\begin{array}{l}\text { AAT CAG TTA TGG TTC CTT } \\
\text { TGA TCG C3 }\end{array}$ & 25 & 40.0 & 62.5 \\
\hline 18S_3A_F & Forward universal & CCT ATC AAC TTT CGA TGG & 18 & 44.4 & 51.6 \\
\hline 18S_3A_F_Block & Forward blocking & $\begin{array}{l}\text { TCG ATG GTA CTT TCT GTG } \\
\text { ССТ AC3 }\end{array}$ & 23 & 47.8 & 62.9 \\
\hline 18S_4A_R & Reverse universal & CCA GAC TTG CCC TCC AAT & 18 & 55.6 & 56.1 \\
\hline 18S_4B_R_Block & Reverse blocking & $\begin{array}{l}\text { CCT CCA ATG GAT CCT CGT } \\
\text { TAA AGG A3 }\end{array}$ & 25 & 48.0 & 65.8 \\
\hline 18S_5A_R & Reverse universal & CTT GGC AAA TGC TTT CGC & 18 & 50.0 & 53.9 \\
\hline 18S_5B_R_Block & Reverse blocking & $\begin{array}{l}\text { GCT TTC GCT TTC GTC CGT } \\
\text { CTT G3 }\end{array}$ & 22 & 54.5 & 64.0 \\
\hline
\end{tabular}




\subsubsection{Designed primer trials}

To verify the applicability of the universal primers (without the addition of predator-blocking primers), PCRs were conducted using predator and sponge DNA. Predator DNA was extracted from two liver samples of Pygoplites diacanthus using a DNeasy Blood and Tissue Kit (Qiagen) following the protocol of the manufacturer. Three samples verified by BLAST as Poriferan were used for sponge DNA. As part of the optimisation process, PCR was conducted in $10 \mu \mathrm{l}$ reactions consisting of $5 \mu$ l MyTaq Red Mix (Bioline), $0.2 \mu \mathrm{l}$ of each universal primer $(10 \mu \mathrm{m}), \sim 25 \mathrm{ng}$ of template DNA and a volume of distilled water to reach $10 \mu \mathrm{l}$. Four primer sets were tested (Table 3.2), and gel electrophoresis confirmed that all universal primers amplified both predator and sponge DNA.

Table 3. 2 Four 18S primer sets trialled during this study.

\begin{tabular}{lllc}
\hline Set & Forward primer & Reverse primer & BP \\
\hline Set 1 & 18S_2F & 18S_4R & 492 \\
& GGC TCA TTA AAT CAG TTA T & CCA GAC TTG CCC TCC AAT & \\
Set 2 & 18S_2F & 18S_5R & 893 \\
& GGC TCA TTA AAT CAG TTA T & CTT GGC AAA TGC TTT CGC & \\
Set 3 & 18S_3F & 18S_4R & 255 \\
& CCT ATC AAC TTT CGA TGG & CCA GAC TTG CCC TCC AAT & \\
Set 4 & 18S_3F & 18S_5R & 656 \\
& CCT ATC AAC TTT CGA TGG & CTT GGC AAA TGC TTT CGC & \\
\hline
\end{tabular}

PCRs were conducted using the same samples and the four primer sets (Table 3.2) with the addition of the associated blocking primers (Table 3.1) at two different concentrations ( $5 \mathrm{X}$ and $10 \mathrm{X}$ ) to determine the most effective combination (Vestheim \& Jarman, 2008). The PCR recipe was as described previously for a $20 \mu \mathrm{l}$ reaction, with the addition of either $0.4 \mu \mathrm{l}(10 \mathrm{X})$ or $0.2 \mu \mathrm{l}(5 \mathrm{X})$ of each blocking primer $(100 \mu \mathrm{m})$. Gel electrophoresis confirmed that the most effective combination was set 2 with blocking primers included at $10 \mathrm{X}$ concentration (no bands could be visualised for predator DNA samples yet sponge DNA samples continued to amplify) (Figure 3.2). Set 1 showed some reduction in predator DNA amplification (faint bands) but no reduction at $5 \mathrm{X}$ concentration. Set 3 completely failed as all samples continued to amplify and faint bands could still be determined from predator samples at both concentrations using set 4 . 


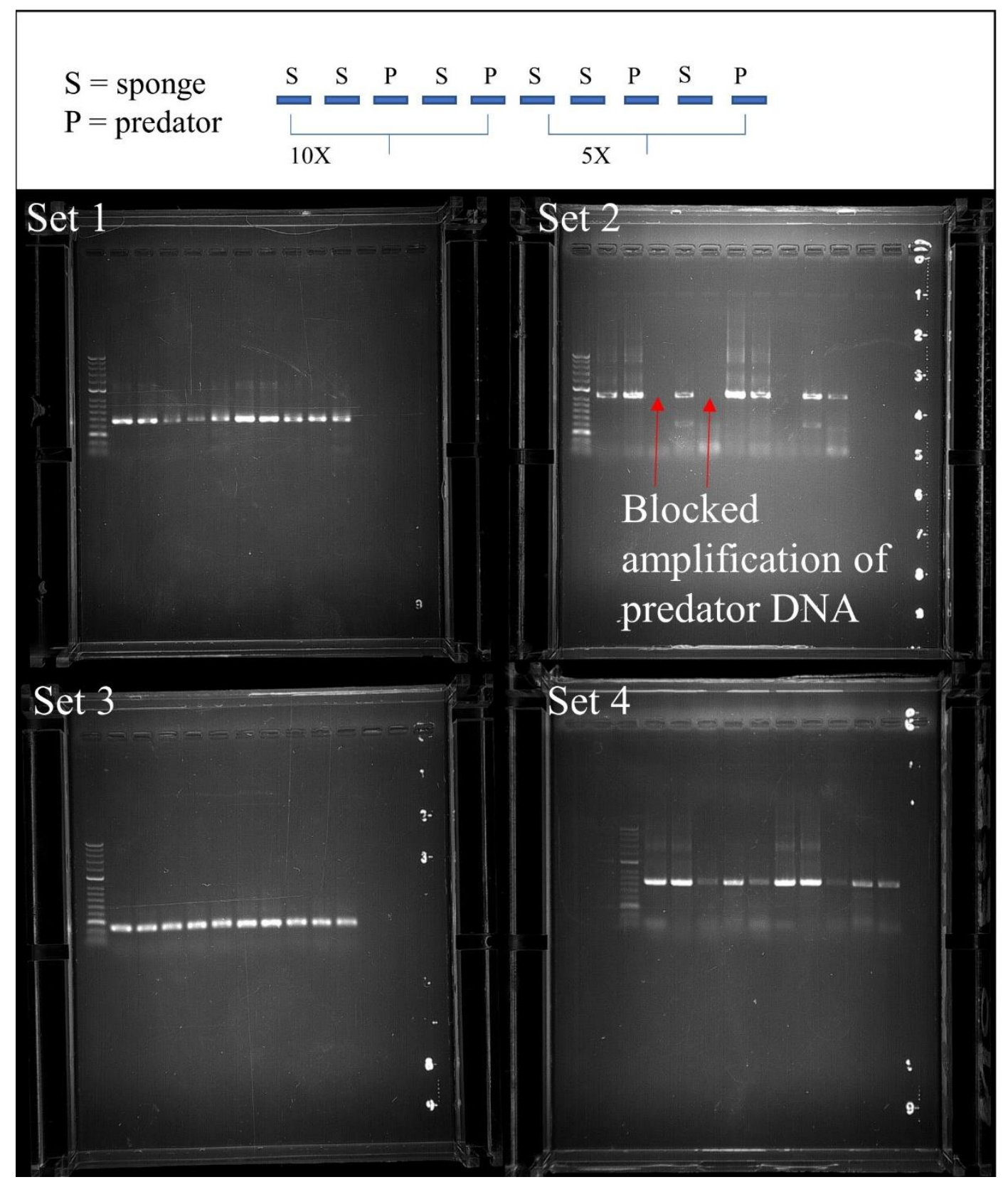

Figure 3. 2 Gel electrophoresis of four primer sets (Table 3.2) designed to block predator DNA from amplification. Predator-blocking primers were tested at $5 \mathrm{X}$ and $10 \mathrm{X}$ concentration (see the top of diagram) on DNA extracts from sponges (S) and the predator (P). Set 2 successfully blocked the amplification of predator DNA at 10 times concentration.

After determining the most efficient predator-blocking primer set, PCR was performed on the remaining sponge samples along with a sponge control, a predator control and a negative control. PCR was conducted in $25 \mu 1$ reactions consisting of $12.5 \mu 1$ MyTaq Red Mix (Bioline), $0.5 \mu 1$ of each universal primer $(10 \mu \mathrm{m}), 0.5 \mu \mathrm{l}$ of each blocking primer $(100 \mu \mathrm{m}), \sim 25 \mathrm{ng}$ of template DNA and a volume of distilled water to reach $25 \mu$ l. $5 \mu$ l of Bovine Serum Albumin (BSA) was added to the reaction to 
improve PCR yield. PCR cycling conditions were: $94^{\circ} \mathrm{C}$ for 5 minutes; the 35 cycles of $94^{\circ} \mathrm{C}$ for 30 seconds, $48^{\circ} \mathrm{C}$ for 55 seconds, $72^{\circ} \mathrm{C}$ for 45 seconds and a final extension step of $72^{\circ} \mathrm{C}$ for 7 minutes. In total, 32 samples were successfully amplified and sent for purification and sequencing on an ABI 3730 capillary sequencer (Macrogen, South Korea).

\subsubsection{Data analysis}

Generated sequences were screened for contamination from other targets (e.g. fungus) and for duplicate samples (e.g. the same sponge sequence from the same stomach). Remaining sequences were quality checked using CodonCode Aligner (http://www.codoncode.com/aligner) by clipping bases until there were fewer than 3 bases with a phred quality score of less than 20 in a 25 bp window and removing any sequences shorter than $200 \mathrm{bp}$ in length. A demosponge dataset was created using $18 \mathrm{~S}$ rDNA sequence data downloaded from the GenBank database, the minimum inclusion was 500 bp and downloaded sequences were limited to the 6 orders represented by sequences obtained by this study (Appendix C). All sequences were aligned using ClustalW function in BioEdit version 7.0.5.3 (Hall et al. 1999). A phylogenetic tree was constructed of aligned sequence data using ModelFinder in IQ-TREE multicore version 1.6.11 (Kalyaanamoorthy et al. 2017), which calculates the log-likelihoods of an initial parsimony tree for many different models, choosing the model that minimises the Bayesian information criterion (BIC). The glass sponge Rhabdocalyptus dawsoni was used as an outgroup (accession number: AF100949) and branch supports were obtained using the SH-aLRT test (Guindon et al. 2010) and ultrafast bootstrap (Hoang et al. 2018). The best-fit model according to BIC was TIM2+F+I+G4. Branch supports are reported as SH-aLRT support (\%) / ultrafast bootstrap support (\%) and high support for the existence of a clade was determined by SH-aLRT $\geq 85 \%$ / UFBoot $\geq 95 \%$. 


\subsection{Results}

Out of the 32 samples sent for sequencing, seven amplified fungus, two amplified crinoid and 23 amplified sponge. Of the 23 sponge sequences, only 14 met the stringent quality control standard outlined above. The identity of one of these samples could not be resolved beyond Porifera and was removed from the dataset. The remaining 13 sponges represented six orders of Porifera (Figure 3.3).

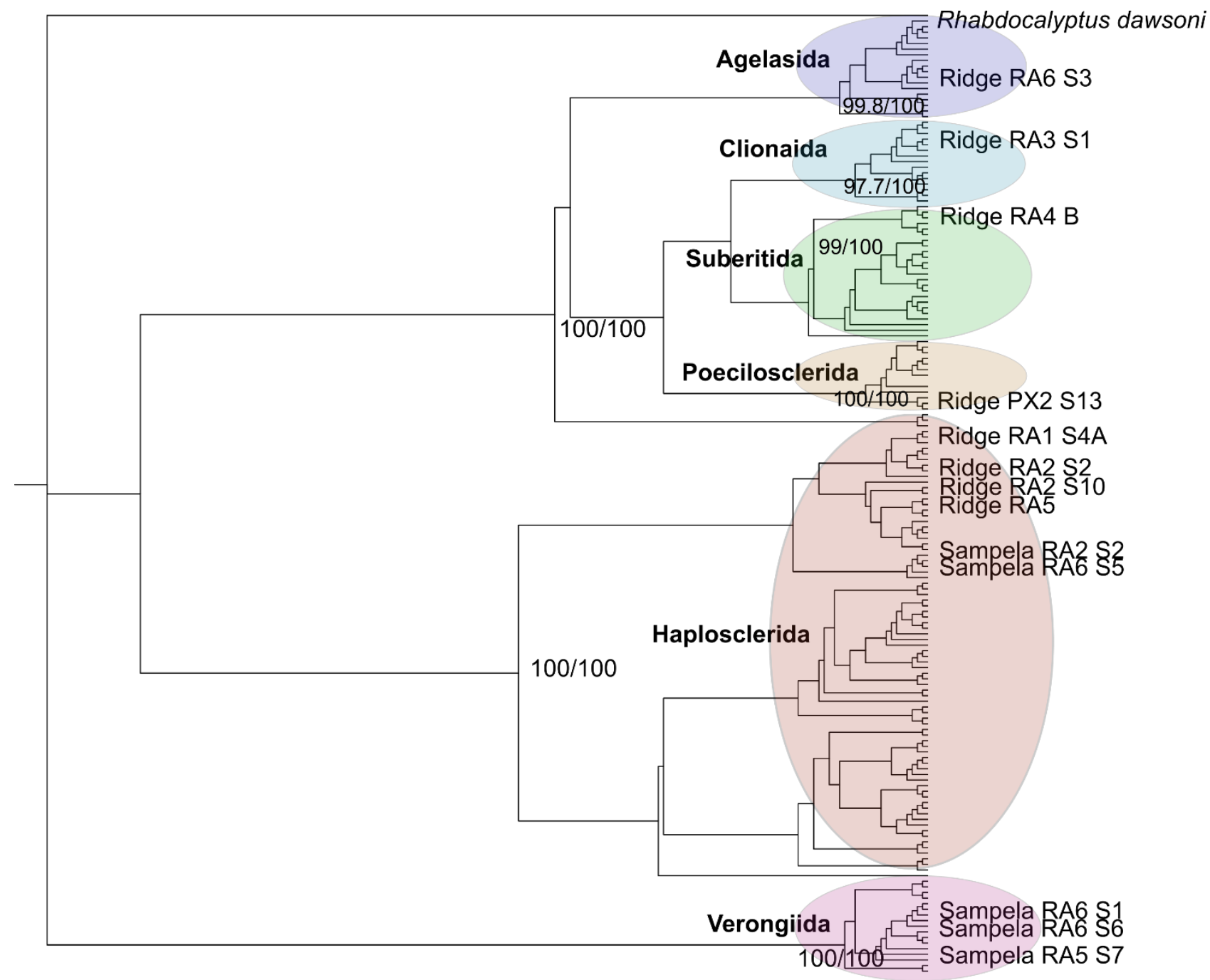

Figure 3. 3 Cladogram showing the placement of 13 sponges within six orders of Porifera dissected from the stomach contents of the angelfishes Pygoplites diacanthus (RA) and Pomacanthus xanthometopon (PX) caught at two sites in the Wakatobi MNP and based on 18S sequence data. The outgroup is the glass sponge Rhabdocalyptus dawsoni (AF100949). Branch supports reported as SHaLRT support (\%) / ultrafast bootstrap support (\%). 
Six sponges were placed in the order Haplosclerida and came from Pygoplites diacanthus specimens collected at both Sampela and the Ridge (Figure 3.4). The 18S data provided strong support that one sponge (Ridge RA2 S10) was placed into a clade with the Indo-Pacific sponge Chalinula hooperi (Bakus \& Nishiyama, 2000) (91.7/100) and another sponge (Ridge RA5) had strong support for placement within a clade of Petrosia sponges (98.6/96). The sponge Ridge RA1 S4A also formed a highly supported clade (97.8/99) with the species Haliclona curacaoensis (van Soest, 1980) and Niphates erecta (Duchassaing \& Michelotti, 1864). For the remaining samples in this order, identities could not be resolved beyond Haplosclerida. The Haplosclerida sponges formed four weakly supported major clades. All of the sponges placed in the order Haplosclerida were placed within a weakly supported major clade containing mainly Petrosiidae and Niphatidae sponges, with some interspersed Haliclona.

The second order that was represented by more than one sponge was Verongiida and all of these sponges came from stomachs of $P$. diacanthus collected at Sampela (Figure 3.5). There was strong support for all three sponges being placed within a clade containing Pseudoceratinidae and Verongula sponges (86.5/97). The remaining sponges were all classified as separate orders and were sequenced from the stomachs of $P$. diacanthus and Pomacanthus xanthometopon collected at The Ridge. There was strong support for the placement of one sponge (Ridge RA6 S3) within a clade of Agelasidae sponges (87.5/95) and another sponge (Ridge RA4 B) had strong support for placement within a clade of Aaptos sponges from the order Suberitida (98.7/100). The sponge Ridge RA3 S1 had strong support for placement within a clade containing both Clionaidae and Spirastrellidae genera (97.2/99) and the only sponge that was successfully sequenced from the gut contents of P. xanthometopon (Ridge PX2 S13) was grouped in the order Poecilosclerida and had strong support for placement into a clade containing Guitarra sp. $(88.1 / 100)$. 


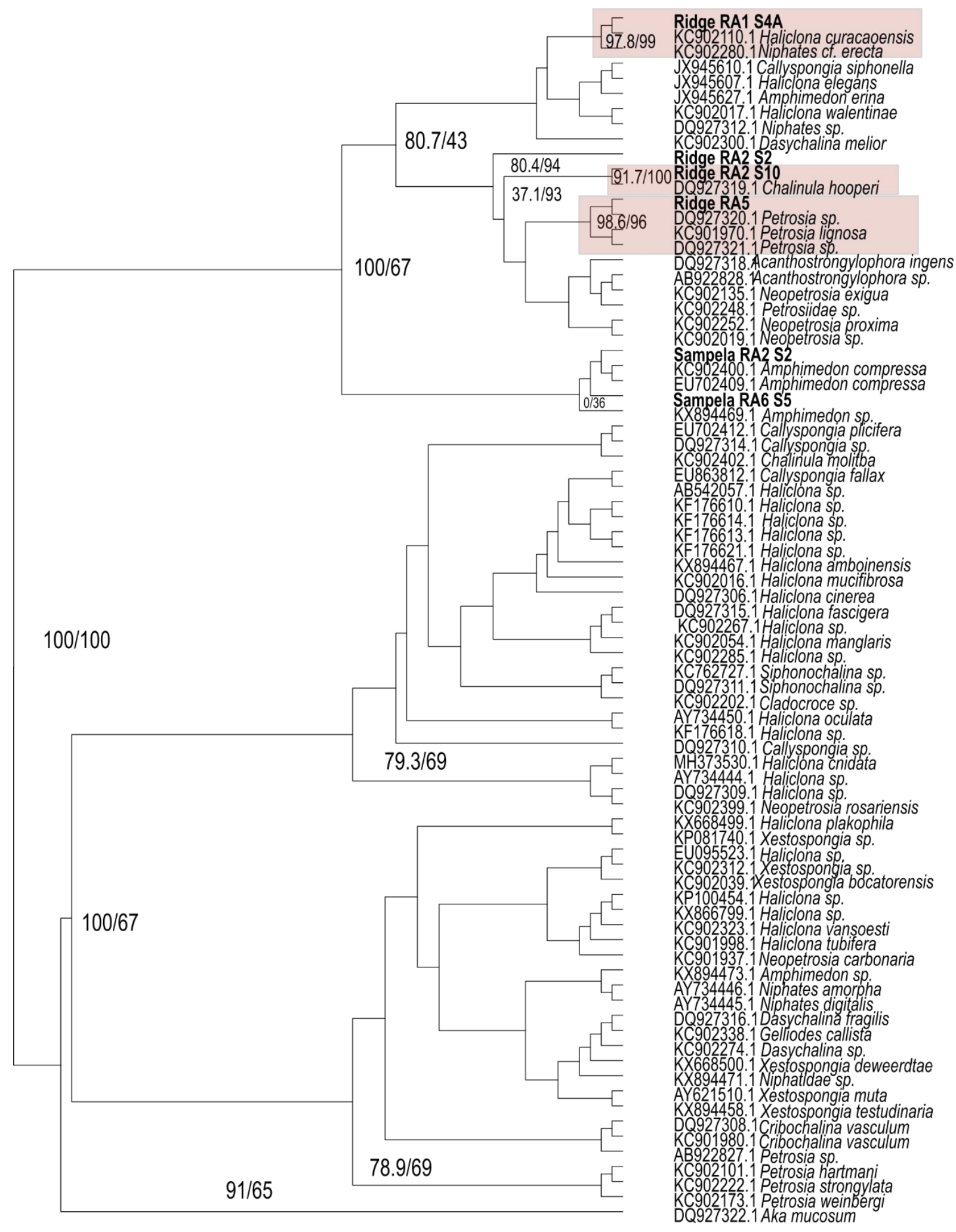

Figure 3. 4 Cladogram showing the placement within the order Haplosclerida of six sponges sampled from the stomach contents of the angelfish Pygoplites diacanthus (RA) caught at two sites in the Wakatobi MNP and based on 18S sequence data. Branch supports are reported as SH-aLRT support (\%) / ultrafast bootstrap support (\%). 

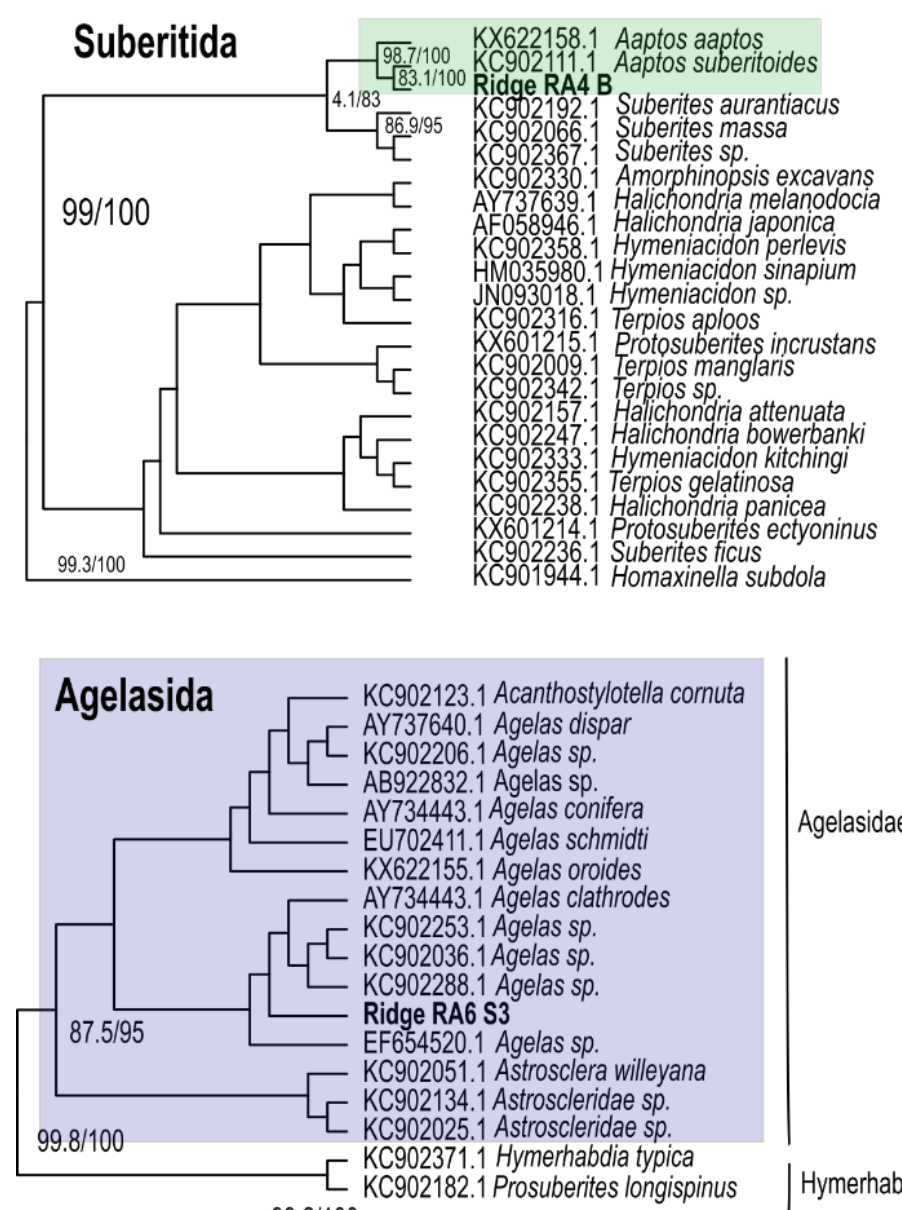

$99.2 / 100$
Verongiida
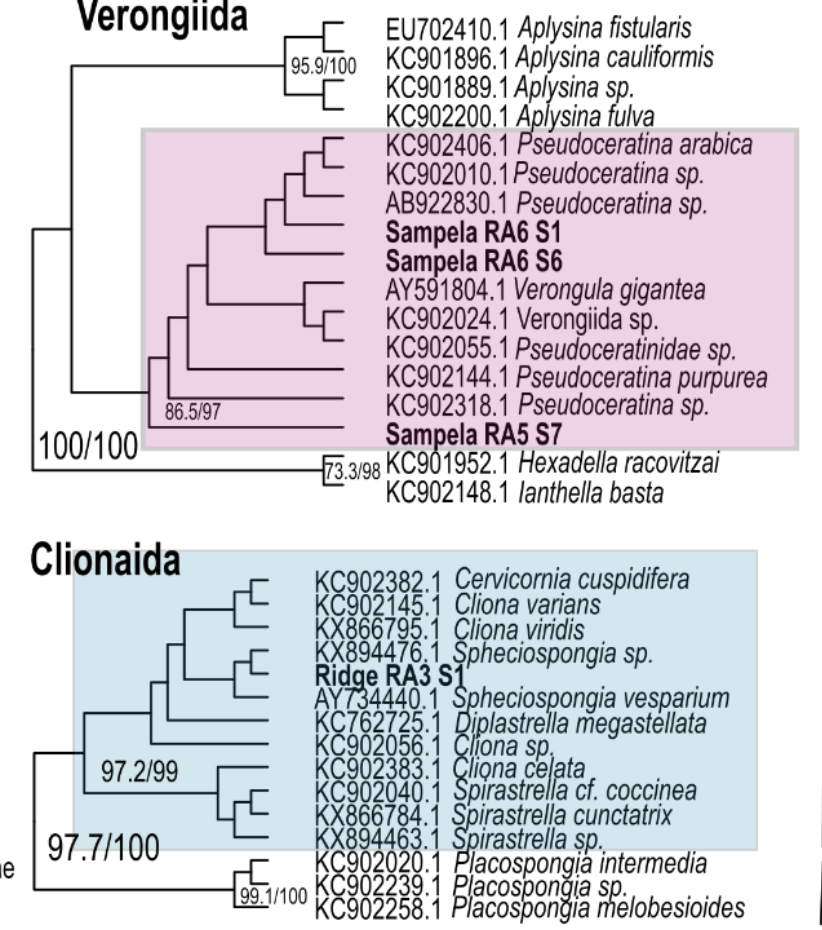

Pseudoceratinidae and

Aplysinidae

Clionidae and
Spirastrellidae
Placospongia

Figure 3. 5 Cladogram

showing the placement of seven sponge sequences amplified from the stomach contents of the angelfishes Pygoplites diacanthus (RA) and Pomacanthus xanthometopon (PX) caught at two sites in the Wakatobi MNR. Branch supports are reported as SH-aLRT support (\%) / ultrafast bootstrap support (\%).

\footnotetext{
Poecilosclerida — LN870429.1 Abyssocladia dominalba

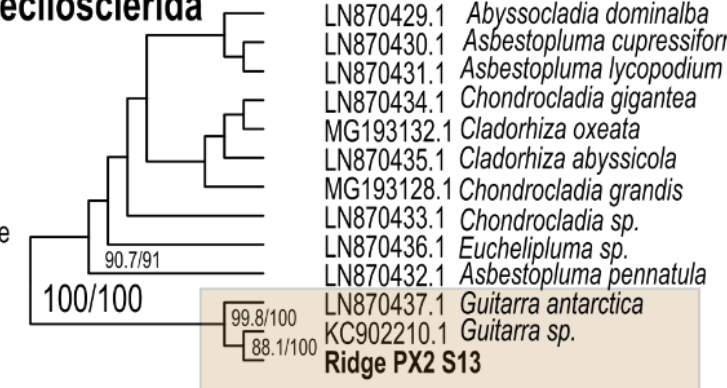




\subsection{Discussion}

Resolving predator-prey dynamics is essential to understand the structuring of ecological communities (Leray et al. 2015; Nielsen et al. 2018). This chapter developed molecular methods to identify sponges from the stomach contents of spongivorous angelfishes from the Indo-Pacific. Fourteen sponges produced sequences of high enough quality to be included in the final dataset. These sponges represented 6 orders of Porifera, indicating that Pygoplites diacanthus exhibited significant dietary plasticity within the Porifera phylum. Many of the sponges were placed into clades with sponges that exhibit deterrent properties including sponges from the family Agelasidae, the genus Aaptos and the order Verongiida, suggesting that $P$. diacanthus consumed sponges with substantial chemical defences.

\subsubsection{Taxonomy of predated sponges}

From 13 angelfish stomachs, 14 unique sponge sequences were retrieved spanning six orders of Porifera, indicating significant dietary plasticity, similar to the diets of angelfish in the Caribbean (Randall \& Hartman, 1968; Hourigan et al. 1989; Wulff, 1994) and the Pacific (Verdín Padilla et al. 2010). The majority of samples were represented by the order Haplosclerida, which are an extremely diverse order of Porifera (van Soest \& Hooper, 2002). The Haplosclerida sequences were separated into four weakly supported clades, although one clade was only represented by one species, Aka mucosum. The other 3 clades all contained members of multiple families. Many of the genera in this order were not monophyletic, presenting substantial difficulties classifying sponges from this order (Redmond et al. 2013). In a study on the phylogenetics of Demospongiae, Redmond et al (2013) found 5 highly supported clades, one of which (Clade C) is equivalent to the clade in this study where the Haplosclerida samples were situated (Redmond et al. 2013). This clade is made up of mainly Petrosiidae and Niphatidae samples, with some interspersed Haliclona (Redmond et al. 2013). Within this group, there was strong support for the placement of one sponge into a clade with the Indo-Pacific sponge Chalinula hooperi (Bakus \& Nishiyama, 2000) commonly found in the shallow waters of pristine, offshore reefs (Cleary \& de Voogd, 2007) that produces substances toxic to corals (Bakus \& Nishiyama, 2000). Two congeners Chalinula nematifera (de Laubenfels, 1954) and Chalinula milnei (de Laubenfels, 1954) that have a documented distribution in the Wakatobi (Chapter 2; Rossi et al. 2015) are also coral-killing sponges that secrete mucus containing toxic substances causing coral mortality (Porter \& Targett, 1988). Coral-killing species such as $C$. nematifera that have a wide distribution across Indonesia, high growth rates (Rossi et al. 2015) and the ability to overgrow many species of coral (Turicchia et al. 2018) have the potential to seriously threaten Indo-Pacific reefs. Considering that angelfishes may play an important role in controlling the distribution of these species, angelfish abundances should be closely monitored, as the impacts of coral-killing species could be exacerbated if angelfish populations decline.

There was strong support for the placement of one sponge into a clade containing sponges from the genus Petrosia. This supports observations made in Chapter 2 in which in situ observations of the 
spongivores Pygoplites diacanthus and Zanclus cornutus revealed a preference for some sponges from the family Petrosiidae. Some species of Petrosia have also been shown to be palatable to generalist fishes in the Red Sea (Burns et al. 2003). Another sponge had high support for placement alongside two Caribbean sponges Niphates erecta and Haliclona curacaoensis. Species of Haliclona have been reported from the gut contents of spongivorous fishes in the Caribbean (Randall \& Hartman, 1968; Hourigan et al. 1989) and the Pacific (Verdín Padilla et al. 2010). Similarly, sponges from the genus Niphates are thought to be palatable to spongivorous fishes and invest heavily in growth to compensate for biomass removal (Pawlik, 2011). For the three other samples in this group, identity could not be resolved beyond the order Haplosclerida.

Three sponges in the Verongiida group had high support for placement into a clade including sponges from the genera Pseudoceratina and Verongula. Verongiida sponges lack spicules, instead, they are structurally supported by 3D internal scaffolds made of fibrous chitin (Żółtowska- Aksamitowska et al. 2018). Sponges from the genus Pseudoceratina are reported to produce diverse secondary metabolites with biological activities including anti-fouling, anti-microbial and anti-cancer properties (reviewed in Żółtowska- Aksamitowska et al. 2018). Some studies have found that sponges in the order Verongiida are avoided by angelfishes and have defensive compounds that deter predation (Pawlik et al. 1995; Burns et al. 2003; Wulff, 2006; Loh \& Pawlik, 2014). However, three species of angelfish were observed taking bites from Pseudoceratina crassa in the Caribbean (Hourigan et al. 1989) and results presented here indicate that Pygoplites diacanthus consumed Verongiida sponges.

There was high support for one sponge belonging to a clade with two species of Aaptos. Aaptos suberitoides is commonly found on Wakatobi reefs and has been found to produce numerous compounds with antitumor, antimicrobial, and antiviral activity (reviewed in Cleary et al. 2018). Meylan (1998) documented the closely related Aaptos aaptos as one of the ten most important sponges predated by the Hawksbill turtle, even though it produces toxic secondary metabolites (Nakamura et al. 1982). Similarly, Aaptos niger was reported to form part of the diet of a spongivorous nudibranch and the angelfish Holacanthus passer (Verdín Padilla et al. 2010). However, data presented in this chapter represents the first account of a species of Aaptos being predated by a spongivorous fish in the IndoPacific. There was also strong support for the placement of one sponge into a clade of sponges from the family Agelasidae that are known for producing bromopyrrole alkaloids (Wilson et al. 1999; Lindel et al. 2000) that deter predation (Chanas \& Pawlik, 1996). An unknown species of Agelas represented the largest volume of sponge in the gut contents of the angelfish Holacanthus ciliaris and was also predated by a filefish (Randall \& Hartman, 1968). Hence some species in this family appear to attract predation, even with substantial chemical defences.

There was strong support for one sponge belonging to a clade containing the bio-eroding families Clionaidae and Spirastrellidae. This also supports observations made in Chapter 2 where Pygoplites 
diacanthus was recorded taking bites from Spechiospongia sp. (Chapter 2, Figure 2.6). It is also consistent with observations from the Caribbean, which have recorded bio-eroding sponges from the genera Spirastrella, Cliona and Spechiospongia in angelfish gut contents (Randall \& Hartman, 1968). The only sponge that could be amplified from the gut contents of Pomacanthus xanthometopon had strong support for placement into a clade of sponges from the genus Guitarra (Carter, 1874) from the Guitarridae family. To date, there are 15 described species of Guitarra, but none have a documented distribution in the Indo-Pacific (https://www.marinespecies.org). Highlighting rare or previously unknown species can be an advantage of using gut contents to assess predated sponges (Wulff, 2006). For example, the sponge Iotrochota birotulata was commonly found in the gut contents of the spongivorous urchin Eucidaris tribuloides in Brazil despite having no known local distribution (Santos et al. 2002). Finally, the identity of one sample could not be resolved beyond the higher classification of Porifera. This is likely due to poor data coverage for sponges from the Indo-Pacific, one of the most speciose regions of Porifera on the planet (Maldonado et al. 2017). Resolving the taxonomy of predated sponges using molecular methods will be easier in future studies, as global barcoding initiatives increase the availability of sponge sequences.

\subsubsection{Predator-blocking primers}

Using molecular methods in diet tracing studies can help to overcome some of the problems associated with visual identification including capturing rare or highly digested items, or liquid components (Nielsen et al. 2018). Yet, working with mixed samples presents an entirely new range of problems including predator DNA swamping (Vestheim \& Jarman, 2008), presence of PCR inhibitors (e.g. faeces and bile, Penn et al. 2016) and choosing appropriate regions to amplify degraded DNA (Vestheim \& Jarman, 2008). The most successful primer set designed during this study (Set 2) completely blocked the amplification of predator DNA when blocking primers were included at 10 times concentration. Vestheim \& Jarman (2008) also found that blocking primers were most effective at removing krill DNA from diet samples when they were included at 10-fold molar excess. When this primer set was applied to the original trial samples, predator DNA that previously amplified was successfully blocked and sponge DNA that was present in the samples amplified. Blocking primers have been successfully applied to help identify the diet of Antarctic krill (Vestheim \& Jarman, 2008), a coral predator (Leray et al. 2013) and Australian fur seals (Deagle et al. 2009). However, this study represents the first known attempt to identify predated sponge samples recovered from the gut contents of spongivorous fish.

Although the primers designed in this study prevented the amplification of predator DNA, they amplified two groups of non-target sequences, fungus and crinoids. Seven of the DNA sequences were verified by basic local alignment search tool (BLAST) to be a fungus. Some marine sponges have been found to possess significant fungal diversity (Gaino et al. 2014), although it seems more likely that these samples were part of the predator's gut microbial community, the composition of which is understood 
to be heavily influenced by diet (Muegge et al. 2011; Clements et al. 2014). In addition to fungus, one crinoid sequence was amplified and sequenced. This could be non-targeted predation, as crinoids in the Wakatobi are regularly seen attached to sponges (pers. obs.); however, the same feeding behaviour has been recorded in video observations (unpublished data) indicating that crinoids are likely a minor prey item for Pygoplites diacanthus. The amplification of non-target sequences highlights the difficulties in designing primers that target an entire phylum but exclude other non-sponge prey, parasites or gut microbiota (O'Rorke et al. 2012; Vestheim \& Jarman, 2008). This study targeted the $18 \mathrm{~S}$ gene because of prior amplification success but future studies characterising diet using gut content samples are likely to take advantage of next-generation sequencing (NGS) and metabarcoding techniques (O'Rorke et al. 2012; Pompanon et al. 2012). NGS allows the sequencing of many species from the same sample providing a high degree of resolution on diverse diets, and also reduces the influence of non-target sequences that can be screened from the dataset using NGS methods (O'Rorke et al. 2012; Pompanon et al. 2012).

\subsubsection{Conclusion}

This study is the first to successfully sequence sponges from the gut contents of spongivorous fish and has yielded several genera previously unknown to be predated in the Indo-Pacific. As one of the most important groups of spongivores on coral reefs, resolving the diet preferences of angelfishes is an essential step on the way to determining the ecological importance of spongivory. Using molecular methods of diet characterisation, this study yielded significant information on the diversity and taxonomy of predated sponges, overcoming problems associated with observational approaches such as cryptic feeing behaviour and unidentifiable gut contents. 


\section{Chapter 4. Niche width expansion and a loss of trophic diversity on a sponge-dominated reef in The Coral Triangle}

\subsection{Abstract}

Coral reefs are extremely productive, diverse ecosystems. Yet, widespread shifts in benthic community structure due to habitat degradation are affecting organic matter transfer between trophic levels, altering food web structure and dynamics. Optimal foraging theory suggests the niche width of a species increases in response to a decrease in per capita prey, as they adjust their foraging behaviour to include non-preferred food. Trophic specialists with less flexible diets are the most susceptible to environmental disturbance and may be disproportionately affected, leading to a system dominated by generalists. In this chapter, I investigated how changes in resource availability affect niche widths and trophic diversity in a coral reef fish assemblage. I used stable isotope analysis and sampled coral reef fish representing functional feeding groups, prey items and basal carbon sources at a sponge-dominated reef system and an adjacent, higher quality reef site. The fish assemblage at the sponge-dominated site had a significantly lower mean trophic position in comparison to the higher quality site. Four out of seven fish species had wider isotopic niches at the sponge-dominated site, although the isotopic niche of the detritivore was significantly smaller. The obligate corallivore had a significantly wider isotopic niche at the sponge-dominated site and increased proximity to the isotopic niche of the detritivore suggests that it supplemented its diet with detritus. Patterns of niche width expansion observed by the specialists (the spongivore and the corallivore) at the sponge-dominated site were not reflected by their main food sources (sponges and corals). The fish assemblage sampled at the sponge-dominated site used a significantly lower range of resources $\left(\delta^{13} \mathrm{C}\right.$ range) and obtained more carbon from benthic production than at the high-quality site. Trophic diversity was lower and functional redundancy higher, suggesting that fish at the sponge-dominated site had more similar diets. Low coral and macroalgal cover, and relative isolation from oceanic upwelling, suggest that the sponge-dominated site was mainly fuelled by detrital production. Observed differences in trophic structure between the two sites are likely due to fewer organic matter pathways supporting secondary production at the sponge-dominated site, which ultimately leads to a simplification of trophic structure. Whilst trophic niche expansion may facilitate the survival of populations in the short term, it is expected to lead to intensified competition for increasingly scarce resources. 


\subsection{Introduction}

Coral reefs are one of the most productive ecosystems on the planet (Odum \& Odum, 1955; Hughes et al. 2003; Atkinson \& Falter, 2003). They support extremely high biodiversity (Hoeksema, 2017) and provide numerous benefits to coastal communities including food, coastal protection and livelihoods (Bryant et al. 1998; Diaz et al. 2015). Yet, persistently high levels of natural and anthropogenic disturbance have caused widespread changes to benthic community structure on a global scale (Hughes et al. 2003), transforming food web structure and dynamics (Bellwood et al. 2004; Graham et al. 2014; Pratchett et al. 2014). Coral reef fish assemblages are exceptionally diverse (Brandl et al. 2016) and perform critical ecosystem functions including herbivory (Bellwood et al. 2004) and the transfer of pelagic nutrients to benthic communities (Hobson, 1991), but they are also extremely vulnerable to disturbance (Emslie et al. 2018). Species are not affected randomly by disturbance (Smith \& Knapp, 2003), and those that share vulnerable traits are disproportionately affected (Mouillot et al. 2013). Resource specialisation will likely determine a species' response and susceptibility to perturbations (Layman et al. 2007; Graham et al. 2011). On coral reefs, obligate corallivores that are heavily dependent on corals for food and habitat are predicted to be the most vulnerable to extinction from climate disturbances (Graham et al. 2011), whereas those with more plastic niches are expected to compete more effectively in degraded habitats (Clavel et al. 2011). Some amount of habitat degradation may even be beneficial for some functional groups in the short term (Rogers et al. 2018) through the provision of alternative food (Kramer et al. 2014) or a reduction in competition. Understanding how species and communities respond to habitat degradation is critical to predicting the capacity of future coastal environments to provide crucial goods and services (Sale et al. 2014).

Optimal foraging theory predicts that individuals choose prey in a way that maximises their overall rate of energy gain (Pyke et al. 1977; Brooker et al. 2014). Therefore, a decrease in per capita prey is expected to lead to an increase in niche width (Rossi et al. 2015) as consumers include sub-optimal prey in their diet following a decline in preferred food (Rossi et al. 2015; Calizza et al. 2017). This can lead to increased competition for resources and the exclusion of poor competitors (Calizza et al. 2017). Diet switching to sub-optimal items may have a cost at the individual level e.g. loss of physiological condition (Berumen et al. 2005) and the population level by reducing the fecundity (Jones \& McCormick, 2002), growth (Feary et al. 2009) and trophic position of consumers (Hempson et al. 2015). For example, a decrease in the trophic position of the coral grouper Plectropomus maculatus on the Great Barrier Reef was linked to a shift from pelagic to benthic prey following widespread coral bleaching and mortality (Hempson et al. 2015). Increased generalism may also have a cost at the community level, as disturbance-mediated shifts towards generalist-dominated communities lead to functional homogenisation (Olden et al. 2004), a state where persisting species all perform similar ecological roles (Clavel et al. 2011; Mouillot et al. 2013). Community reorganisation in favour of 
generalists following environmental disturbance has been documented in many ecosystems worldwide including coral reefs (Munday, 2004), seagrass meadows (Calizza et al. 2017) and temperate forests (Valladares et al. 2012). This is expected to have various impacts on ecosystems depending on which ecosystem functions are lost (Graham et al. 2011; Bellwood et al. 2019).

Food webs are most stable at high levels of complexity (Johnson et al. 2014), which poses a challenge for researchers trying to link environmental change with the functioning of consumers (Middelburg, 2014). Gut content analysis is typically used to quantify the relative abundance of prey thus determining predator-prey relationships and niche breadth (Levin, 1968; Layman et al. 2007). However, gut content analysis can be biased towards structural items at the expense of soft-bodied taxa (Nielsen et al. 2018) and it only provides a dietary snapshot (Pinnegar \& Poulin, 1999). It also does not provide information on assimilated products, which may differ substantially from bulk ingested matter (Nielsen et al. 2018). Stable isotope analysis (SIA) is a useful tool for elucidating trophodynamics in marine systems and relies on the basic premise that isotopes fractionate as a result of physical, chemical and biological processes (Middelburg, 2014). It incorporates dietary information from longer time periods (Pinnegar \& Poulin, 1999) and can be performed on producers and consumers, providing an end-to-end reconstruction of food webs (Middelburg, 2014). Nitrogen isotope ratios $\left({ }^{15} \mathrm{~N} /{ }^{14} \mathrm{~N}\right.$ noted $\left.\delta^{15} \mathrm{~N}\right)$ are used to estimate trophic position because the lighter isotope $\left({ }^{14} \mathrm{~N}\right)$ is lost at a faster rate than the heavy isotope $\left({ }^{15} \mathrm{~N}\right)$ during excretion and assimilation (Fry, 2006). This leaves the consumer enriched in ${ }^{15} \mathrm{~N}$ by an estimated 2\%o - 4\%o relative to its diet (De Niro \& Epstein, 1981; Minagawa \& Wada, 1984). Hence, $\delta^{15} \mathrm{~N}$ values can be used to estimate food chain length and the trophic positions of consumers (Minagawa $\&$ Wada, 1984). Carbon isotopes are used to determine sources of nutrition because different photosynthetic pathways (C3 or C4) result in variation in $\delta^{13} \mathrm{C}$ values (O'Leary, 1988). Carbon is not thought to fractionate to the same extent as nitrogen (0-1\%) (De Niro \& Epstein, 1981; Post, 2002) hence $\delta^{13} \mathrm{C}$ values of consumers generally reflect the main source of carbon consumed. Bivariate isotope data $\left(\delta^{15} \mathrm{~N}\right.$ and $\left.\delta^{13} \mathrm{C}\right)$ have been conceptualised as the 'isotopic niche' (Bearhop et al. 2004; Newsome et al. 2007) that fits Hutchinson's ecological niche concept (Hutchinson, 1957; Hutchinson, 1978) because it represents both scenopoetic (habitat) and bionomic (resource) axes (Hutchinson, 1978; Newsome et al. 2007). Intraspecific variation in isotope ratios can be used as a measure of niche width (Bearhop et al. 2004) because it indicates among-individual differences in diet, e.g. generalist or specialist consumers (Bearhop et al. 2004; Jackson et al. 2011). The rise of the isotopic niche as a proxy for trophic niche (Newsome et al. 2007) allows researchers to measure trophic specialisation among species in a community and investigate how dynamics change in response to different environmental conditions.

From 2002 to 2007, the Sampela reef system in the Wakatobi Marine National Park (MNP) experienced $>50 \%$ decline in hard coral cover and a concurrent increase in sponge density (McMellor \& Smith, 
2010; Powell et al. 2014). This sponge assemblage at Sampela is dominated by Lamellodysedia herbacea, an encrusting phototrophic species with adaptations including rapid photo-acclimatisation and effective sediment clearance that allow it to proliferate under poor environmental conditions (Biggerstaff et al. 2015; Biggerstaff et al. 2017). Research on the Sampela reef system has mainly centred on identifying the main drivers of change (Powell, et al. 2014; Biggerstaff et al. 2015; Biggerstaff et al. 2017) rather than assessing the consequences to trophic structure and functioning. Given that sponge-dominated reefs may be a potential future scenario for some reef systems (Bell et al. 2013) it is essential to understand how changes to benthic community composition affect trophic structure and functioning.

In this chapter, I used stable isotope analysis to investigate how changes in resource availability affect niche widths and trophic diversity in a coral reef fish assemblage. I sampled the stable isotope ratios of seven coral reef fish species each representing a different functional feeding group, associated prey and basal carbon sources at a low quality, sponge-dominated reef and an adjacent higher quality reef site. My specific aims were: i) to compare the trophic position and $\delta^{13} \mathrm{C}$ values of fish between reefs and species; ii) to compare isotopic niche size of fish species between reefs; iii) to investigate isotopic discrimination and spatial variation in basal carbon sources and benthic prey; iv) to compare the relative proportion of benthic and pelagic organic matter contributing to fish diets at both sites; and, v) to compare trophic structure between reefs using Layman community metrics derived from stable isotope data. 


\subsection{Methods}

\subsubsection{Study sites}

The Wakatobi Marine National Park (see Chapter 2, Figure 2.1) is Indonesia's third-largest marine national park and is located within the coral triangle, a region supporting extremely high marine biodiversity (Allen, 2008; Veron et al. 2009). Reefs in Southeast Asia are considered the most threatened in the world (Burke et al. 2011). From 2002-2007, live coral cover on the reefs surrounding Kaledupa and Hoga island declined by 50\% (McMellor \& Smith, 2011). The Sampela reef system is located $500 \mathrm{~m}$ from the intertidal Bajo settlement at Kaledupa Island that is home to $>1000$ people, hence pressure on this reef system from destructive fishing practices, pollution and coral mining historically has been high. From 2002 to 2007, live coral cover at this site declined from $32.6 \pm 2.0 \%$ to $12.2 \pm 1.6 \%$ (McMellor \& Smith, 2010) but since 2007, live coral cover has remained relatively stable and at the time of this survey was estimated as $9.5 \% \pm 1.6 \%$ (Chapter 2). This site has sedimentation rates estimated at four times higher than other reef sites in the area (Crabbe \& Smith, 2005; Curtis-Quick, 2013), has high abiotic cover and low structural complexity. The comparison site was located on an adjacent reef system on the island of Hoga at a site known locally as The Ridge (hereafter described as the high-quality site). Like the sponge-dominated site, this reef also experienced a 50\% decline in live coral cover between 2002 and 2007 (McMellor \& Smith, 2010) and stabilised at approximately 30\% (Curtis-Quick, 2013). At the time of this study, live coral cover was three times higher than the sponge-dominated site $(29.7 \% \pm 6.0 \%)$ (Chapter 2$)$. This site also has higher structural complexity, lower abiotic cover and lower sedimentations rates (Crabbe \& Smith, 2005; Powell et al. 2014). Both reef systems are separated by a channel that is approximately $1 \mathrm{~km}$ wide and extends to a depth of $40 \mathrm{~m}$, limiting the movement of coral reef fish between reef systems.

\subsubsection{Sample collection}

\subsubsection{Fish}

Fish collections were carried out on both reef systems by local Bajau spearfishers over three weeks during July and August 2017. Seven coral reef fish species representing different functional feeding groups were sampled at both sites. Species were identified as representing a specific functional feeding group based on in situ observations, gut content data (Chapter 2) and literature references (Table 4.2). Adult fishes in a similar size range were targeted at both locations to avoid variation in isotopic ratios related to dietary ontogeny or size-based metabolic processes (de la Moriniere et al. 2003; Carassou et al. 2008), therefore one-way ANOVAs were used to test for any differences in sizes (TL mm) between sites (Appendix D, Table 2). Fish collections were opportunistic, spearing a maximum of two individuals of each species per trip. All samples were collected under permit and sample sizes were limited to 5-10 individuals per site due to ethical considerations (Appendix D, Table 1). Fish were frozen at $-20^{\circ} \mathrm{C}$ until dissection when a section of anterior dorsal muscle tissue was collected and stored at - 
$20^{\circ} \mathrm{C}$. Muscle tissue was sampled as it presents more homogenous isotopic values compared to other tissues (Pinnegar \& Polunin. 1999), more closely reflects the animal's diet (Grey et al. 2009) and represents nitrogen and carbon isotope values assimilated over a few months (Tieszen et al. 1983).

Table 4. 1 Seven coral reef fish species targeted by this study and major recorded prey items (>10\% gut contents) from this study (Chapter 2) and literature references (all images licenced under Creative Commons BY-C 3.0).

\begin{tabular}{|c|c|c|c|}
\hline Species & $\begin{array}{l}\text { Common name } \\
\text { (Family) }\end{array}$ & $\begin{array}{l}\text { Functional group } \\
\text { (Major recorded prey) }\end{array}$ & References \\
\hline Zanclus cornutus & $\begin{array}{l}\text { Moorish Idol } \\
\text { (Zanclidae) }\end{array}$ & $\begin{array}{l}\text { Facultative spongivore/ } \\
\text { Omnivore } \\
\text { (Sponges, calcareous sediments, } \\
\text { algae) }\end{array}$ & $\begin{array}{l}\text { Chapter 2; Powell } \\
\text { et al. } 2015\end{array}$ \\
\hline Pygoplites diacanthus & $\begin{array}{l}\text { Regal angelfish } \\
\text { (Pomacanthidae) }\end{array}$ & $\begin{array}{l}\text { Obligate spongivore } \\
\text { (Sponges) }\end{array}$ & $\begin{array}{l}\text { Chapter 2; Powell } \\
\text { et al. } 2015\end{array}$ \\
\hline Forcipiger flavissimus & $\begin{array}{l}\text { Longnose } \\
\text { butterflyfish } \\
\text { (Chaetodontidae) }\end{array}$ & $\begin{array}{l}\text { Invertivore } \\
\text { (Sessile polychaetes, decapod } \\
\text { shrimp) }\end{array}$ & $\begin{array}{l}\text { Chapter 2; } \\
\text { Nagelkerken et al. } \\
2009\end{array}$ \\
\hline Ctenochaetus binotatus & $\begin{array}{l}\text { Two-spot } \\
\text { bristletooth } \\
\text { (Acanthuridae) }\end{array}$ & $\begin{array}{l}\text { Detritivore } \\
\text { (Organic detritus/ sediments) }\end{array}$ & $\begin{array}{l}\text { Chapter 2; Randall } \\
\& \text { Clements, } 2001 .\end{array}$ \\
\hline Chaetodo & $\begin{array}{l}\text { Klein's } \\
\text { butterflyfish } \\
\text { (Chaetodontidae) }\end{array}$ & $\begin{array}{l}\text { Facultative corallivore } \\
\text { (Hard coral, copepods, hydroids, } \\
\text { polychaetes, isopods, } \\
\text { amphipods, algae) }\end{array}$ & $\begin{array}{l}\text { Chapter 2; } \\
\text { Nagelkerken et al. } \\
2009\end{array}$ \\
\hline Chaetodon lunulatus & $\begin{array}{l}\text { Oval } \\
\text { butterflyfish } \\
\text { (Chaetodontidae) }\end{array}$ & $\begin{array}{l}\text { Obligate corallivore } \\
\text { (Hard coral) }\end{array}$ & $\begin{array}{l}\text { Pratchett et al. } \\
\text { 2005; Nagelkerken } \\
\text { et al. 2009; }\end{array}$ \\
\hline $\begin{array}{l}\text { Neoglyphidodon } \\
\text { nigroris }\end{array}$ & $\begin{array}{l}\text { Black-and-gold } \\
\text { chromis } \\
\text { (Pomacentridae) }\end{array}$ & $\begin{array}{l}\text { Planktivore } \\
\text { (Salps, tunicates, algae) }\end{array}$ & $\begin{array}{l}\text { Eurich et al. 2019; } \\
\text { Allen, } 1975 .\end{array}$ \\
\hline
\end{tabular}




\subsubsection{Carbon sources and prey}

Suspended particulate organic matter (SPOM) was sampled to represent the base of the pelagic food web (Briand et al. 2016; Carassou et al. 2008). Five litres of sub-surface seawater were collected using prewashed containers (Whatman $\mathrm{GF} / \mathrm{F}$ filtered seawater, nominal pore size $0.7 \mu \mathrm{m}$ ). Water samples were pre-filtered through a $200 \mu \mathrm{m}$ mesh to remove larger particles such as zooplankton and salps, before filtering onto $\mathrm{GF} / \mathrm{F}$ pre-combusted filters $\left(450^{\circ} \mathrm{C}, 5\right.$ hours) under low pressure ( $5 \mathrm{in} . \mathrm{Hg}$ vacuum) using a vacuum pump to avoid the lysis of fragile cells. Fragments of Porites lutea, Pavona varians and Pocillopora verrucosa were collected because of adequate abundances at each site. Coral fragments were blasted with GF/F filtered seawater using a water pick and the resulting solution, representing coral tissue, mucus and symbionts, was filtered onto pre-combusted GF/F filters papers under low pressure using a vacuum pump. Macroalgal cover on Wakatobi reefs is low (Table 4.1) and the only algae found at both sites was a green turfing alga that was scraped from the benthos. A brown macroalga Dictyota sp. was collected at the sponge-dominated site and the calcareous Halimeda sp. at the highquality site. The detritivorous sea cucumber Synaptula sp. was collected at both sites to represent the base of the detrital food web (detritus +1 trophic position) as detritus is hard to isolate in marine systems (McMahon et al. 2016). Samples of the sponges Xestospongia sp., Hyrtios erecta, Lamellodysedia herbacea and Clathria sp. were collected because of adequate populations at each site and due to observations of spongivore activity (Chapter 2). L. herbacea was collected because of its role in a coral - sponge regime shift (Powell et al. 2014). Three to five replicates were collected for each item and all samples were frozen at $-20^{\circ} \mathrm{C}$ until processing (Appendix D, Table 1).

\subsubsection{Sample processing}

All samples were prepared and processed at the National Institute for Water and Atmospheric Research (NIWA). Carbon sources and potential prey items were acidified to remove carbonates. Filter papers (retaining coral tissue and SPOM) were placed on acid-resistant trays in a desiccator with concentrated hydrochloric acid $(\mathrm{HCl})$ left under a fume hood overnight (approx. 16 hours). After fuming, filters were rinsed with double distilled water (DDW) dried at $60^{\circ} \mathrm{C}$ and stored with desiccant in plastic sealed containers. For the remaining prey items, samples were placed in falcon tubes and treated with $10 \%$ $\mathrm{HCl}$ for 24 hours. Acid was added in 24-hour intervals until samples stopped effervescing at which

point samples went through three wash cycles (rinsed with DDW and centrifuged at $2500 \mathrm{rpm}$ for 15 minutes) before the resulting samples were oven-dried at $60^{\circ} \mathrm{C}$. A subset of paired acidified and nonacidified samples was prepared to test for any effect of acid treatment on nitrogen isotope values (Bunn et al. 1995; Pinnegar \& Polunin, 1999; Kennedy et al. 2005). Paired t-tests and one non-parametric Wilcoxon Rank-Sum test showed that acidification had no significant effect on $\delta^{15} \mathrm{~N}$ values (Appendix D, Table 3). 
Fish muscle tissue was pre-frozen at $-80^{\circ} \mathrm{C}$ for two hours and then freeze-dried overnight. Lipids were not removed from fish tissue samples as bulk tissue mass $\mathrm{C}$ : $\mathrm{N}$ ratios were $<3.5$ indicative of pure protein and the absence of lipids (Post et al. 2007). All samples were homogenised using a mortar and pestle and instruments were ethanol cleaned and rinsed three times with DDW between samples. Samples were weighed into tin capsules (0.5-0.6 mg fish, 2-4 mg sponge, $0.5 \mathrm{mg}$ acidified sponge, $4 \mathrm{mg}$ algae, $0.5-0.7 \mathrm{mg}$ acidified algae) and a quarter of each filter papers were prepared for coral and phytoplankton samples. Samples were analysed on a DELTA VPlus isotope ratio mass spectrometer (IRMS) (Thermo Fischer Scientific, Bremen, Germany). $\mathrm{CO}_{2}$ and $\mathrm{N}_{2}$ reference gas standards were introduced to the mass spectrometer with every sample analysis. ISODAT (Thermo Fisher Scientific, Bremen) software was used to calculate $\delta^{15} \mathrm{~N}$ values against atmospheric air, and $\delta^{13} \mathrm{C}$ values relative to the international standard Carrara Marble NSB-19 (National Institute of Standards and Technology (NIST), Gaithersberg, MD, USA). This was further calibrated against the original Pee Dee Belemnite (PDB) limestone standard and then corrected for 17O. Carbon isotope data were corrected via a twopoint normalisation process using NIST 8573 (USGS40 L-glutamic acid; certified $\delta^{13} \mathrm{C}=-26.39 \pm 0.09$ $\%$ ) and NIST 8542 (IAEA-CH-6 Sucrose; certified $\delta^{13} \mathrm{C}=-10.45 \pm 0.07 \%$ ). A two-point normalisation process using NIST 8573 (USGS40 L-glutamic acid; certified $\delta^{15} \mathrm{~N}=-4.52 \pm 0.12 \%$ ) and IAEA-N-2 (ammonium sulphate: certified $\delta^{15} \mathrm{~N}=+20.41 \pm 0.2 \%$ ) was applied to $\delta^{15} \mathrm{~N}$ data. DL-Leucine (DL-2Amino-4-methylpentanoic acid, C6H13NO2, Lot 127H1084, Sigma, Australia) was run every ten samples to check analytical precision and enable drift corrections to be made if necessary. NIST 8547 (IAEA-N1 ammonium sulphate; certified $\delta^{15} \mathrm{~N}=+0.43 \pm 0.04 \%$ ) and USGS65 Glycine (certified $\delta^{13} \mathrm{C}$ $=-20.29 \pm 0.04 \%$; certified $\delta^{15} \mathrm{~N}=20.68 \pm 0.06 \%$ ) were run daily to check isotopic accuracy with two laboratory standards L Proline and homogenized squid run as an additional precision check. Repeat analysis of standards produced data accurate to within better than $0.15 \%$ for both $\delta^{15} \mathrm{~N}$ and $\delta^{13} \mathrm{C}$, and precision of better than $0.22 \%$ for $\delta^{15} \mathrm{~N}$ and $0.24 \%$ for $\delta^{13} \mathrm{C}$.

Ratios of ${ }^{13} \mathrm{C} /{ }^{12} \mathrm{C}$ and ${ }^{15} \mathrm{~N} /{ }^{14} \mathrm{~N}$ were expressed relative to internal standards. The relative abundances of stable isotopes were expressed according to the following:

$\delta \mathrm{X}=\left[\left(\mathrm{R}_{\text {sample }} / \mathrm{R}_{\text {standard }}\right)-1\right] \times 10^{3}$

where $\mathrm{X}$ is ${ }^{15} \mathrm{~N}$ or ${ }^{13} \mathrm{C}$ and $\mathrm{R}$ is the ratio ${ }^{15} \mathrm{~N} /{ }^{14} \mathrm{~N}$ or ${ }^{13} \mathrm{C} /{ }^{12} \mathrm{C}$. 


\subsection{Data analysis}

\subsubsection{Spatial and interspecific variation in trophic position and $\delta^{13} \mathrm{C}$ values}

Trophic position (TP) was calculated according to the scaled equation by Hussey et al. (2014), which accounts for the narrowing of nitrogen isotope fractionation $\left(\Delta^{15} \mathrm{~N}\right)$ at higher trophic positions (Caut et al. 2009; Hussey et al. 2014).

$\mathrm{TP}=\frac{\log \left(\delta^{15} \mathrm{Nlim}-\delta^{15} \mathrm{Nbase}\right)-\log \left(\delta^{15} \mathrm{Nlim}-\delta^{15} \text { Nconsumer }\right)}{\mathrm{K}}+\mathrm{TP}$ baseline

Where $\delta^{15} \mathrm{Nlim}$ is the saturating isotope limit as TP increases $(21.93 \%$ ) and $\mathrm{K}$ is the rate at which $\delta^{15}$ Nconsumer approaches $\delta^{15} \mathrm{Nlim}$ per trophic level increase $(0.14)$. The TP baseline $(\mathrm{TP}=2)$ was represented by the detritivorous primary consumer Synaptula sp. because of the minimal variation in $\delta^{15} \mathrm{~N}$ values in samples of that species at both sites (Appendix D, Table S1).

I tested for differences in trophic position and $\delta^{13} \mathrm{C}$ values between sites and species with permutational analysis of variance using the PERMANOVA+ add-in to PRIMER version 6.1 (PRIMER-E Ltd, Plymouth, UK) with fish size (TL mm) included as a covariate. This was done using Type I (sequential) sums of squares and based on a Euclidean distance matrix with 999 permutations of the residuals under a reduced model. Pairwise comparisons were used to identify intraspecific differences between reefs and interspecific differences within reefs. Data were checked for multivariate homogeneity of group dispersions using PERMDISP.

\subsubsection{Isotopic niches of coral reef fishes}

To examine differences in the isotopic niche (a generalised proxy for trophic niche) of fish species between reefs, I used the SIBER package for R (Jackson et al. 2011) to calculate the standard ellipse of each species at both sites (Figure 4.1). The standard ellipse is a measure of deviation for bivariate data comparable to standard deviation for univariate data (Jackson et al. 2011). In $\delta$ space, the standard ellipse is located by the means of $\mathrm{X}$ and $\mathrm{Y}$ and the shape and size are determined by the associated covariance matrix (Jackson et al. 2011). It contains approximately $40 \%$ of the sample data and as such the standard ellipse area (SEA) represents the core niche area of a species (Jackson et al. 2011). Standard ellipses are less sensitive to sample size variation than other traditional measures of niche width e.g. the total area of the convex hull (TA) (Layman et al. 2007), which increases with sample size (Jackson et al. 2011).

To determine if any significant differences in isotopic niche size existed between reef systems, I used Bayesian inference techniques ( $10^{4}$ iterations) described by Jackson et al (2011) to generate probability 
distributions of the $\mathrm{SEA}_{\mathrm{c}}\left(\mathrm{c}=\right.$ small sample size corrected). Differences in $\mathrm{SEA}_{\mathrm{c}}$ size were considered significant when $\geq 95 \%$ of posterior draws for one group/species was smaller than the other (critical pvalue $\leq 0.05$ ). Bayesian inference techniques allow researchers to make direct statistical comparisons otherwise not afforded by point estimates of dispersion (Jackson et al. 2011). The main assumption of using these statistical techniques is that data approximate a multivariate normal distribution (MVN) (Jackson et al. 2011) so prior to analysis groups were checked for MVN using Royston's Multivariate Normality Test that uses Shapiro-Wilk's W statistic.

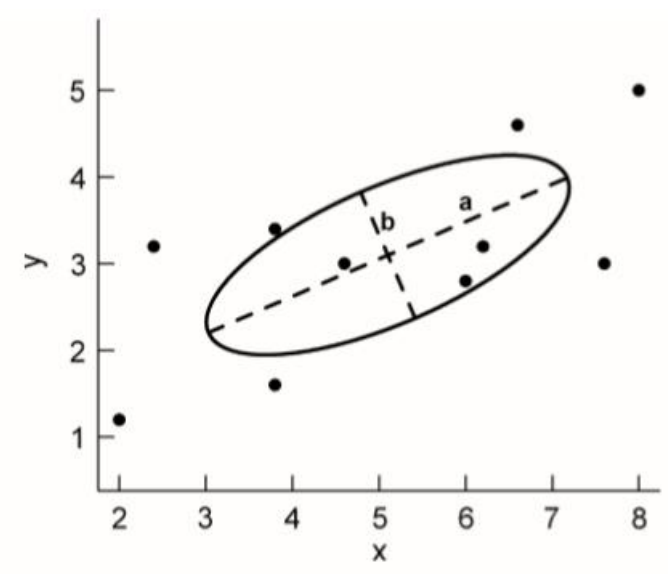

Figure 4. 1 Example standard ellipse from Batschelet, (1981) and reproduced in Jackson et al. (2011). Black circles are sample data, the black ellipse is the standard ellipse containing $40 \%$ of the sample data. Semi-major axis (a) and semi-minor axis (b) are shown on the diagram.

\subsubsection{Carbon sources and benthic prey}

To examine differences in isotope values between carbon sources and benthic prey, I used PERMANOVA+ with Type III sums of squares and based on a Euclidean distance matrix constructed using $\delta^{15} \mathrm{~N}$ and $\delta^{13} \mathrm{C}$ data with 999 permutations of the residuals under a reduced model. This provided an overall picture of isotopic discrimination between sampled species/taxa and was used to check to for large differences in metabolic pathways between species within groups (e.g. sponges). Individual source items were grouped into major taxa (SPOM, corals, sponges, algae) and reanalysed using the same PERMANOVA design to assess isotopic discrimination in major groups and between site variation in isotope values. For groups with appropriate replication (corals, sponges, detritus), I investigated differences in isotopic niche size ( $S E A_{C}$ ) between sites (see section 4.2.2) to account for any differences observed in the isotopic niches of fish between sites. 


\subsubsection{Pelagic and benthic carbon contributions to coral reef fish diets}

To compare the proportional contribution of pelagic and benthic sources of carbon to fish consumers between sites I used the SIMMR package (Stable Isotope Mixing Models in R) (Parnell et al. 2016) to run dual isotope mixing models. SIMMR works by fitting a Bayesian model with Markov Chain Monte Carlo algorithm (MCMC) producing simulations of possible values for each carbon source based on the available data. Models were run separately for both sites to adjust for site-specific values (Appendix $\mathrm{D}$, Table 16). For the pelagic carbon signature, I used the mean \pm standard deviation (SD) of SPOM with samples pooled between sites because the isotope values of SPOM did not vary significantly between sites (Appendix D, Table 15). For the benthic carbon signature, I used the mean \pm SD of corals and detritus $+1 \mathrm{TP}$ (pooled) with site-specific values due to a significant difference in isotopic values of detritus $+1 \mathrm{TP}$ between reefs (Appendix D, Table 15). Turf algae were not included in the benthic signature because of low $\delta^{15} \mathrm{~N}$ values. Trophic enrichment factors used in the mixing models were $\Delta^{15} \mathrm{~N}$ $3.4 \pm 0.98 \%$ and $\Delta^{13} \mathrm{C} 0.39 \pm 1.3 \%$ (Post, 2002). These enrichment factors were estimated from two primary consumers (filter-feeding bivalves and grazing snails) covering littoral and pelagic food webs (Post, 2002). Values cited are the mean \pm SD enrichment factors of both aquatic food webs and wide variation in these values propagates the same degree of error through proportional contribution estimates. Pelagic production was corrected for +2 trophic positions because it was assumed that fish would either consume filter-feeding organisms or phytoplankton feeders (e.g. copepods). Benthic production was corrected for +1 trophic position because corals are consumed directly by coral-feeding fishes and detritus was sampled using a proxy detritivorous sea cucumber and thus already corrected for +1 trophic position.

\subsubsection{Quantitative comparison of trophic structure}

The isotopic values of fish were used to quantitatively compare trophic structure between sites using the community-wide metrics proposed by Layman et al. (2007) (hereafter community metrics). These community metrics are calculated based on the spread and extent of bivariate isotope data (Jackson et al. 2011). The range of $\delta^{15} \mathrm{~N}$ and $\delta^{13} \mathrm{C}$ values provide respective information on food chain length and diversification of resource use. Mean distance to the centroid (CD) is the average Euclidean distance of each species to community centroid (bivariate mean of all data points) and an indicator of trophic diversity. Mean nearest neighbour distance (NND) and the standard deviation of nearest neighbour distance (SDNND) are both metrics that describe trophic redundancy (Layman et al. 2007). It is important to note that in this context, trophic redundancy relates to multiple species having more similar diets rather than suggesting similar functional roles. NND indicates the proximity of species in isotope space and is measured as the average Euclidean distance to each species' nearest neighbour with low values indicating a large proportion of species with similar trophic preferences. SDNND is a measure of evenness of spatial density and packing (Layman et al. 2007; Jackson et al. 2011) with low values representing a more uniform distribution of species. I used Bayesian inference techniques proposed by 
Jackson et al. (2011) to propagate sampling error in the mean isotope ratio of community members thus providing a measure of uncertainty in community metrics and allowing statistical comparison of isotopic values between sites (Jackson et al. 2011). 


\subsection{Results}

\subsubsection{Spatial and interspecific variation in trophic position and $\delta^{13} \mathrm{C}$ values}

The trophic position of fish was influenced by site ( pseudoF $_{1,68}=41.97, p=0.001$ ), species (pseudoF 6 , $\left.{ }_{68}=126.18, \mathrm{p}=0.001\right)$ and size $\left(\mathrm{pseudoF}_{1,68}=11.64, \mathrm{p}=0.002\right)$ (Appendix $\mathrm{D}$, Table 4). Fish from the sponge-dominated site had an overall lower mean trophic position than the high-quality site $(2.67 \pm$ 0.04 and $2.80 \pm 0.04$ respectively [mean $\pm \mathrm{SE}$ ]) (Figure 4.2).

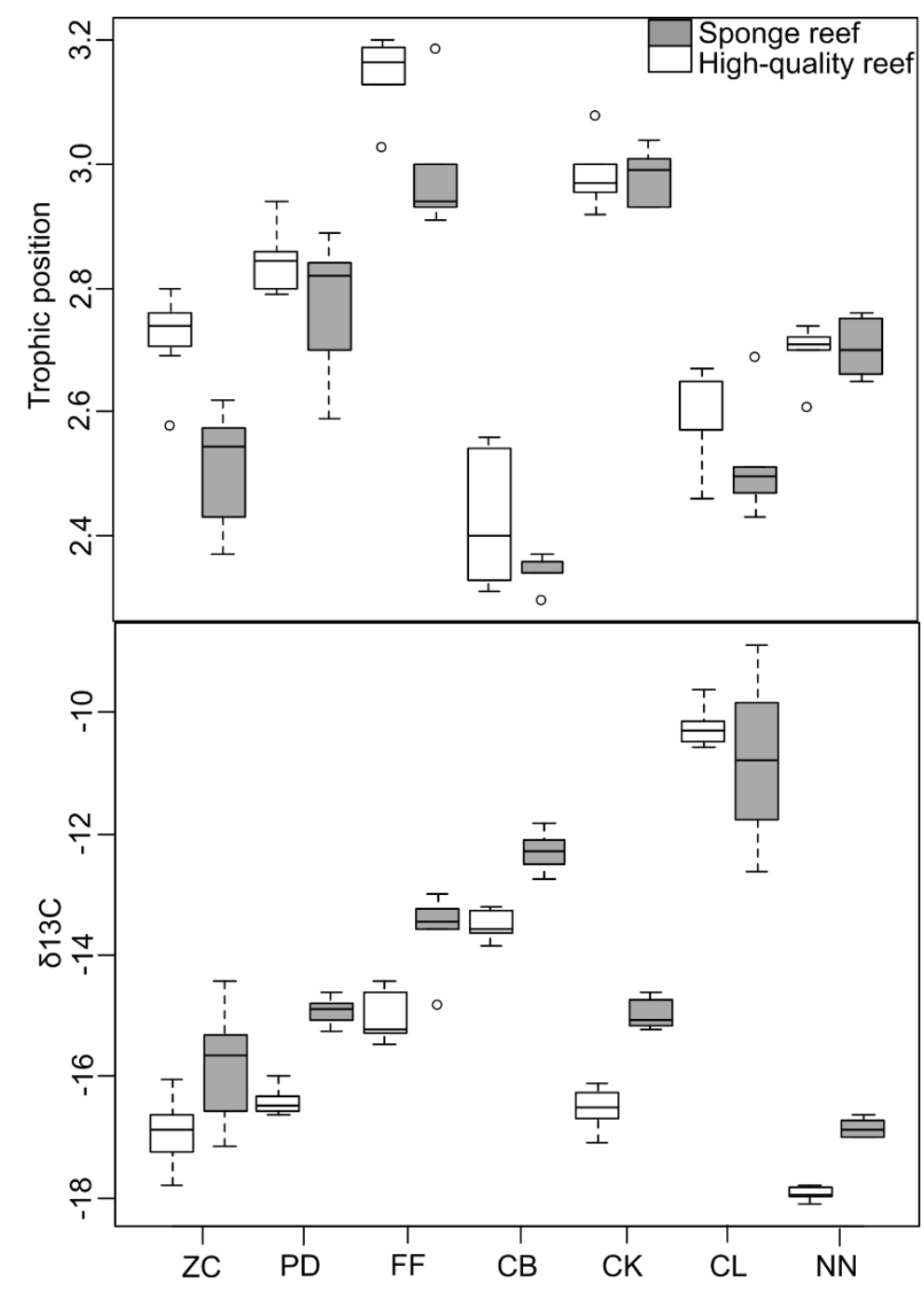

Figure 4. 2 Boxplots of trophic position and $\delta^{13} \mathrm{C}$ values of seven species of reef fish compared between two reef systems of contrasting quality in the Wakatobi MNP, Indonesia. ZC = Zanclus cornutus, PD $=$ Pygoplites diacanthus, $\mathrm{FF}=$ Forcipiger flavissimus, $\mathrm{CB}=$ Ctenochaetus binotatus, $\mathrm{CK}=$ Chaetodon kleinii, $\mathrm{CL}=$ Chaetodon lunulatus, $\mathrm{NN}=$ Neoglyphidodon nigroris . 
At the high-quality site, the invertivore Forcipiger flavissimus had the highest trophic position $(3.15 \pm$ 0.03 [mean $\pm \mathrm{SE}])$ and the detritivore Ctenochaetus binotatus had the lowest $(2.43 \pm 0.05$ [mean $\pm \mathrm{SE}])$ (Figure 4.2). Pairwise tests showed that only Zanclus cornutus and Neoglyphidodon nigroris had similar trophic positions, all other species were significantly different to one another (all pairwise comparisons $\mathrm{p}<0.05$ ) (Appendix D, Table 6). At the sponge-dominated site, Z. cornutus and Chaetodon lunulatus, Pygoplites diacanthus and N. nigroris and F. flavissimus and Chaetodon Kleinii had similar trophic positions, all other species were significantly different to one another (all pairwise comparisons $\mathrm{p}<0.05$ ). The highest trophic position was shared by $F$. flavissimus $(2.99 \pm 0.05$ [mean $\pm \mathrm{SE}])$ and C. kleinii $(2.98$ $\pm 0.02[$ mean $\pm \mathrm{SE}])$ and the lowest was occupied by $C$. binotatus $(2.34 \pm 0.01$ [mean $\pm \mathrm{SE}])$.

Between-site pairwise tests indicated that the trophic positions of $Z$. cornutus and $F$. flavissimus were significantly lower at the sponge-dominated site $(\mathrm{p}=0.001$ and $\mathrm{p}=0.03$ respectively) (Figure 4.2) (Appendix D, Table 8). However, size data indicated that Z. cornutus caught at the sponge-dominated site were significantly smaller than the high-quality site (Appendix D, Table 2), $105 \mathrm{~mm} \pm 5 \mathrm{~mm}$ and $141 \mathrm{~mm} \pm 5 \mathrm{~mm}$, respectively (mean $\pm \mathrm{SE})(\mathrm{F}=26.78, \mathrm{p}<0.001)$. Therefore, the PERMANOVA analysis was performed again removing $Z$. cornutus from the dataset and trophic position remained significantly lower at the sponge-dominated site $\left(\mathrm{pseudoF}_{1,56}=11.63, \mathrm{p}<0.001\right)$.

Fish $\delta^{13} \mathrm{C}$ values did not covary with size $\left(\mathrm{pseudoF}_{1,55}=1.47, \mathrm{p}=0.23\right)$ so it was removed from the model (Appendix D, Table 5). There were significant differences in $\delta^{13} \mathrm{C}$ values between sites (pseudoF $F_{1,69}=41.97, p=0.001$ ). Fish from the sponge-dominated site were ${ }^{13} \mathrm{C}$-enriched compared to fish from the high-quality site $(-14.27 \% 0 \pm 0.32 \%$ and $-15.39 \% 0 \pm 0.37 \%$ [mean $\pm \mathrm{SE}]$ ) (Figure 4.2). Species also had a significant effect on $\delta^{13} \mathrm{C}$ values $\left(\mathrm{pseudoF}_{6,69}=184.38, \mathrm{p}=0.001\right)$ and there was a significant interaction detected between site and species ( pseudoF $\left._{6,69}=4.46, \mathrm{p}=0.001\right)$. At the highquality site, $Z$. cornutus, $P$. diacanthus and $C$. kleinii had comparable $\delta^{13} \mathrm{C}$ values, all other species were significantly different to one another (all pairwise comparisons $\mathrm{p}<0.05$ ) (Appendix D, Table 7). At the sponge-dominated site, $P$. diacanthus and C. kleinii, and C. binotatus and C. lunulatus had comparable $\delta^{13} \mathrm{C}$ values, all other species were significantly different to one another (all pairwise comparisons $\mathrm{p}<0.05$ ). All species were significantly enriched in ${ }^{13} \mathrm{C}$ at the sponge-dominated site (all pairwise comparisons $\mathrm{p}<0.05$ ) aside from Z. cornutus and C. lunulatus (Appendix D, Table 8). 


\subsubsection{Isotopic niches of coral reef fishes}

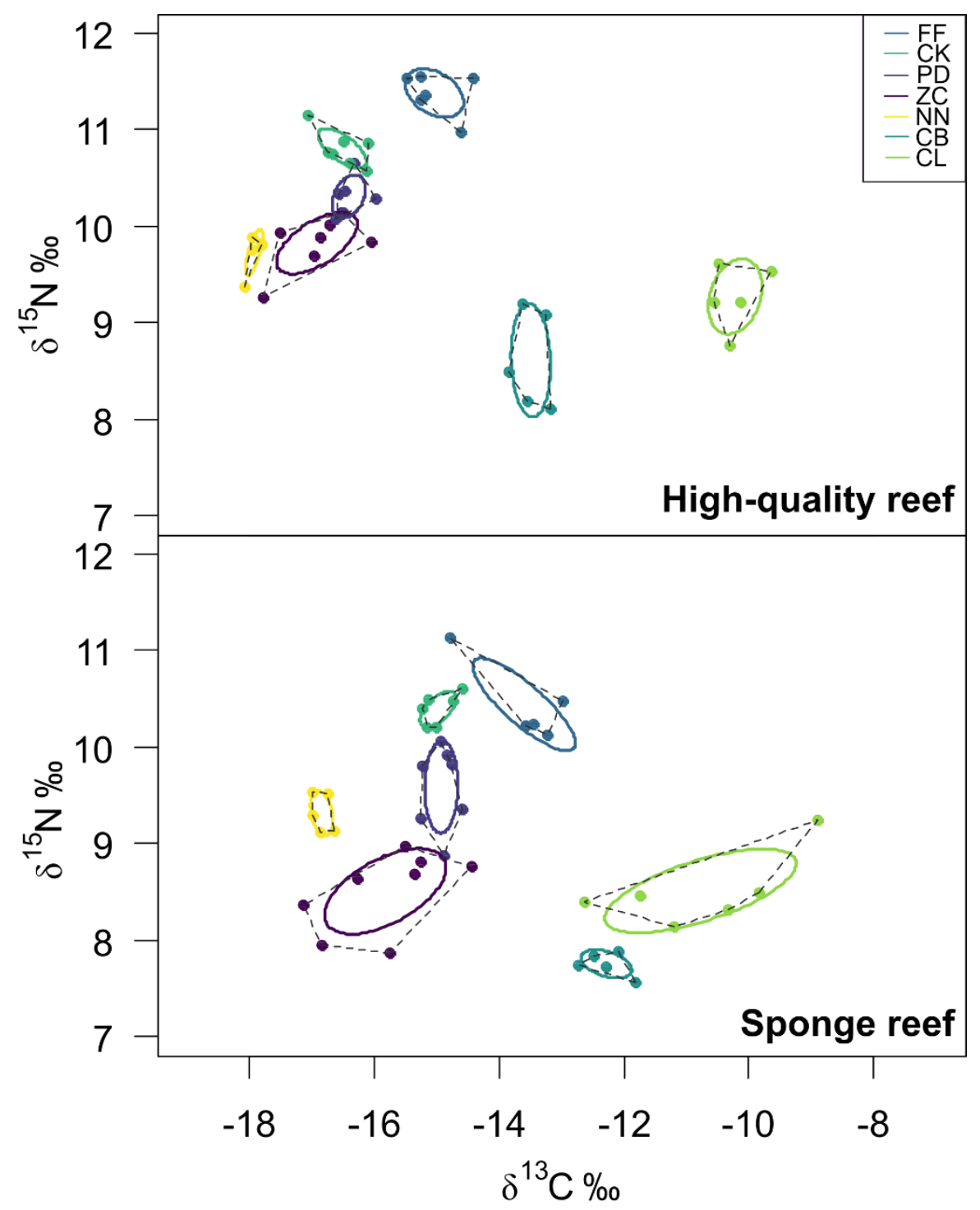

Figure 4. 3 Isotopic niches (standard ellipse area - SEAc) of seven species of reef fish each representing a different functional feeding group sampled at two sites in the Wakatobi MNP, Indonesia. SEAc represented by solid ellipses and dashed polygon is the isotopic total area (TA). ZC = Zanclus cornutus, $\mathrm{PD}=$ Pygoplites diacanthus, $\mathrm{FF}=$ Forcipiger flavissimus, $\mathrm{CB}=$ Ctenochaetus binotatus, $\mathrm{CK}=$ Chaetodon kleinii, $\mathrm{CL}=$ Chaetodon lunulatus, $\mathrm{NN}=$ Neoglyphidodon nigroris .

The corallivore Chaetodon lunulatus had a statistically larger isotopic niche at the sponge-dominated site $\left(\mathrm{SEA}_{\mathrm{B}}>95 \%, \mathrm{p}<0.05\right)$ (Appendix D, Table 9). Zanclus cornutus, Pygoplites diacanthus and Forcipiger flavissimus also had larger isotopic niches at the sponge-dominated site and were close to the critical p-value $\left(\mathrm{SEA}_{\mathrm{B}}>92 \%, \mathrm{p}=0.07\right)$. The detritivore Ctenochaetus binotatus had a statistically smaller isotopic niche at the sponge-dominated site $(\mathrm{p}<0.05)$ (Figure 4.3). 


\subsubsection{Carbon sources and benthic prey}

Source isotope values were significantly different between sites ( pseudoF $\left._{1,69}=12.07, p=0.002\right)$ and sources (pseudoF $F_{11,69}=100.71, \mathrm{p}=0.001$ ) (Figure 4.4) (Appendix D, Table 10). Pairwise tests were conducted for each site separately due to differences in algal types collected. Green turf algae had the lowest $\delta^{15} \mathrm{~N}$ values of any source item and it was isotopically separated from Dictyota sp. at the spongedominated site $(\mathrm{p}(\mathrm{MC})=0.006)$ and Halimeda sp. $(\mathrm{p}(\mathrm{MC})=0.004)$ at the high-quality site (Appendix D, Table 11/12). Dictyota overlapped with both Hyrtios and Porites with no significant differences in isotope values. SPOM and Lamellodysedia herbacea were the most ${ }^{13} \mathrm{C}$ depleted sources sampled. They showed no difference in isotope values at either site.

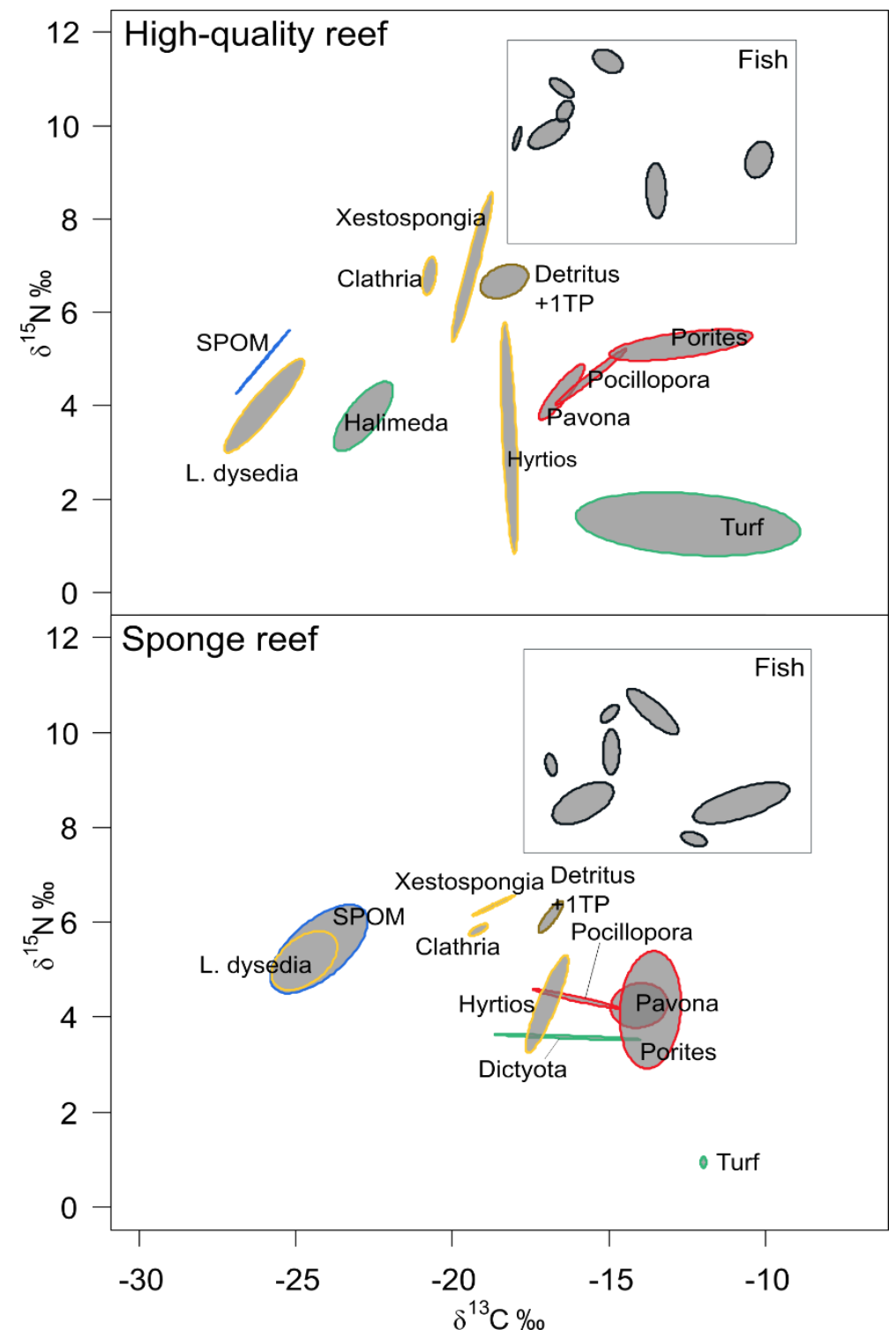

Figure 4. 4 Isotopic niches (standard ellipse area - SEAc) of carbon sources and potential prey collected at two sites in the Wakatobi MNP, Indonesia. Insert is Figure 4.3. 
All three corals showed little difference in $\delta^{15} \mathrm{~N}$ values but more variation in $\delta^{13} \mathrm{C}$ values (Figure 4.4). At the high-quality site, Pavona and Pocillopora had similar isotope values but Porites was isotopically separated $(\mathrm{p}(\mathrm{MC})=0.012$ and $\mathrm{p}(\mathrm{MC})=0.045)$ whereas at the sponge-dominated site Pavona and Porites had similar isotope values but Pocillopora was isotopically separated $(\mathrm{p}(\mathrm{MC})=0.032$ and $\mathrm{p}(\mathrm{MC})=0.041)$. Sponges were ${ }^{13} \mathrm{C}$ depleted relative to corals although Hyrtios had similar isotope values to Pavona at the high-quality site and Pocillopora at the sponge-dominated site. The sponge species had a wide range of $\delta^{15} \mathrm{~N}$ and $\delta^{13} \mathrm{C}$ values and, except for Xestospongia and Clathria, they were isotopically distinct. Detritus (+1TP) was isotopically distinct at the sponge-dominated site but had similar isotope values to Xestospongia at the high-quality site.

Source items were grouped into major taxa (algae, sponges, corals and SPOM) with L. dysedia removed from the analysis because $\delta^{13} \mathrm{C}$ values were $\sim 7 \%$ lower relative to the spongivores and due to being isotopically distinct from other sponges. One sample of Hyrtios from the high-quality site was also removed due to a very low $\delta^{15} \mathrm{~N}$ value, potentially caused by the inclusion of outer tissue containing symbionts, known to cause depleted ${ }^{15} \mathrm{~N}$ in sponges (Freeman et al. 2014). Both groups of algae that were not replicated between sites were also removed. There were significant differences between major

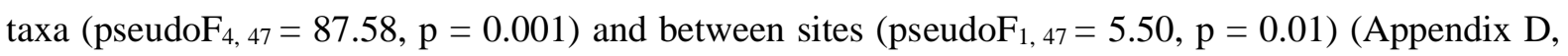
Table 13). Pairwise tests showed that all major sources had significantly different isotope ratios to one another (Figure 4.5) (Appendix D, Table S14). The only sources that showed a difference in isotope values between sites were detritus $(+1 \mathrm{TP})(\mathrm{t}=4.20, \mathrm{p}(\mathrm{MC})=0.002)$ and sponges $(\mathrm{t}=1.98, \mathrm{p}(\mathrm{MC})=$ 0.041) (Appendix D, Table 15). Bayesian analysis of SEA indicated that the isotopic niche sizes of corals and sponges were similar at both sites. There was a $>90 \%$ probability that the isotopic niche of detritus (+1TP) was smaller at the sponge-dominated site.

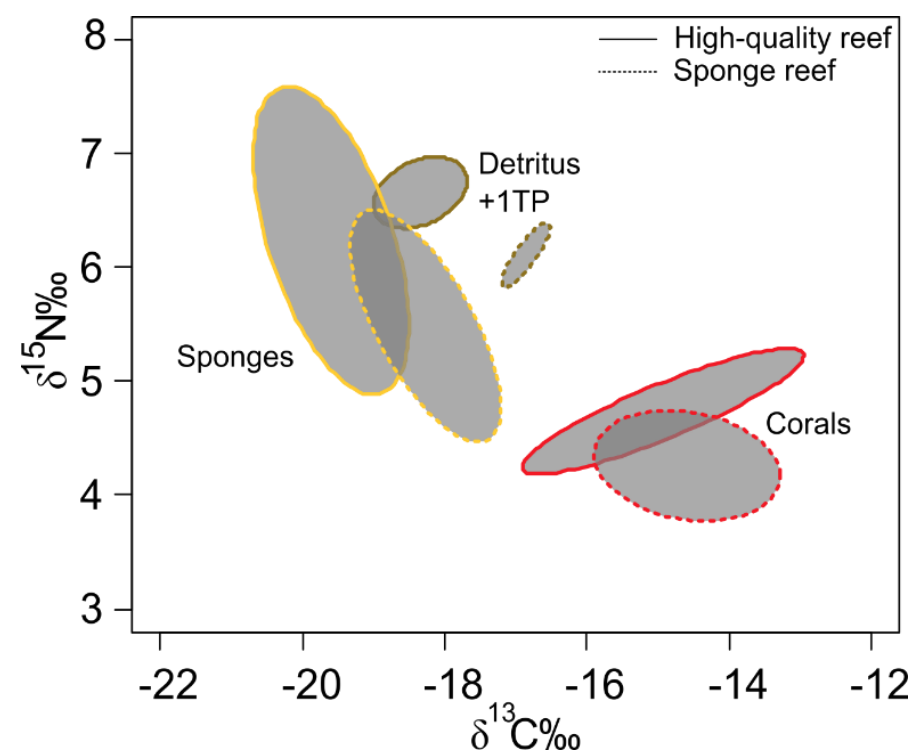

Figure 4. 5 Isotopic niches (standard ellipse area - SEAC) of sponges, corals and detritus $+1 \mathrm{TP}$ collected at two sites in the Wakatobi MNP, Indonesia. 


\subsubsection{Pelagic and benthic carbon contributions to coral reef fish diets}

All species showed a higher proportional use of benthic carbon than pelagic carbon at both sites (Figure 4.6). Pelagic contributions were higher and benthic contributions lower at the high-quality site for the majority of species, except for Forcipiger flavissimus, for which there was considerable uncertainty in proportion estimates and Ctenochaetus binotatus which, showed little difference in values between sites. At both sites, the species with the largest contribution of pelagic carbon was the planktivore Neoglyphidodon nigroris (32\% $\pm 9 \%(\mathrm{HQ})$ and $25.6 \pm 8 \%$ (LQ [mean $\pm \mathrm{SD}]$ ) whereas C. binotatus had the highest contribution of benthic carbon $(89 \% \pm 8 \%$ (HQ) and $90 \pm 7 \%$ [mean \pm SD]).

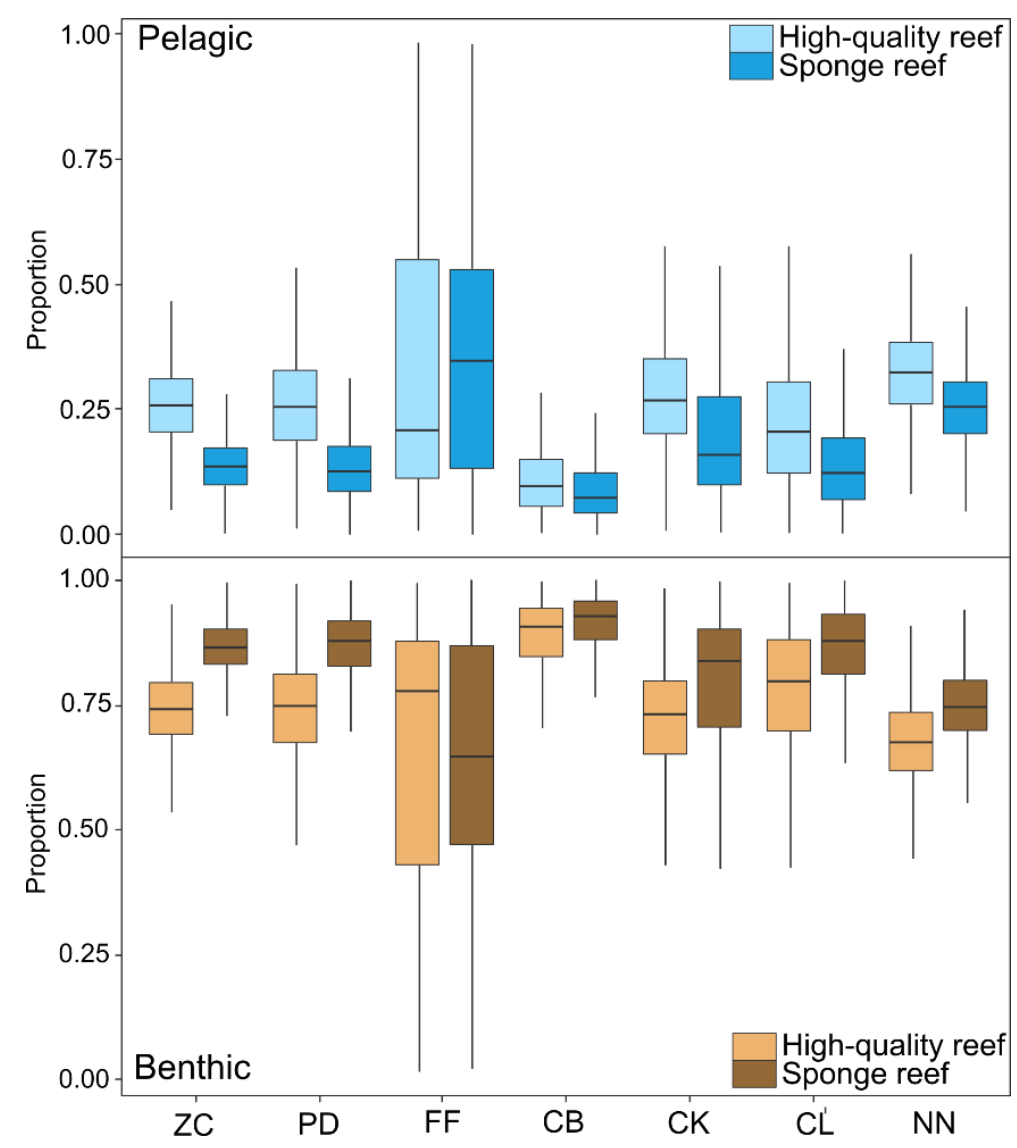

Figure 4. 6 Relative contributions of pelagic and benthic carbon to the diet of seven coral reef fish species representing functional feeding groups sampled at two sites in the Wakatobi MNP, Indonesia. Boxes represent the credible interval of 50\% and error bars the credible interval of $95 \% . \mathrm{ZC}=$ Zanclus cornutus, $\mathrm{PD}=$ Pygoplites diacanthus, $\mathrm{FF}=$ Forcipiger flavissimus, $\mathrm{CB}=$ Ctenochaetus binotatus, $\mathrm{CK}$ $=$ Chaetodon kleinii, $\mathrm{CL}=$ Chaetodon lunulatus, $\mathrm{NN}=$ Neoglyphidodon nigroris . 


\subsubsection{Quantitative comparison of trophic structure}

Bayesian analysis of community metrics showed that the sponge-dominated site had lower trophic diversity ( $>80 \%$ probability lower CD), significantly lower diversity of basal resources $(>95 \%$ probability smaller $\delta^{13} \mathrm{C}$ range) and higher trophic redundancy than the high-quality site $(>95 \%$ probability smaller SDNND; > 77\% probability smaller NND) (Figure 4.7).

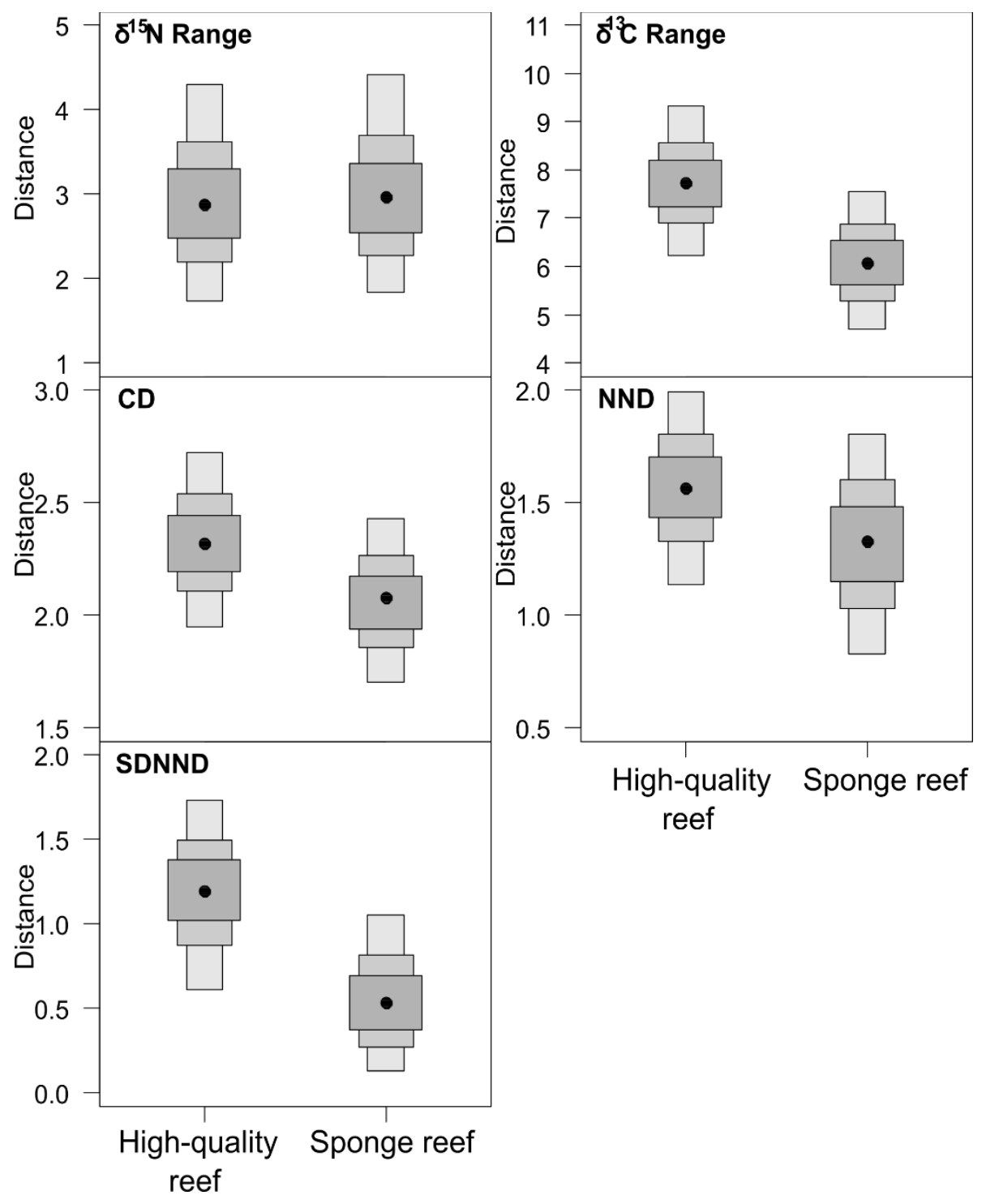

Figure 4. 7 Bayesian results of the Layman community metrics for two sites (higher-quality and spongedominated) sampled in the Wakatobi MNP Indonesia. Black circles represent the mode and boxes correspond to the $50 \%, 75 \%$ and $95 \%$ credible intervals. $\delta^{15} \mathrm{~N}$ Range $=$ Range of $\delta^{15} \mathrm{~N}$ values. $\delta^{13} \mathrm{C}$ Range $=$ Range of $\delta^{13} \mathrm{C}$ values. $\mathrm{CD}=$ Mean distance to the centroid. NND $=$ Mean nearest neighbour distance. SDNND $=$ Standard deviation of nearest neighbour distance. 


\subsection{Discussion}

A deeper understanding of how individual species and entire communities respond to environmental change is key to predicting the future functioning of coral reefs (Sale et al. 2014). In this chapter, I examined how changes in resource availability affect foraging strategies and trophic diversity in a coral reef fish assemblage. Results indicated that the majority of fish at the sponge-dominated site responded to a low-quality environment by expanding their diet, increasing diet similarity and reducing trophic diversity at the community level. This can be expected to reduce community stability as resource partitioning decreases, eroding species co-existence.

\subsubsection{Spatial and interspecific variation in trophic position and $\delta^{13} \mathrm{C}$ values}

Reduction of food chain length and mean trophic position of consumers are indicators of habitat degradation (Pauly \& Watson, 2005; Layman et al. 2007; Hempson et al. 2017). In my study, the mean trophic position of fish (species pooled) on the sponge-dominated reef was significantly lower than on the high-quality reef. This could indicate an increased reliance on benthic carbon sources as benthic carbon tends to exhibit lower $\delta^{15} \mathrm{~N}$ values than pelagic carbon (Hempson et al. 2017; Eurich et al. 2019). For example, Hempson et al. (2017) found that the trophic position of the coral grouper Plectropomus maculatus decreased as a result of diet switching from planktivorous damselfishes to algal-feeding damselfishes. In this study, between-site pairwise tests indicated that Zanclus cornutus and Forcipiger flavissimus both had significantly lower trophic positions at the sponge-dominated reef. Individuals of $Z$. cornutus sampled at the sponge-dominated site were significantly smaller than individuals sampled at the high-quality site, therefore spatial differences in trophic position could be the result of dietary ontogeny (de la Morinière. 2003) or size-related processes which affect $\delta^{15} \mathrm{~N}$ tissue values (Carassou et al. 2008). F. flavissimus occupied the highest trophic position at the high-quality site, but at the spongedominated site, it had the same trophic position as Chaetodon kleinii, indicating a comparatively shorter food chain. Lower trophic positions may reflect diet switching to suboptimal prey at the spongedominated site (Rossi et al. 2015; Calizza et al. 2017), as F. flavissimus is known to have one of the widest diets of all butterflyfish (Harmelin-Vivien \& Bouchon-Navarro, 1983). Whilst this adaptability may assist survival in the short term, over longer time scales a reduction in food quality could reduce fecundity, growth rates and maturity (Jones \& McCormick, 2002; Graham et al. 2007) due to a loss of physiological condition (Berumen et al. 2005).

With the exception of Chaetodon lunulatus and Zanclus cornutus, fish $\delta^{13} \mathrm{C}$ values were significantly depleted at the high-quality site indicating greater reliance on oceanic production (Fry et al. 1982; de la Moriniere et al. 2003; Wyatt et al. 2012) likely caused by increased proximity to the open ocean. Wyatt et al. (2012) observed the same spatial pattern in the $\delta^{13} \mathrm{C}$ values of herbivores, carnivores and planktivores at Ningaloo Reef, but not with detritivores or corallivores (Wyatt et al. 2012). This was explained by the dominance of reef-derived material in the diets of both feeding groups across a back 
reef to open ocean gradient (Wyatt et al. 2012) and may explain why C. lunulatus and Z. cornutus did not show the same depletion in ${ }^{13} \mathrm{C}$ as the other fish at the high-quality site. Similarly, Carassou et al. (2008) attributed higher $\delta^{13} \mathrm{C}$ and lower $\delta^{15} \mathrm{~N}$ in parrotfish tissues to the role of detritus in their diets therefore higher $\delta^{13} \mathrm{C}$ values could be an indication of increased consumption of detritus at the spongedominated site. Interestingly at the high-quality site, the species with similar $\delta^{13} \mathrm{C}$ values were $Z$. cornutus, Pygoplites diacanthus and Chaetodon kleinii, with trophic positions increasing respectively $(2.72 \pm 0.03,2.85 \pm 0.02$ and $2.98 \pm 0.02$ [mean $\pm \mathrm{SE}$ ] $)$. This supports the conclusion from Chapter 2 that the trophic ecologies of these three species are tightly linked to sponges, with $Z$. cornutus and $P$. diacanthus consuming sponge tissue and $C$. kleinii targeting sponge-associated fauna.

\subsubsection{Isotopic niches of coral reef fishes}

Optimal foraging theory predicts that individuals choose prey in a way that maximizes their overall rate of energy gain (Pyke et al. 1977; Brooker et al. 2014). Hence in habitats where preferred food is limited, consumers adjust their foraging strategy to include non-preferred prey (Berumen et al. 2005), which leads to wider trophic niches (Rossi et al. 2015). The isotopic niche of the corallivore Chaetodon lunulatus was statistically larger on the sponge-dominated reef and three further species (Forcipiger flavissimus, Zanclus cornutus and Pygoplites diacanthus) had isotopic niches that were close to being statistically larger $(\mathrm{p}=0.07)$ although sample sizes may have been too low to detect statistical significance. Nevertheless, this indicates a decrease in resource specialisation at the sponge-dominated site for the majority of consumers. Similar patterns of niche width expansion have been observed in tropical streams altered by agricultural practices (Parreira de Castro et al. 2016) and in degraded Posidonia meadow beds (Calizza et al. 2017) indicating the potential for habitat disturbance to lead to generalist-dominated communities (Clavel et al. 2011).

On Indo-Pacific reefs, Chaetodon lunulatus is considered to be an obligate corallivore (Nagelkerken et al. 2009) that depends on coral for $\geq 80 \%$ of its diet (Cole et al. 2008). Unlike other specialist corallivores that have sharply declined in abundance and suffered localised extinction following coral loss (Kokita \& Nakazono 2001; Munday, 2004; Brooker et al. 2014), this study suggests that $C$. lunulatus can adopt more generalist foraging behaviour in coral-poor habitats. This success could be attributed to flexible prey choice within the Scleractinian order (Berumen et al. 2006; Pratchett et al. 2005) yet there was no difference in the size or location the isotopic niche of corals between sites suggesting that $C$. lunulatus supplemented its diet with another source of carbon. Increased proximity to the isotopic niche of the detritivore Ctenochaetus binotatus indicates that detrital carbon is more important for C. lunulatus at the sponge-dominated site. This is consistent with the findings of McMahon et al. (2016) who showed that microbially re-worked detritus was an important secondary source of carbon for a suite of reef species, including the obligate corallivore Chaetodon trifascialis. Although the majority of species sampled had larger isotopic niches at the sponge-dominated site, the detritivore $C$. binotatus had a 
statistically smaller isotopic niche. This was consistent with detritus (+1 TP), which also had less variable isotopic values at the sponge-dominated site, possibly indicating a lower diversity of sources contributing to the detrital pool than at the high-quality site.

Intraspecific and interspecific competition for food affects foraging strategies (Dill, 1983) and hence could have an impact on isotopic niche size. Inspection of monitoring data collected from six sites in the Hoga/Kaledupa channel for 2017 (including the two sites sampled during this study) indicated that there was no statistical difference in the density of Chaetodon lunulatus or obligate corallivores between the sponge-dominated site and the higher quality site (Operation Wallacea unpublished monitoring data, 2017; Appendix D, Table 17). In Chapter 2, densities of Pygoplites diacanthus and Forcipiger flavissimus were lower at the sponge-dominated site but here was no difference in the densities of Zanclus cornutus or Chaetodon binotatus indicating no obvious relationship between intraspecific competition and isotopic niche size. Similarly, predation risk was not considered during this study although it is known to affect the foraging strategies of fishes (Dill, 1983). Predation risk could be higher at the sponge-dominated site due to reduced structural complexity and fewer refuge holes providing protection from predators (Rodgers et al. 2014), although this would generally be expected to reduce movement and access to resources, which would decrease niche width (Calizza et al. 2013).

\subsubsection{Carbon sources and benthic prey}

There was considerable variation in prey and carbon source values, with only one overlap in isotopic niche observed between sponges and detritus $+1 \mathrm{TP}$ at the high-quality site. The detrital signature was inferred from a proxy detritivore, Synaptula sp., following McMahon et al (2016) who also used a detritivorous sea cucumber to characterise detritus on coral reefs (McMahon et al. 2016). Most of the Synaptula sp. collected were found on the outside of sponges and some Synaptula sp. are known to associate with some species of Porifera (Hammond \& Wilkinson, 1985). Similar isotopic values of the two organisms could be the result of Synaptula sp. consuming sponge mucus (Hammond \& Wilkinson, $1985)$ or both groups ingesting similar particles $(>50 \mu \mathrm{m})$ from surface epithelial cells (Maldonado et al. 2012).

The $\delta^{13} \mathrm{C}$ values for SPOM were low (mean -25.13\%) however, similar values have been obtained from coastal waters in the Caribbean (Freeman et al. 2014; van Duyl et al. 2018) and photosynthetically derived carbon can lead to carbon values as low as -27\%o (Levin et al. 2002). Sponges displayed a wide range of $\delta^{15} \mathrm{~N}$ and $\delta^{13} \mathrm{C}$ values and, aside from Xestospongia and Clathria, sponges were isotopically discriminated, suggesting distinct carbon and nitrogen cycling processes (Freeman et al. 2014). The phototrophic sponge Lamellodysedia herbacea had similar isotopic values to SPOM and was significantly more depleted in ${ }^{13} \mathrm{C}$ than the heterotrophic sponges, indicative of nutrition derived from phototrophic symbionts (Fiore et al. 2010). When heterotrophic sponges were grouped, they were ${ }^{15} \mathrm{~N}-$ 
enriched and ${ }^{13} \mathrm{C}$-depleted relative to corals. The same spatial variation in isotopic values was also observed between the spongivore (Pygoplites diacanthus) and the corallivore (Chaetodon lunulatus), however, both specialists were enriched by more than $1 \%$ in ${ }^{13} \mathrm{C}$ than their main food source. Carbon isotopic fractionation has been shown to vary as a function of diet quality (Busst \& Britton, 2016) and diets with high C: $\mathrm{N}$ ratios lead to larger $\Delta^{13} \mathrm{C}$ (Caut et al. 2009; Busst \& Britton, 2016). This may account for the large differences in $\delta^{13} \mathrm{C}$ values between the specialists and their prey observed in this case.

Turf algae had the lowest $\delta^{15} \mathrm{~N}$ values of all sources and they were approximately $2 \%$ lower than both Dictyota sp. and Halimeda sp. This could be due to the method of collection in which algal turfs were scraped from the benthos which likely retained other organisms including benthic diatoms and cyanobacteria. This would be consistent with other studies that have sampled microphytobenthos (diverse assemblages of photosynthetic diatoms, cyanobacteria, flagellates and green algae) in coastal systems have also reported equally low $\delta^{15} \mathrm{~N}$ values (McLeod et al. 2009). Due to the low $\delta^{15} \mathrm{~N}$ values of turf algae and insufficient data for macroalgae for both sites, algae were not included as part of the benthic signature in isotope mixing models. However, as algae generally have higher $\delta^{13} \mathrm{C}$ values than SPOM (Fry \& Sherr, 1984; Fry, 2006) it is unlikely the exclusion of algae would have an impact on proportion estimates.

\subsubsection{Organic matter contributions and community structure}

Pelagic and benthic-derived food differ in stable isotope ratios (Fry et al. 1982) and differences in proportional use are reflected in the stable isotope values of consumers (van Duyl et al. 2018; Eurich et al. 2019). Mixing models estimated a larger contribution of benthic carbon versus pelagic carbon for all species at both sites, which was likely caused by low $\delta^{13} \mathrm{C}$ values of SPOM (range: - $23 \%$ to $-26.9 \%$ ) relative to fish $\delta^{13} \mathrm{C}$ values (range: $-8.9 \%$ to $-18.1 \%$ ). As mentioned, isotopic fractionation can vary as a result of diet quality and environment (McCutchan et al. 2003; Caut et al. 2009; Busst \& Britton, 2016). Therefore, the trophic enrichment factors applied may underestimate carbon fractionation taking place from SPOM to secondary consumers. Accordingly, this discussion is limited to relative contribution rather than specific values. Spatial variation the isotope ratios of pelagic and benthic organic matter was accounted for by using site-specific values in isotope mixing models (Phillips et al. 2014). Most fish showed an increased reliance on pelagic carbon at the high-quality site, likely the result of greater proximity to upwelling (Wyatt et al. 2012). Pelagic nutrients are generally considered higher quality than reef derived nutrients due to lower C: N ratios (Atkinson \& Falter, 2003; Wyatt et al. 2012). Relative isolation from upwelling and low coral and low macroalgal cover indicate that detrital production could be the main carbon source fuelling secondary production at the sponge-dominated site. Quantitative analysis of community structure revealed that consumers on the sponge-dominated site exploited a significantly lower range of resources $\left(\delta^{13} \mathrm{C}\right.$ range). The sponge-dominated site had 
lower trophic diversity (CD) and higher trophic redundancy than the high-quality site suggesting a simplified trophic structure and that consumers have more similar diets. Whilst supplementing dietary requirements with detrital carbon has been described as nutritionally beneficial (Nelson \& Wilkins, 1988), research utilising compound-specific stable carbon isotope ratios showed that a single source of carbon dominated the diets of benthic foraging reef fish and predators, indicating tight links between primary producers and consumers (McMahon et al. 2016). Hence, a reduction in the range and availability of primary producers can destabilise ecosystems by disrupting resource compartmentalisation among co-existing species (Calizza et al. 2017).

\subsubsection{Study limitations}

This study used a comparative approach to compare differences in trophic structure and consumer niche widths between a sponge-dominated reef and an adjacent, higher quality "reference site". The selection of reference sites is inevitably subjective and high spatial and temporal variability on coral reefs cannot easily be encompassed by the use of a single reference site. However, due to the high cost of stable isotope analysis, the decision was made to sample two sites fully and represent more species at the assemblage level, than sample at a wider range of sites but with fewer species represented. This enabled a thorough comparison between these two sites but inevitably limits any extrapolation from this one sponge-dominated site to all sponge-dominated reefs. Future studies with access to other reef systems that have shifted to sponge-dominance should increase replication at the site level to better understand the trophic consequences of shifts to sponge dominance.

\subsubsection{Conclusion}

Understanding how populations and communities persist under different environmental conditions is a critical step towards predicting the capacity of future coastal environments to provide crucial goods and services. In this chapter, I used stable isotopes and Bayesian modelling to investigate how habitat quality affects foraging strategies and trophic diversity in a coral reef fish assemblage. I have shown that the majority of species, including the obligate corallivore, had wider trophic niches at the spongedominated site. Fish at the sponge-dominated site also used a significantly lower range of resources, had lower trophic diversity and obtained more carbon from benthic production than at the high-quality reef site. Results suggest a more simplified trophic structure at the sponge-dominated site characterised by fish with more similar diets. 


\section{Chapter 5. Resource partitioning by temperate sponges is driven by differential use of pelagic and benthic organic matter}

\section{1 Abstract}

Co-occurring species in competitive ecosystems partition resources to facilitate coexistence. For marine sponges, trophic diversity is heightened by selective filtration of suspended particles, associated symbiont communities and the uptake of dissolved organic matter (DOM). Resolving the diversity of nutritional pathways used by sponges is essential to understand how sponge assemblages may react to future changes in carbon sources. In this chapter, I investigated niche partitioning and resource use among co-occurring temperate sponges. My approach was to measure the carbon and nitrogen stable isotope ratios of five abundant sponge species at two depths at two sites on opposing ends of Doubtful Sound, Fiordland. I also measured stable isotope ratios of picoplankton $(<2 \mu \mathrm{m}$ size phytoplankton), the 2-200 $\mu \mathrm{m}$ fraction of the water column, macroalgae and terrestrial organic matter (TOM) and used isotope mixing models to estimate the contribution of carbon sources to sponge species. Sponges displayed a wide range of $\delta^{15} \mathrm{~N}$ values spanning two trophic levels. Sponges at the Inner Fiord had higher $\delta^{15} \mathrm{~N}$ values than the Outer Fiord and $30 \mathrm{~m}$ sponges had higher $\delta^{15} \mathrm{~N}$ values than $10 \mathrm{~m}$ sponges, spatial differences that were not reflected by water column resources. There was a high degree of interspecific resource partitioning with the majority of isotopic niche overlaps observed at the Inner Fiord site at $10 \mathrm{~m}$. Comparisons of isotopic niche size suggested more diverse resource use at the Outer Fiord site for Axinella richardsoni, Cymbastela tricalyciformis and Raspailia topsenti. Neither picoplankton nor TOM contributed significantly to the diets of most sponges, rather the 2-200 $\mu \mathrm{m}$ fraction of the water column was important for Raspailia topsenti, Axinella richardsoni and Tethya sp. at the Inner Fiord with the proportional contribution of macroalgal-derived organic matter increasing at the Outer Fiord. Interestingly, macroalgal-derived organic matter was the most important carbon source for both Cymbastela tricalyciformis and Latrunculia fiordensis at the Outer Fiord site. These species were found in low abundances at the Inner Fiord where macroalgal coverage was also low. The only evidence of TOM assimilation was by two sponges sampled opportunistically by remotely operated underwater vehicle (ROV) at $60 \mathrm{~m}$ at the Inner Fiord, suggesting either direct consumption of picoplankton or participation in a chemosynthetic food web driven by microbial decomposition of TOM. This study has demonstrated a high degree of resource partitioning between co-existing temperate sponges driven by differential use of pelagic and benthic organic matter. However, TOM may support some sponges via microbial pathways where marine production is limited. 


\section{2 Introduction}

Understanding how species co-exist, especially when they appear to rely on a common resource, has been a central theme in ecology for nearly a century (Grinnell, 1917; Schoener, 1986). The term 'ecological niche' was first popularised by Grinnell (1917) who described it as the habitat and accompanying behavioural adaptations of a species. His concept focused on the environment and suggested that ecological equivalents could be found in different locations implying invariant rules and the existence of unoccupied niches (Schoener, 2009). Hutchinson (1957) advanced the concept by suggesting that the ecological niche could be quantitatively described in space as an ' $n$ dimensional hypervolume' (or fundamental niche) described by scenopoetic (environmental components of niche space) and bionomic (trophic components of niche space) axes (Hutchinson, 1957; Hutchinson, 1978; Schoener, 2009). However, interspecific competition for resources means that often the fundamental niche is not fully exploited, and species are restricted to a realised niche (Hutchinson, 1978). For some scientists, the focus shifted to understanding the evolution of interspecific differences in resource use (MacArthur \& Levins, 1967) as closely-related species cannot coexist indefinitely if niche overlap is high (Gause, 1934; MacArthur \& Levins, 1967; Schoener, 2009) and specialisation is often necessary to avoid extinction (MacArthur \& Levins, 1967). Differential resource use mediates species coexistence and regulates diversity (Schoener, 1986). Resolving resource partitioning is thus essential to understand how communities may react to future change in resource availability (Middelburg, 2014).

Temperate subtidal reefs support a diverse array of suspension feeders that are reliant on similar food resources suggesting a degree of resource partitioning (Stuart \& Klumpp, 1984). Marine sponges provide a significant trophic link between benthic and pelagic systems through active suspension feeding (Lesser, 2006). They can consume a range of particle sizes (Maldonado et al. 2012), although they are most efficient at filtering picoplankton $(0.7-2 \mu \mathrm{m})$ due to the structure of their aquiferous system (Reiswig, 1971; Pile at al. 1996). Once considered non-selective, (Maldonado et al. 2012), several studies have demonstrated the ability of sponges to selectively retain some particles over others (Yahel et al. 2006; Weisz et al. 2007; Maldonado et al. 2012). For example, Hanson et al. (2009) demonstrated that Callyspongia sp. optimised nutritional intake by consistently selecting against low DNA (LDNA) bacteria that have lower carbon and nutrient contents than high DNA (HDNA) bacteria. In addition to heterotrophic selectivity, partnerships with symbionts allow host sponges to engage in alternative metabolic pathways (Taylor et al. 2007), particularly under nutrient-limited conditions (Freeman \& Thacker, 2011, Freeman et al. 2014). These metabolic interactions can be phototrophic or chemotrophic depending on the symbionts, available substrate and oxygen conditions (Vacelet et al. 1995; Taylor et al. 2007). For example, some deep-sea sponges have been shown to harbour methanotrophic symbionts and possess carnivorous feeding structures (Vacelet et al. 1995). Dissolved organic carbon (DOC), operationally defined as the organic carbon that passes through a GF/F filter paper (nominal pore size $0.7 \mu \mathrm{m}$ ) (Maldonado et al. 2012), has also been identified as a key nutritional 
resource for sponges (Yahel et al. 2003; de Goeij et al. 2013; McMurray et al. 2016). A series of isotopic tracer experiments (de Goeij et al. 2013; Rix et al 2016; Rix et al 2017) showed that sponges assimilate DOM and return it to the benthos as particulate detritus in a process called 'the sponge loop' (de Goeij et al. 2013; Rix et al 2018). However, the ubiquity of the sponge loop remains undetermined as none of the nine emergent sponge species studies by McMurray et al. (2018) produced significant quantities of detritus (McMurray et al. 2018). Both coral- and algal-derived DOM have been shown to support the sponge holobiont (Rix et al. 2016; Rix et al. 2017), however, the internal routing of these two carbon sources varies between the sponge host and its associated microbial community (Rix et al 2017).

Stable isotope analysis (SIA) has emerged as a powerful tool for ecologists investigating niche partitioning and organic matter cycling (Fry, 2006; Middelburg, 2014). Nitrogen isotopes are commonly used to depict trophic position due to the predictable (but see Mill et al. 2007; Hussey et al. 2014) stepwise enrichment from the source to the consumer of approximately 2-4\%o (Minagawa \& Wada, 1984; Fry, 1988). Carbon isotopes generally show less variation per trophic level transfer (around 0 1\%) (but see Caut et al. 2009; Busst \& Britton, 2016) and can be used to identify organic matter sources that vary in carbon isotope values due to different photosynthetic pathways (Post, 2002; Bearhop et al. 2004). $\delta^{15} \mathrm{~N}$ and $\delta^{13} \mathrm{C}$ values can be used to visualise a species in $\delta$-space and thus describe its isotopic niche (Chapter 4; Newsome et al. 2007; Jackson et al. 2011), a generalised proxy for trophic niche (Catry et al. 2016). These techniques have been used to identify niche separation among co-occurring sponges in tropical and temperate systems (Thurber, 2007; Freeman et al. 2014; Freeman et al. 2016). For example, Freeman et al. (2014) used SIA to show that high microbial abundance (HMA) sponges occupy a unique niche space compared to low microbial abundance (LMA) sponges. However, host species identity was found to drive stable isotope signatures more than symbiont abundance (Freeman et al. 2014).

Resolving the relative contribution of different sources of organic matter (OM) to an organism's diet relies on isotopic discrimination between sources (Parnell et al. 2010; Philips et al. 2014). Benthic and pelagic sources of OM differ in stable isotope ratios, as pelagic sources tend to exhibit lower $\delta^{13} \mathrm{C}$ values and higher $\delta^{15} \mathrm{~N}$ values than benthic primary producers (Fry, 2006; van Duyl et al. 2011). Suspended detrital (non-living) particles from benthic and pelagic sources are consumed by sponges (Hadas et al. 2009; McMurray et al. 2016). For example, detritus was estimated to constitute $20 \%$ of the diet of the giant barrel sponge Xestospongia muta, approximately double the contribution of living particulate organic carbon (LPOC) (McMurray et al. 2016). Primary producers e.g. marine algae also release DOC into the water column as a photosynthetic biproduct (Wild et al. 2004; Wild et al. 2010) that is then taken up by the sponge holobiont (Rix et al. 2016; Rix et al. 2017). Both detrital and dissolved OM are generally thought to reflect the isotopic signature of the source (Benner et al. 1997; Fry et al. 1998), hence bulk isotope values of sources can be used as a proxy to infer both detrital and dissolved OM from primary producers (van Duyl et al. 2011; van Duly et al. 2018). 
Van Duyl et al. (2011) used isotopic discrimination between sources and fatty acid analysis to show that coral cavity sponges in the Caribbean rely on reef-derived OM from coral mucus and crustose coralline algae (CCA) rather than pelagic production. In a later study, van Duyl et al. (2018) showed that co-occurring sponges inhabiting an atoll in the Caribbean relied on different proportions of benthicand pelagic-derived OM. Recently, it has been proposed that the high proportion of heterotrophic sponge species in the Caribbean could be explained by an ability to consume refractory DOC originating from terrestrial environments considered to be unavailable to microbes (Pawlik et al. 2016). However, there is no evidence that sponges assimilate refractory compounds directly from terrestrial OM (TOM), which are typically high molecular weight (HMW) compounds and generally considered resistant to degradation (Fasching et al. 2014). If sponges can utilise a portion of refractory TOM, it could explain global patterns of sponge abundance (Pawlik et al. 2016) and would highlight an essential, yet overlooked, link between the terrestrial, marine pelagic and marine benthic systems. TOM can be differentiated from marine OM by its high C: $\mathrm{N}$ ratio (McLeod et al. 2007), hence SIA can be used to investigate the relative contribution of TOM, pelagic and benthic production to the diet of sponges in coastal systems.

Substantial gradients in the composition and availability of OM (Wing et al. 2012) make Fiordland in Southwest New Zealand an ideal system to study OM cycling. Heavy rainfall transports large quantities of TOM into the fiords where it makes up a substantial fraction of carbon source pools (McLeod \& Wing, 2009), with the relative input of marine OM (phytoplankton and macroalgae) increasing along a seaward gradient (McLeod et al. 2007). TOM has been shown to support upper trophic levels via the chemoautotrophic activities of bacterial symbionts that fix dissolved $\mathrm{CO}_{2}\left(\mathrm{McLeod}_{\text {et al. 2007; Rodgers }}\right.$ et al. 2008; McLeod et al. 2009) although smaller inputs of marine OM likely support the majority of macroinvertebrate consumers (McLeod et al. 2009). Sponges are most abundant between $40-60 \mathrm{~m}$ depth with abundance increasing from the head of the fiords to mid and outer locations (Bell, unpublished data), consistent with patterns of marine production (Wing et al. 2014). However, even where marine production is limited, sponges cover $\sim 6.5 \%$ of the substrate (Bell, unpublished data) suggesting that sponges can make use of diverse sources of OM on temperate reefs in the fiords.

In this chapter, I investigated niche partitioning and resource use among co-occurring temperate sponges. Specifically, my aims were: i) to investigate spatial variation in carbon and nitrogen stable isotope ratios of sponges and water column resources; ii) to assess interspecific niche partitioning and shifts in resource use from $10 \mathrm{~m}$ to $30 \mathrm{~m}$ by calculating the isotopic niche (a proxy for trophic niche) of each species; iii) to investigate shifts in the diversity of resources used by each species; and, iv) to calculate organic matter contributions to sponge diets. 


\subsection{Methods}

\subsubsection{Study Sites}

Fiordland in southwest New Zealand is an extensive coastal forest incised by deep fiords, contained within the Te Wāhipounamu World Heritage Area. It is characterised by heavy rainfall (6-8 m annually) (Gibbs et al. 2000) and densely vegetated, mountainous terrain. Doubtful Sound is the deepest of the 14 fiords in the park and the second-longest, with three distinct arms (Figure 5.1). The Inner Fiord site was $40 \mathrm{~km}$ from the open sea and in some parts only $1 \mathrm{~km}$ wide. In this narrow part of the fiord, freshwater input is vastly increased by an outflow from the Manapouri hydroelectric power station, which can release an average $450 \mathrm{~m}^{-3} \mathrm{~s}^{-1}$ freshwater into Deep Cove (McLeod et al. 2010). In parts of the fiord, this has extended the low salinity layer (LSL) to $5 \mathrm{~m}$ depth (Boyle et al. 2001). The Outer Fiord site was $1 \mathrm{~km}$ from the mouth of the fiord.

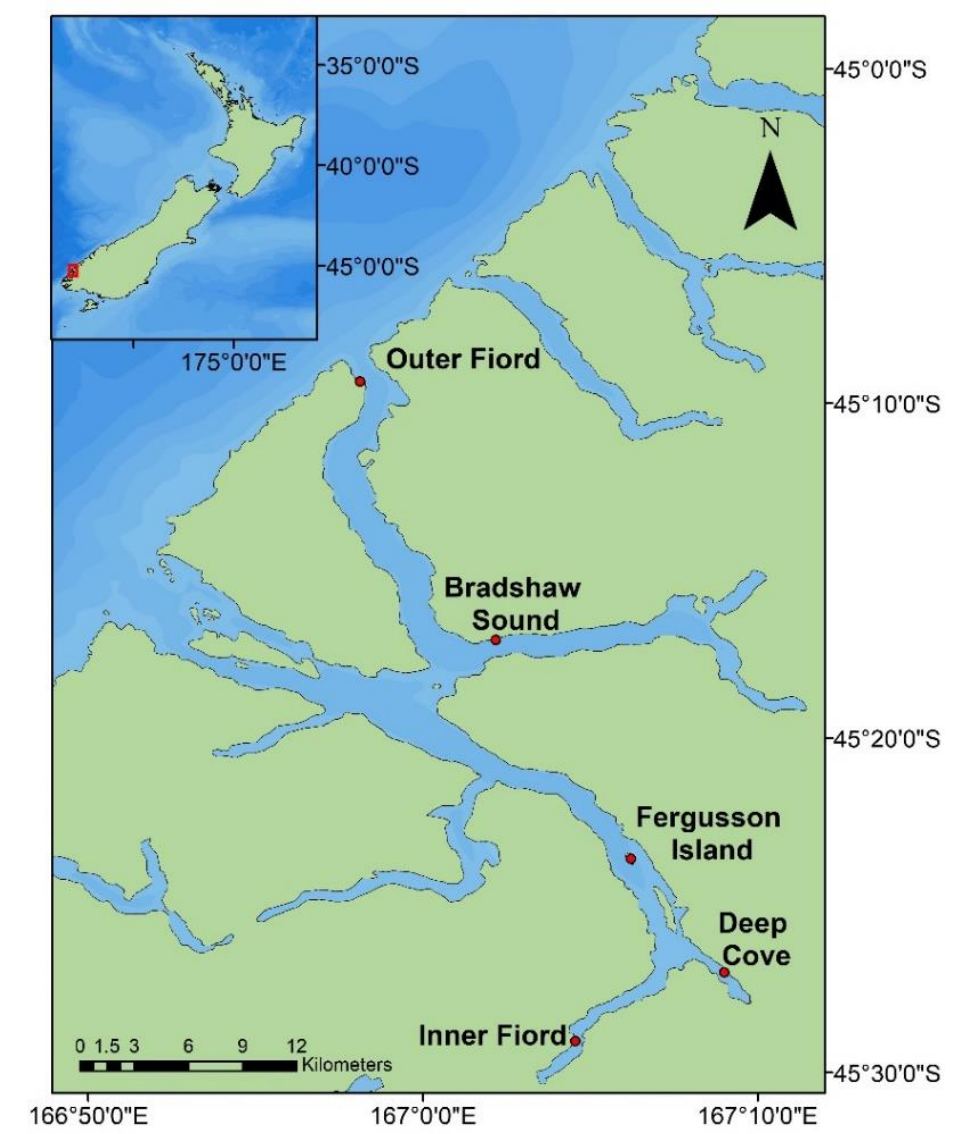

Figure 5. 1 Map showing locations of sample sites in Doubtful Sound, Fiordland visited during February 2019 on the MV Southern Winds. Sponges were collected the Inner Fiord and Outer Fiord at opposing ends of Doubtful Sound, with three additional deep sponges collected by ROV at Fergusson Island. Organic matter samples were collected at the Inner Fiord and Outer Fiord, and an intermediate site in Bradshaw Sound. 


\subsubsection{Sample collection}

All samples were collected during a one-week voyage in February 2019. Water column samples were collected from the Inner Fiord and Outer Fiord (Figure 5.1) at $10 \mathrm{~m}$ and $30 \mathrm{~m}$ using a 5 litre Niskin bottle, with one additional sample gathered opportunistically from $80 \mathrm{~m}$ at the Inner Fiord site. All samples were screened $(200 \mu \mathrm{m})$, then filtered into different size fractions to represent two different food sources for sponges. The screened sample was filtered on to a pre-combusted Whatman GFM filter paper (nominal pore size $2 \mu \mathrm{m}$ ) to obtain the $2-200 \mu \mathrm{m}$ size fraction. The resulting filtrate $(<2 \mu \mathrm{m})$ was filtered on to a pre-combusted Whatman GF/F filter paper (nominal pore size $0.7 \mu \mathrm{m}$ ) to obtain the 0.7$2 \mu \mathrm{m}$ (picoplankton) size fraction. Samples of the most abundant macroalgae were collected via SCUBA at the Inner Fiord and Outer Fiord sites (10-15 m), and an intermediate site in Bradshaw Sound (Figure 5.1). Ulva sp. was the only macroalga found at the Inner Fiord so five samples were collected from this site and five from Bradshaw Sound. Five samples of Ecklonia radiata and Codium sp. were collected from both the Outer Fiord site and Bradshaw Sound. Terrestrial organic matter (TOM) was collected at all three sites by sieving surface water for vascular plant detritus (Appendix E, Table 2 for sample size info). Macroalgal samples and leaf litter were rinsed with filtered seawater $(<0.7 \mu \mathrm{m})$ to remove sediments and epibiota, then rinsed with double distilled water (DDW) and stored at $-20^{\circ} \mathrm{C}$.

Five sponge species were collected via SCUBA at the Inner Fiord and Outer Fiord from $10 \mathrm{~m}$ and $30 \mathrm{~m}$. I aimed to collect five samples of each species from each depth, however, replication varies due to variation in abundances (see Appendix E, Table 1 for sample size info). Five additional sponge samples of unknown species were also collected opportunistically using an ROV, two from a depth of $60 \mathrm{~m}$ at the Inner Fiord and three from a depth of $55 \mathrm{~m}$ at a site near Fergusson Island in the main channel (Figure 5.1). Once collected, sponges were placed in buckets with filtered seawater for 2 hours to remove ambient seawater, then a section of sponge tissue was dissected and stored at $-20{ }^{\circ} \mathrm{C}$. This time interval was deemed sufficient based on pumping rates for other New Zealand temperate sponges (Perea-Blázquez et al. 2012). For most species, there was either no observable difference in ectosome and choanosome (e.g. Axinella richardsoni), or the specimen was too thin to separate tissue types (e.g. Cymbastela tricalyciformis). However, for Tethya sp. and Latrunculia fiordensis, tissue from the choanosome was collected for isotopic analysis. C. tricalyciformis is often found with an unidentified species of zoanthid (Epizoanthus sp.) embedded in its tissue; these were removed with sterile tweezers during processing. Dissecting instruments were cleaned with $70 \% \mathrm{EtOH}$ and rinsed with DDW between samples.

\subsubsection{Sample processing}

Frozen samples were returned to Wellington and processed for stable isotope analysis at the National Institute of Water and Atmospheric Research (NIWA). All filter papers were dried at $60^{\circ} \mathrm{C}$, then acidified overnight by fumigation in a desiccator with concentrated hydrochloric acid $(\mathrm{HCl})$ to remove 
carbonates. They were then rinsed again with DDW and dried at $60^{\circ} \mathrm{C}$. Sponges were tested for the presence of carbonates by doing an $\mathrm{HCl}$ acid drop test on small subsamples of each species. Effervescing was noted for some species; therefore, all sponges were acidified according to the protocol outlined in Chapter 4. Simultaneous carbon and nitrogen analyses were carried out on the same acidified sample, as initial tests showed there was no effect of acidification on $\delta^{15} \mathrm{~N}$ values (see Chapter 4). Macroalgae and TOM were similarly tested for the presence of carbonates, but none were detected, so these samples were analysed unacidified for stable isotopes. Organic matter sources and sponges were dried at $60^{\circ} \mathrm{C}$ and homogenised into a fine powder using a mortar and pestle. Samples were weighed into tin boats for analysis $\left(2.5-7 \mathrm{mg}\right.$ sponges, $2 \mathrm{mg}$ macroalgae, $2 \mathrm{mg}$ for TOM $\delta^{13} \mathrm{C}, 8 \mathrm{mg}$ for TOM $\delta^{15} \mathrm{~N}$ ). Due to extremely high C: $\mathrm{N}$ ratios, TOM samples were analysed twice to obtain values for both $\delta^{15} \mathrm{~N}$ and $\delta^{13} \mathrm{C}$. Picoplankton filter papers were cut into $1 / 4$ and folded into tin capsules and GFM filter papers were hole punched (x 5) with resulting circles placed into tin capsules. Samples were analysed on a DELTA VPlus isotope ratio mass spectrometer (IRMS) (See Chapter 4 for a detailed description of methods). Ratios of ${ }^{13} \mathrm{C} /{ }^{12} \mathrm{C}$ and ${ }^{15} \mathrm{~N} /{ }^{14} \mathrm{~N}$ were expressed relative to the internal standards relative to the international standard Carrara Marble NSB-19 (National Institute of Standards and Technology (NIST), Gaithersberg, MD, USA) for carbon and atmospheric nitrogen for nitrogen. Stable isotope values for carbon and nitrogen are expressed as delta $(\delta)$ values, according to the equation:

$\delta \mathrm{X}=\left[\left(\mathrm{R}_{\text {sample }} / \mathrm{R}_{\text {standard }}-1\right] \times 10^{3}\right.$

where $\mathrm{X}$ is ${ }^{13} \mathrm{C}$ or ${ }^{15} \mathrm{~N}$ and $\mathrm{R}$ is the ratio ${ }^{13} \mathrm{C} /{ }^{12} \mathrm{C}$ or ${ }^{15} \mathrm{~N} /{ }^{14} \mathrm{~N}$.

\subsection{Data Analysis}

\subsubsection{Spatial variation in the stable isotope ratios of sponges and water column resources}

To investigate spatial variation in the isotope ratios of sponges (all species combined) and water column resources, I used PERMANOVA + add-in to PRIMER version 6.1 (PRIMER-E Ltd, Plymouth, UK). This was done separately for the isotope ratios of sponges, picoplankton and the 2-200 fraction of the water column, using Type III sums of squares and based on a Euclidean distance matrix of $\delta^{13} \mathrm{C}$ and $\delta^{15} \mathrm{~N}$ values with the factors "site" and "depth" included in the model. Test assumptions were checked using PERMDISP.

\subsubsection{Isotopic niches of sponge species}

To investigate interspecific resource partitioning, I also used PERMANOVA+ (as above) to construct Euclidean distance matrices of $\delta^{13} \mathrm{C}$ and $\delta^{15} \mathrm{~N}$ values for each site and depth with the factor "species" included in the model. Models were run separately for each site and depth due to slight differences in 
species composition (e.g. Latrunculia fiordensis was not present at the Inner Fiord at $10 \mathrm{~m}$ and Raspailia topsenti was not present the Outer Fiord at $10 \mathrm{~m}$ ). Pairwise tests were used to confirm isotopic separation between species.

To compare the diversity of resources used between depths and sites, I estimated the isotopic niche (a generalised proxy for tropic niche) by calculating the standard ellipse of each sponge species at each site using the SIBER package (Stable isotope Bayesian Ellipses in R) (Jackson et al. 2011). The standard ellipse contains approximately $40 \%$ of the sample data and can be considered as a measure of deviation for bivariate data comparable to standard deviation for univariate data that is less sensitive to sample size than other traditional measures of niche width (Jackson et al. 2011; Chapter 4). To compare the size of ellipses between depths and sites, I used Bayesian inference techniques ( $10^{4}$ iterations) to generate probability distributions of the standard ellipse area adjusted for small sample size $\left(\mathrm{SEA}_{\mathrm{c}}\right)$ and inferred statistical significance when $\geq 95 \%$ of posterior draws for one species/group was smaller than the other. This is a robust method of comparing isotopic niche size between groups even when sample sizes differ (Jackson et al. 2011). Species with small ellipses (low intraspecific variation in stable isotope ratios) use a narrow range of resources and those with large ellipses (high intraspecific variation in stable isotope ratios) use a higher diversity of resources. I also calculated the overlap in $\mathrm{SEA}_{\mathrm{c}}$ between groups as a shared percentage of isotopic space with species relying on similar resources expected to have a higher percentage overlap. The main assumption of these statistical techniques is that data approximates a multivariate normal distribution (MVN) (Jackson et al. 2011) thus groups were checked for MVN using the Henze-Zirkler multivariate normality test (Appendix E, Table 12).

\subsubsection{Organic matter contributions to sponge diets}

The key to the successful application of isotope mixing models is discrimination between carbon sources (McLeod et al. 2007; Parnell et al. 2010). I, therefore, used PERMANOVA+ (as above) on a resemblance matrix based on Euclidean distance with subsequent pairwise tests to check for betweensource differences in isotope values. To estimate the contributions of TOM, picoplankton, the 2-200 $\mu \mathrm{m}$ size fraction and macroalgal-derived OM to sponge diets, I used the SIMMR package (Stable Isotope Mixing Models in R) (Parnell, 2016) which uses the Markov chain Monte Carlo (MCMC) algorithm to estimate possible values for each carbon source based on the data. Initial estimates are usually poor and discarded as part of the burn-in phase. Subsequent estimates are stored and used for the posterior distribution (the best estimates of the dietary proportions based on the data). The isotope mixing model package SIMMR requires three parameters: (1) the bivariate isotope data of sponges; (2) the means \pm standard deviation of carbon sources; and (3) trophic enrichment factors (TEF) for $\delta^{15} \mathrm{~N}$ and $\delta^{13} \mathrm{C}$. I ran separate models for each site and adjusted the input values for picoplankton, the 2-200 $\mu \mathrm{m}$ size fraction, and macroalgae, to reflect spatial variation in these values (Appendix E, Table 18). For each species, I pooled samples between depths to increase the sample size to $n=10$ at each site for 
most species, apart for Cymbastela tricalyciformis (Inner Fiord) and Raspailia topsenti (Outer Fiord) where sample sizes were limited by abundance. There is little information on specific TEFs for sponges (Freeman \& Thacker, 2011), therefore I adopted TEF values from Post (2002) of $\Delta^{15} \mathrm{~N} 3.4 \pm 0.98 \%$ and $\Delta{ }^{13} \mathrm{C} 0.39 \pm 1.3 \%$. These factors were estimated from two primary consumers (filter-feeding bivalves and grazing snails) covering littoral and pelagic food webs (Post, 2002) and are hence appropriate for this study. 


\subsection{Results}

\subsubsection{Spatial variation in the stable isotope ratios of sponges and water column resources}

There were significant differences in the isotope values of sponges between the Inner Fiord and Outer Fiord (pseudoF $\left.F_{1,81}=4.52, \mathrm{p}=0.015\right)$ (Appendix $\mathrm{E}$, Table 3 ) driven by significant differences in sponge $\delta^{15} \mathrm{~N}$ values ( $p$ seudoF $F_{1,81}=8.05, \mathrm{p}=0.005$ ), which were higher at the Inner Fiord in comparison to the Outer Fiord $\left(9.83 \% \%_{0} \pm 0.20 \%\right.$; $9.08 \%{ }_{0} \pm 0.21 \%$ [mean \pm SE] $)$ (Figure 5.2). There was no difference in sponge $\delta^{13} \mathrm{C}$ values between sites. There were also significant differences in the isotope ratios of

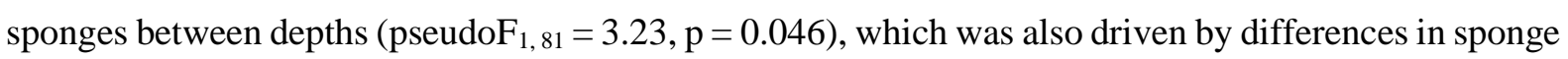
$\delta^{15} \mathrm{~N}$ values (pseudoF $\left.F_{1,81}=4.64, \mathrm{p}=0.039\right)$, which were higher at $30 \mathrm{~m}$ than at $10 \mathrm{~m}(9.69 \% \mathrm{\%} \pm 0.19 \%$; $9.17 \% \pm \pm 0.23 \%$ [mean $\pm \mathrm{SE}]$ ). There was no difference in sponge $\delta^{13} \mathrm{C}$ values between depths.

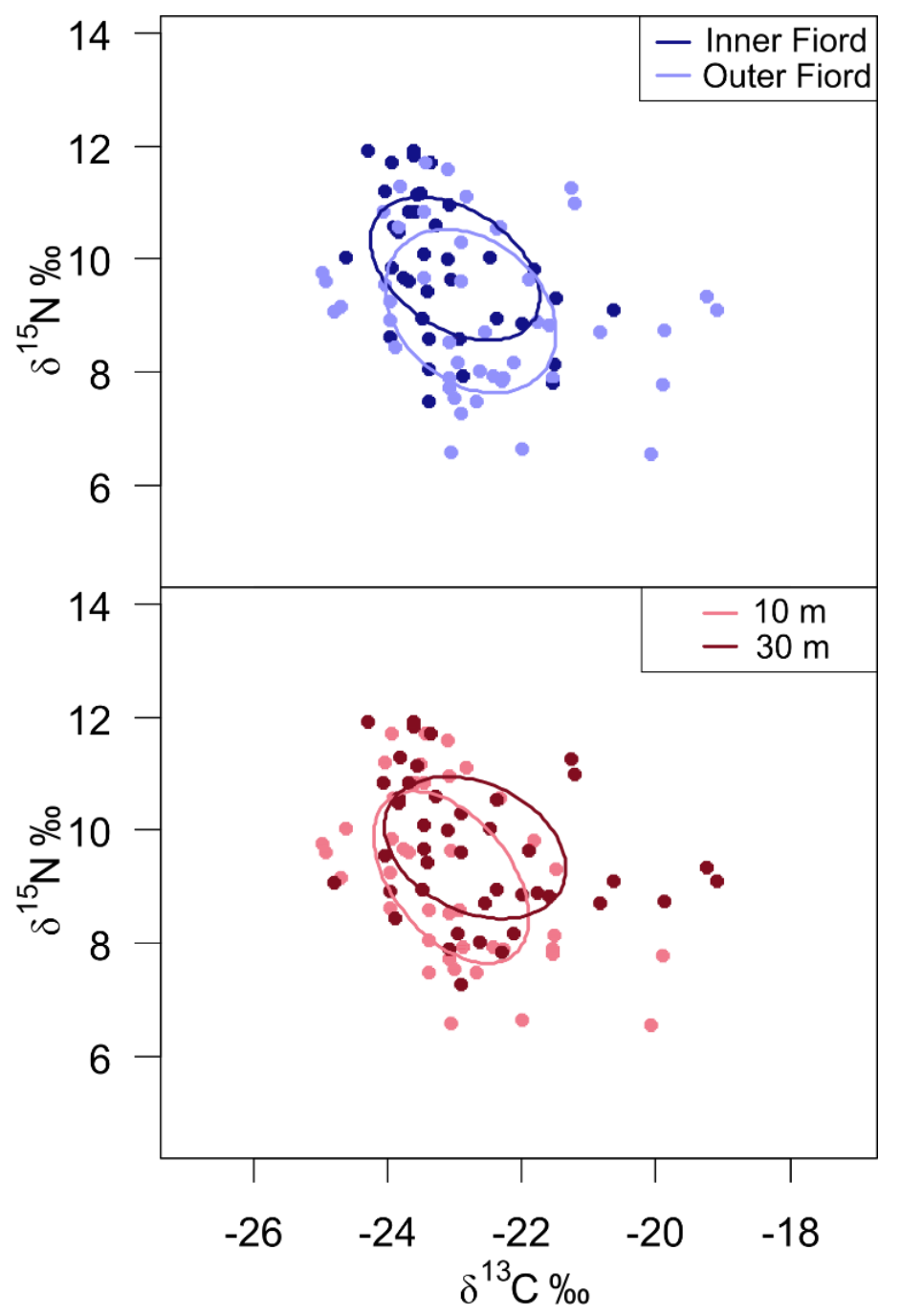

Figure 5. 2 The isotopic niches (standard ellipse area - SEAc) of sponges (all species combined) grouped by site (Inner Fiord and Outer Fiord) and depth $(10$ and $30 \mathrm{~m})$ collected from Doubtful Sound in Fiordland in February 2019. 
For the $2-200 \mu$ fraction of the water column, stable isotope ratios were significantly different between sites ( $\mathrm{pseudoF}_{1,14}=5.88, \mathrm{p}=0.007$ ), driven by $\delta^{13} \mathrm{C}$ values, which were lower at the Inner Fiord than the Outer Fiord $(-25.15 \%, \pm 0.75 \% ;-24.10 \% \neq \pm 0.21 \%$ [mean $\pm \mathrm{SD}]$ ) (Figure 5.3). There was also a significant difference between depths ( $\mathrm{pseudoF}_{1,14}=3.49, \mathrm{p}=0.048$ ) (Appendix E, Table 6). Pairwise tests indicated that there was no difference in isotope ratios between depths at the Inner Fiord, but at the Outer Fiord, there was a significant difference between $10 \mathrm{~m}$ and $30 \mathrm{~m}(\mathrm{t}=7.22, \mathrm{p}=0.001)$, driven by $\delta^{15} \mathrm{~N}$ values which were lower at $30 \mathrm{~m}$ compared to $10 \mathrm{~m}\left(7.87 \%_{0} \pm 0.24 \% ; 6.15 \%\right.$ o $\pm 0.36 \%$ [mean $\pm \mathrm{SD}])$. There was no difference in the stable isotope ratios of picoplankton between sites or depths (Appendix E, Table 7).

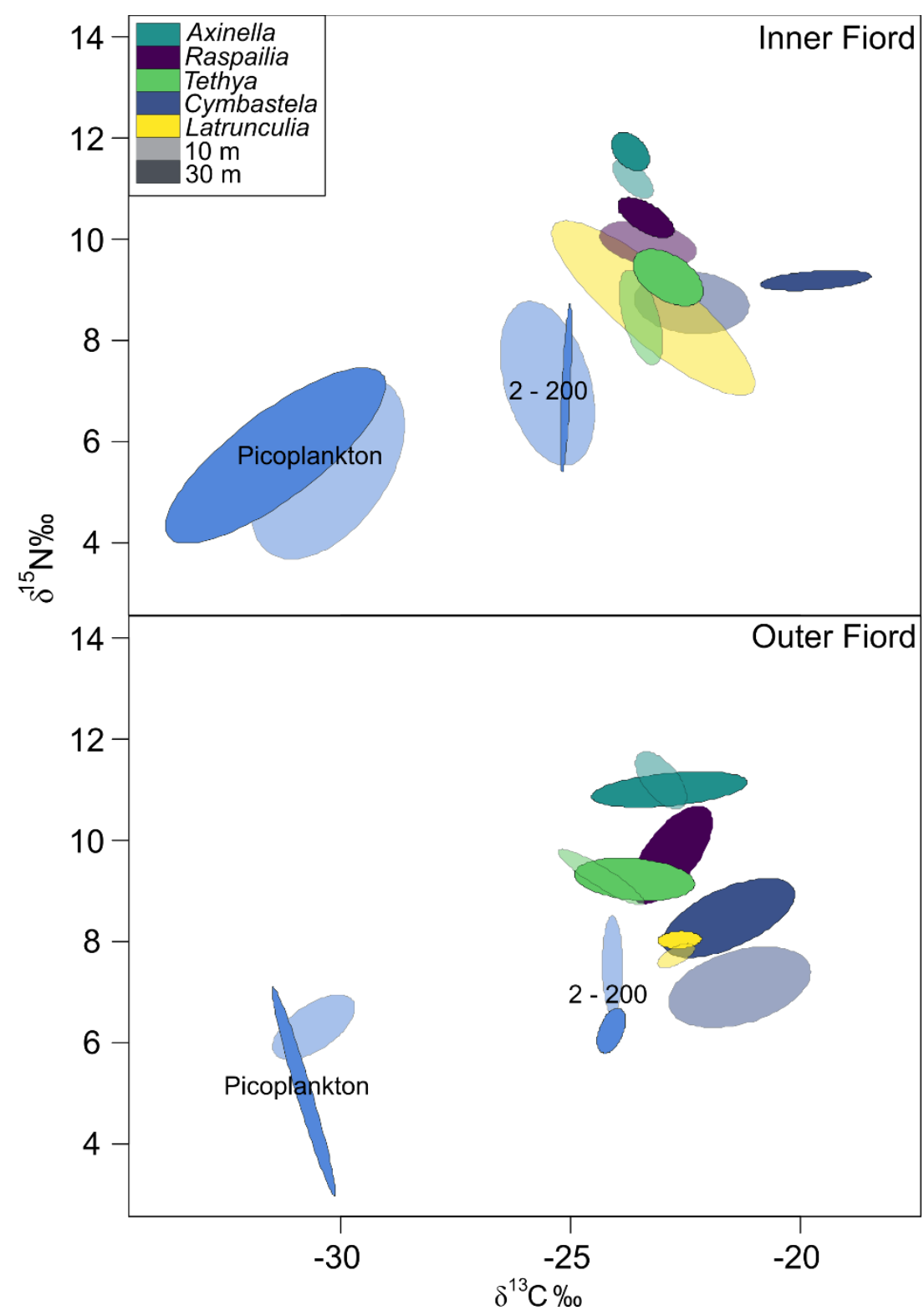

Figure 5. 3 Isotopic niches (standard ellipse area - SEAc) of sponge species, picoplankton and the 2$200 \mu \mathrm{m}$ size fraction of the water column collected from Doubtful Sound in Fiordland grouped by site (Inner Fiord and Outer Fiord) and depth (10 and $30 \mathrm{~m})$. 


\subsubsection{Isotopic niches of sponge species}

\subsubsection{Interspecific niche partitioning}

At the Inner Fiord at $10 \mathrm{~m}$, Latrunculia fiordensis occupied a similar position to Raspailia topsenti (shared 3.7\% total SEAc), Cymbastela tricalyciformis (shared $19.3 \%$ total SEAc) and Tethya sp. (shared $16.2 \%$ total SEAc) but was isotopically separated from Axinella richardsoni $(\mathrm{p}=0.02)$ (Figure 5.3). There was also no difference in the placement of C. tricalyciformis and Tethya sp. (shared $8.1 \%$ total SEAc) but other species were isotopically distinct (all pairwise comparisons $\mathrm{p}<0.05$ ) (Appendix E, Table 8). At the Inner Fiord at $30 \mathrm{~m}$, all species were isotopically distinct (all pairwise comparisons $\mathrm{p}<0.05$ ) (Appendix E, Table 9).

At the Outer Fiord at $10 \mathrm{~m}$, all species were isotopically distinct (all pairwise comparisons $\mathrm{p}<0.05$ ) (Appendix E, Table 10). At the Outer Fiord at $30 \mathrm{~m}, R$. topsenti occupied a similar position to Tethya sp. (23.8\% total SEAc) as did C. tricalyciformis and L. fiordensis (8.4\% total SEAc). All other species were isotopically distinct (all pairwise comparisons $\mathrm{p}<0.05$ ) (Appendix E, Table 11).

\subsubsection{Resource use between depths and sites}

At the Inner Fiord site, both Cymbastela tricalyciformis and Tethya sp. had significantly different isotope values between $10 \mathrm{~m}$ and $30 \mathrm{~m}(\mathrm{p}=0.03$ and $\mathrm{p}=0.05$ respectively) (Figure 5.3). There was a $>95 \%$ probability that the isotopic niche of $C$. tricalyciformis was larger at $10 \mathrm{~m}$ and a $>85 \%$ probability that the isotopic niche of Raspailia topsenti was larger at $10 \mathrm{~m}$. For both Tethya sp. and Axinella richardsoni isotope niche size was similar between depths (Appendix E, Table 14).

At the Outer Fiord site, there were no differences in isotopic niche placement between depths (all pairwise comparisons $\mathrm{p}<0.05$ ). There was a $>85 \%$ probability that the isotopic niche of $A$. richardsoni was larger at $30 \mathrm{~m}$, but for all other species, isotope niche size was similar between depths (Appendix E, Table 14).

When samples were pooled between depths, A. richardsoni was the only species that demonstrated a statistical difference in isotopic niche size between the two sites, having a statistically larger isotopic niche at the Outer Fiord (>99\% probability) (Figure 5.4). Both C. tricalyciformis and R. topsenti had a $\geq 85 \%$ probability of having a larger isotopic niche at the Outer Fiord site (Appendix E, Table 15). 


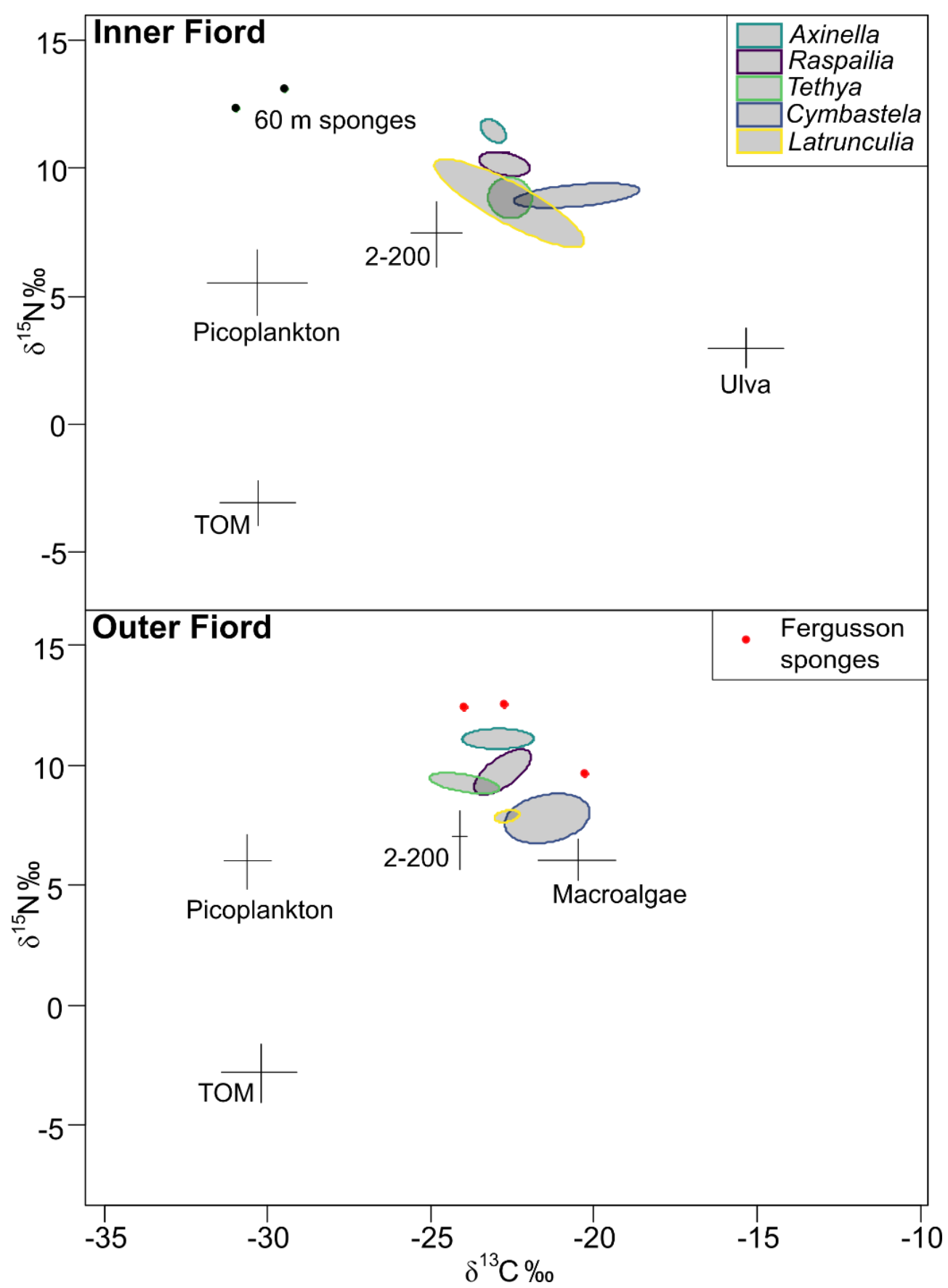

Figure 5. 4 Isotope biplots of carbon sources (mean \pm SD) and isotopic niches (standard ellipse area SEAc) of sponge species (samples pooled between depths) collected from Doubtful Sound in Fiordland at the Inner Fiord and Outer Fiord. NB: Fergusson sponges (three individual unknown species collected from $55 \mathrm{~m}$ at Fergusson Island) and $60 \mathrm{~m}$ sponges (Inner Fiord) were collected by ROV. 
Isotope values were significantly different between carbon sources $\left(\mathrm{pseudo}_{5,68}=226.06, \mathrm{p}=0.0001\right)$ and pairwise tests showed that all sources were significantly different to one another (Figure 5.4) (Appendix E, Table 17). The source with the lowest $\delta^{15} \mathrm{~N}$ values was TOM $\left(\delta^{15} \mathrm{~N},-2.77 \%\right.$. $\pm 1.12 \%$ $[$ mean $\pm \mathrm{SD}])$. Both picoplankton and TOM had similarly low $\delta^{13} \mathrm{C}$ values $(-30.14 \% \mathrm{~m} \pm 1.12 \%$ and $29.71 \% \pm 1.13$, respectively [mean $\pm \mathrm{SD}$ ]), however, picoplankton had a higher average $\delta^{15} \mathrm{~N}$ values $(5.48 \% \pm 1.19 \%$ [mean \pm SD] $)$. Picoplankton and the 2-200 $\mu \mathrm{m}$ fraction had distinct carbon and nitrogen ratios, and the 2-200 fraction had significantly higher $\delta^{15} \mathrm{~N}$ and $\delta^{13} \mathrm{C}$ values than picoplankton. Ulva sp. had lower $\delta^{15} \mathrm{~N}$ and higher $\delta^{13} \mathrm{C}$ values than Codium sp. or Ecklonia radiata. Both Codium sp. and E. radiata had similar $\delta^{13} \mathrm{C}$ values and were only separated by $\delta^{15} \mathrm{~N}$, with E. radiata having marginally higher $\delta^{15} \mathrm{~N}$ values than Codium sp. $\left(\delta^{15} \mathrm{~N}, 6.62 \%{ }_{0} \pm 0.99 \%\right.$ and $5.45 \%$ o $\pm 0.37 \%$ respectively [mean $\pm \mathrm{SD}]$ ). Due to having similar carbon and nitrogen isotopic values, E. radiata and Codium sp. were pooled for subsequent mixing model analysis representing the macroalgal-OM signature at the Outer Fiord site.

Aside from the two deep-water sponges retrieved from $60 \mathrm{~m}$ at the Inner Fiord (Figure 5.4), sponges showed limited use of picoplankton (mean $>15 \%$ ) or TOM (mean $>5 \%$ ) (Figure 5.5). The mixing model for the Inner Fiord estimated that the 2-200 $\mu \mathrm{m}$ size fraction of the water column was an important OM source for Raspailia topsenti $(70 \% \pm 9 \%$ [mean $\pm \mathrm{SD}])$, Axinella richardsoni $(63 \% \pm 20 \%$ [mean \pm $\mathrm{SD}])$ and Tethya sp. $(50 \% \pm 10 \%$ [mean $\pm \mathrm{SD}])$. Macroalgal- derived organic matter was most important to Cymbastela tricalyciformis $(38 \% \pm 10 \%$ [mean \pm SD] $)$ (Appendix E, Table 19). At the Outer Fiord, macroalgal- derived OM was an important carbon source for both C. tricalyciformis ( $74 \% \pm 8 \%$ [mean $\pm \mathrm{SD}])$ and Latrunculia fiordensis $(59 \% \pm 7 \%$ [mean $\pm \mathrm{SD}])$. R. topsenti also relies on macroalgalderived $\mathrm{OM}$ for an estimated $(48 \% \pm 16 \%$ [mean $\pm \mathrm{SD}])$ and less on the 2-200 $\mu \mathrm{m}$ size fraction of the water column at this site $(36 \% \pm 20 \%$ [mean \pm SD] $)$. Tethya sp. relies on macroalgal OM $(39 \% \pm 17 \%$ [mean $\pm \mathrm{SD}])$ and the $2-200$ fraction $(37 \% \pm 12 \%$ [mean $\pm \mathrm{SD}])$ in roughly equal proportions. Only $A$. richardsoni shows little change in resource use between the two sites with the 2-200 $\mu \mathrm{m}$ size fraction estimated to contribute $(62 \% \pm 19 \%$ [mean \pm SD]) (Appendix E, Table 20). 

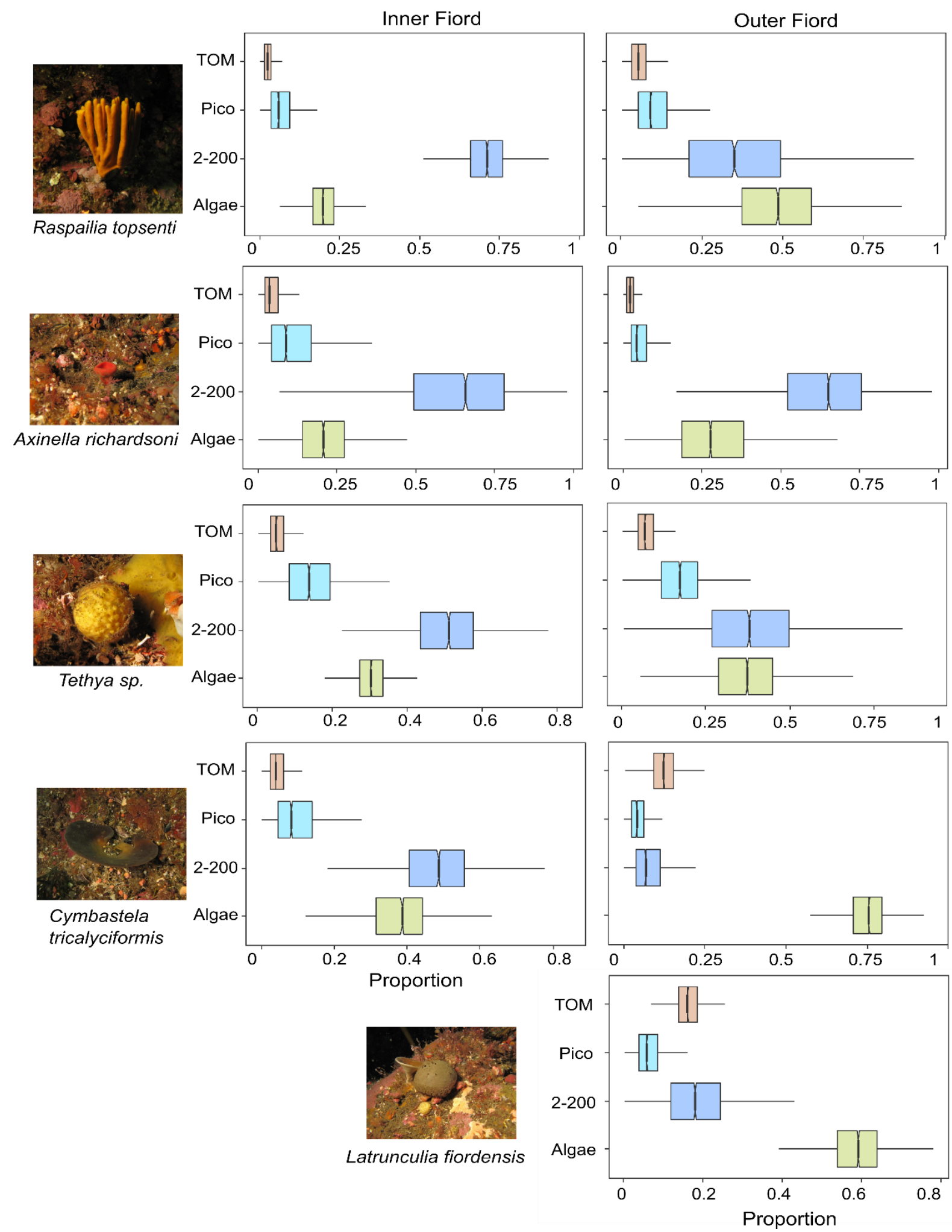

Figure 5. 5 Isotope mixing model posterior estimates of the proportional contribution of each carbon source to the diet of five sponge species at two different sites in Doubtful Sound, Fiordland. Boxes represent the credible interval of $50 \%$ and error bars the credible interval of $95 \%$. 


\subsection{Discussion}

Differential resource use is fundamental for maintaining biodiverse communities (Schoener, 1986). In this chapter, I have shown that resource partitioning is high among temperate, co-occurring sponges, suggesting that differential resource use facilitates co-existence and also limits distribution. Despite the dominance of TOM in the OM pool, the only evidence of its assimilation was from two sponges collected at $60 \mathrm{~m}$ at the inner site, whereas the $10 \mathrm{~m}$ and $30 \mathrm{~m}$ sponges relied mainly on marine production. Isotope mixing models did not identify picoplankton as a significant carbon source for sponges, which could not be easily explained, but may relate to the degradation of dissolved TOM (dTOM) by heterotrophic bacteria. Marine OM supports the majority of sponges in Fiordland but there is evidence that terrestrial production may support some sponges where marine OM is limited.

\subsubsection{Spatial and interspecific variation in isotope ratios}

Fiordland sponges displayed a wide range of $\delta^{15} \mathrm{~N}$ values, from $6.57 \%$ (Cymbastela tricalyciformis) to 13.13\% (unidentified sp., Inner Fiord). Assuming trophic enrichment to be $\sim 3.4 \%$ (Post, 2002), these values span two trophic levels. This is consistent with other studies that have measured sponge nitrogen isotope values, some of which have found $\delta^{15} \mathrm{~N}$ values to span up to three trophic levels (Bergmann et al. 2009). This could indicate specialisation on particular size fractions of suspended particulate organic matter (SPOM) (Thurber, 2007; Mintenbeck et al. 2007) or the possible influence of nitrogen cycling within the sponge holobiont (Southwell et al. 2008), although no information has been published regarding the microbial communities of the species sampled in this study. Sponge $\delta^{15} \mathrm{~N}$ values presented in this chapter are higher than the values presented for tropical sponges in Chapter 4 . This is consistent with other studies that have found temperate sponges have higher $\delta^{15} \mathrm{~N}$ values than tropical sponges (Freeman et al. 2016). This may indicate reduced reliance on symbiont-derived nutrients (Freeman \& Thacker, 2011; Freeman et al. 2016) as HMA sponges tend to exhibit lower $\delta^{15} \mathrm{~N}$ values than LMA sponges (Freeman et al. 2016). It could also relate to water temperature as lower temperatures are associated with higher fractionation (Sackett et al. 1965).

Increasing sponge $\delta^{15} \mathrm{~N}$ values with depth has also been observed in the Arctic (Bergmann et al. 2009), the Antarctic (Mintenbeck et al. 2007) and the sub-Antarctic Indian Ocean (Puccinelli et al. 2018). However, in these studies, the depth range spanned hundreds of metres whereas, in this study, sponges were ${ }^{15} \mathrm{~N}$-enriched from $10 \mathrm{~m}$ to $30 \mathrm{~m}$ depth. An increase in sponge $\delta^{15} \mathrm{~N}$ values as a function of depth has been linked to isotopic changes in SPOM that take place as particles sink through the water column (Altabet, 1987; Mintenbeck et al. 2007). Microbial degradation of SPOM leads to ${ }^{15} \mathrm{~N}$ enrichment as the lighter isotope $\left({ }^{14} \mathrm{~N}\right)$ is lost (Fry, 2006; Mintenbeck et al. 2007). Small particles filtered by sponges sink at a low velocity with likely greater exposure to microbial activity, leading to higher $\delta^{15} \mathrm{~N}$ values (Mintenbeck et al. 2007; Parzanini et al. 2019). Thus, higher $\delta^{15} \mathrm{~N}$ sponge values at depth are thought to reflect the process of SPOM ${ }^{15} \mathrm{~N}$ enrichment (Mintenbeck et al. 2007). That being the case, we would 
expect to see a corresponding increase in SPOM water column $\delta^{15} \mathrm{~N}$ values at $30 \mathrm{~m}$, but the opposite was observed at the Outer Fiord site where the 2-200 $\mu \mathrm{m}$ size fraction had a lower $\delta^{15} \mathrm{~N}$ value at $30 \mathrm{~m}$. An increase in SPOM $\delta^{15} \mathrm{~N}$ values alongside sponge $\delta^{15} \mathrm{~N}$ values, as a function of increasing depth, has been observed in some (Puccinelli et al. 2018), but not all studies (Bergmann et al. 2009; Sitnikova et al. 2016). Another possible explanation is that $30 \mathrm{~m}$ sponges are feeding on a higher proportion of resuspended benthic particulate matter, which due to microbial reworking, is expected to be more enriched in ${ }^{15} \mathrm{~N}$ than SPOM (Mintenbeck et al. 2007; Bergmann et al. 2009). However, calm conditions in deeper waters of the inner fiords suggest that benthic resuspension through water movement is unlikely. Additionally, a high concentration of dTOM in surface waters limits light availability at $30 \mathrm{~m}$, which changes redox conditions, thus affecting processes of nitrification and denitrification (Solomon et al. 2015). Both processes have been shown to take place within the sponge holobiont (Southwell et al. 2008; Hoffmann et al. 2009; Fiore et al. 2013) and can be expected to influence sponge $\delta^{15} \mathrm{~N}$ values (Southwell et al. 2008).

\subsubsection{Isotopic niches of sponge species}

Minimal overlap in isotopic niches (all observed $<20 \%$ total SEA ) indicates that biogeochemical cycling of carbon and nitrogen is highly variable between species (Freeman et al. 2016; Freeman et al. 2020). Species identity has been shown to contribute substantially to the variance in isotopic values in studies on tropical (Freeman et al. 2014; Freeman et al. 2020) and temperate reef systems (Freeman et al. 2016), with species often separated in isotope space (Thurber, 2007; Freeman et al. 2016; Freeman et al. 2020). This indicates a high degree of metabolic diversity that could be caused by selective feeding or species-specific metabolic processes occurring within the sponge holobiont that affect carbon and nitrogen cycling (Freeman et al. 2016). The most significant overlaps were found between Latrunculia fiordensis and Tethya sp. and Cymbastela tricalyciformis at the Inner Fiord, indicating similar resource use patterns. However, the sample size for L. fiordensis was very small due to low abundance $(\mathrm{n}=3)$ and there was substantial variation in stable isotope ratios between these three samples. Aside from these overlaps, there was only one small overlap between $C$. tricalyciformis and Tethya sp. hence resource partitioning was high between sponge species at the Inner Fiord site despite depleted resources. In contrast to Inner Fiord, the niche of L. fiordensis was much smaller at the Outer Fiord, indicating a narrow range of consumed particles; it also overlapped with $C$. tricalyciformis. Low abundances observed for both of these species at the Inner Fiord site suggests that their distribution may be limited by food availability.

The only species to show any significant differences in niche placement between depths were $C$. tricalyciformis and Tethya sp. at the Inner Fiord. C. tricalyciformis had higher $\delta^{13} \mathrm{C}$ values at $30 \mathrm{~m}$ suggesting it may use different resources at this depth, although the sample size for this species was also small $(n=3)$ due to low abundances. Pooling samples between depths indicated that three out of 
four species where comparisons could be made (sample sizes $\geq 5$ ) had larger niches at the Outer Fiord site indicating more diverse resource use, likely reflecting increased marine productivity towards the mouth of the fiords (Wing et al. 2014).

\subsubsection{Organic matter use by Fiordland sponges}

The carbon sources (picoplankton, the $2-200 \mu \mathrm{m}$ size fraction, TOM and macroalgae) sampled in this study had distinct isotope values, which increases the discriminatory power of mixing models (Phillips et al. 2014). Values obtained for macroalgae and TOM were similar to values reported from Fiordland by other studies (McLeod et al. 2007; McLeod et al. 2009; Wing et al. 2012). Only one study has sampled size-fractionated SPOM in Fiordland during a phytoplankton bloom (Wing et al. 2012). However, Wing et al. (2012) only reported isotopic values from the 20-200 $\mu \mathrm{m}$ size fraction (-21.6 \pm $0.2 \delta^{13} \mathrm{C}$ [mean $\left.\pm \mathrm{SE}\right]$ ) and filter papers were not acidified, so meaningful comparisons between the values of the two studies cannot be made. The only other study that used size-fractionated SPOM to investigate sponge diets was conducted on a tropical reef (van Duyl et al. 2011). Van Duyl et al. (2011) reported no significant differences in mean $\delta^{13} \mathrm{C}$ values between the three size fractions analysed, which contrasts with this study, as picoplankton were $\sim 6 \%$ more depleted than the 2-200 $\mu \mathrm{m}$ size fraction. Additionally, Fiordland picoplankton was extremely ${ }^{13} \mathrm{C}$ depleted (mean $-30.14 \%$ ) relative to $\delta^{13} \mathrm{C}$ values (mean approximately -23\%) reported by van Duyl et al. (2011) for a similar particle size range $(0.7-1.2 \mu \mathrm{m})$.

One possible explanation for the ${ }^{13} \mathrm{C}$-depleted picoplankton values is that it represents heterotrophic bacteria degrading dTOM. The isotopic value of the bulk DOM pool will reflect the relative input of sources (Guillemette et al. 2016). Therefore, in the fiords, DOM $\delta^{13} \mathrm{C}$ values likely reflect TOM $\delta^{13} \mathrm{C}$ values which makes up a significant proportion of the OM pool, particularly in the inner fiord (McLeod \& Wing, 2009). TOM is dominated by high molecular weight (HMW) compounds that are generally assumed to be resistant to microbial degradation due to their molecular structure and high C: $\mathrm{N}$ content (McKnight et al. 1998). However, several recent studies have challenged this assumption (Ward et al. 2013; Fasching et al. 2014; Fitch et al 2018) showing that bacteria produce extracellular enzymes that hydrolyse or oxidise the complex structures present in dTOM into more labile carbon (Fitch et al. 2018). This can either be quickly respired and lost from the system as $\mathrm{CO}_{2}$ or assimilated into bacterial biomass (Kirchman, 2013). Additionally, in sufficient light conditions, dTOM can also be degraded by photooxidation, which also leads to the production of more labile DOC (Kirchman, 2013; Fitch et al. 2018). The picoplankton $\delta^{13} \mathrm{C}$ values presented here suggests that dTOM is incorporated into bacterial biomass (Guillemette et al. 2016) assuming that carbon fractionation from bulk TOM to dTOM and from dTOM to bacteria is minimal (Guillemette et al. 2016).

If, as suggested, the picoplankton signature represents the biomass of heterotrophic bacteria degrading dTOM, then it would be expected that $\delta^{13} \mathrm{C}$ values would be transferred up the food chain via the 
microbial loop (Azam et al. 1983) and via sponges that preferentially consume picoplankton (Reiswig, 1971; Pile at al. 1996). However, the isotope mixing model outputs presented in this chapter suggested that sponges sampled at $10 \mathrm{~m}$ and $30 \mathrm{~m}$ did not consume a substantial amount of picoplankton. This is in contrast to the majority of sponge feeding studies which indicate that sponges are most efficient at retaining picoplankton (Pile et al. 1999; Maldonado et al. 2012). This could be explained if the isotopic fractionation of carbon from picoplankton to sponge is greater than the value of $0.39 \pm 1.3 \%$ applied in the mixing models. There is little information about the fractionation of carbon and nitrogen from different dietary sources for sponges (Freeman et al. 2011) and in some circumstances, carbon fractionation can be much higher than conventional literature estimates (Busst \& Britton, 2016). However, similar enrichment factors have been used by other researchers to investigate sponge feeding using isotopic mixing models e.g. $1 \pm 1 \%$ (van Duyl et al. 2011; Freeman et al. 2011), $0.5 \pm 0.5 \%$ (van Duyl et al. 2018) and one of these studies also found that phytoplankton and bacterioplankton are not the main food source for some sponges (van Duyl et al. 2011). Considering that two sponges sampled at $60 \mathrm{~m}$ at the Inner Fiord had similar $\delta^{13} \mathrm{C}$ values to picoplankton and TOM, the enrichment factors applied were likely adequate, but the $10 \mathrm{~m}$ and $30 \mathrm{~m}$ sponges did not metabolise dTOM-degrading bacteria. Picoplankton may be dominated by dTOM-degrading bacteria, but it is likely made up of other particles which are less abundant but may be utilised preferentially by sponges. Size-fractionated SPOM will contain multiple types of organisms, all with distinct metabolic pathways, so the values presented here will represent the dominant organism (Hansman \& Sessions, 2016). It is possible that sponges are consuming specific picoplankton particles, but that the signature of these particles is swamped by the dominant organism.

Mixing model results suggest that $C$. tricalyciformis and L. fiordensis rely on macroalgal-derived OM for $<50 \%$ of their nutritional requirements. Macroalgal OM could be ingested by sponges as dissolved compounds (Rix et al. 2017) or as particulate detrital material (McMurray et al. 2016), which would likely exhibit similar $\delta^{13} \mathrm{C}$ values but higher $\delta^{15} \mathrm{~N}$ values relative to bulk tissue as a result of microbial reworking. The ability of sponges to assimilate algal DOM has been demonstrated by isotopic tracer experiments (Rix et al. 2017) and through fatty acid analysis (de Goeij et al. 2008; van Duyl et al. 2012) and other studies have used isotopic values of macroalgal tissue to infer the assimilation of algal products (van Duyl et al. 2011; van Duyl et al. 2018). For example, stable isotope analysis of organic matter sources indicated that reef-derived DOM from coral mucus and coralline algae contributed significantly to the diet of cavity sponges in the Caribbean (Van Duyl et al. 2011). Similarly, isotopic values of sponges on the Saba Bank indicated that they rely on both benthic- and pelagic-derived OM (van Duyl et al. 2018). These studies assume that DOC closely reflects the isotopic value of its source material (Fry et al. 1998; Benner et al. 1997), although this has been shown to vary by $\pm 2 \%$ for some sources (Hullar et al. 1996). Methods employed in this chapter account for spatial variability in organic 
matter source values and incorporate error associated with isotope fractionation, therefore, can be considered robust estimates of source contributions and associated uncertainty (Parnell et al. 2010).

The only evidence of TOM assimilation by Fiordland sponges was from two sponges sampled at $60 \mathrm{~m}$ the Inner Fiord site. These sponges had extremely low $\delta^{13} \mathrm{C}$ values (-29\%o to $-30 \%$ ) that were comparable to picoplankton and TOM. This suggests either they consume picoplankton directly, or that they host a microbial community containing chemoautotrophic bacteria and indirectly access products of TOM degradation. Similar $\delta^{13} \mathrm{C}$ values have been observed for chemoautotrophic bacterial mats (Levin et al. 2002) and the chemoautotrophic bivalve Solemya parkinsonii found in the fiords (McLeod et al. 2007). Chemoautotrophic bacteria fix carbon fuelled by energy derived from sulphate oxidation, a metabolic pathway (form I Rubisco) discriminates against ${ }^{13} \mathrm{CO}_{2}$ producing $\delta^{13} \mathrm{C}$ values ranging from $-27 \%$ to $-37 \%$ (Levin et al. 2002). Typically, high microbial abundance sponges, and other invertebrates with chemoautotrophic endosymbionts, have low $\delta^{15} \mathrm{~N}$ values (Freeman et al. 2014; van Duyl et al. 2018; McLeod et al. 2007). However, in deep, freshwater environments, ${ }^{13} \mathrm{C}$ depleted sponges that receive carbon from methanotrophic and/or chemoautotrophic bacteria have been found both with extremely ${ }^{15} \mathrm{~N}$-depleted and ${ }^{15} \mathrm{~N}$-enriched tissues (Sitnikova et al. 2016), likely resulting from different microbial metabolic pathways (Southwell et al. 2008; van Duyl et al. 2018). Therefore, enriched ${ }^{15} \mathrm{~N}$ values could be the result of sponge-hosted nitrification, which has been shown to occur with an isotopic fractionation factor of $11 \%$ (Southwell et al. 2008) or denitrification which leads to higher $\delta^{15} \mathrm{~N}$ values (Parzanini et al. 2019). Only the deep sponges sampled at the inner site had extremely low $\delta^{13} \mathrm{C}$ values, the sponges collected from $55 \mathrm{~m}$ at Fergusson Island had similar $\delta^{13} \mathrm{C}$ values to the 10 and $30 \mathrm{~m}$ sponges. This is likely due to differences in hydrodynamic conditions between the two sites. Fergusson Island is in the middle of the main channel where wind and waves induce the vertical mixing of stratified water leading to greater nutrient transport across depths (Wing \& Jack, 2014). At the inner site, however, waters are highly stratified with a shallow photic zone leading to nutrient limitation at depth. Nutrient limited conditions often cause invertebrates to form associations with microbial symbionts to access the products of autotrophic metabolism (Freeman et al. 2014). These associations allow sponges to inhabit seemingly inhospitable environments and expand across ecological niches in marine ecosystems (Freeman et al. 2020).

\subsubsection{Study limitations}

This survey was conducted over a week-long expedition in February; hence it was limited to a two site comparison and temporal variation in isotope values was not considered. Nitrogen and carbon isotope values of sponges are estimated to represent the last 1-2 months dietary assimilation (Freeman \& Thacker, 2011; Simister et al. 2013; van Duyl et al. 2018) and phytoplankton blooms are known to occur in the fiords (Wing et al. 2012), which can increase $\delta^{13} \mathrm{C}$ values (Miller et al. 2012) and affect mixing model estimates. However, assuming that the time frame for dietary assimilation is 
approximately equivalent between sponge species, the difference between the lowest and highest carbon values of individual sponges collected from 10 and $30 \mathrm{~m}$ was approximately $6 \%$ which supports differential resource use, even in the event of a phytoplankton bloom. Similarly, spatial variation in the $\delta^{15} \mathrm{~N}$ and $\delta^{13} \mathrm{C}$ values of SPOM has previously been cited as low in this system (Wing \& Jack, 2012).

\subsubsection{Conclusion}

Understanding the diversity of resources utilised by marine sponges is essential to predict the impact of shifts in organic matter subsidies and resource availability. This study has demonstrated that marine sponges have diverse trophic strategies that facilitate coexistence under different gradients of organic matter composition and availability. For the $10 \mathrm{~m}$ to $30 \mathrm{~m}$ sponges, this was mainly driven by differential use of the 2-200 fraction of the water column and macroalgal-derived OM, with little evidence of TOM assimilation. However, in the highly stratified, nutrient-limited waters at the Inner Fiord site, TOM was utilised by $60 \mathrm{~m}$ sponges though microbially-mediated pathways. 


\section{Chapter 6. General Discussion}

\subsection{Summary of key findings}

The primary aim of my thesis was to investigate sponge trophic interactions to gain insight into how sponge-reefs of the future might function. In summary, my main findings were: i) Far from being negligible, sponge biomass consumption on Wakatobi reefs was comparable to coral consumption in the Pacific, and the species with the greatest predatory impact was the angelfish Pygoplites diacanthus; ii) Pygoplites diacanthus had a wide diet within the Porifera phylum, similar to angelfishes in the Caribbean and the Pacific, and consumed sponges with substantial chemical defences; iii) fish sampled at a sponge-dominated reef had lower mean trophic positions and the majority of species had wider isotopic niches than fish from an adjacent, higher quality reef. They also used a significantly lower range of carbon sources, had lower trophic diversity and obtained more carbon from benthic production; and iv) niche partitioning amongst co-occurring sponges on temperate reefs was high, facilitated by differential use of the 2-200 $\mu \mathrm{m}$ fraction of the water column and macroalgal- derived organic matter. Here, I discuss my findings with respect to current thinking on marine ecosystems in the Anthropocene.

\subsection{Trophic consequences of sponge dominance}

The Sampela reef system provides an analogue for what may occur on some shallow coral reefs in the future that shift towards sponge dominance due to a decline in corals relative to sponges, as opposed to an increase in sponges relative to corals (Bell et al. 2018b). The distinction between these two types of sponge-dominant reef states is relevant because qualitative modelling suggests that they will lead to different outcomes of different ecosystem components (e.g. macroalgae, grazers, phytoplankton etc) (Bell et al. 2018b). Although there is evidence that some sponges, particularly Lamellodysedia herbacea, may be increasing in abundance at Sampela (Biggerstaff, 2016), benthic quadrat data presented in this thesis suggested that sponge abundance was similar at Sampela, B1 and The Ridge, but assemblage composition differed between sites (Chapter 2). For spongivores, changing sponge dominance as a result of declining corals generally yielded ambiguous responses in qualitative modelling scenarios, whereas changing sponge dominance as a result of increasing sponge abundance led to some positive outcomes (Bell et al. 2018b). Observations from the Sampela reef system may shed some light on the ambiguous responses predicted for spongivores in situations where sponge-dominated reef states are caused by declining corals relative to sponges.

It has been suggested that increasing sponge-dominance may support a greater abundance of spongivorous fishes (Bell et al. 2013). Previous studies have suggested that there is a higher density of spongivorous fishes on the sponge-dominated site relative to surrounding reefs (Powell, 2013; Powell et al. 2014). This contrasts with observations from this thesis which showed that sponge consumption was lowest on the sponge-dominated site, due to low densities of spongivorous fishes (Chapter 2). The contrasting outcomes of Powell et al. (2014) and this thesis can be explained by differences in the 
species categorised as spongivores. Here, sponge-grazing fishes were determined to be either obligate or facultative spongivores through the quantification of sponge in gut contents. Whereas in the 2014 study, Powell et al. included several species I have found to have no quantifiable predatory impact on sponge assemblages. Additionally, Powell et al. (2014) included detritivorous surgeonfishes (genus Ctenochaetus) and epilithic algal grazers (genus Acanthurus) that may be numerous at Sampela because it is degraded relative to surrounding reefs, with a high percentage of rock covered with algal turfs and sediment (Tebbett et al. 2017; Chapter 2). Low densities of spongivores on the sponge-dominated reef could be explained by sponge assemblage composition. At Sampela, the sponge assemblage is dominated by Lamellodysedia herbacea (Powell et al. 2014; Biggerstaff et al. 2015; Chapter 2), which accounts for approximately $40 \%$ of total sponge abundance but does not appear to be preferred or readily consumed by spongivores (Chapter 2). As previously discussed in Chapter 2, using percentage cover to assess sponge abundance does not adequately capture large, emergent species, and Sampela also has a large population of barrel sponges (McGrath, 2018), the biomass of which likely exceeds $L$. dysedia. Nevertheless, Powell et al. (2014) used counts of sponge patches to assess sponge abundance and also reported that $L$. dysedia dominated the sponge assemblage at Sampela. In Chapter 3, DNA analysis did not identify L. herbacea in the gut contents of spongivorous angelfishes (Chapter 3). Similarly, the grazing rate on L. herbacea was low in comparison to Xestospongia spp. and Petrosia corticata (Chapter 2; Appendix A). The only spongivorous fish filmed taking bites from of L. dysedia was Zanclus cornutus, although tissue removal could not be verified by video analysis. In Chapter 4 , stable isotope analysis of Z. cornutus and Pygoplites diacanthus muscle tissue did not support L. dysedia as a substantial food source for spongivores as it was $\sim 7 \%{ }^{13} \mathrm{C}$ depleted relative to muscle tissue (Chapter 4). The majority of reefs that have transitioned to sponge dominance following widespread coral mortality usually involve the increases of one or two competitive species (Williams, et al., 1999; Aronson, et al., 2002; Powell et al. 2014). Perhaps the ambiguous response of spongivores in qualitative modelling scenarios reflects continuing uncertainties regarding future sponge assemblage composition and the diet preferences of spongivores.

The success of spongivores on future sponge-dominated reef states may depend on the capacity for spongivores to adapt their diet preferences. Some obligate spongivores that consume a narrow range of sponge species e.g. Hawksbill turtles (Meylan, 1988; Pawlik et al. 2018) may be less resilient to changes to sponge assemblage composition than angelfishes that consume a wide range of species within the Porifera phylum (Chapter 3; Randall \& Hartman, 1968; Hourigan et al. 1989; Verdín Padilla et al. 2010). Results from Chapter 4 indicated that Pygoplites diacanthus had a wider isotopic niche at the sponge-dominated site in contrast to the adjacent, higher-quality reef site suggesting some degree of dietary plasticity. However, niche width expansion due to a reduction in preferred prey is also expected to lead to greater interspecific competition with other spongivores (e.g. Zanclus cornutus) and generalists and could be another reason why some spongivores may not necessarily benefit from future 
sponge-dominated reef states. Interestingly, although diet similarity was higher in the fish assemblage on the sponge-dominated reef, there was no evidence that $P$. diacanthus and $Z$. cornutus were using more of the same resources, which would have been shown by a greater overlap in isotopic niches. This contrasts with other studies that have also reported trophic niche width increases of consumers in response to decreasing resources. For example, interspecific competition strength increased in macroinvertebrate assemblages in low coverage seagrass meadows where trophic niche widths also increased (Calizza et al. 2017). The difference between the findings of Calizza et al. (2017) and this study could relate to consumer vagility which adds greater spatial complexity to trophic interactions (Duffy et al. 2007). Layman et al. (2007) found that the niche width of the grey snapper Lutjanus griseus decreased in response to increasing tidal creek fragmentation and subsequent reductions in potential prey taxa. Different niche width responses to a decrease in available prey between my study and Layman et al. (2007) likely relate to the foraging constraints caused by a disruption to hydrological connectivity in fragmented tidal creeks (Layman et al. 2007).

Although I have presented evidence in this thesis that sponge consumption is similar in magnitude to coral consumption as an energy pathway on Indo-Pacific reefs, it appears to support few species directly and is likely a relatively minor pathway supporting secondary production. The results of the comparative study in Chapter 4 highlight the importance of a wide range of organic matter pathways in the maintenance of resource specialisation and trophic diversity. The importance of producer diversity has been demonstrated in terrestrial plants, where long-term experiments have shown that loss of plant diversity propagates through food webs, decreasing arthropod species richness and shifting trophic structure towards herbivore dominance (Haddad et al. 2009). In benthic marine communities, higher producer diversity increased the stability of a diverse, productive consumer community, whereas producer biomass did not affect stability or diversity (Ramus \& Long, 2016). Additionally, on coral reefs, biodiversity hotpots with larger background species pools (i.e. greater resource specialisation) were found to be more sensitive to a loss of coral diversity than reefs with lower species pools (Holbrook et al. 2015). Increased diversity within guilds of primary producers enhances the temporal stability of organic matter subsidies to consumers (Tilman \& Downing, 1994). Hence, sponge-dominated reef such as Sampela that have fewer organic matter pathways supporting secondary production will ultimately be less stable and less productive than coral dominated reefs.

\subsection{Indirect trophic pathways}

Aside from the 'true spongivores' that remove sponge tissue e.g. Pygoplites diacanthus, Zanclus cornutus, there was extensive sponge-grazing observed by detritivores (e.g. Ctenochaetus binotatus and Acanthurus spp.) raising questions about the nature of this interaction. Gut content analysis confirmed that the diet of $C$. binotatus is dominated by reef sediments and detritus (Chapter 2; Tebbett et al. 2017). Nevertheless, the extent of grazing activity on Xestospongia spp. across a range of sites suggests that 
this feeding behaviour may confer some nutritional benefit to detritivores. There are two possible explanations for sponge-grazing by detritivores: (1) the sponge loop and (2) mucus production (de Goeij et al. 2013; McGrath et al. 2017).

\subsubsection{The sponge loop}

In the 'sponge loop', dissolved organic carbon is taken up by sponges (Yahel et al. 2003; de Goeij et al. 2013) from diverse sources including benthic primary producers (e.g. algae and corals) (Rix et al. 2016; Rix et al. 2017), metabolised, and eventually released as particulate detritus, which is subsequently ingested by detritivorous invertebrates (de Goeij et al. 2013; Rix et al. 2018). To date, there is no evidence that sponge detritus is consumed directly detritivorous fishes, but the shedding of sponge cells as detritus could be a possible explanation for the sponge-grazing behaviour of $C$. binotatus. Yet, the ubiquity of the sponge loop has not been proven beyond observations of cryptic, encrusting sponges (McMurray et al. 2018; Bell et al. 2018b). For example, McMurray et al. (2018) found no evidence of detritus production in 8 emergent abundant Caribbean sponge species, including the Caribbean barrel sponge Xestospongia muta. Instead, some sponges (low microbial abundance sponges) were net consumers of detritus (McMurray et al. 2018). Similarly, Wooster et al. (2019) found no evidence that Xestospongia testudinaria in the Red Sea released DOC that had been metabolised back to the benthos in the form of detritus. Therefore, it seems unlikely that $C$. binotatus graze on Xestospongia spp. because they are consuming sponge detritus. The extent to which the sponge loop supports higher trophic levels across global reef ecosystems is currently unknown (Bell et al. 2018b). Given the potential relevance to the future functioning of sponge-dominated reefs, this should be considered a priority research area for sponge ecologists (Bell et al. 2018b).

\subsubsection{Mucus production}

In turbid habitats, sediments accumulate on the surface of marine sponges, the effects of which can be sub-lethal e.g. reduced pumping rates affecting respiration or feeding (Tjensvoll et al. 2013), or lethal e.g. smothering (Wulff, 1997). In response to sedimentation, some sponges have been documented to produce mucus as a sediment-clearing mechanism (Bannister et al. 2012; Biggerstaff, 2017; McGrath et al. 2017). This response appears to be relatively widespread, for example, both McGrath et al. (2017) and Biggerstaff (2017) observed mucus production in every sponge following experimentally manipulated sediment additions to both Xestospongia testudinaria and Lamellodysedia herbacea. Additionally, in a census of $X$. testudinaria at the sponge-dominated site of Sampela, 99\% of sponges were observed with mucus-bound sediment on their external surface (McGrath et al. 2017). Aside from sediment clearance, little is known about the ecological role of sponge mucus on coral reefs (McGrath et al. 2017). Several fish species are known to consume coral mucus (Cole et al. 2008), which is energyrich (Benson \& Muscatine, 1974; Wild et al. 2004) and also released by corals as a sediment clearance mechanism, increasing the organic content of suspended particles (Wild et al. 2004). Hence, detritivores 
such as $C$. binotatus may be attracted to grazing on sediment-bound mucus on sponge surfaces because it is nutritionally beneficial. To my knowledge, only one study appears to have considered the trophic role of sponge mucus (Hammond \& Wilkinson, 1985). The sea cucumber Synaptula lamperti ingested organic exudates (mucus) released by the sponge Ianthella basta (Hammond \& Wilkinson, 1985). Given the extensive mucus production noted for some sponges (McGrath et al. 2017), sponge mucus may play an important role in organic matter cycling in the surrounding environment.

\subsection{Sponge trophic roles}

Recently, Lesser \& Slattery (2020) suggested that sponges on shallow coral reefs may encounter food limitation on future coral reefs due to increased water stratification caused by increasing sea surface temperature (SST) and decreasing salinity. Stabilized surface waters would prevent vertical mixing hence limiting the transport of deep-water nutrients and decreasing net primary productivity (NPP) with ramifications for filter-feeding organisms such as sponges (Lesser \& Slattery, 2020). Ultimately this would lead to a decline in sponge abundance, countering the hypothesis that sponges could be climate change 'winners' on future coral reefs (Bell et al. 2013; Lesser \& Slattery, 2020). Under the conditions outlined by Lesser \& Slattery (2020), photoautotrophic species may reasonably be expected to dominate future sponge assemblages on coral reefs as they are less reliant on heterotrophy and receive carbon (and to some extent nitrogen) from symbionts (Erwin \& Thacker, 2008; Freeman et al. 2011; Fiore et al. 2013). Additionally, photoautotrophic sponges appear to have increased tolerance to thermal stress (Bennett et al. 2017) indicating a potential advantage over heterotrophic sponges.

In Chapter 5, the conditions in the inner fiords in Doubtful Sound were similar to those described by Lesser \& Slattery (2020), as large freshwater inputs and low wave exposure lead to highly stratified surface waters (Wing \& Jack, 2014). However, I found no evidence of photoautotrophic species in the 10 and $30 \mathrm{~m}$ sponges collected from the inner fiords, likely due to low light penetration caused by topographic shading and a high concentration of dissolved tannins in the water column (Wing \& Jack, 2014). Instead, evidence of autotrophic metabolic pathways via chemosynthesis was indicated by the stable isotope ratios of two $60 \mathrm{~m}$ sponges, although it cannot be ruled out that they were directly consuming dTOM-metabolising bacteria. Nevertheless, the differences in isotope ratios observed between the shallow sponges and the two $60 \mathrm{~m}$ sponges likely relate to nutrient limitation caused by isolation from oceanic productivity and a highly stratified water column. Interestingly, the 10 and $30 \mathrm{~m}$ sponges did not show the same ability to assimilate TOM through microbially-mediated pathways, particularly through the direct consumption of dTOM-degrading bacteria, which appeared to be highly abundant in the picoplankton fraction of the water column. Pawlik et al. (2016) suggested that sponges in the Caribbean may be able to make use of refractory DOC from terrestrial sources that are unavailable to microbes and that this may explain the presence of predominantly heterotrophic species on Caribbean reefs. Observations made in this thesis suggest that sponges are likely unable to process refractory DOC 
directly, probably due to a lack of necessary enzymes to metabolise complex structures present in TOM (Fitch et al 2018). Similarly, refractory DOC may not necessarily be unavailable to microbes, as the isotopic value of picoplankton presented in Chapter 5 strongly suggested that this fraction of the water column in the fiords was dominated by heterotrophic bacteria degrading terrestrial DOM. Lack of evidence supporting the consumption of dTOM-degrading bacteria by 10 and $30 \mathrm{~m}$ sponges could not be easily explained but may relate to the poor nutritional quality of the resource. TOM has extremely high C: $\mathrm{N}$ ratios (>15) (McLeod et al. 2007) and several studies have indicated that sponges are limited by the availability of nitrogen (Hadas et al. 2009; Lesser et al. 2019). Some studies have shown negative selectivity for low DNA bacteria with lower carbon and nutrient contents than high DNA (HDNA) bacteria (Hanson et al. 2009). Therefore, the shallow sponges may actively select against abundant dTOM-degrading bacteria, which could be a poor-quality food source due to high $\mathrm{C}$ : $\mathrm{N}$ ratios (Busst \& Britton, 2016).

Stable isotope values of heterotrophic sponges presented in Chapter 4 were similar to the values obtained for the detrital proxy Synaptula sp. indicating they have similar diets. These observations add to the growing body of knowledge that detritus (non-living particulate organic carbon) plays more of a role in the diets of some marine sponges than is currently appreciated. Measuring the uptake of detritus by sponges can be complicated by the release of sponge detritus (faecal pellets and shed cells) (Hadas et al. 2009) hence, few studies have quantified the consumption of detritus by marine sponges (Maldonado et al. 2012). Detritus constituted 1/3 of organic carbon ingested by the Red Sea sponge Negombala magnifica (Hadas et al. 2009), 20\% of the diet of the giant barrel sponge Xestospongia muta (McMurray et al. 2016) and $>34 \%$ of the diet of Xestospongia testudinaria in the Red Sea (Wooster et al. 2019). Xestospongia spp. have a wide distribution across Wakatobi reefs, but they are found in high densities at the sponge-dominated site of Sampela (Bell et al. 2014) which also appears to be a site fuelled by detrital production (Chapter 4). Perhaps one of the reasons that Xestospongia spp. appear to be successful in this otherwise low-quality, highly sedimented environment is that detritus is an important component in the diet of these species.

Stable isotope mixing models in Chapter 5 suggested that Fiordland sponges have diets that are dominated by the 2-200 $\mu \mathrm{m}$ fraction of the water column and macroalgal-derived organic matter. However, one of the limitations with this approach is that the macroalgal contributions cannot be distinguished between DOC released by algae or algal detritus. Yet, even direct techniques e.g. In-Ex methods cannot determine the source of DOC and/or detritus consumed by sponges, only isotopic tracer experiments can directly trace organic material from sources to sponges, and subsequent uptake by detritivores (de Goeij et al. 2013; Rix et al. 2017; Rix et al. 2018). 


\subsection{Different methods of diet characterisation}

In this thesis, I used three different methods of diet characterisation: (1) visual observations, (2) gut content analysis and (3) stable isotope analysis. Using all three methods was paramount to providing a more nuanced picture of the trophic ecologies of sponge-grazing fishes, particularly when one method provided a different outcome (Chapter 2). For example, in the case of Chaetodon kleinii, visual observations indicated this species was a spongivore, but gut content analysis revealed mainly mobile invertebrates and soft coral (Chapter 2). However, the proximity of the isotopic niche to the obligate spongivore (Chapter 4) supports the observations that the trophic ecology of this species is tightly linked to sponges, perhaps through the consumption of sponge-associated fauna. Nagelkerken et al. (2009) also applied these three methods to the diets of butterflyfishes in Indonesia (including C. kleinii). They also found that each method often indicated a different diet and that all three necessary to provide more detail on a specific diet (Nagelkerken et al. 2009). Nagelkerken et al. (2009) also asserted that predator and prey stable isotope ratios reflected commonly observed enrichment factors. However, I would argue that this is not the case, as the majority of coral feeding Chaetodontids had mean $\delta^{13} \mathrm{C}$ values of approximately $-12.5 \%$ yet the mean $\delta^{13} \mathrm{C}$ value of corals was approximately $-15 \%$ (Nagelkerken et al. 2009). This indicates carbon trophic enrichment of roughly $2.5 \%$, larger than the commonly cited 0 1\%o (DeNiro \& Epstein, 1981) or $0.39 \pm 1.3 \%$ (Post, 2002) used in this thesis (Chapter 4; Chapter 5).

\subsection{Trophic enrichment}

Recently, researchers have been critical of the use of constant trophic enrichment factors (Caut et al. 2008; Caut et al. 2009; Bond \& Diamond, 2011; Busst \& Britton, 2016) for ignoring variations related to size, tissue type, nutritional stress, excretory mechanisms and feeding rates (Mill et al. 2007). Similarly, prey types have a notable influence on trophic enrichment (Caut et al. 2009). In Chapter 4, I measured the stable isotope ratios of two reef specialists and their respective food sources, the obligate spongivore Pygoplites diacanthus (Chapter 2) and the obligate corallivore, Chaetodon lunulatus (Pratchett et al. 2005; Nagelkerken et al. 2009). The difference in nitrogen isotope values recorded between $P$. diacanthus and sponges was $\sim 4.1 \%$ and between $C$. lunulatus was $\sim 4.4 \%$, towards the upper estimate of the trophic enrichment factors for nitrogen (Post, 2002). Nitrogen enrichment $>3.4 \%$ o has been explained by the 'isotopic routing' of small amounts of animal material that may act as a dietary supplement (Gannes et al. 1997; Mill et al. 2007). This could be an explanation for $P$. diacanthus as DNA dietary analysis conducted in Chapter 3 identified crinoid DNA from the stomach contents of one individual (Chapter 3). In addition, gut content analysis conducted in Chapter 2 recorded small volumes of bivalves and polychaetes from the stomach contents of $P$. diacanthus (Chapter 2). Similarly, Nagelkerken et al. (2009) recorded small volumes of gastropods in the stomach contents of $C$. lunulatus. However, the difference in carbon isotope values recorded between P. diacanthus and C. lunulatus and their respective food sources was $\sim 4.1 \%$ and $\sim 4.4 \%$, which is much higher than traditional literature estimates of carbon enrichment (De Niro \& Epstein, 1981; Post, 2002). In a laboratory-based feeding 
experiment, temperate omnivores had $\delta^{13} \mathrm{C}$ enrichment factors ranging from $2 \%_{0}-5.6 \%$ and nitrogen enrichment factors ranging from $2-6.9 \%$ with low protein diets always resulting in the highest discrimination factor for each tissue (Busst \& Britton, 2016). The protein quality hypothesis suggests that low-quality protein sources will lead to higher enrichment factors and that as dietary nitrogen concentration increases, more amino acids are catabolised hence discrimination factors are smaller in high protein diets (Macko et al. 1986; Busst \& Britton, 2016). My observations suggest that spongivores and corallivores may also have trophic enrichment factors that are substantially different from traditional literature estimates. Long-term controlled feeding studies using a diet with a known isotopic ratio are the best way to calculate trophic enrichment factors (Sweeting et al. 2007; Bond \& Diamond, 2011; Busst \& Britton, 2016), however, this approach is impractical in remote, tropical study sites. As an alternative, wild studies have used stomach content material as a proxy for diet when the diet is well known (Mill et al. 2007), which has the potential to alleviate the uncertainty associated with isotopic enrichment (Guelinckx et al. 2008).

\subsection{Research limitations}

\subsubsection{Field observations}

Visual observations of spongivore feeding activity were constrained by safe diving limits that included a maximum diving depth of $18 \mathrm{~m}$. Unfortunately, a lot of activity by prominent spongivores including Pygoplites diacanthus and Pomacanthus spp. tends to exceed this depth limit, potentially due to higher sponge abundance at depth (Bell et al. 2018b). Similarly, aside from Pygoplites diacanthus and Zanclus cornutus, other spongivores (Pomacanthus spp.) and potential spongivores (e.g. Coradion melanopus) are found in low densities hence they were not frequently observed by divers or in video footage. Low densities also meant that it was unethical to carry out destructive sampling of some species to obtain gut content data and restricted the sample sizes of others e.g. Pomacanthus imperator and Pomacanthus xanthometopon (Chapter 2). Developing methods that do not require destructive sampling e.g. using DNA analysis of faecal matter (Deagle \& Tollit, 2007; Deagle et al. 2009) or taking fin clips for stable isotope analysis (Wang et al. 2017) would be a promising advance on future studies of coral reef trophic ecology. These possibilities were discussed during thesis planning but ultimately, they were rejected because they would have required a large investment in method development and presented lots of uncertainties regarding data yield.

\subsubsection{Invertebrate spongivores}

This study was limited to vertebrate sponge predators which are thought to have the biggest predatory impact on sponge assemblages on shallow coral reefs (Randall \& Hartman, 1968; Meylan, 1988). However, tropical sponges also have a range of invertebrate predators. Generalist macro-invertebrate grazers that have been documented consuming sponges in the Western Atlantic include the starfish Oreaster reticulatus (Wulff, 1995; Wulff, 2017) and three predatory urchins, Lytechinus variegatus, 
Tripneustes ventricosus, and Eucidaris tribuloides (Reiswig, 1973). Eucidaris tribuloides individuals sampled in Brazil had large enough quantities of sponge in their gut content to indicate deliberate feeding rather than incidental ingestion (Santos et al. 2002). Sponge spicules were found in the faecal content in 5/23 species of opisthobranchs living on the Mexican Pacific coast (Verdín Padilla et al. 2010). The false limpet Tylodina fungina and the nudibranch Tayuva lilacina (formerly Discodoris ketos) were highly specialised on only one species of sponge whilst the widest diet was maintained by Doriprismatica sedan (formerly Glossodoris sedan) consuming 16 species of sponge (Verdín Padilla et al. 2010). In a study investigating the lipid biochemistry of nudibranchs in Vietnam, Zhukova (2014) identified an abundance of very-long-chain fatty acids (so-called demospongic acids) as a unique feature of the fatty acid profiles of nudibranchs. The presence of demospongic acids was explained by specialised feeding on sponges by nudibranchs (Zhukova, 2014). The sponge-dwelling brittlestar Ophiothrix lineata is almost exclusively associated with the Caribbean sponge Calyspongia vaginalis (Henkel \& Pawlik, 2014). O. lineata consumes the larvae of its host without providing any discernible benefit (e.g. sediment removal), indicating this interaction ranges from commensalism to parasitism depending on the reproductive status of $C$. vaginalis (Henkel \& Pawlik, 2014). Predation on sponges at different life cycle stages (e.g. larvae, juvenile) has rarely been considered by sponge ecologists (but see Henkel \& Pawlik, 2014; Mariani \& Uriz, 2001) but may play a role in structuring sponge assemblages. Analysis of the intestinal tracts of sponge-inhabiting shrimp from the Indo-Pacific, the Caribbean and the Indian Ocean have characterised several species as parasites due to the prevalence of spicules and spongin in gut contents (Ďuriš et al. 2011). Similarly, the polychaete Branchiosyllis oculata readily feeds on sponge tissue (Pawlik, 1983) and Xestospongia spp. in the Wakatobi MNP are infested with an unidentified white polychaete (family Syllidae) (pers. obs). This link between these inquilines and upper trophic levels is poorly understood and, to my knowledge, studies are yet to directly link sponge-associated fauna to the feeding activities of coral reef fishes.

\subsection{Future research directions}

\subsubsection{Adaptation to sponge predation}

Research presented in this thesis suggests that spongivorous angelfishes consume sponges with substantial chemical defences (Chapter 3). Phylogenetic analysis placed sponges predated by angelfishes in clades with sponges that are known to possess substantial chemical defences e.g. Agelasidae, Aaptos and Chalinula. However, it should be noted that interspecific variation in deterrent properties has been documented for some genera (e.g. Haliclona). Hence, being grouped in a clade with chemically defended species does not unequivocally indicate that predated sponges were similarly defended. Yet, for some sponges that were grouped in clades represented by sponges appear to be consistently chemically defended (e.g. Agelas, Aaptos) (Loh \& Pawlik, 2014), it seems likely that they share the same defensive properties. The presence of chemically defended sponges in angelfish 
stomachs is an interesting observation because it thought that Caribbean angelfishes mainly consume chemically undefended, palatable sponges (Pawlik, 2011; Pawlik et al. 2018). Whereas other researchers contend that angelfishes feed rotationally on many sponges, including highly defended species (Wulff, 1994; Hourigan et al. 1989; Lesser \& Slattery, 2013). Without dietary proportion data, the extent of predation on chemically defended species by Indo-Pacific angelfishes remains unknown. Similarly, there is no evidence that Indo-Pacific sponges fall into the same ecological categories noted by Pawlik (2011) and little published information on the chemical defences of Indo-Pacific sponges. One interesting avenue of research would be to test whether the Caribbean sponge categories (defended, open reef sponges; undefended but tolerant, palatable sponges; and palatable species that are restricted to cryptic habitats) are true of Indo-Pacific sponges. This would assist in determining the role of spongivory as a top-down control on sponge assemblages. Palatability assessments should be conducted using both generalist and specialist predators to account for differences in their tolerance of chemical defences (Schupp et al. 1999). Additionally, sponges that are deemed palatable and defended by feeding choice experiments should be verified using field observations of live sponges as assessing palatability using pellets may not always be reflective of ecological reality (Lesser \& Slattery 2013; Wulff, 2017).

The presence of chemically defended sponges in angelfish stomachs raises some interesting questions about post-ingestive processes that allow the consumption of highly potent prey. To date, most adaptations for sponge predation considered by ecologists have been limited to morphology e.g. jaw and gut length (Konow \& Bellwood, 2011) and behaviour e.g. 'smorgasbord' feeding (Randall \& Hartman, 1968; Wulff, 1994) or avoidance (Pawlik, 2018). To date, no researchers have considered digestive mechanisms (beyond morphology) e.g. gut microbiome, that angelfishes may possess that allow them to specialise on sponges. However, one study has shown that angelfishes have a novel intestinal microbiome containing anaerobic bacteria (Satoh et al. 2014). Conversely, spongivorous opisthobranchs have attracted significant attention for their ability to detoxify and/or excrete harmful chemicals (Cimino \& Ghiselin, 2009; da Cruz et al. 2012). Some nudibranchs can even sequester defensive metabolites from sponges, enhancing their defensive strategies (da Cruz et al. 2012). For example, the nudibranch Hypselodoris cantabrica requires the defensive metabolite nakafurance-9 directly from its prey, the sponge Dysedia fragilis, which it accumulates in higher concentrations than D. fragilis, making H. cantabrica better defended than its prey (da Cruz et al. 2012). An appreciation of the post-ingestive processes of terrestrial herbivores had been a crucial step towards defining herbivory in terrestrial systems (Clements et al. 2014). Hence, it is likely that addressing these knowledge gaps could contribute significantly to our understanding of spongivory in tropic marine systems. 


\subsection{Concluding remarks}

To conclude, this thesis has shown that the identity of spongivores in the Wakatobi Marine National park, and wide range of sponges consumed by the most important sponge predator Pygoplites diacanthus, are consistent with known global patterns of spongivory. Using the Sampela reef system as an example for Anthropocene shallow coral reefs that transition to sponge dominance due to a decline in corals, I have shown that they provide fewer organic matter pathways for secondary production resulting in a less complex trophic structure characterised by fish with more similar diets. Similarly, observations from this thesis suggest that obligate spongivores are unlikely to benefit from shifts to sponge dominance when they result in low diversity sponge assemblages on low diversity reefs. However, sponges mediate alternative trophic pathways that are currently under-appreciated in reef food web models, likely due to considerable uncertainties surrounding the ubiquity of these pathways. 


\section{References}

Abràmoff, M. D., Magalhães, P. J., \& Ram, S. J. (2004). Image processing with ImageJ. Biophotonics International, 11(7), 36-41.

Adam, T. C., Duran, A., Fuchs, C. E., Roycroft, M. V., Rojas, M. C., Ruttenberg, B. I., \& Burkepile, D. E. (2018). Comparative analysis of foraging behaviour and bite mechanics reveals complex functional diversity among Caribbean parrotfishes. Marine Ecology Progress Series, 597, 207-220.

Adlard, R. D. \& Lester, R. J. G. (1995). Development of a diagnostic test for Mikrocytos roughleyi, the aetiological agent of Australian winter mortality of the commercial rock oyster, Saccostrea commercialis (Iredale \& Roughley). Journal of Fish Diseases, 18, 609-614.

Allen, G.R. (1975). Damselfishes of the south seas. TFH Publications, Neptune City.

Allen, G. R. (2008). Conservation hotspots of biodiversity and endemism for Indo-Pacific coral reef fishes. Aquatic Conservation: Marine and Freshwater Ecosystems, 18, 541-556.

Allen, G. R., \& Adrim, M. (2003). Review: Article Coral Reef Fishes of Indonesia. Zoological Studies, $42(1), 1-72$.

Altabet, M. A. (1988). Variations in nitrogen isotopic composition between sinking and suspended particles: implications for nitrogen cycling and particle transformation in the open ocean. Deep Sea Research Part A, Oceanographic Research Papers, 35(4), 535-554.

Anderson, M., Gorley, R. N., \& Clarke, K. R. (2008). PERMANOVA + for PRIMER user manual: Guide to software and statistical methods. PRIMER-E: Plymouth, UK.

Andréa, B. R., Batista, D., Sampaio, C. L. S., \& Muricy, G. (2007). Spongivory by juvenile angelfish (Pomacanthidae) in Salvador, Bahia State, Brazil. In Custódio, M.R., Lôbo-Hajdu, G., Hajdu, E. and Muricy, G. (eds) Porifera research: biodiversity, innovation and sustainability. Série Livros 28. Rio de Janeiro: Museu Nacional, pp. 233-237

Aronson, R. B., Precht, W. F., Toscano, M. A., \& Koltes, K. H. (2002). The 1998 bleaching event and its aftermath on a coral reef in Belize. Marine Biology, 141(3), 435-447.

Atkinson, M.J. \& Falter, J.L. (2003) Coral reefs. In: Black K, Shimmield G (eds) Biogeochemistry of marine systems. CRC Press, Boca Raton, pp 40-64.

Ayling, A. M. (1981). The Role of Biological Disturbance in Temperate Subtidal Encrusting Communities. Ecology, 62(3), 830-847.

Azam, F., Fenchel, J. G., Gray, J. S., Meyer-Reil, L. A., \& Thingstad, F. (1983). The Ecological Role of Water-Column Microbes in the Sea. Marine Ecology Progress Series, 10, 257-263.

Bakus, G. J., \& Green, G. (1974). Toxicity in Sponges and Holothurians: A Geographic Pattern. Science, 185, 951-953.

Bakus, G. J., \& Nishiyama, G. K. (2000). Three species of toxic sponges from Cebu, Philippines. Proceedings of the Biological Society of Washington, 113(4), 1162-1172. 
Bannister, R. J., Battershill, C. N., \& de Nys, R. (2012). Suspended sediment grain size and mineralogy across the continental shelf of the Great Barrier Reef: Impacts on the physiology of a coral reef sponge. Continental Shelf Research, 32, 86-95.

Barnosky, A. D., Matzke, N., Tomiya, S., Wogan, G. O. U., Swartz, B., Quental, T. B., .. Ferrer, E. A. (2011). Has the Earth's sixth mass extinction already arrived? Nature, 471, 51-57.

Baroin, A., Perasso, R., Qu, L.H., Brugerolle, G., Bachellerie, J.P., Adoutte, A. (1988) Partial phylogeny of the unicellular eukaryotes based on rapid sequencing of a portion of $28 \mathrm{~S}$ ribosomal RNA. PNAS 85(10), 3474-3478.

Batschelet, E. (1981) Circular Statistics in Biology. Academic Press, London.

Bearhop, S., Adams, C. E., Waldron, S., Fuller, R. A., \& Macleod, H. (2004). Determining trophic niche width: A novel approach using stable isotope analysis. Journal of Animal Ecology, 73,1007-1012.

Becerro, M. A., Paul, V. J., \& Starmer, J. (1998). Intracolonial variation in chemical defences of the sponge Cacospongia sp. and its consequences on generalist fish predators and the specialist nudibranch predator Glossodoris pallida. Marine Ecology Progress Series, 168, 187-196.

Becerro, M. A., Thacker, R. W., Turon, X., Uriz, M. J., \& Paul, V. J. (2003). Biogeography of sponge chemical ecology: Comparisons of tropical and temperate defences. Oecologia, 135(1), 91-101.

Becerro, M. A., Turon, X., Uriz, M. J., \& Templado, J. (2003). Can a sponge feeder be a herbivore? Tylodina perversa (Gastropoda) feeding on Aplysina aerophoba (Demospongiae). Biological Journal of the Linnean Society, 78(4), 429-438.

Bell, J. J., Jompa, J., Haris, A., Werorilangi, S., Shaffer, M., \& Mortimer, C. (2019). Domination of mesophotic ecosystems in the Wakatobi Marine National Park (Indonesia) by sponges, soft corals and other non-hard coral species. Journal of the Marine Biological Association of the United Kingdom, 99(4), 771-775.

Bell, J. J., Bennett, H. M., Rovellini, A., \& Webster, N. S. (2018a). Sponges to be winners under nearfuture climate scenarios. BioScience, 68(12), 955-968.

Bell, J. J., Rovellini, A., Davy, S. K., Taylor, M. W., Fulton, E. A., Dunn, M. R., ... Webster, N. S. (2018b). Climate change alterations to ecosystem dominance: how might sponge-dominated reefs function? Ecology, 99,1920-1931.

Bell, J. J., Davy, S. K., Jones, T., Taylor, M. W., \& Webster, N. S. (2013). Could some coral reefs become sponge reefs as our climate changes? Global Change Biology, 19(9), 2613-2624.

Bell, J. J., \& Smith, D. (2004). Ecology of sponge assemblages (Porifera) in the Wakatobi region, southeast Sulawesi, Indonesia: Richness and abundance. Journal of the Marine Biological Association of the United Kingdom, 84(3), 581-591.

Bell, J. J., Biggerstaff, A., Bates, T., Bennett, H., Marlow, J., McGrath, E., \& Shaffer, M. (2017). Sponge monitoring Moving beyond diversity and abundance measures. Ecological Indicators, 78, 470488.

Bell, J. J., Smith, D., Hannan, D., Haris, A., Jompa, J., \& Thomas, L. (2014). Resilience to disturbance despite limited dispersal and self-recruitment in tropical barrel sponges: Implications for conservation and management. PLOS ONE, 9(3). 
Bellwood, D. R., Hughes, T. P., Folke, C., \& Nyström, M. (2004). Confronting the coral reef crisis. Nature, 429, 827-833.

Bellwood, D. R., \& Choat, J. H. (1990). A functional analysis of grazing in parrotfishes (family Scaridae): the ecological implications. Environmental Biology of Fishes, 28, 189-214.

Bellwood, D. R., Hoey, A. S., Ackerman, J. L., \& Depczynski, M. (2006). Coral bleaching, reef fish community phase shifts and the resilience of coral reefs. Global Change Biology, 12,1587-1594.

Bellwood, D. R., Streit, R. P., Brandl, S. J., \& Tebbett, S. B. (2019). The meaning of the term 'function' in ecology: A coral reef perspective. Functional Ecology, 33, 948-961.

Bellwood, D. R., Hoey, A. S., Bellwood, O., \& Goatley, C. H. R. (2014). Evolution of long-toothed fishes and the changing nature of fish-benthos interactions on coral reefs. Nature Communications, 5, $1-6$.

Benner, R., Biddanda, B., Black, B., \& McCarthy, M. (1997). Abundance, size distribution, and stable carbon and nitrogen isotopic compositions of marine organic matter isolated by tangential-flow ultrafiltration. Marine Chemistry, 57, 243-263.

Bennett, H. M., Altenrath, C., Woods, L., Davy, S. K., Webster, N. S., \& Bell, J. J. (2017). Interactive effects of temperature and pCO2 on sponges: from the cradle to the grave. Global Change Biology, 23, 2031-2046.

Benson, A. A., \& Muscatine, L. (1974). Wax in coral mucus, energy transfer from corals to reef fishes. Limnology and Oceanography, 19, 810-814.

Bergmann, M., Dannheim, J., Bauerfeind, E., \& Klages, M. (2009). Trophic relationships along a bathymetric gradient at the deep-sea observatory HAUSGARTEN. Deep-Sea Research Part I: Oceanographic Research Papers, 56, 408-424.

Berumen, M. L., Pratchett, M. S., \& Goodman, B. A. (2011). Relative gut lengths of coral reef butterflyfishes (Pisces: Chaetodontidae). Coral Reefs, 30, 1005-1010.

Berumen, M. L., \& Pratchett, M. S. (2006). Effects of resource availability on the competitive behaviour of butterflyfishes (Chaetodontidae). Proceedings 10th Int. Coral Reef Symp., 644-650.

Berumen, M. L., Pratchett, M. S., \& McCormick, M. I. (2005). Within-reef differences in diet and body condition of coral-feeding butterflyfishes (Chaetodontidae). Marine Ecology Progress Series, 287, $217-227$.

Biggerstaff, A., Smith, D. J., Jompa, J., \& Bell, J. J. (2015). Photoacclimation supports environmental tolerance of a sponge to turbid low-light conditions. Coral Reefs, 34(4), 1049-1061.

Biggerstaff, A. (2016). Transitions from coral- to sponge-dominated reef states: An example from within the Coral Triangle. Victoria University of Wellington, PhD Thesis.

Biggerstaff, A., Smith, D. J., Jompa, J., \& Bell, J. J. (2017). Metabolic responses of a phototrophic sponge to sedimentation supports transitions to sponge-dominated reefs. Scientific Reports, 7, 1-11.

Blowes, S. A., Supp, S. R., Antão, L. H., Bates, A., Bruelheide, H., Chase, J. M., ... Dornelas, M. (2019). The geography of biodiversity change in marine and terrestrial assemblages. Science, 366, 339345 . 
Bond, A. L., \& Diamond, A. W. (2011). Recent Bayesian stable isotope mixing models are highly sensitive to variation in discrimination factors. Ecological Applications, 21, 1017-1023.

Boyle, M. C., Jillett, J. B., \& Mladenov, P. V. (2001). Intertidal communities in Doubtful Sound, New Zealand: Changes over time. New Zealand Journal of Marine and Freshwater Research, 35(4), 663673.

Brandl, S. J., Emslie, M. J., \& Ceccarelli, D. M. (2016). Habitat degradation increases functional originality in highly diverse coral reef fish assemblages. Ecosphere, $7(11)$.

Brandl, S. J., Goatley, C. H. R., Bellwood, D. R., \& Tornabene, L. (2018). The hidden half: ecology and evolution of cryptobenthic fishes on coral reefs. Biological Reviews, 93(4), 1846-1873.

Briand, M. J., Bonnet, X., Guillou, G., \& Letourneur, Y. (2016). Complex food webs in highly diversified coral reefs: Insights from $\delta^{13} \mathrm{C}$ and $\delta^{15} \mathrm{~N}$ stable isotopes. Food Webs, 8, 12-22.

Brooker, R. M., Munday, P. L., Brandl, S. J., \& Jones, G. P. (2014). Local extinction of a coral reef fish explained by inflexible prey choice. Coral Reefs, 33(4), 891-896.

Bruno, J. F., \& Selig, E. R. (2007). Regional decline of coral cover in the Indo-Pacific: Timing, extent, and subregional comparisons. PLOS ONE, 2(8).

Bryant, D., Burke, L., McManus, J., \& Sp. (2016). Reefs at risk: a map-based indicator of threats to the world's coral reefs. World Resources Institute, Washington DC.

Bunn, S. E., Loneragan, N. R., \& Kempster, M. A. (1995). Effects of acid washing on stable isotope ratios of $\mathrm{C}$ and $\mathrm{N}$ in penaeid shrimp and seagrass: Implications for food-web studies using multiple stable isotopes. Limnology and Oceanography, 40, 622-625.

Burgess, W. (1974). Evidence for the Elevation to Family Status of the Angelfishes (Pomacanthidae), Previously Considered to be a Subfamily of the Butterflyfish Family, Chaetodontidae. Pacific Science, $28,57-71$.

Burke, L., Reytar, K., Spalding, M., \& Perry, A. (2011). Reefs at Risk Revisited. World Resources Institute, Washington DC.

Burns, E., Ifrach, I., Carmeli, S., Pawlik, J. R., \& Ilan, M. (2003). Comparison of anti-predatory defences of Red Sea and Caribbean sponges. I. Chemical defence. Marine Ecology Progress Series, $252,105-114$.

Busst, G. M. A., \& Britton, J. R. (2016). High variability in stable isotope diet-tissue discrimination factors of two omnivorous freshwater fishes in controlled ex situ conditions. Journal of Experimental Biology, 219, 1060-1068.

Calizza, E., Costantini, M. L., Careddu, G., \& Rossi, L. (2017). Effect of habitat degradation on competition, carrying capacity, and species assemblage stability. Ecology and Evolution, 7(15), 57845796.

Calizza, E., Costantini, M. L., Carlino, P., Bentivoglio, F., Orlandi, L., \& Rossi, L. (2013). Posidonia oceanica habitat loss and changes in litter- associated biodiversity organization: A stable isotope-based preliminary study. Estuarine Coastal and Shelf Science, 135, 137-145. 
Carassou, L., Kulbicki, M., Nicola, T. J. R., \& Polunin, N. V. C. (2008). Assessment of fish trophic status and relationships by stable isotope data in the coral reef lagoon of New Caledonia, southwest Pacific. Aquatic Living Resources, 12, 1-12.

Cardinale, B. J., Duffy, J. E., Gonzalez, A., Hooper, D. U., Perrings, C., Venail, P., ... Naeem, S. (2012). Biodiversity loss and its impact on humanity. Nature, 486, 59-67.

Catry, T., Lourenço, P. M., Lopes, R. J., Carneiro, C., Alves, J. A., Costa, J., ... Granadeiro, J. P. (2016). Structure and functioning of intertidal food webs along an avian flyway: A comparative approach using stable isotopes. Functional Ecology, 30, 468-478.

Caut, S., Angulo, E., \& Courchamp, F. (2009). Variation in discrimination factors ( $\Delta 15 \mathrm{~N}$ and $\Delta 13 \mathrm{C})$ : The effect of diet isotopic values and applications for diet reconstruction. Journal of Applied Ecology, $46,443-453$.

Caut, S., Angulo, E., \& Courchamp, F. (2008). Caution on isotopic model use for analyses of consumer diet. Canadian Journal of Zoology, 86(5), 438-445.

Ceballos, G., Ehrlich, P. R., \& Dirzo, R. (2017). Biological annihilation via the ongoing sixth mass extinction signalled by vertebrate population losses and declines. Proceedings of the National Academy of Sciences of the United States of America, 114(30).

Chanas, B., \& Pawlik, J. R. (1995). Defences of Caribbean sponges against predatory reef fish. 2. Spicules, tissue toughness, and nutritional quality. Marine Ecology Progress Series, 127, 195-231.

Choat, J. H., Clements, K. D., \& Robbins, W. D. (2002). The trophic status of herbivorous fishes on coral reefs 1: Dietary analyses. Marine Biology, 140(3), 613-623.

Chow, S., Suzuki, S., Matsunaga, T., Lavery, S., Jeffs, A., \& Takeyama, H. (2011). Investigation on Natural Diets of Larval Marine Animals Using Peptide Nucleic Acid-Directed Polymerase Chain Reaction Clamping. Marine Biotechnology, 13(2), 305-313.

Cimino, G. Ghiselin, M.T. (2009) Chemical defence and the evolution of opisthobranch gastropods. Proc Calif Acad Sci 60(10):175-422.

Clarke, K. R., \& Warwick, R. M. (2001). Change in Marine Communities: An approach to statistical analysis and interpretation. 2nd edition. PRIMER-E: Plymouth, UK.

Clavel, J., Julliard, R., \& Devictor, V. (2011). Worldwide decline of specialist species: Toward a global functional homogenization? Frontiers in Ecology and the Environment, 9, 222-228.

Cleary, D. F. R., \& De Voogd, N. J. (2007). Environmental associations of sponges in the Spermonde Archipelago, Indonesia. Journal of the Marine Biological Association of the United Kingdom, 87(6), $1669-1676$.

Cleary, D. F. R., Polónia, A. R. M., Becking, L. E., de Voogd, N. J., Purwanto, Gomes, H., \& Gomes, N. C. M. (2018). Compositional analysis of bacterial communities in seawater, sediment, and sponges in the Misool coral reef system, Indonesia. Marine Biodiversity, 48(4), 1889-1901.

Clements, K. D., Angert, E. R., Montgomery, W. L., \& Choat, J. H. (2014). Intestinal microbiota in fishes: What's known and what's not. Molecular Ecology, Vol. 23, pp. 1891-1898. 
Clements, W. H., \& Livingston, R. J. (1983). Overlap and Pollution-Induced Variability in the Feeding Habits of Filefish (Pisces: Monacanthidae) from Apalachee Bay, Florida. Copeia, 2, 331-338.

Clifton, J., \& Unsworth, R. K. F. (2013). Future directions for marine conservation in the Coral Triangle. In: Clifton J, Unsworth RKF, Smith DJ, editors. Marine research and conservation in the Coral Triangle: the Wakatobi National Park. New York: Nova Publishers (pp. 251-258).

Cole, A. J., Lawton, R. J., Pratchett, M. S., \& Wilson, S. K. (2011). Chronic coral consumption by butterflyfishes. Coral Reefs, 30(1), 85-93.

Cole, A. J., Pratchett, M. S., \& Jones, G. P. (2008). Diversity and functional importance of coral-feeding fishes on tropical coral reefs. Fish and Fisheries 9, 286-307.

Coleman, R. R., Eble, J. A., DiBattista, J. D., Rocha, L. A., Randall, J. E., Berumen, M. L., \& Bowen, B. W. (2016). Regal phylogeography: Range-wide survey of the marine angelfish Pygoplites diacanthus reveals evolutionary partitions between the Red Sea, Indian Ocean, and the Pacific Ocean. Molecular Phylogenetics and Evolution, 100, 243-253.

Conrad, K. F., Warren, M. S., Fox, R., Parsons, M. S., \& Woiwod, I. P. (2006). Rapid declines of common, widespread British moths provide evidence of an insect biodiversity crisis. Biological Conservation, 132(3), 279-291.

Cox, E. F. (1986). The effects of a selective corallivore on growth rates and competition for space between two species of Hawaiian corals. Journal of Experimental Marine Biology and Ecology, 101, $161-174$.

Crabbe, M. J. C., \& Smith, D. J. (2005). Sediment impacts on growth rates of Acropora and Porites corals from fringing reefs of Sulawesi, Indonesia. Coral Reefs, 24(3), 437-441.

Cullen, L. C. (2007). Marine resource dependence, resource use patterns and identification of economic performance criteria within a small island community: Kaledupa, Indonesia. The University of Essex. $\mathrm{PhD}$ thesis.

Curtis-Quick, J. A. (2013). Drivers of change of reef fish assemblages within the Coral Triangle. The University of Essex. $\mathrm{PhD}$ thesis.

da Cruz, J. F., Gaspar, H., \& Calado, G. (2012). Turning the game around: Toxicity in a nudibranchsponge predator-prey association. Chemoecology, 22(1), 47-53.

Dayton, P. K., Robilliard, G. A., Paine, R. T., \& Dayton, L. B. (1974). Biological accommodation in the benthic community at McMurdo Sound, Antarctica. Ecological Monographs, 44, 105-128.

de Bakker, D. M., van Duyl, F. C., Bak, R. P. M., Nugues, M. M., Nieuwland, G., \& Meesters, E. H. (2017). 40 Years of benthic community change on the Caribbean reefs of Curaçao and Bonaire: the rise of slimy cyanobacterial mats. Coral Reefs, 36(2), 355-367.

de Goeij, J. M., Van Den Berg, H., Van Oostveen, M. M., Epping, E. H. G., \& Van Duyl, F. C. (2008). Major bulk dissolved organic carbon (DOC) removal by encrusting coral reef cavity sponges. Marine Ecology Progress Series, 357, 139-151.

de Goeij, J. M., van Oevelen, D., Vermeij, M. J. A., Osinga, R., Middelburg, J. J., de Goeij, A. F. P. M., \& Admiraal, W. (2013). Surviving in a Marine Desert: The Sponge Loop Retains Resources Within Coral Reefs. Science, 342(6154), 108-110. 
de Goeij, J. M., Lesser, M. P., \& Pawlik, J. R. (2017). Nutrient Fluxes and Ecological Functions of Coral Reef Sponges in a Changing Ocean. In J. L. Carballo \& J. J. Bell (Eds.), Climate Change, Ocean Acidification and Sponges: Impacts Across Multiple Levels of Organization (pp. 373-410).

de la Moriniere, E. C., Nagelkerken, I., van der Velde, G., Pollux, B. J. a., Hemminga, M. a., \& Huiskes, a. H. L. (2003). Ontogenetic dietary changes of coral reef fishes in the mangrove-seagrass-reef continuum: stable isotopes and gut- content analysis. Marine Ecology Progress Series, 246, 279-289.

Deagle, B. E., Kirkwood, R., \& Jarman, S. N. (2009). Analysis of Australian fur seal diet by pyrosequencing prey DNA in faeces. Molecular Ecology, 18(9), 2022-2038.

Deagle, B. E., \& Tollit, D. J. (2007). Quantitative analysis of prey DNA in pinniped faeces: Potential to estimate diet composition? Conservation Genetics, 8(3), 743-747.

Delecat, S., Arp, G., \& Reitner, J. (2011). Aftermath of the Triassic--Jurassic Boundary Crisis: Spiculite Formation on Drowned Triassic Steinplatte Reef-Slope by Communities of Hexactinellid Sponges (Northern Calcareous Alps, Austria). In Advances in Stromatolite Geobiology (pp. 355-390).

DeNiro, M. J., \& Epstein, S. (1981). Influence of diet on the distribution of nitrogen isotopes in animals. Geochimica et Cosmochimica Acta, 45(3), 341-351.

DeNiro, M. J., \& Epstein, S. (1978). Influence of diet on the distribution of carbon isotopes in animals. Geochimica et Cosmochimica Acta, 42, 495-506.

Depczynski, M., \& Bellwood, D. R. (2004). Microhabitat utilisation patterns in cryptobenthic coral reef fish communities. Marine Biology, 145(3), 455-463.

Diaz, M. C., \& Rützler, K. (2001). Sponges: An essential component of Caribbean coral reefs. Bulletin of Marine Science, 69(2), 535-546.

Díaz, S., Demissew, S., Carabias, J., Joly, C., Lonsdale, M., Ash, N., ... Zlatanova, D. (2015). The IPBES Conceptual Framework - connecting nature and people. Current Opinion in Environmental Sustainability, Vol. 14, pp. 1-16.

Dill, L.M. (1983) Adaptive flexibility in the foraging behaviour of fishes. Can, J, Fish, Aquat. Sci. 40, 398-408.

Duffy, J. E., Paul, V. J., Duffy, A. J. E., \& Paul, V. J. (1992). Nutritional quality and the effectiveness of chemical defences against tropical reef fishes. Oecologia, 90(3), 333-339.

Duffy, J. E., Cardinale, B. J., France, K. E., McIntyre, P. B., Thébault, E., \& Loreau, M. (2007). The functional role of biodiversity in ecosystems: Incorporating trophic complexity. Ecology Letters, 10, $522-538$.

Dunlap, M., \& Pawlik, J. R. (1998). Spongivory by parrotfish in Florida mangrove and reef habitats. Marine Ecology, 19(4), 325-337.

Dunlap, M., \& Pawlik, J. R. (1996). Video-monitored predation by Caribbean reef fishes on an array of mangrove and reef sponges. Marine Biology, 126(1), 117-123.

Dunn, M. R., Szabo, A., McVeagh, M. S., \& Smith, P. J. (2010). The diet of deepwater sharks and the benefits of using DNA identification of prey. Deep-Sea Research Part I: Oceanographic Research Papers, 57(7), 923-930. 
Dunshea, G. (2009). DNA-based diet analysis for any predator. PLoS ONE, 4(4).

Eagle, J. V, \& Jones, G. P. (2004). Mimicry in coral reef fishes: Ecological and behavioural responses of a mimic to its model. Journal of Zoology, 264(1), 33-43.

Emslie, M. J., Cheal, A. J., MacNeil, M. A., Miller, I. R., \& Sweatman, H. P. A. (2018). Reef fish communities are spooked by scuba surveys and may take hours to recover. PeerJ, 6, e4886.

Eurich, J. G., Matley, J. K., Baker, R., McCormick, M. I., \& Jones, G. P. (2019). Stable isotope analysis reveals trophic diversity and partitioning in territorial damselfishes on a low-latitude coral reef. Marine Biology, 166(2), 1-14.

Fasching, C., Behounek, B., Singer, G. A., \& Battin, T. J. (2014). Microbial degradation of terrigenous dissolved organic matter and potential consequences for carbon cycling in brown-water streams. Scientific Reports, 4, 1-7.

Feary, D. A., McCormick, M. I., \& Jones, G. P. (2009). Growth of reef fishes in response to live coral cover. Journal of Experimental Marine Biology and Ecology, 373(1), 45-49.

Fernández-Rivera Melo, F. J., Reyes-Bonilla, H., Martínez-Castillo, V., \& Pérez-Alarcón, F. (2018). Northernmost Occurrence of Zanclus cornutus (Zanclidae) in the Eastern Pacific (Northern Gulf of California, Mexico). Thalassas, 34(2), 301-304.

Lesser, M. P., Fiore, C., Slattery, M., \& Zaneveld, J. (2016). Climate change stressors destabilize the microbiome of the Caribbean barrel sponge, Xestospongia muta. Journal of Experimental Marine Biology and Ecology, 475, 11-18.

Fitch, A., Orland, C., Willer, D., Emilson, E. J. S., \& Tanentzap, A. J. (2018). Feasting on terrestrial organic matter: Dining in a dark lake changes microbial decomposition. Global Change Biology, 24(11), 5110-5122.

Freeman, C. J., Easson, C. G., \& Baker, D. M. (2016). Niche structure of marine sponges from temperate hard-bottom habitats within Gray's Reef National Marine Sanctuary. Journal of the Marine Biological Association of the United Kingdom, 96(2), 559-565.

Freeman, C. J., Easson, C. G., \& Baker, D. M. (2014). Metabolic diversity and niche structure in sponges from the Miskito Cays, Honduras. PeerJ, 2014(12), 1-20.

Freeman, C. J., \& Thacker, R. W. (2011). Complex interactions between marine sponges and their symbiotic microbial communities. Limnology and Oceanography, 56(5), 1577-1586.

Freeman, C. J., Easson, C. G., Matterson, K. O., Thacker, R. W., Baker, D. M., \& Paul, V. J. (2020). Microbial symbionts and ecological divergence of Caribbean sponges: A new perspective on an ancient association. ISME Journal.

Frisch, A. J., Ireland, M., Rizzari, J. R., Lönnstedt, O. M., Magnenat, K. A., Mirbach, C. E., \& Hobbs, J. P. A. (2016). Reassessing the trophic role of reef sharks as apex predators on coral reefs. Coral Reefs, $35(2), 459-472$.

Folmer, O., Black, M., Hoeh, W., Lutz, L., Vrijenhoek, R. (1994). DNA primers for amplification of mitochondrial cytochrome c oxidase subunit I from diverse metazoan invertebrates. Mol Mar Biol Biotechnol. 3(5):294-9. 
Fry, B., Lutes, R., Northam, M., Parker, P.L., Ogden, J. (1982) A C-13/C-12 comparison of food webs in Caribbean seagrass meadows and coral reefs. Aquat Bot 14, 389-398

Fry, B., \& Sherr, E.B., (1984). $\delta^{13} \mathrm{C}$ measurements as indicators of carbon flow in marine and freshwater ecosystems. Contributions in Marine Science 27, 13-47.

Fry, B. (2006) Stable Isotope Ecology. Springer Science+Business Media, LLC.

Fry, B. (2002). Stable isotopic indicators of habitat use by Mississippi River fish. Journal of the North American Benthological Society. 21(4), 676-685.

Fry, B., Hopkinson, C. S., Nolin, A., \& Wainright, S. C. (1998). 13C/12C composition of marine dissolved organic carbon. Chemical Geology, 152(1-2), 113-118.

Gaino, E., Bo, M., Betti, F., Bertolino, M., Scoccia, F., \& Bavestrello, G. (2014). Ultrastructural evidence of a fungus-sponge association in the Ligurian Sea: a case study of Clathrina coriacea (Porifera: Calcarea). Italian Journal of Zoology, 81(4), 501-507.

Gannes, L. Z., O'Brien, D. M., \& Del Rio, C. M. (1997). Stable isotopes in animal ecology: Assumptions, caveats, and a call for more laboratory experiments. Ecology, 78(4), 1271-1276.

Gause, G. E (1934). The struggle for existence. Reprinted 1969. Hafner, New York, USA.

Gibbs, N., Bowman, M., Dietrich, D. (2000). Maintenance of near-surface stratification in Doubtful Sound, A New Zealand fjord. Estuarine, Coastal and Shelf Science, 51, 683-704.

Goebel, N. L., Wing, S. R., \& Boyd, P. W. (2005). A mechanism for the onset of diatom blooms in a fjord with persistent salinity stratification. Estuarine, Coastal and Shelf Science, 64(2-3), 546-560.

Goulson, D., Lye, G. C., \& Darvill, B. (2008). Decline and Conservation of Bumble Bees. Annual Review of Entomology, 53(1), 191-208.

Graham, N. A. J., Chabanet, P., Evans, R. D., Jennings, S., Letourneur, Y., Aaron Macneil, M., ... Wilson, S. K. (2011). Extinction vulnerability of coral reef fishes. Ecology Letters, 14(4), 341-348.

Graham, N. A. J., Cinner, J. E., Norström, A. V., \& Nyström, M. (2014). Coral reefs as novel ecosystems: embracing new futures. Current Opinion in Environmental Sustainability, 7, 9-14.

Green, A. L., \& Bellwood, D. R. (2009). Monitoring Functional Groups of Herbivorous Reef Fishes as Indicators of Coral Reef Resilience A practical guide for coral reef managers in the Asia Pacific Region. IUCN, Gland, Switzerland, 2009.

Grey, J., Graham, C. T., Britton, J. R., \& Harrod, C. (2009). Stable isotope analysis of archived roach (Rutilus rutilus) scales for retrospective study of shallow lake responses to nutrient reduction. Freshwater Biology, 54(8), 1663-1670.

Grinnell, J. (1917). The Niche-Relationships of the California Thrasher. The Auk, 34(4), 427-433.

Guelinckx, J., Dehairs, F., \& Ollevier, F. (2008). Effect of digestion on the $\delta 13 \mathrm{C}$ and $\delta 15 \mathrm{~N}$ of fish-gut contents. Journal of Fish Biology, 72(1), 301-309. 
Guillemette, F., Leigh McCallister, S., \& Del Giorgio, P. A. (2016). Selective consumption and metabolic allocation of terrestrial and algal carbon determine allochthony in lake bacteria. ISME Journal, 10(6), 1373-1382.

Guindon, S., Dufayard, J. F., Lefort, V., Anisimova, M., Hordijk, W., \& Gascuel, O. (2010). New algorithms and methods to estimate maximum-likelihood phylogenies: Assessing the performance of PhyML 3.0. Systematic Biology, 59(3), 307-321.

Hadas, E., Shpigel, M., \& Ilan, M. (2009). Particulate organic matter as a food source for a coral reef sponge. Journal of Experimental Biology, 212(22), 3643-3650.

Hadas, E., Marie, D., Shpigel, M., \& Ilan, M. (2006). Virus predation by sponges is a new nutrient-flow pathway in coral reef food webs. Limnology and Oceanography, 51(3), 1548-1550.

Haddad, N. M., Crutsinger, G. M., Gross, K., Haarstad, J., Knops, J. M. H., \& Tilman, D. (2009). Plant species loss decreases arthropod diversity and shifts trophic structure. Ecology Letters, 12(10), 10291039.

Hall, T.A. (1999) BioEdit: A User-Friendly Biological Sequence Alignment Editor and Analysis Program for Windows 95/98/NT. Nucleic Acids Symposium Series, 41, 95-98.

Hallmann, C. A., Sorg, M., Jongejans, E., Siepel, H., Hofland, N., Schwan, H., ... De Kroon, H. (2017). More than 75 percent decline over 27 years in total flying insect biomass in protected areas. PLoS ONE, 12(10).

Halpern, B. S., Walbridge, S., Selkoe, K. A., Kappel, C. V, Micheli, F., Agrosa, C., ... Watson, R. (2008). A Global Map of Human Impact on Marine Ecosystems. Science, 319, 948-953.

Hammond, L. \& Wilkinson, C. R. (1985). Exploitation of sponge exudates by coral reef Holothuroids. Journal of Experimental Marine Biology and Ecology, 94, 1-9.

Hansman, R. L., \& Sessions, A. L. (2016). Measuring the in situ carbon isotopic composition of distinct marine plankton populations sorted by flow cytometry. Limnology and Oceanography: Methods, 14(2), 87-99.

Hanson, C. E., McLaughlin, M. J., Hyndes, G. A., \& Strzelecki, J. (2009). Selective uptake of prokaryotic picoplankton by a marine sponge (Callyspongia sp.) within an oligotrophic coastal system. Estuarine, Coastal and Shelf Science, 84(2), 289-297.

Harmelin-Vivien, M. L., \& Bouchon-Navaro, Y. (1983). Feeding diets and significance of coral feeding among Chaetodontid fishes in Moorea (French Polynesia). Coral Reefs: Journal of the International Society for Reef Studies, 2(2), 119-127.

Harmelin-Vivien, M., \& Bouchon-Navaro, Y. (1982). Trophic relationships among Chaetodontid fishes in the Gulf of Aqaba. Proceeding of 4th International Coral Reef Symposium. 2, 537-544.

Hay, M. E. (1996). Marine chemical ecology: What's known and what's next? Journal of Experimental Marine Biology and Ecology, 200(1-2), 103-134.

Hempson, T. N., Graham, N. A. J., MacNeil, M. A., Williamson, D. H., Jones, G. P., \& Almany, G. R. (2017). Coral reef mesopredators switch prey, shortening food chains, in response to habitat degradation. Ecology and Evolution, 7(8), 2626-2635. 
Henkel, T. P., \& Pawlik, J. R. (2014). Cleaning mutualist or parasite? Classifying the association between the brittlestar Ophiothrix lineata and the Caribbean reef sponge Callyspongia vaginalis. Journal of Experimental Marine Biology and Ecology, 454, 42-48.

Hiatt, R., \& Strasburg, D. (1960). Ecological Relationships of the Fish Fauna on Coral Reefs of the Marshall Islands. Ecological Monographs, 30(1), 65-127.

Hill, M. S., Lopez, N. A., \& Young, K. A. (2005). Anti-predator defences in western North Atlantic sponges with evidence of enhanced defence through interactions between spicules and chemicals. Marine Ecology Progress Series, 291(2000), 93-102.

Hoang, D. T., Chernomor, O., von Haeseler, A., Minh, B. Q., \& Vinh, L. S. (2018). UFBoot2: Improving the Ultrafast Bootstrap Approximation. Molecular biology and evolution. Molecular Biology and Evolution, 35(2), 518-522.

Hobson, E.S. (1974). Feeding relationship of teleostean fishes on coral reefs in Kona, Hawaii. Fishery Bulletin, 72(4), 915-1031.

Hobson, E.S. (1991). Trophic relationships of fishes specialised to feed on zooplankters above coral reefs. In Sale, P.F. (ed.). The Ecology of Fishes on Coral Reefs. Academic Press, Inc.

Hoegh-Guldberg, O. (1999). Climate change, coral bleaching and the future of the world's coral reefs. Marine and Freshwater Research, 50(8), 839-866.

Hoeksema, B. W. (2018). The hidden biodiversity of tropical coral reefs. Biodiversity, 18(1), 7-11.

Hoey, A. S., Brandl, S. J., \& Bellwood, D. R. (2013). Diet and cross-shelf distribution of rabbitfishes (f. Siganidae) on the northern Great Barrier Reef: Implications for ecosystem function. Coral Reefs, 32(4), 973-984.

Hoffmann, F., Larsen, O., Thiel, V., Rapp, H. T., Pape, T., Michaelis, W., \& Reitner, J. (2005). An anaerobic world in sponges. Geomicrobiology Journal, 22(1-2), 1-10.

Holbrook, S. J., Schmitt, R. J., Messmer, V., Brooks, A. J., Srinivasan, M., Munday, P. L., \& Jones, G. P. (2015). Reef fishes in biodiversity hotspots are at greatest risk from loss of coral species. PLoS ONE, $10(5), 1-12$.

Holt, R. D. (2009). Bringing the Hutchinsonian niche into the 21st century: Ecological and evolutionary perspectives. Proceedings of the National Academy of Sciences of the United States of America, 106(SUPPL. 2), 19659-19665.

Hooper, H. L., Connon, R., Callaghan, A., Fryer, G., Yarwood-Buchanan, S., Biggs, J., ... Sibly, R. M. (2008). The ecological niche of Daphnia magna characterized using population growth rate. Ecology, 89(4), 1015-1022.

Höss, M., Kohn, M., Pääbo, S., Knauer, F., Schröder, W. (1992). Excrement analysis by PCR. Nature, 359, 199.

Hourigan, T. F., Stanton, F. G., Motta, P. J., Kelley, C. D., \& Carlson, B. (1989). The feeding ecology of three species of Caribbean angelfishes (family Pomacanthidae). Environmental Biology of Fishes, 24(2), 105-116. 
Howell, K.-L., Piechaud, N., Downie, A.-L. \& Kenny, A. (2016) The distribution of deep-sea sponge aggregations in the North Atlantic and implications for their effective spatial management. Deep Sea Research Part I: Oceanographic Research Papers. 115, 309-320.

Hughes, T. P. (1994). Catastrophes, phase shifts, and large-scale degradation of a. Science, 265(5178), 1547.

Hughes, T. P., Baird, A. H., Bellwood, D. R., Card, M., Connolly, S. R., Folke, C., .. Roughgarden, J. (2003). Climate change, human impacts, and the resilience of coral reefs. Science, 301, 929-933.

Hughes, T. P., Barnes, M. L., Bellwood, D. R., Cinner, J. E., Cumming, G. S., Jackson, J. B. C., ... Scheffer, M. (2017). Coral reefs in the Anthropocene. Nature, Vol. 546, pp. 82-90.

Hullar, M. A. J., Fry, B., Peterson, B. J., \& Wright, R. T. (1996). Microbial utilization of estuarine dissolved organic carbon: A stable isotope tracer approach tested by mass balance. Applied and Environmental Microbiology, 62(7), 2489-2493.

Hussey, N. E., Macneil, M. A., Mcmeans, B. C., Olin, J. A., Dudley, S. F. J., Cliff, G., ... Fisk, A. T. (2014). Rescaling the trophic structure of marine food webs. Ecology Letters, 17(2), 239-250.

Hutchinson, G. E. (1957). Concluding remarks. Cold Spring Harbour Symposia on Quantitative Biology., 22(2), 415-427.

Hutchinson, G. E. (1978). An introduction to population biology. Yale University Press, New Haven, Connecticut, USA.

IPBES, (2019). Global assessment report on biodiversity and ecosystem services of the Intergovernmental Science-Policy Platform on Biodiversity and Ecosystem Services. Brondizio, E.S., Settele, J., Diaz, S. \& Ngo, H.T. (eds). IPBES secretariat, Bonn, Germany.

Jackson, A. L., Inger, R., Parnell, A. C., \& Bearhop, S. (2011). Comparing isotopic niche widths among and within communities: SIBER - Stable Isotope Bayesian Ellipses in R. Journal of Animal Ecology, $80(3), 595-602$.

Jackson, J. B. C., Kirby, M. X., Berger, W. H., Bjorndal, K. A., Botsford, L. W., Bourque, B. J., ... Warner, R. R. (2001). Historical overfishing and the recent collapse of coastal ecosystems. Science, 293(5530), 629-637.

Jarman, S. N., Deagle, B. E., \& Gales, N. J. (2004). Group-specific polymerase chain reaction for DNAbased analysis of species diversity and identity in dietary samples. Molecular Ecology, 13(5), 13131322.

Johnson, S., Domínguez-García, V., Donetti, L., \& Muñoz, M. A. (2014). Trophic coherence determines food-web stability. Proceedings of the National Academy of Sciences of the United States of America, 111(50), 17923-17928.

Jones, G.P., \& McCormick, M.I., (2002) In Sale, P.F. (ed), Coral Reef Fishes: Dynamics and Diversity in a Complex System. Academic Press, pp. 221-238.

Kalyaanamoorthy, S., Minh, B.Q., Wong, T.K.F., von Haeseler, A., Jermiin, L.S. (2017). ModelFinder: Fast model selection for accurate phylogenetic estimates. Nat. Methods, 14, 587-589. 
Kennedy, P., Kennedy, H., \& Papadimitriou, S. (2005). The effect of acidification on the determination of organic carbon, total nitrogen and their stable isotopic composition in algae and marine sediment. Rapid Communications in Mass Spectrometry, 19(8), 1063-1068

Kirchman, D. L., \& Kirchman, D. L. (2013). Degradation of organic material. Processes in Microbial Ecology, 79-98.

Knapp, I.S., Forsman, Z.H., Williams, G.J., Toonen, R.J., Bell, J.J. (2015). Cryptic species obscure introduction pathway of the blue Caribbean sponge (Haliclona (Soestella) caerulea), (order: Haplosclerida) to Palmyra- Atoll, Central Pacific. Peer J 3, e1170.

Kohler, K. E., \& Gill, S. M. (2006). Coral Point Count with Excel extensions (CPCe): A Visual Basic program for the determination of coral and substrate coverage using random point count methodology. Computers and Geosciences, 32(9), 1259-1269.

Kokita, T., \& Nakazono, A. (2001). Rapid response of an obligately corallivorous filefish Oxymonacanthus longirostris (Monacanthidae) to a mass coral bleaching event. Coral Reefs, 20(2), $155-158$.

Konow, N., \& Bellwood, D. R. (2011). Evolution of high trophic diversity based on limited functional disparity in the feeding apparatus of marine angelfishes (f. Pomacanthidae). PLoS ONE, 6(9).

Konow, N., \& Ferry, L. A. (2013). Functional morphology of butterflyfishes. In Biology of Butterflyfishes (pp. 19-47).

Kramer, M. J., Bellwood, D. R., \& Bellwood, O. (2014). Benthic crustacea on coral reefs: A quantitative survey. Marine Ecology Progress Series, 511, 105-116.

Lavrov, D.V., Wang, X.J., Kelly, M. (2008) Reconstructing ordinal relationships in the Demospongiae using mitochondrial genomic data. Mol Phylogenet Evol 49,111-124.

Layman, C. A., Quattrochi, J. P., Peyer, C. M., \& Allgeier, J. E. (2007). Niche width collapse in a resilient top predator following ecosystem fragmentation. Ecology Letters, 10(10), 937-944.

León, Y. M., \& Bjorndal, K. A. (2002). Selective feeding in the hawksbill turtle, an important predator in coral reef ecosystems. Marine Ecology Progress Series, 245, 249-258.

Leong, W. \& Pawlik, J. (2010). Evidence of a resource trade-off between growth and chemical defences among Caribbean coral reef sponges. Marine Ecology Progress Series, 406, 71-78.

Leray, M., Agudelo, N., Mills, S. C., \& Meyer, C. P. (2013). Effectiveness of Annealing Blocking Primers versus Restriction Enzymes for Characterization of Generalist Diets: Unexpected Prey Revealed in the Gut Contents of Two Coral Reef Fish Species. PLoS ONE, 8(4).

Leray, M., Meyer, C. P., \& Mills, S. C. (2015). Metabarcoding dietary analysis of coral dwelling predatory fish demonstrates the minor contribution of coral mutualists to their highly partitioned, generalist diet. PeerJ, 2015(6), 1-19.

Lesser, M. P. (2006). Benthic-pelagic coupling on coral reefs: Feeding and growth of Caribbean sponges. Journal of Experimental Marine Biology and Ecology, 328(2), 277-288.

Lesser, M. P., Mueller, B., Pankey, M. S., Macartney, K. J., Slattery, M., \& Goeij, J. M. (2019). Depthdependent detritus production in the sponge, Halisarca caerulea. Limnology and Oceanography, 1-17. 
Lesser, M. P., \& Slattery, M. (2013). Ecology of Caribbean sponges: Are top-down or bottom-up processes more important? PLoS ONE, 8(11), 1-9.

Lesser, M. P., \& Slattery, M. (2020). Will Coral Reef Sponges be Winners in the Anthropocene? Global Change Biology, (February), 1-10.

Lessios, H. A. (1988). Mass Mortality of Diadema Antillarum in the Caribbean: What Have We Learned? In Annual Review of Ecology and Systematics, 19(1988), 371-393.

Levin, L. A., \& Michener, R. H. (2002). Isotopic evidence for chemosynthesis-based nutrition of macrobenthos: The lightness of being at Pacific methane seeps. Limnology and Oceanography, 47(5), $1336-1345$.

Lindel, T., Hoffmann, H., Hochgürtel, M., \& Pawlik, J. R. (2000). Structure-activity relationship of inhibition of fish feeding by sponge- derived and synthetic pyrrole-imidazole alkaloids. Journal of Chemical Ecology, 26(6), 1477-1496.

Loh, T. L., \& Pawlik, J. R. (2009). Bitten down to size: Fish predation determines growth form of the Caribbean coral reef sponge Mycale laevis. Journal of Experimental Marine Biology and Ecology, 374(1), 45-50.

Macko, S. A., Fogel, M. L., Engel, M. H., \& Hare, P. E. (1986). Kinetic fractionation of stable nitrogen isotopes during amino acid transamination. Geochimica et Cosmochimica Acta, 50, 2143-2146.

Maldonado, M., Aguilar, R., Bannister, R. J., Bell, J. J., Conway, K. W., Dayton, P. K., ... Young, C. M. (2017). Sponge grounds as key marine habitats: A synthetic review of types, structure, functional roles, and conservation concerns. In Marine Animal Forests: The Ecology of Benthic Biodiversity Hotspots (pp. 145-183).

Maldonado, M., Ribes, M., \& van Duyl, F. C. (2012). Nutrient Fluxes Through Sponges. Biology, Budgets, and Ecological Implications. In Advances in Marine Biology (1st ed., Vol. 62, pp. 113-182).

Manly, B., McDonald, L., Thomas, D., McDonald, T., \& Erickson, W. (2002). Resource selection by animals. Second Edition. Kluwer Academic Publishers, Dordrecht.

Manly, B. F. J. (1993). Comments on design and analysis of multiple-choice feeding-preference experiments. Oecologia, 93(1), 149-152.

Mariani, S., \& Uriz, M. J. (2001). Copepods of the genus Asterocheres (Copepoda: Siphonostomatoida) feeding on sponges: Behavioural and ecological traits. Invertebrate Biology, 120(3), 269-277.

Marshell, A., \& Mumby, P. J. (2015). Journal of Experimental Marine Biology and Ecology The role of surgeonfish (Acanthuridae) in maintaining algal turf biomass on coral reefs. Journal of Experimental Marine Biology and Ecology, 473, 152-160.

Martin, D. \& Britayev, T.A., (1998).). Symbiotic Polychaetes: Review of known species. Oceanogr. Mar. Biol. Ann. Rev. 36, 217-340

MacArthur, R. H., \& Levins, R. (1967). The limiting similarity, convergence and divergence of coexisting species. American Naturalist 101, 377-385.

McCauley, D. J., Pinsky, M. L., Palumbi, S. R., Estes, J. A., Joyce, F. H., \& Warner, R. R. (2015). Marine defaunation: Animal loss in the global ocean. Science, 347(6219). 
McClenachan, L., Jackson, J. B. C., \& Newman, M. J. H. (2006). Conservation implications of historic sea turtle nesting beach loss. Frontiers in Ecology and the Environment, 4(6), 290-296.

McClintock, J. B., Amsler, C. D., Baker, B. J., \& van Soestt, R. W. M. (2005). Ecology of Antarctic Marine Sponges: An Overview. Integrated Computer Biology, 45, 359-368.

McCutchan, J. H., Lewis, W. M., Kendall, C., \& McGrath, C. C. (2003). Variation in Trophic Shift for Stable Isotope Ratios of Carbon, Nitrogen, and Sulphur. Oikos, 102(2), 378-390.

McGrath, E. C., Smith, D. J., Jompa, J., \& Bell, J. J. (2017). Adaptive mechanisms and physiological effects of suspended and settled sediment on barrel sponges. Journal of Experimental Marine Biology and Ecology, 496, 74-83.

McKnight, D.M. \& Aiken, G.R. (1998) Sources and Age of Aquatic Humus. In: Hessen D.O., Tranvik L.J. (eds) Aquatic Humic Substances. Ecological Studies (Analysis and Synthesis), vol 133. Springer, Berlin, Heidelberg

McLeod, R. J., \& Wing, S. R. (2007). Hagfish in the New Zealand Fjords are supported by Chemoautotrophy of forest carbon. Ecology, 88(4), 809-816.

McLeod, R.J., Wing, S.R., Davis, J.P. (2010) Habitat conversion and species loss alters the composition of carbon sources to benthic communities. Mar Ecol Prog Ser 411, 127-136.

McLeod, R. J., \& Wing, S. R. (2009). Strong pathways for incorporation of terrestrially derived organic matter into benthic communities. Estuarine, Coastal and Shelf Science, 82(4), 645-653.

McMahon, K. W., Thorrold, S. R., Houghton, L. A., \& Berumen, M. L. (2016). Tracing carbon flow through coral reef food webs using a compound-specific stable isotope approach. Oecologia, 180(3), 809-821.

McMellor S, Smith DJ (2010) Coral reefs of the Wakatobi: abundance and biodiversity Chapter 2 In: Clifton J, Unsworth RKF, Smith DJ, editors. Marine research and conservation in the Coral Triangle: the Wakatobi National Park. New York: Nova Publishers, pp. 11-26.

McMurray, S. E., Finelli, C. M., \& Pawlik, J. R. (2015). Population dynamics of giant barrel sponges on Florida coral reefs. Journal of Experimental Marine Biology and Ecology, 473, 73-80.

McMurray, S. E., Johnson, Z. I., Hunt, D. E., Pawlik, J. R., \& Finelli, C. M. (2016). Selective feeding by the giant barrel sponge enhances foraging efficiency. Limnology and Oceanography, 61(4), 12711286.

McMurray, S. E., Pawlik, J. R., \& Finelli, C. M. (2014). Trait-mediated ecosystem impacts: How morphology and size affect pumping rates of the Caribbean giant barrel sponge. Aquatic Biology, 23(1), $1-13$.

McMurray, S. E., Stubler, A. D., Erwin, P. M., Finelli, C. M., \& Pawlik, J. R. (2018). A test of the sponge-loop hypothesis for emergent Caribbean reef sponges. Marine Ecology Progress Series, 588, $1-14$.

Meylan, A. (1998). Spongivory in Hawksbill Turtles: A Diet of Glass. Science, 239(4838), 393-395.

Middelburg, J. J. (2014). Stable isotopes dissect aquatic food webs from the top to the bottom. Biogeosciences, 11(8), 2357-2371. 
Mill, A. C., Pinnegar, J. K., \& Polunin, N. V. C. (2007). Explaining isotope trophic-step fractionation: Why herbivorous fish are different. Functional Ecology, 21(6), 1137-1145.

Miller, E. A., McClenachan, L., Uni, Y., Phocas, G., Hagemann, M. E., \& Van Houtan, K. S. (2019). The historical development of complex global trafficking networks for marine wildlife. Science Advances, 5(3).

Miller, R. J., \& Page, H. M. (2012). Kelp as a trophic resource for marine suspension feeders: A review of isotope-based evidence. Marine Biology, 159(7), 1391-1402.

Minagawa, M., \& Wada, E. (1984). Stepwise enrichment of ${ }^{15} \mathrm{~N}$ along food chains: Further evidence and the relation between $\delta^{15} \mathrm{~N}$ and animal age. Geochimica et Cosmochimica Acta, 48(5), 1135-1140.

Mintenbeck, K., Jacob, U., Knust, R., Arntz, W. E., \& Brey, T. (2007). Depth-dependence in stable isotope ratio $\delta 15 \mathrm{~N}$ of benthic POM consumers: The role of particle dynamics and organism trophic guild. Deep-Sea Research Part I: Oceanographic Research Papers, 54(6), 1015-1023.

Moritz, C., Vii, J., Lee Long, W., Tamelander, J., Thomassin, A., and Planes, S. (eds.). (2018). Status and Trends of Coral Reefs of the Pacific. Global Coral Reef Monitoring Network, 220.

Mouillot, D., Graham, N. A. J., Villéger, S., Mason, N. W. H., \& Bellwood, D. R. (2013). A functional approach reveals community responses to disturbances. Trends in Ecology and Evolution, 28, 167-177.

Muegge, B. D., Kuczynski, J., Knights, D., Clemente, J. C., González, A., Fontana, L., ... Gordon, J. I. (2011). Diet drives convergence in gut microbiome functions across mammalian phylogeny and within humans. Science, 332(6032), 970-974.

Munday, P. L. (2004). Habitat loss, resource specialization, and extinction on coral reefs. Global Change Biology, 10(10), 1642-1647.

Nagelkerken, I., Van Der Velde, G., Wartenbergh, S. L. J., Nugues, M. M., \& Pratchett, M. S. (2009). Cryptic dietary components reduce dietary overlap among sympatric butterflyfishes (Chaetodontidae). Journal of Fish Biology, 75(6), 1123-1143.

Nakamura, H., Kobayashi, J., Ohizumi, Y., \& Hirata, Y. (1982). Isolation and structure of aaptamine a novel heteroaromatic substance possessing $\alpha$-blocking activity from the sea sponge Aaptos. Tetrahedron Letters, Vol. 23, pp. 5555-5558.

Nelson S.G., Wilkins S.D. (1988). Sediment processing by the surgeonfish Ctenochaetus striatus at Moorea, French Polynesia. J. Fish Biol. 32, 817-824.

Newsome, S. D., Rio, Martinez del, C., Bearhop, S., \& Phillips, D. L. (2007). A Niche for Isotope Ecology. Frontiers in Ecology and the Environment, 5(8), 429-436.

Nielsen, J. M., Clare, E. L., Hayden, B., Brett, M. T., \& Kratina, P. (2018). Diet tracing in ecology: Method comparison and selection. Methods in Ecology and Evolution, 9(2), 278-291.

Nielsen, L. A. \& Johnson, D. L. (1992). Fisheries Techniques. Bethesda, MD: American Fisheries Society.

Odum, H. T., \& Odum, E. P. (1955). Trophic Structure and Productivity of a Windward Coral Reef Community on Eniwetok Atoll. Ecological Monographs, 25(3), 291-320. 
Olden, J. D., Poff, N. L. R., Douglas, M. R., Douglas, M. E., \& Fausch, K. D. (2004). Ecological and evolutionary consequences of biotic homogenization. Trends in Ecology and Evolution, 19(1), 18-24.

Olivotto, I., Planas, M., Simões, N., Holt, G. J., Avella, M. A., \& Calado, R. (2011). Advances in Breeding and Rearing Marine Ornamentals. Journal of the World Aquaculture Society, 42(2), 135-166.

O’Rorke, R., Lavery, S., \& Jeffs, A. (2012). PCR enrichment techniques to identify the diet of predators. Molecular Ecology Resources, Vol. 12, pp. 5-17.

Paine, R. T. (1966). Food Web Complexity and Species Diversity. The American Naturalist, Vol. 100, pp. $65-75$.

Paine, R. T. (1969). The Pisaster-Tegula Interaction: Prey Patches, Predator Food Preference, and Intertidal Community Structure. Ecology, 50(6), 950-961.

Parnell, A. C., Inger, R., Bearhop, S., \& Jackson, A. L. (2010). Source partitioning using stable isotopes: Coping with too much variation. PLoS ONE, 5(3), 1-5.

Parnell, A. C., Phillips, D. L., Bearhop, S., Semmens, B. X., Ward, E. J., Moore, J. W., ... Inger, R. (2013). Bayesian stable isotope mixing models. Environmetrics, 24(6), 387-399.

Parnell, A. (2016) Simmr: a stable isotope mixing model. https://cran.rproject.org/web/packages/simmr/index.html 2016

Parreira de Castro, D. M., Reis de Carvalho, D., Pompeu, P. D. S., Moreira, M. Z., Nardoto, G. B., \& Callisto, M. (2016). Land use influences niche size and the assimilation of resources by benthic macroinvertebrates in tropical headwater streams. PLoS ONE, 11(3), 1-19.

Parzanini, C., Parrish, C. C., Hamel, J. F., \& Mercier, A. (2019). Reviews and syntheses: Insights into deep-sea food webs and global environmental gradients revealed by stable isotope $\left(\delta^{15} \mathrm{~N}, \delta^{13} \mathrm{C}\right)$ and fatty acid trophic biomarkers. Biogeosciences, 16(14), 2837-2856.

Pauly, D., \& Watson, R. (2005). Background and interpretation of the "Marine Trophic Index" as a measure of biodiversity. Philosophical Transactions of the Royal Society B: Biological Sciences, $360(1454), 415-423$.

Pawlik, J. R. (1997). Fish predation on Caribbean reef sponges: an emerging perspective of chemical defences. Proc. 8th Int. Coral Reef Symp, Vol. 2, pp. 1255-1258.

Pawlik, J. R., Chanas, B., Toonen, R. J., \& Fenical, W. (1995). Defences of Caribbean sponges against predatory reef fish. I. Chemical deterrency. Marine Ecology Progress Series, 127(1-3), 183-194.

Pawlik, J. R. (2011). The Chemical Ecology of Sponges on Caribbean Reefs: Natural Products Shape Natural Systems. BioScience, 61(11), 888-898.

Pawlik, J. R. (1983). A Sponge-Eating Worm from Bermuda: Branchiosyllis Oculata. Marine Ecology, $4(1), 65-79$.

Pawlik, J. R., Loh, T. L., \& McMurray, S. E. (2018). A review of bottom-up vs. top-down control of sponges on Caribbean fore-reefs: What's old, what's new, and future directions. PeerJ, 2018(1), e4343.

Pawlik, J. R., Burkepile, D. E., \& Thurber, R. V. (2016). A Vicious Circle? Altered Carbon and Nutrient Cycling May Explain the Low Resilience of Caribbean Coral Reefs. BioScience, Vol. 66, pp. 470-476. 
Perea-Blázquez, A., Davy, S. K., \& Bell, J. J. (2013). Low functional redundancy in sponges as a result of differential picoplankton use. Biological Bulletin, 224(1), 29-34.

Pérez-España, H., \& Abitia-Cárdenas, L. A. (1996). Description of the digestive tract and feeding habits of the king angelfish and the Cortes angelfish. Journal of Fish Biology, 48(5), 807-817.

Peters, K. J., Amsler, C. D., McClintock, J. B., Van Soest, R. W. M., \& Baker, B. J. (2009). Palatability and chemical defences of sponges from the western Antarctic Peninsula. Marine Ecology Progress Series, 385, 77-85.

Phillips, D. L., Inger, R., Bearhop, S., Jackson, A. L., Moore, J. W., Parnell, A. C., ... Ward, E. J. (2014). Best practices for use of stable isotope mixing models in food-web studies. Canadian Journal of Zoology, 92(10), 823-835.

Pile, A. J., Patterson, M. R., \& Witman, J. D. (1996). In situ grazing on plankton $<10 \mu \mathrm{m}$ by the boreal sponge Mycale lingua. Marine Ecology Progress Series, 141(1-3), 95-102.

Pinnegar, J. K., \& Polunin, N. V. C. (1999). Differential fractionation of $\delta^{13} \mathrm{C}$ and $\delta^{15} \mathrm{~N}$ among fish tissues: Implications for the study of trophic interactions. Functional Ecology, 13(2), 225-231.

Pinsky, M. L., Eikeset, A. M., McCauley, D. J., Payne, J. L., \& Sunday, J. M. (2019). Greater vulnerability to warming of marine versus terrestrial ectotherms. Nature. 569(7754), 108-111.

Pitt, J. M. (1997). The Feeding Ecology of Rabbitfish (Siganidae) at Green Island Reef: ontogenetic and Interspecific Differences in Diet, Morphology and Habitat Utilisation. PhD thesis, James Cook University.

Pompanon, F., Deagle, B. E., Symondson, W. O. C., Brown, D. S., Jarman, S. N., \& Taberlet, P. (2012). Who is eating what: Diet assessment using next-generation sequencing. Molecular Ecology, 21, 19311950 .

Porter, J. W., \& Targett, N. M. (1988). Allelochemical Interactions Between Sponges and Corals. The Biological Bulletin, 175(2), 230-239.

Post, D. M. (2002). Using stable isotopes to estimate trophic position: Models, methods, and assumptions. Ecology, 83(3), 703-718.

Post, D. M., Layman, C. A., Arrington, D. A., Takimoto, G., Quattrochi, J., \& Montaña, C. G. (2007). Getting to the fat of the matter: Models, methods and assumptions for dealing with lipids in stable isotope analyses. Oecologia, 152(1), 179-189.

Powell, A. L. (2013). The impacts of predation and habitat degradation on coral reef sponge assemblages in SE Sulawesi, Indonesia. PhD thesis. Victoria University of Wellington.

Powell, A., Jones, T., Smith, D. J., Jompa, J., \& Bell, J. J. (2015). Spongivory in the Wakatobi Marine National Park, Southeast Sulawesi, Indonesia. Pacific Science, 69(4), 487-508.

Powell, A., Smith, D. J., Hepburn, L. J., Jones, T., Berman, J., Jompa, J., \& Bell, J. J. (2014). Reduced diversity and high sponge abundance on a sedimented Indo-pacific reef system: Implications for future changes in environmental quality. PLOS ONE, 9(1).

Pratchett, M. S., Graham, N. A. J., \& Cole, A. J. (2013). Specialist corallivores dominate butterflyfish assemblages in coral-dominated reef habitats. Journal of Fish Biology, 82(4), 1177-1191. 
Pratchett, M. S. (2005). Dietary overlap among coral-feeding butterflyfishes (Chaetodontidae) at Lizard Island, northern Great Barrier Reef. Marine Biology, 148(2), 373-382.

Pratchett, M. S., Hoey, A. S., \& Wilson, S. K. (2014). Reef degradation and the loss of critical ecosystem goods and services provided by coral reef fishes. Current Opinion in Environmental Sustainability, 7, 37-43.

Puccinelli, E., McQuaid, C. D., \& Ansorge, I. J. (2018). Factors affecting trophic compositions of offshore benthic invertebrates at a sub-Antarctic archipelago. Limnology and Oceanography, 63(5), 2206-2228.

Purcell, S. W., \& Bellwood, D. R. (1993). A functional analysis of food procurement in two surgeonfish species, Acanthurus nigrofuscus and Ctenochaetus striatus (Acanthuridae). Environmental Biology of Fishes, 37(2), 139-159.

Pyke, G. H., Pulliam, H. R., \& Charnov, E. L. (1977). Optimal Foraging: A selective review of theory and tests. The Quarterly Review of Biology, 52(2), 137-154.

Ramus, A. P., \& Long, Z. T. (2016). Producer diversity enhances consumer stability in a benthic marine community. Journal of Ecology, 104(2), 572-579.

Randall, J. E. \& Clements, K. D. (2001). Second revision of the surgeonfish genus Ctenochaetus (Perciformes: Acanthuridae), with descriptions of two new species. Indo-Pacific Fishes 32, 33.

Randall, J. E., \& Hartman, W. D. (1968). Sponge-feeding fishes of the West Indies. Marine Biology, 1(3), 216-225.

Randall, J.E. (1955) Fishes of the Gilbert Islands. Atoll Res. Bull. 47, 243 p.

Reaser, J. K., Pomerance, R., \& Thomas, P. O. (2008). Society for Conservation Biology Coral Bleaching and Global Climate Change: Scientific Findings and Policy Recommendations. Conservation Biology, 14(5), 1500-1511.

Redmond, N. E., Morrow, C. C., Thacker, R. W., Diaz, M. C., Boury-Esnault, N., Cárdenas, P., ... Collins, A. G. (2013). Phylogeny and systematics of Demospongiae in light of new small-subunit ribosomal DNA (18S) sequences. Integrative and Comparative Biology, 53(3), 388-415.

Reiswig, H. M. (1971). In situ pumping activities of tropical Demospongiae. Marine Biology, 9(1), 3850.

Reiswig, H. M. M. (1973). Population Dynamics of Three Jamaican Demospongiae. Bulletin of Marine Science, 23(2), 191-226.

Rhoades, D. F., \& Cates, R. G. (1976). Toward a General Theory of Plant Antiherbivore Chemistry. In J. W. Wallace \& R. L. Mansell (Eds.), Biochemical Interaction Between Plants and Insects (pp. 168213).

Rix, L., de Goeij, J. M., Mueller, C. E., Struck, U., Middelburg, J. J., van Duyl, F. C., ... van Oevelen, D. (2016). Coral mucus fuels the sponge loop in warm- and cold-water coral reef ecosystems. Scientific Reports, 6(1), 18715. 
Rix, L., de Goeij, J. M., van Oevelen, D., Struck, U., Al-Horani, F. A., Wild, C., \& Naumann, M. S. (2017). Differential recycling of coral and algal dissolved organic matter via the sponge loop. Functional Ecology, 31(3), 778-789.

Rix, L., De Goeij, J. M., Van Oevelen, D., Struck, U., Al-Horani, F. A., Wild, C., \& Naumann, M. S. (2018). Reef sponges facilitate the transfer of coral-derived organic matter to their associated fauna via the sponge loop. Marine Ecology Progress Series, 589, 85-96.

Rodgers, K. L., \& Wing, S. R. (2008). Spatial structure and movement of blue cod Parapercis colias in Doubtful Sound, New Zealand, inferred from $\delta^{13} \mathrm{C}$ and $\delta^{15} \mathrm{~N}$. Marine Ecology Progress Series, 359, 239-248.

Rogers, A., Blanchard, J. L., \& Mumby, P. J. (2018). Fisheries productivity under progressive coral reef degradation. Journal of Applied Ecology, 55, 1041-1049.

Rossi, G., Montori, S., Cerrano, C., \& Calcinai, B. (2015). The coral-killing sponge Chalinula nematifera (Porifera: Haplosclerida) along the eastern coast of Sulawesi Island (Indonesia). Italian Journal of Zoology, 82(1), 143-148.

Rossi, L., Lascio, A., Carlino, P., Calizza, E., \& Costantini, M. L. (2015). Predator and detritivore niche width helps to explain biocomplexity of experimental detritus-based food webs in four aquatic and terrestrial ecosystems. Ecological Complexity, 23, 14-24.

Rot, C., Goldfarb, I., Ilan, M., Huchon, D. (2006). Putative cross-kingdom horizontal gene transfer in sponge (Porifera) mitochondria. BMC Evol Biol 6,71.

Rovellini, A., Dunn, M. R., Fulton, E. A., Webster, N. S., Smith, D. J., Jompa, J., ... Bell, J. J. (2019). Decadal variability in sponge abundance and biodiversity on an Indo-Pacific coral reef. Marine Ecology Progress Series, 620, 63-76.

Ruzicka, R. R., Colella, M. A., Porter, J. W., Morrison, J. M., Kidney, J. A., Brinkhuis, V., ... Colee, J. (2013). Temporal changes in benthic assemblages on Florida Keys reefs 11 years after the 1997/1998 El Niño. Marine Ecology Progress Series, 489, 125-141.

Sale, P. F., Agardy, T., Ainsworth, C. H., Feist, B. E., Bell, J. D., Christie, P., ... Sheppard, C. R. C. (2014). Transforming management of tropical coastal seas to cope with challenges of the 21st century. Marine Pollution Bulletin, 85(1), 8-23.

Salm, R. V. (1983). Coral reefs of the Western Indian Ocean: A Threatened Heritage. Ambio, 12(6), 349-353.

Sano, M. (1989). Feeding habits of Japanese butterflyfishes (Chaetodontidae). Environmental Biology of Fishes, 25(1-3), 195-203.

Santos, C. P., Coutinho, A. B., \& Hajdu, E. (2002). Spongivory by Eucidaris tribuloides from Salvador, Bahia (Echinodermata: Echinoidea). Journal of the Marine Biological Association of the United Kingdom, 82(2), 295-297.

Satoh, R., Saito, T., Ogata, H., Ohsaki, A., Iida, T., Asahina, K., ... Hagey, L. R. (2014). NMethyltaurine $\mathrm{N}$-acyl amidated bile acids and deoxycholic acid in the bile of angelfish (Pomacanthidae): A novel bile acid profile in Perciform fish. Steroids, 80, 15-23. 
Schoener, T.W. (2009). Ecological niche. Pages 3-13. In: S.A. Levin (Ed.). The Princeton Guide to Ecology. Princeton University Press, Princeton, NJ.

Schoener, Thomas W. (1986). "The Ecological Niche". In Cherret, J. M. (ed.). Ecological concepts: the contribution of ecology to an understanding of the natural world. Cambridge: Blackwell Scientific Publications.

Schrader, C., Schielke, A., Ellerbroek, L., \& Johne, R. (2012). PCR inhibitors - occurrence, properties and removal. Journal of Applied Microbiology, 113, 1014-1026.

Schupp, P., Eder, C., Paul, V., \& Proksch, P. (1999). Distribution of secondary metabolites in the sponge Oceanapia sp. and its ecological implications. Marine Biology, 135(4), 573-580.

Seo, K. S., \& Lee, Y. (2009). A First Assessment of Invasive Marine Species on Chinese and Korean Coasts. In G. Rilov \& J. A. Crooks (Eds.), Biological Invasions in Marine Ecosystems: Ecological, Management, and Geographic Perspectives (pp. 577-585).

Shen, K.-N., Chang, C.-W., Chen, C.-H., \& Hsiao, C.-D. (2016). Next-generation sequencing yields the complete mitochondrial genome of the Regal angelfish, Pygoplites diacanthus (Perciformes: Pomacanthidae). Mitochondrial DNA. Part A, DNA Mapping, Sequencing, and Analysis, 27(6), $4149-4150$.

Simister, R., Taylor, M. W., Rogers, K. M., Schupp, P. J., \& Deines, P. (2013). Temporal molecular and isotopic analysis of active bacterial communities in two New Zealand sponges. FEMS Microbiology Ecology, 85(1), 195-205.

Sitnikova, T., Kiyashko, S., Bukshuk, N., Zemskaya, T., Khlystov, O., \& Moore, M. V. (2016). Stable isotope signatures and distribution of deepwater sponges in Lake Baikal. Hydrobiologia, 773(1), 1122.

Slattery, M., Gochfeld, D. J., Diaz, M. C., Thacker, R. W., \& Lesser, M. P. (2016). Variability in chemical defence across a shallow to mesophotic depth gradient in the Caribbean sponge Plakortis angulospiculatus. Coral Reefs, 35(1), 11-22.

Smith, B. N., \& Epstein, S. (1970). Biogeochemistry of the Stable Isotopes of Hydrogen and Carbon in Salt Marsh Biota. Plant Physiology, 46(5), 738-742.

Smith, M. D., \& Knapp, A. (2003). Dominant species maintain ecosystem function with non-random species loss. Ecology Letters, 6, 509-517.

Solomon, C. T., Jones, S. E., Weidel, B. C., Buffam, I., Fork, M. L., Karlsson, J., ... Saros, J. E. (2015). Ecosystem Consequences of Changing Inputs of Terrestrial Dissolved Organic Matter to Lakes: Current Knowledge and Future Challenges. Ecosystems, 18(3), 376-389.

Southwell, M. W., Popp, B. N., \& Martens, C. S. (2008). Nitrification controls on fluxes and isotopic composition of nitrate from Florida Keys sponges. Marine Chemistry, 108(1-2), 96-108.

Stefanoudis, P. V., Gress, E., Pitt, J. M., Smith, S. R., Kincaid, T., Rivers, M., ... Rogers, A. D. (2019). Depth-dependent structuring of reef fish assemblages from the shallows to the rariphotic zone. Frontiers in Marine Science, 6(JUN), 1-16. 
Stringell, T. B., Clerveaux, W. V., Godley, B. J., Kent, F. E. A., Lewis, E. D. G., Marsh, J. E., ... Broderick, A. C. (2016). Taxonomic distinctness in the diet of two sympatric marine turtle species. Marine Ecology, 37(5), 1036-1049.

Swearingen, D. C., \& Pawlik, J. R. (1998). Variability in the chemical defence of the sponge Chondrilla nucula against predatory reef fishes. Marine Biology, 131(4), 619-627.

Sweeting, C. J., Barry, J., Barnes, C., Polunin, N. V. C., \& Jennings, S. (2007). Effects of body size and environment on diet-tissue $\delta 15 \mathrm{~N}$ fractionation in fishes. Journal of Experimental Marine Biology and Ecology, 340(1), 1-10.

Symondson, W. O. C. (2002). Molecular identification of prey in predator diets. Molecular Ecology, Vol. 11, pp. 627-641.

Taylor, M. W., Radax, R., Steger, D., \& Wagner, M. (2007). Sponge-Associated Microorganisms: Evolution, Ecology, and Biotechnological Potential. Microbiology and Molecular Biology Reviews, 71(2), 295-347.

Tebbett, S. B., Goatley, C. H. R., \& Bellwood, D. R. (2017). Clarifying functional roles: algal removal by the surgeonfishes Ctenochaetus striatus and Acanthurus nigrofuscus. Coral Reefs, 36(3), 803-813.

Thorn, J. S., Nijman, V., Smith, D., \& Nekaris, K. A. I. (2009). Ecological niche modelling as a technique for assessing threats and setting conservation priorities for Asian slow lorises (Primates: Nycticebus). Diversity and Distributions, 15(2), 289-298.

Thurber, A. R. (2007). Diets of Antarctic sponges: Links between the pelagic microbial loop and benthic metazoan food web. Marine Ecology Progress Series, 351, 77-89.

Tieszen, L. L., Boutton, T. W., Tesdahl, K. G., \& Slade, N. A. (1983). Fractionation and turnover of stable carbon isotopes in animal tissues: Implications for $\delta^{13} \mathrm{C}$ analysis of diet. Oecologia, 57(1-2), 3237.

Tilman, D., \& Downing, J. A. (1994). Biodiversity and stability in grasslands. Nature, 367(6461), 363365 .

Tjensvoll, I., Kutti, T., Fosså, J. H., \& Bannister, R. J. (2013). Rapid respiratory responses of the deepwater sponge Geodia barretti exposed to suspended sediments. Aquatic Biology, 19(1), 65-73.

Topçu, N. E., Pérez, T., Grégori, G., \& Harmelin-Vivien, M. (2010). In situ investigation of Spongia officinalis (Demospongiae) particle feeding: Coupling flow cytometry and stable isotope analysis. Journal of Experimental Marine Biology and Ecology, 389(1-2), 61-69.

Turicchia, E., Hoeksema, B. W., \& Ponti, M. (2018). The coral-killing sponge Chalinula nematifera as a common substrate generalist in Komodo National Park, Indonesia. Marine Biology Research, 14(8), $827-833$.

Vacelet, J., Boury-Esnault, N., Fiala-Medioni, A., \& Fisher, C. R. (1995). A methanotrophic carnivorous sponge. Nature, 170(1993), 295-296.

Vacelet, J. (1975) Etude en microscopie electronique de l'association entre bacteries et spongiaires du genre Verongia (Dictyoceratida). J Microsc Biol Cell 23, 271-288. 
Valladares, G., Cagnolo, L., \& Salvo, A. (2012). Forest fragmentation leads to food web contraction. Oikos, 121(2), 299-305.

Van Duyl, F. C., Moodley, L., Nieuwland, G., van Ijzerloo, L., van Soest, R. W. M., Houtekamer, M., ... Middelburg, J. J. (2011). Coral cavity sponges depend on reef-derived food resources: Stable isotope and fatty acid constraints. Marine Biology, 158(7), 1653-1666.

Van Duyl, F. C., Mueller, B., \& Meesters, E. H. (2018). Spatio-temporal variation in stable isotope signatures $(\delta 13 \mathrm{C}$ and $\delta 15 \mathrm{~N})$ of sponges on the Saba Bank. PeerJ, 2018(8), 1-25.

Van Soest, R. W. M., \& Soest, R. W. M. V. A. N. (1989). The Indonesian sponge fauna: A status report. Netherlands Journal of Sea Research, 23(2), 223-230.

Van Soest, R. W. M., Boury-Esnault, N., Vacelet, J., Dohrmann, M., Erpenbeck, D., de Voogd, N. J., ... Hooper, J. N. A. (2012). Global diversity of sponges (Porifera). PLoS ONE, Vol. 7.

Venables, W. N., \& Ripley, B. D. (2002). Modern Applied Statistics with S. Fourth Edition. Springer.

Verdín Padilla, C. J., Carballo, J. L., \& Camacho, M. L. (2010). A Qualitative Assessment of SpongeFeeding Organisms from the Mexican Pacific Coast. The Open Marine Biology Journal, 4, 39-46.

Veron, J. E. N., Hoegh-guldberg, O., Lenton, T. M., Lough, J. M., Obura, D. O., Pearce-kelly, P., ... Rogers, A. D. (2009). The coral reef crisis: The critical importance of < $350 \mathrm{ppm}$ CO 2. Marine Pollution Bulletin, 58(10), 1428-1436.

Vestheim, H., \& Jarman, S. N. (2008). Blocking primers to enhance PCR amplification of rare sequences in mixed samples - A case study on prey DNA in Antarctic krill stomachs. Frontiers in Zoology, 5, 1-11.

Vicente, J., Silbiger, N. J., Beckley, B. A., Raczkowski, C. W., \& Hill, R. T. (2016). Impact of high pCO2 and warmer temperatures on the process of silica biomineralization in the sponge Mycale grandis. ICES Journal of Marine Science. 73, 704-714.

Wagner, D., Kosaki, R. K., Spalding, H. L., Whitton, R. K., Pyle, R. L., Sherwood, A. R., .. Calcinai, B. (2014). Mesophotic surveys of the flora and fauna at Johnston Atoll, Central Pacific Ocean. Marine Biodiversity Records, 7.

Walters, K.D. \& Pawlik, J.R. (2005). Is there a trade-off between wound-healing and chemical defences among Caribbean reef sponges? Integr Comp Biol. 45(2):352-358.

Wang, S. K., Xu, C., Wang, Y., Yang, G., Zhang, T. T., Zhao, F., \& Zhuang, P. (2017). Nonlethal sampling for stable isotope analysis of juvenile Chinese sturgeon (Acipenser sinensis): Comparing $\delta^{13} \mathrm{C}$ and $\delta^{15} \mathrm{~N}$ signatures in muscle and fin tissues. Journal of Applied Ichthyology, 33(5), 877-884.

Ward, N. D., Keil, R. G., Medeiros, P. M., Brito, D. C., Cunha, A. C., Dittmar, T., ... Richey, J. E. (2013). Degradation of terrestrially derived macromolecules in the Amazon River. Nature Geoscience, 6(7), 530-533.

Weisz, J. B., Hentschel, U., Lindquist, N., \& Martens, C. S. (2007). Linking abundance and diversity of sponge-associated microbial communities to metabolic differences in host sponges. Marine Biology, 152(2), 475-483. 
Weisz, J. B., Massaro, A. J., Ramsby, B. D., Hill, S., Weisz, J. B., Massaro, A. J., ... Hill, M. S. (2010). Zooxanthellar Symbionts Shape Host Sponge Trophic Status Through Translocation of Carbon. Biological Bulletin. 219(3), 189-197.

Wild, C., Huettel, M., Klueter, A., Kremb, S. G., Rasheed, M. Y. M., \& Jørgensen, B. B. (2004). Coral mucus functions as an energy carrier and particle trap in the reef ecosystem. Nature, 428(6978), 66-70.

Wild, C., Naumann, M., Niggl, W., Haas, A. (2010). Carbohydrate composition of mucus released by scleractinian warm- and cold-water reef corals. Aquat Biol 10, 41-45.

Wilkinson, C. R. (1987). Interocean Differences in Size and Nutrition of Coral Reef Sponge Populations. Science, 236(4809), 1654-1657.

Wilkinson, C., 2004. Executive summary. In: Wilkinson, C. (Ed.), Status of Coral Reefs of the World, Australian Institute of Marine Science, Townsville, Australia, vol. 1. pp. 7-66.

Williams, E. H., Bartels, P. J., \& Bunkley-Williams, L. (1999). Predicted disappearance of coral-reef ramparts: A direct result of major ecological disturbances. Global Change Biology, 5(8), 839-845.

Wilson, D. M., Puyana, M., Fenical, W., \& Pawlik, J. R. (1999). Chemical defence of the Caribbean reef sponge Axinella corrugata against predatory fishes. Journal of Chemical Ecology, 25(12), 28112823.

Wilson, S. K., Bellwood, D. R., Choat, J. H., \& Furnas, M. J. (2003). Detritus in the epilithic algal matrix and its use by coral reef fishes. Oceanography and Marine Biology, Vol 41, 41(January 2003), 279-309.

Wing, S. R., Beer, N. A., \& Jack, L. (2012). Resource base of blue cod Parapercis colias subpopulations in marginal fjordic habitats is linked to chemoautotrophic production. Marine Ecology Progress Series, $466,205-214$.

Wing, S. R., \& Jack, L. (2014). Fiordland: The ecological basis for ecosystem management. New Zealand Journal of Marine and Freshwater Research, 48(4), 577-593.

Wing, S., \& Jack, L. (2012). Resource specialisation among suspension-feeding invertebrates on rock walls in Fiordland, New Zealand, is driven by water column structure and feeding mode. Marine Ecology Progress Series, 452, 109-118.

Wooster, M.K., McMurray, S.E., Pawlik, J.R., Morán, X.A.G., Berumen, M.L. (2019). Feeding and respiration by giant barrel sponges across a gradient of food abundance in the Red Sea. Limnol. Oceanogr. 64:1790-801

Wulff, J. L. (1997). Parrotfish predation on cryptic sponges of Caribbean coral reefs. Marine Biology, $129(1), 41-52$.

Wulff, J. (2001). Assessing and monitoring coral reef sponges: Why and how? Bulletin of Marine Science, 69(2), 831-846.

Wulff, J. (2017). Bottom-up and top-down controls on coral reef sponges: disentangling within-habitat and between-habitat processes. Ecology, 98(4), 1130-1139.

Wulff, J. (2012). Ecological Interactions and the Distribution, Abundance, and Diversity of Sponges. In Advances in Marine Biology (1st ed., Vol. 61, pp. 273-344). 
Wulff, J. L. (1997). Causes and consequences in sponge diversity and abundance between the Caribbean and Eastern Pacific of Panama. Proceeding of 8th International Coral Reef Symposium, 2, 1377-1382.

Wulff, J. L. (2006). Ecological interactions of marine sponges. Canadian Journal of Zoology, Vol. 84, pp. 146-166.

Wulff, J. L. (1994). Sponge feeding by Caribbean angelfishes, trunkfishes, and filefishes. In: Van Soest RWM, van Kempen TMG, Braekman J-C, eds. Sponges in Time and Space: Biology, Chemistry, Paleontology. Rotterdam/Brookfield: A.A. Balkema.

Wulff, L. (1995). Sponge-feeding by the Caribbean starfish Oreaster reticulatus. Marine Biology, 123(2), 313-325

Wyatt, A. S. J., Waite, A. M., \& Humphries, S. (2012). Stable isotope analysis reveals community-level variation in fish trophodynamics across a fringing coral reef. Coral Reefs, 31(4), 1029-1044.

Yahel, G., Eerkes-Medrano, D. I., \& Leys, S. P. (2006). Size independent selective filtration of ultraplankton by hexactinellid glass sponges. Aquatic Microbial Ecology, 45(2), 181-194.

Yahel, G., Sharp, J. H., Marie, D., Häse, C., \& Genin, A. (2003). In situ feeding and element removal in the symbiont-bearing sponge Theonella swinhoei: Bulk DOC is the major source for carbon. Limnology and Oceanography, 48(1), 141-149.

Zhukova, N. V. (2014). Lipids and fatty acids of nudibranch molluscs: Potential sources of bioactive compounds. Marine Drugs, 12(8), 4578-4592.

Żółtowska-Aksamitowska, S., Tsurkan, M. V, Lim, S. C., Meissner, H., Tabachnick, K., Shaala, L. A., ... Ehrlich, H. (2018). The demosponge Pseudoceratina purpurea as a new source of fibrous chitin. International Journal of Biological Macromolecules, 112, 1021-1028. 


\section{Appendices}

\section{Appendix A}

Trial video observations of sponge-grazing

Petrosia corticata at the Ridge (with feeding scars)

During the 148 minutes of footage recorded on the exposed inner tissue of Petrosia corticata, 888 bites were recorded giving a grazing intensity rate of $112.6 \mathrm{~min}^{-1} \mathrm{~m}^{-2}$. The majority of bites were directed at an area of exposed choanosome and sponge tissue was observed being removed by all species. The most voracious predator was Zanclus cornutus which took $59.5 \%$ of bites, followed by Pygoplites diacanthus taking 25.5\% and Siganus punctatus took 6.6\%. Other species observed taking bites included Pomacanthus imperator, Heniochus singularius, Centropyge nox and Scarus ghobban (terminal phase). Pomacanthus imperator took the highest no. of bites in a single feeding event (34).

Lamellodysedia herbacea at Sampela (no feeding scars)

In the 130 minutes of footage recorded on $L$. dysedia, 68 bites were observed on the sponge surface giving a total grazing intensity rate of $4.4 \mathrm{~min}^{-1} \mathrm{~m}^{-2}$. Scarus flavipectoralis juveniles took the most numerous bites (45.6\%), followed by Ctenochaetus binotatus (29.4\%). Zanclus cornutus and Centropyge kleinii took 8 and 7 bites respectively and 2 bites were made by Centropyge tibicen. Although bites were recorded on sponge surface, there was no evidence of sponge tissue being removed in the video.

Aaptos suberitoides at Sampela (with feeding scars)

In the 230 minutes of footage recorded on Aaptos suberitoides, 133 bites were recorded giving a grazing intensity rate of $4.6 \mathrm{~min}^{-1} \mathrm{~m}^{-2}$. The most numerous bites recorded by the angelfish Centropyge bicolor (76.7\%) followed by the juvenile parrotfish Scarus flavipectoralis $(9.8 \%) . \leq 5 \%$ of bites were recorded by Scarus niger, Centropyge tibicen and Zanclus cornutus. Canthigaster valentini, Chaetodon kleinii, Halichoeres prosopeion and Sufflamen bursa all took only one bite in the whole video. Although bites were recorded on sponge surface, there was no evidence of sponge tissue being removed in the video.

Green tubular sponge (Theonella sp?) at KDS (with feeding scars)

In the 33 minutes of footage recorded on the green tubular sponge, a total of 385 bites were recorded by six species. The majority of bites were taken by Pygoplites diacanthus (295) and were directed towards an exposed bit of choanosome which made up approximately $4.8 \%$ of total sponge area. This area of exposed inner tissue had a grazing intensity rate from Pygoplites diacanthus of 265.8 bites min ${ }^{1} \mathrm{~m}^{-2}$ whereas the undisturbed sponge surface had a grazing intensity rate of 10.3 bites $\mathrm{min}^{-1} \mathrm{~m}^{-2}$. Zanclus cornutus took the second-highest number of bites (47) all of which were directed towards the white exposed inner tissue giving a grazing intensity rate of 74.8 bites $\min ^{-1} \mathrm{~m}^{-2}$. Pomacanthus xanthometopon 
was also sighted feeding from the sponge, taking 4 bites on the white exposed inner tissue. Other species noted were Centropyge tibicen, Chaetodon kleinii and Ctenochaetus binotatus, taking 25, 9 and 4 bites respectively, all from the undisturbed sponge surface.

Xestospongia spp. at Buoy 1

During the 96 minutes of video footage recorded on Xestospongia sp. at Buoy 1, 2423 bites were recorded giving a grazing intensity rate of $61.4 \mathrm{~min}^{-1} \mathrm{~m}^{-2}$. Ctenochaetus binotatus took the most numerous bites (62.5\%) followed by Coradion melanopus (21.3\%), Zanclus cornutus (5.1\%) and Forcipiger flavissimus (4.5\%). Eight additional species: Chaetodon kleinii, Thalassoma lunare, Anampses meleagrides, Balistapus undulatus, Neoglyphidodon melas, Scarus niger (terminal phase), Odonus niger and Halichoeres prosopeion were all observed taking < $2 \%$ of total bites recorded.

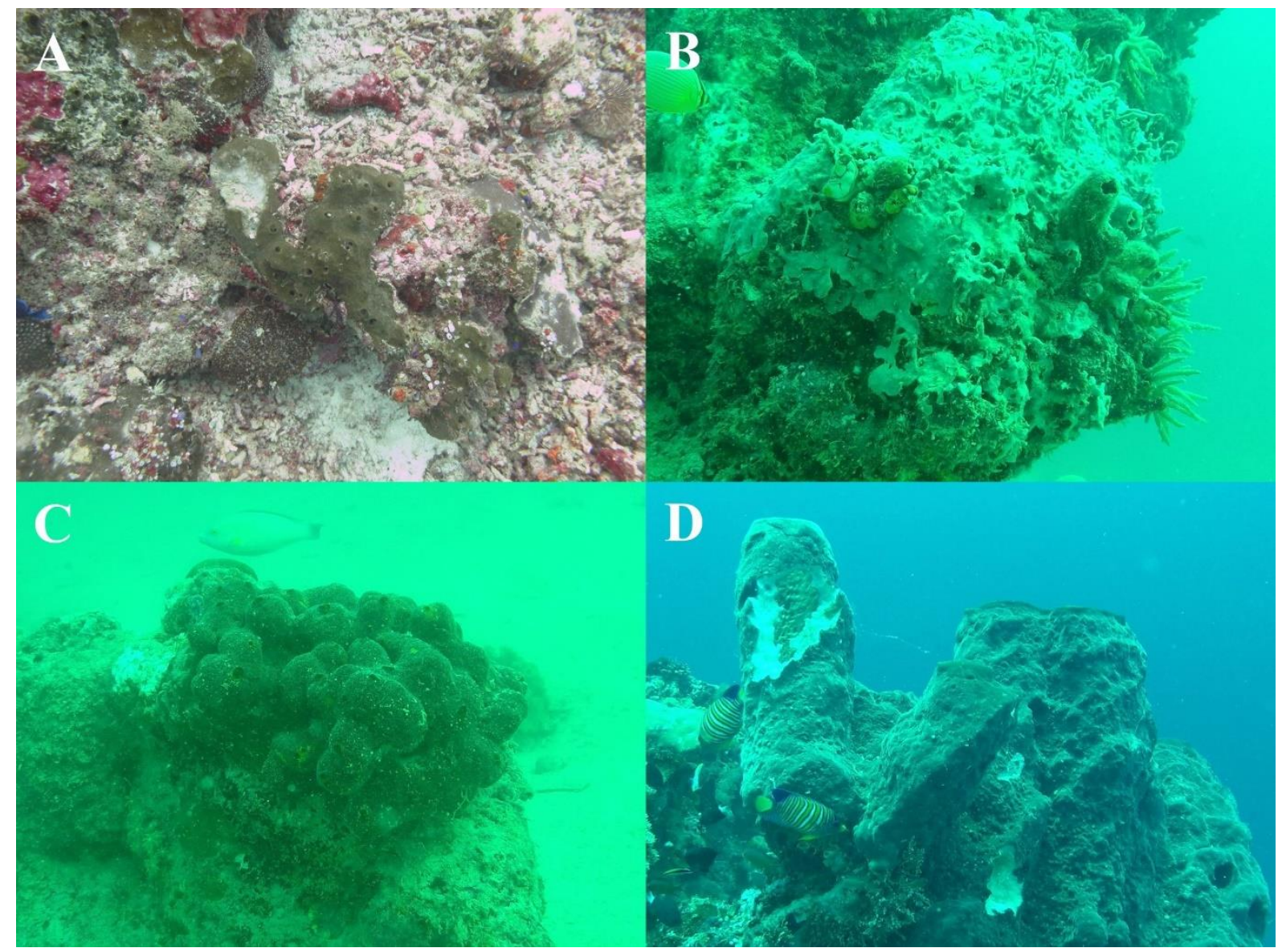

Figure 1. Screenshots of: $\mathrm{A}=$ Petrosia corticata; $\mathrm{B}=$ Lamellodysedia herbacea; $\mathrm{C}=$ Aaptos suberitoides; $\mathrm{D}=$ Green tubular sponge. 


\section{Appendix B}

Table 1. Negative binominal modelling of fish predation (total bites) between sites in the Wakatobi MNP with the 2D area of sponge $\left(\mathrm{m}^{-2}\right)$ captured in the frame and the length of footage $\left(\mathrm{min}^{-1}\right)$ fitted as offsets in the model. Note, Sampela was used as the reference for the factor to which the other sites were compared.

\begin{tabular}{|c|c|c|c|c|}
\hline Coefficients & Estimate & SE & $\mathrm{Z}$ value & $\operatorname{Pr}(>|z|)$ \\
\hline Intercept & -10.801 & 0.2511 & -43.02 & $<2 \mathrm{e}-16$ \\
\hline $\mathrm{B} 1$ & 0.9199 & 0.3549 & 2.592 & 0.0095 \\
\hline Ridge & 1.0476 & 0.3676 & 2.85 & 0.0044 \\
\hline KDS & 0.5753 & 0.3674 & 1.566 & 0.1174 \\
\hline \multicolumn{2}{|c|}{ Dispersion parameter } & 1.992 & & \\
\hline \multicolumn{2}{|c|}{ SE } & 0.486 & & \\
\hline \multicolumn{2}{|l|}{ AIC } & 456.01 & & \\
\hline \multicolumn{2}{|c|}{$2 \times$ log-likelihood } & 446.01 & & \\
\hline
\end{tabular}

Table 2. PERMANOVA (main test) of the effect of site on the identity of fish taking bites from Xestospongia spp. in the Wakatobi Marine National Park, Indonesia.

\begin{tabular}{|lrrrrrr|}
\hline Factor & df & SS & MS & Pseudo-F & P(perm) & Unique perms \\
\hline Site & 3 & 11042 & 3680.5 & 1.73 & 0.012 & 999 \\
Res & 26 & 55262 & 2125.2 & & & \\
Total & 29 & 66304 & & & & \\
& \multicolumn{7}{l}{ PERMDISP on group factor 'Site', F = 1.38, $\mathrm{p}=0.47$} & & & \\
\hline
\end{tabular}

Table 3. PERMANOVA (main test) of the effect of site on sponge-grazing fish densities in the Wakatobi Marine National Park, Indonesia.

\begin{tabular}{|lrrrrrr|}
\hline Factor & df & SS & MS & Pseudo-F & P(perm) & Unique perms \\
\hline Site & 3 & 5719.8 & 1906.6 & 3.95 & 0.001 & 999 \\
Res & 20 & 9643.5 & 482.17 & & & \\
Total & 23 & 15363 & & & & \\
& \\
\hline \multicolumn{7}{l}{ PERMDISP on group factor 'Site', $\mathrm{F}=3.1, \mathrm{p}=0.11$} \\
\hline
\end{tabular}


Table 4. Repeated measures analysis on a subset $(n=12)$ of quadrats to determine the appropriate number of points used in CPCe analysis. $\mathrm{A}=$ main test and $\mathrm{B}=$ pairwise tests. 60 points recorded significantly more benthic categories than $5,10,20$ points and there was a very close to significant result with 30 points. There was no difference in the number of benthic categories recorded between 60 and 120 points.

\begin{tabular}{lrrrlr}
\hline A & df & \multicolumn{1}{c}{ Sum Sq } & Mean Sq & F & $\operatorname{Pr}(>\mathrm{F})$ \\
\hline Points & 5 & 130.61 & 26.122 & 62.32 & $<0.001$ \\
Residuals & 55 & 23.06 & 0.419 & & \\
\hline
\end{tabular}

\begin{tabular}{|c|c|c|c|c|c|}
\hline B & Estimate & $\begin{array}{l}\text { Std. } \\
\text { Error }\end{array}$ & $\mathrm{z}$ value & $\operatorname{Pr}(>|z|)$ & \\
\hline 120points -10 points $==0$ & 3.0833 & 0.2643 & 11.665 & $<0.001$ & *** \\
\hline 20points -10 points $==0$ & 1.4167 & 0.2643 & 5.36 & $<0.001$ & $* * *$ \\
\hline 30points -10 points $==0$ & 2.1667 & 0.2643 & 8.197 & $<0.001$ & *** \\
\hline 5points -10 points $==0$ & -0.4167 & 0.2643 & -1.576 & 0.61419 & \\
\hline 60points -10 points $==0$ & 2.9167 & 0.2643 & 11.035 & $<0.001$ & *** \\
\hline 20points -120 points $==0$ & -1.6667 & 0.2643 & -6.305 & $<0.001$ & *** \\
\hline 30points -120 points $==0$ & -0.9167 & 0.2643 & -3.468 & 0.00694 & ** \\
\hline 5 points -120 points $==0$ & -3.5 & 0.2643 & -13.242 & $<0.001$ & *** \\
\hline 60points -120 points $==0$ & -0.1667 & 0.2643 & -0.631 & 0.98878 & \\
\hline 30points -20 points $==0$ & 0.75 & 0.2643 & 2.837 & 0.05178 & \\
\hline 5points - 20points $==0$ & -1.8333 & 0.2643 & -6.936 & $<0.001$ & *** \\
\hline 60points -20 points $==0$ & 1.5 & 0.2643 & 5.675 & $<0.001$ & *** \\
\hline 5points -30 points $==0$ & -2.5833 & 0.2643 & -9.773 & $<0.001$ & $* * *$ \\
\hline 60points -30 points $==0$ & 0.75 & 0.2643 & 2.837 & 0.05178 & \\
\hline 60points -5 points $==0$ & 3.3333 & 0.2643 & 12.611 & $<0.001$ & $* * *$ \\
\hline
\end{tabular}

Table 5. PERMANOVA (main test) of the effect of site on benthic community composition in the Wakatobi Marine National Park, Indonesia.

\begin{tabular}{|lrrrrrr|}
\hline Factor & df & SS & MS & Pseudo-F & P(perm) & Unique perms \\
\hline Site & 2 & 8375.6 & 4187.8 & 9.77 & 0.001 & 999 \\
Res & 27 & 11571 & 428.54 & & & \\
Total & 29 & 19946 & & & & \\
& \\
\hline \multicolumn{7}{l}{ PERMDISP on group factor 'Site', F $=1.13, \mathrm{p}=0.39$} \\
\hline
\end{tabular}




\section{Appendix C}

Table 1. Demosponge dataset created using 18S rDNA sequence data downloaded from the GenBank database and used in phylogenetic analyses.

\begin{tabular}{|c|c|c|}
\hline Group & Accession & Definition \\
\hline Outgroup & AF100949 & $\begin{array}{l}\text { Rhabdocalyptus dawsoni } 18 \mathrm{~S} \text { ribosomal RNA gene, complete } \\
\text { sequence }\end{array}$ \\
\hline \multirow[t]{18}{*}{ Agelasida } & KC902123 & $\begin{array}{l}\text { Acanthostylotella cornuta voucher 0CDN8730-X small subunit } \\
18 \text { S ribosomal RNA gene, partial sequence }\end{array}$ \\
\hline & AY737640 & Agelas dispar 18S ribosomal RNA gene, complete sequence \\
\hline & KC902206 & $\begin{array}{l}\text { Agelas sp. USNM } 1133824 \text { small subunit } 18 \text { S ribosomal RNA } \\
\text { gene, partial sequence }\end{array}$ \\
\hline & AB922832 & $\begin{array}{l}\text { Agelas sp. ARY-006 gene for } 18 \mathrm{~S} \text { ribosomal RNA, partial } \\
\text { sequence }\end{array}$ \\
\hline & AY734443 & Agelas conifera $18 \mathrm{~S}$ ribosomal RNA gene, complete sequence \\
\hline & EU702411 & Agelas schmidti $18 \mathrm{~S}$ ribosomal RNA gene, complete sequence \\
\hline & KX622155 & $\begin{array}{l}\text { Agelas oroides voucher TAU_Po.25569 18S ribosomal RNA } \\
\text { gene, partial sequence }\end{array}$ \\
\hline & AY769087 & Agelas clathrodes $18 \mathrm{~S}$ ribosomal RNA gene, partial sequence \\
\hline & KC902253 & $\begin{array}{l}\text { Agelas } \text { sp. n. USNM } 1133819 \text { small subunit } 18 \text { S ribosomal RNA } \\
\text { gene, partial sequence }\end{array}$ \\
\hline & KC902036 & $\begin{array}{l}\text { Agelas sp. USNM } 1204819 \text { small subunit 18S ribosomal RNA } \\
\text { gene, partial sequence }\end{array}$ \\
\hline & KC902288 & $\begin{array}{l}\text { Agelas sp. n. USNM } 1133823 \text { small subunit } 18 \text { S ribosomal RNA } \\
\text { gene, partial sequence }\end{array}$ \\
\hline & EF654520 & $\begin{array}{l}\text { Agelas sp. UCMPWC1026 small subunit ribosomal RNA gene, } \\
\text { partial sequence }\end{array}$ \\
\hline & KC902051 & $\begin{array}{l}\text { Astrosclera willeyana voucher } 0 \mathrm{CDN} 5435-\mathrm{R} \text { small subunit } 18 \mathrm{~S} \\
\text { ribosomal RNA gene, partial sequence }\end{array}$ \\
\hline & KC902134 & $\begin{array}{l}\text { Astroscleridae sp. BMOO-04629 small subunit } 18 \text { S ribosomal } \\
\text { RNA gene, partial sequence }\end{array}$ \\
\hline & KC902025 & $\begin{array}{l}\text { Astroscleridae sp. BMOO-09934 small subunit 18S ribosomal } \\
\text { RNA gene, partial sequence }\end{array}$ \\
\hline & KC901906 & $\begin{array}{l}\text { Amphinomia sulphurea voucher } 0 \mathrm{M} 9 \mathrm{H} 2288-\mathrm{F} \text { small subunit } 18 \mathrm{~S} \\
\text { ribosomal RNA gene, partial sequence }\end{array}$ \\
\hline & KC902371 & $\begin{array}{l}\text { Hymerhabdia typica voucher BELUM: Mc4588 small subunit } \\
18 \mathrm{~S} \text { ribosomal RNA gene, partial sequence }\end{array}$ \\
\hline & KC902182 & $\begin{array}{l}\text { Prosuberites longispinus voucher BELUM: Mc } 7173 \text { small } \\
\text { subunit } 18 \text { S ribosomal RNA gene, partial sequence }\end{array}$ \\
\hline \multirow[t]{6}{*}{ Clionaida } & KC902382 & $\begin{array}{l}\text { Cervicornia cuspidifera voucher 0M9G1351-I small subunit 18S } \\
\text { ribosomal RNA gene, partial sequence }\end{array}$ \\
\hline & KC902145 & $\begin{array}{l}\text { Cliona varians voucher 0M9G1439-C small subunit } 18 \mathrm{~S} \\
\text { ribosomal RNA gene, partial sequence }\end{array}$ \\
\hline & KX866795 & $\begin{array}{l}\text { Cliona viridis voucher Po. } 25908 \text { 18S ribosomal RNA gene, } \\
\text { partial sequence }\end{array}$ \\
\hline & KX894476 & $\begin{array}{l}\text { Spheciospongia sp. DTTH-2018 voucher SPV 18S ribosomal } \\
\text { RNA gene, partial sequence }\end{array}$ \\
\hline & AY734440 & $\begin{array}{l}\text { Spheciospongia vesparium } 18 \mathrm{~S} \text { ribosomal RNA gene, complete } \\
\text { sequence }\end{array}$ \\
\hline & KC762725 & $\begin{array}{l}\text { Diplastrella megastellata isolate 1_9 18S ribosomal RNA gene, } \\
\text { partial sequence }\end{array}$ \\
\hline
\end{tabular}




\begin{tabular}{|c|c|c|}
\hline & KC902056 & $\begin{array}{l}\text { Cliona } \text { sp. SI06x31 small subunit } 18 \text { S ribosomal RNA gene, } \\
\text { partial sequence }\end{array}$ \\
\hline & KC902383 & $\begin{array}{l}\text { Cliona celata voucher BELUM: Mc5497 small subunit } 18 \mathrm{~S} \\
\text { ribosomal RNA gene, partial sequence }\end{array}$ \\
\hline & KC902040 & $\begin{array}{l}\text { Spirastrella cf. coccinea USNM } 1133785 \text { voucher } \\
\text { USNM_1133785 small subunit 18S ribosomal RNA gene, partial } \\
\text { sequence }\end{array}$ \\
\hline & KX866784 & $\begin{array}{l}\text { Spirastrella cunctatrix voucher Po. } 2552718 \mathrm{~S} \text { ribosomal RNA } \\
\text { gene, partial sequence }\end{array}$ \\
\hline & KX894463 & Spirastrella sp. SPS.1 18S ribosomal RNA gene, partial sequence \\
\hline & KC902020 & $\begin{array}{l}\text { Placospongia intermedia voucher SI06x153 small subunit 18S } \\
\text { ribosomal RNA gene, partial sequence }\end{array}$ \\
\hline & KC902239 & $\begin{array}{l}\text { Placospongia sp. USNM } 1133726 \text { small subunit } 18 \text { S ribosomal } \\
\text { RNA gene, partial sequence }\end{array}$ \\
\hline & KC902258 & $\begin{array}{l}\text { Placospongia melobesioides voucher 0M9H2592-K small subunit } \\
18 \mathrm{~S} \text { ribosomal RNA gene, partial sequence }\end{array}$ \\
\hline \multirow[t]{18}{*}{ Suberitida } & KX622158 & $\begin{array}{l}\text { Aaptos voucher TAU_Po.25875 18S ribosomal RNA gene, } \\
\text { partial sequence }\end{array}$ \\
\hline & KC902111 & $\begin{array}{l}\text { Aaptos suberitoides voucher 0CDN8805-G small subunit 18S } \\
\text { ribosomal RNA gene, partial sequence }\end{array}$ \\
\hline & KC902192 & $\begin{array}{l}\text { Suberites aurantiacus voucher MNRJ15701 small subunit } 18 \mathrm{~S} \\
\text { ribosomal RNA gene, partial sequence }\end{array}$ \\
\hline & KC902066 & $\begin{array}{l}\text { Suberites massa voucher BELUM: Mc4528 small subunit } 18 \mathrm{~S} \\
\text { ribosomal RNA gene, partial sequence }\end{array}$ \\
\hline & KC902367 & $\begin{array}{l}\text { Suberites sp. 0M9H2772-G small subunit } 18 \mathrm{~S} \text { ribosomal RNA } \\
\text { gene, partial sequence }\end{array}$ \\
\hline & KC902330 & $\begin{array}{l}\text { Amorphinopsis excavans voucher 0CDN9237-Y small subunit } \\
18 \text { S ribosomal RNA gene, partial sequence }\end{array}$ \\
\hline & Y737639 & $\begin{array}{l}\text { Halichondria melanodocia } 18 \mathrm{~S} \text { ribosomal RNA gene, complete } \\
\text { sequence }\end{array}$ \\
\hline & AF058946 & $\begin{array}{l}\text { Halichondria japonica } 18 \mathrm{~S} \text { ribosomal RNA gene, partial } \\
\text { sequence }\end{array}$ \\
\hline & KC902358 & $\begin{array}{l}\text { Hymeniacidon perlevis voucher BELUM: Mc4938 small subunit } \\
18 \mathrm{~S} \text { ribosomal RNA gene, partial sequence }\end{array}$ \\
\hline & HM035980 & $\begin{array}{l}\text { Hymeniacidon sinapium isolate Hymsin4-ZG3230 18S ribosomal } \\
\text { RNA gene, partial sequence }\end{array}$ \\
\hline & JN093018 & $\begin{array}{l}\text { Hymeniacidon sp. HymSP-TOTAL 18S ribosomal RNA gene, } \\
\text { partial sequence }\end{array}$ \\
\hline & KC902316 & $\begin{array}{l}\text { Terpios aploos voucher } 0 \mathrm{CDN} 3602-\mathrm{Y} \text { small subunit } 18 \mathrm{~S} \\
\text { ribosomal RNA gene, partial sequence }\end{array}$ \\
\hline & KX601215 & $\begin{array}{l}\text { Protosuberites incrustans voucher ZMAPOR20543 18S } \\
\text { ribosomal RNA gene, partial sequence }\end{array}$ \\
\hline & KC902009 & $\begin{array}{l}\text { Terpios manglaris voucher SI06x } 252 \text { small subunit } 18 \mathrm{~S} \\
\text { ribosomal RNA gene, partial sequence }\end{array}$ \\
\hline & KC902342 & $\begin{array}{l}\text { Terpios sp. MNRJ15821 small subunit } 18 \mathrm{~S} \text { ribosomal RNA gene, } \\
\text { partial sequence }\end{array}$ \\
\hline & KC902157 & $\begin{array}{l}\text { Halichondria attenuata voucher BELUM: Mc } 4732 \text { small subunit } \\
18 \text { S ribosomal RNA gene, partial sequence }\end{array}$ \\
\hline & KC902247 & $\begin{array}{l}\text { Halichondria bowerbanki voucher BELUM: Mc4003 small } \\
\text { subunit } 18 \text { S ribosomal RNA gene, partial sequence }\end{array}$ \\
\hline & KC902333 & $\begin{array}{l}\text { Hymeniacidon kitchingi voucher BELUM: Mc3332 small subunit } \\
18 \mathrm{~S} \text { ribosomal RNA gene, partial sequence }\end{array}$ \\
\hline
\end{tabular}




\begin{tabular}{|c|c|c|}
\hline & KC902355 & $\begin{array}{l}\text { Terpios gelatinosa voucher BELUM: Mc } 3315 \text { small subunit } 18 \mathrm{~S} \\
\text { ribosomal RNA gene, partial sequence }\end{array}$ \\
\hline & KC902238 & $\begin{array}{l}\text { Halichondria panicea voucher BELUM: Mc } 4070 \text { small subunit } \\
18 \text { S ribosomal RNA gene, partial sequence }\end{array}$ \\
\hline & KX601214 & $\begin{array}{l}\text { Protosuberites ectyoninus voucher UBAPOR01 18S ribosomal } \\
\text { RNA gene, partial sequence }\end{array}$ \\
\hline & KC902236 & $\begin{array}{l}\text { Suberites ficus voucher BELUM: Mc } 4322 \text { small subunit } 18 \mathrm{~S} \\
\text { ribosomal RNA gene, partial sequence }\end{array}$ \\
\hline & КC901944 & $\begin{array}{l}\text { Homaxinella subdola voucher BELUM: Mc } 5438 \text { small subunit } \\
18 \text { S ribosomal RNA gene, partial sequence }\end{array}$ \\
\hline \multirow[t]{12}{*}{ Poecilosclerida } & LN870429 & $\begin{array}{l}\text { Abyssocladia dominalba partial 18S rRNA gene, specimen } \\
\text { voucher ZMBN103444 }\end{array}$ \\
\hline & LN870430 & $\begin{array}{l}\text { Asbestopluma cupressiformis partial 18S rRNA gene, specimen } \\
\text { voucher ZMBN103450 }\end{array}$ \\
\hline & LN870431 & $\begin{array}{l}\text { Asbestopluma lycopodium partial 18S rRNA gene, specimen } \\
\text { voucher ZMBN103462 }\end{array}$ \\
\hline & LN870434 & $\begin{array}{l}\text { Chondrocladia gigantea partial 18S rRNA gene, specimen } \\
\text { voucher NTNU15204 }\end{array}$ \\
\hline & MG193132 & Cladorhiza oxeata $18 \mathrm{~S}$ ribosomal RNA gene, partial sequence \\
\hline & LN870435 & $\begin{array}{l}\text { Cladorhiza abyssicola partial 18S rRNA gene, specimen voucher } \\
\text { ZMBN103470 }\end{array}$ \\
\hline & MG193128 & $\begin{array}{l}\text { Chondrocladia grandis } 18 \mathrm{~S} \text { ribosomal RNA gene, partial } \\
\text { sequence }\end{array}$ \\
\hline & LN870433 & $\begin{array}{l}\text { Chondrocladia (Meliiderma) sp. n. A JTH-2015 partial 18S } \\
\text { rRNA gene, specimen voucher BMNH2015.6.4.4 }\end{array}$ \\
\hline & LN870436 & $\begin{array}{l}\text { Euchelipluma sp. n. A JTH-2015 partial 18S rRNA gene, } \\
\text { specimen voucher P0108.75DR15 }\end{array}$ \\
\hline & LN870432 & $\begin{array}{l}\text { Asbestopluma pennatula partial 18S rRNA gene, specimen } \\
\text { voucher ZMBN103468 }\end{array}$ \\
\hline & LN870437 & $\begin{array}{l}\text { Guitarra antarctica partial } 18 \mathrm{~S} \text { rRNA gene, specimen voucher } \\
\text { ECOQUIM786e }\end{array}$ \\
\hline & KC902210 & $\begin{array}{l}\text { Guitarra sp. 0CDN7391-S small subunit 18S ribosomal RNA } \\
\text { gene, partial sequence }\end{array}$ \\
\hline \multirow[t]{10}{*}{ Haplosclerida } & KC902110 & $\begin{array}{l}\text { Haliclona curacaoensis voucher USNM_1133790 small subunit } \\
18 \text { S ribosomal RNA gene, partial sequence }\end{array}$ \\
\hline & KC902280 & $\begin{array}{l}\text { Niphates } c f . \text { erecta USNM } 1133780 \text { voucher USNM_1133780 } \\
\text { small subunit } 18 \text { S ribosomal RNA gene, partial sequence }\end{array}$ \\
\hline & JX945610 & $\begin{array}{l}\text { Callyspongia siphonella voucher MCZ: DNA106625 18S } \\
\text { ribosomal RNA gene, partial sequence }\end{array}$ \\
\hline & JX945607 & $\begin{array}{l}\text { Haliclona elegans voucher MCZ: DNA106275 18S ribosomal } \\
\text { RNA gene, partial sequence }\end{array}$ \\
\hline & JX945627 & $\begin{array}{l}\text { Amphimedon erina voucher MCZ: DNA106220 18S ribosomal } \\
\text { RNA gene, partial sequence }\end{array}$ \\
\hline & KC902017 & $\begin{array}{l}\text { Haliclona walentinae voucher MNRJ15645 small subunit } 18 \mathrm{~S} \\
\text { ribosomal RNA gene, partial sequence }\end{array}$ \\
\hline & DQ927312 & $\begin{array}{l}\text { Niphates sp. NIWAKD148 18S ribosomal RNA gene, complete } \\
\text { sequence }\end{array}$ \\
\hline & KC902300 & $\begin{array}{l}\text { Dasychalina melior voucher 0CDN9312-H small subunit } 18 \mathrm{~S} \\
\text { ribosomal RNA gene, partial sequence }\end{array}$ \\
\hline & DQ927319 & $\begin{array}{l}\text { Chalinula hooperi voucher POR17651 18S ribosomal RNA gene, } \\
\text { complete sequence }\end{array}$ \\
\hline & DQ927320 & $\begin{array}{l}\text { Petrosia sp. NIWAKD1068 18S ribosomal RNA gene, complete } \\
\text { sequence }\end{array}$ \\
\hline
\end{tabular}




\begin{tabular}{|c|c|c|}
\hline & KC901970 & $\begin{array}{l}\text { Petrosia lignosa voucher 0CDN9353-Z small subunit } 18 \mathrm{~S} \\
\text { ribosomal RNA gene, partial sequence }\end{array}$ \\
\hline & DQ927321 & $\begin{array}{l}\text { Petrosia sp. NIWAKD1020 18S ribosomal RNA gene, complete } \\
\text { sequence }\end{array}$ \\
\hline & DQ927318 & $\begin{array}{l}\text { Acanthostrongylophora ingens voucher POR17500 18S } \\
\text { ribosomal RNA gene, complete sequence }\end{array}$ \\
\hline & AB922828 & $\begin{array}{l}\text { Acanthostrongylophora sp. AKK2-001 gene for } 18 \mathrm{~S} \text { ribosomal } \\
\text { RNA, partial sequence }\end{array}$ \\
\hline & KC902135 & $\begin{array}{l}\text { Neopetrosia exigua voucher 0CDN8774-V small subunit } 18 \mathrm{~S} \\
\text { ribosomal RNA gene, partial sequence }\end{array}$ \\
\hline & KC902248 & $\begin{array}{l}\text { Petrosiidae sp. 0CDN2354-S small subunit } 18 \mathrm{~S} \text { ribosomal RNA } \\
\text { gene, partial sequence }\end{array}$ \\
\hline & KC902252 & $\begin{array}{l}\text { Neopetrosia proxima voucher USNM_1133725 small subunit } \\
\text { 18S ribosomal RNA gene, partial sequence }\end{array}$ \\
\hline & KC902019 & $\begin{array}{l}\text { Neopetrosia sp. USNM } 1133759 \text { small subunit } 18 \text { S ribosomal } \\
\text { RNA gene, partial sequence }\end{array}$ \\
\hline & KC902400 & $\begin{array}{l}\text { Amphimedon compressa voucher USNM_1133713 small subunit } \\
18 \mathrm{~S} \text { ribosomal RNA gene, partial sequence }\end{array}$ \\
\hline & EU702409 & $\begin{array}{l}\text { Amphimedon compressa } 18 \mathrm{~S} \text { ribosomal RNA gene, complete } \\
\text { sequence }\end{array}$ \\
\hline & KX894469 & $\begin{array}{l}\text { Amphimedon sp. DTTH-2018 voucher AMC } 18 \mathrm{~S} \text { ribosomal RNA } \\
\text { gene, partial sequence }\end{array}$ \\
\hline & EU702412 & $\begin{array}{l}\text { Callyspongia plicifera } 18 \mathrm{~S} \text { ribosomal RNA gene, complete } \\
\text { sequence }\end{array}$ \\
\hline & DQ927314 & $\begin{array}{l}\text { Callyspongia sp. NIWAKD1668 18S ribosomal RNA gene, } \\
\text { complete sequence }\end{array}$ \\
\hline & KC902402 & $\begin{array}{l}\text { Chalinula molitba voucher CD06x } 1 \text { small subunit } 18 \mathrm{~S} \text { ribosomal } \\
\text { RNA gene, partial sequence }\end{array}$ \\
\hline & EU863812 & Callyspongia fallax $18 \mathrm{~S}$ ribosomal RNA gene, partial sequence \\
\hline & AB542057 & Haliclona sp. Sa080513 gene for 18S rRNA, partial sequence \\
\hline & KF176610 & Haliclona sp. BC1 18S ribosomal RNA gene, partial sequence \\
\hline & KF176614 & Haliclona sp. BC1 18S ribosomal RNA gene, partial sequence \\
\hline & KF176613 & Haliclona sp. BC1 18S ribosomal RNA gene, partial sequence \\
\hline & KF176621 & Haliclona sp. BC1 18S ribosomal RNA gene, partial sequence \\
\hline & KX894467 & $\begin{array}{l}\text { Haliclona amboinensis voucher HAA.1 18S ribosomal RNA } \\
\text { gene, partial sequence }\end{array}$ \\
\hline & KC902016 & $\begin{array}{l}\text { Haliclona mucifibrosa voucher MNRJ15705 small subunit 18S } \\
\text { ribosomal RNA gene, partial sequence }\end{array}$ \\
\hline & DQ927306 & $\begin{array}{l}\text { Haliclona cinerea voucher POR14138 18S ribosomal RNA gene, } \\
\text { complete sequence }\end{array}$ \\
\hline & DQ927315 & $\begin{array}{l}\text { Haliclona fascigera voucher NIWAKD150 18S ribosomal RNA } \\
\text { gene, complete sequence }\end{array}$ \\
\hline & KC902267 & $\begin{array}{l}\text { Haliclona sp. BMOO-07065 small subunit } 18 \text { S ribosomal RNA } \\
\text { gene, partial sequence }\end{array}$ \\
\hline & KC902054 & $\begin{array}{l}\text { Haliclona manglaris voucher USNM_1133711 small subunit 18S } \\
\text { ribosomal RNA gene, partial sequence }\end{array}$ \\
\hline & KC902285 & $\begin{array}{l}\text { Haliclona sp. BMOO-07059 small subunit } 18 \mathrm{~S} \text { ribosomal RNA } \\
\text { gene, partial sequence }\end{array}$ \\
\hline & KC762727 & $\begin{array}{l}\text { Siphonochalina sp. 2-A 18S ribosomal RNA gene, partial } \\
\text { sequence }\end{array}$ \\
\hline & DQ927311 & $\begin{array}{l}\text { Siphonochalina sp. POR14630 18S ribosomal RNA gene, } \\
\text { complete sequence }\end{array}$ \\
\hline
\end{tabular}




\begin{tabular}{|c|c|c|}
\hline & KC902202 & $\begin{array}{l}\text { Cladocroce sp. 0CDN9562-C small subunit 18S ribosomal RNA } \\
\text { gene, partial sequence }\end{array}$ \\
\hline & AY734450 & Haliclona oculata $18 \mathrm{~S}$ ribosomal RNA gene, complete sequence \\
\hline & KF176618 & Haliclona sp. BC7 18S ribosomal RNA gene, partial sequence \\
\hline & DQ927310 & $\begin{array}{l}\text { Callyspongia sp. POR14635 18S ribosomal RNA gene, complete } \\
\text { sequence }\end{array}$ \\
\hline & MH373530 & $\begin{array}{l}\text { Haliclona cnidata voucher S1_2015 18S small subunit ribosomal } \\
\text { RNA gene, partial sequence }\end{array}$ \\
\hline & AY734444 & Haliclona sp. sp5 18S ribosomal RNA gene, complete sequence \\
\hline & DQ927309 & $\begin{array}{l}\text { Haliclona sp. NIWAKD550 18S ribosomal RNA gene, complete } \\
\text { sequence }\end{array}$ \\
\hline & KC902399 & $\begin{array}{l}\text { Neopetrosia rosariensis voucher USNM_1133857 small subunit } \\
\text { 18S ribosomal RNA gene, partial sequence }\end{array}$ \\
\hline & KX668499 & $\begin{array}{l}\text { Haliclona plakophila voucher USNM:1254650 18S ribosomal } \\
\text { RNA gene, partial sequence }\end{array}$ \\
\hline & KP081740 & $\begin{array}{l}\text { Xestospongia sp. JV-2014 isolate XSPPRA12 18S ribosomal } \\
\text { RNA gene, partial sequence }\end{array}$ \\
\hline & EU095523 & $\begin{array}{l}\text { Haliclona sp. DS-2007a 18S ribosomal RNA gene, partial } \\
\text { sequence }\end{array}$ \\
\hline & KC902312 & $\begin{array}{l}\text { Xestospongia sp. USNM } 1204834 \text { small subunit } 18 \text { S ribosomal } \\
\text { RNA gene, partial sequence }\end{array}$ \\
\hline & KC902039 & $\begin{array}{l}\text { Xestospongia bocatorensis voucher SI04x40 small subunit } 18 \mathrm{~S} \\
\text { ribosomal RNA gene, partial sequence }\end{array}$ \\
\hline & KP100454 & $\begin{array}{l}\text { Haliclona sp. NBL-2014 18S ribosomal RNA gene, partial } \\
\text { sequence }\end{array}$ \\
\hline & KX866799 & $\begin{array}{l}\text { Haliclona sp. Po.25929 18S ribosomal RNA gene, partial } \\
\text { sequence }\end{array}$ \\
\hline & KC902323 & $\begin{array}{l}\text { Haliclona vansoesti voucher SI06x152 small subunit } 18 \mathrm{~S} \\
\text { ribosomal RNA gene, partial sequence }\end{array}$ \\
\hline & KC901998 & $\begin{array}{l}\text { Haliclona tubifera voucher SI06x97 small subunit } 18 \text { S ribosomal } \\
\text { RNA gene, partial sequence }\end{array}$ \\
\hline & KC901937 & $\begin{array}{l}\text { Neopetrosia carbonaria voucher SI06x50 small subunit 18S } \\
\text { ribosomal RNA gene, partial sequence }\end{array}$ \\
\hline & KX894473 & $\begin{array}{l}\text { Amphimedon sp. AMQ 18S ribosomal RNA gene, partial } \\
\text { sequence }\end{array}$ \\
\hline & AY734446 & Niphates amorpha $18 \mathrm{~S}$ ribosomal RNA gene, partial sequence \\
\hline & AY734445 & Niphates digitalis $18 \mathrm{~S}$ ribosomal RNA gene, partial sequence \\
\hline & DQ927316 & $\begin{array}{l}\text { Dasychalina fragilis voucher POR14455 18S ribosomal RNA } \\
\text { gene, complete sequence }\end{array}$ \\
\hline & KC902338 & $\begin{array}{l}\text { Gelliodes callista voucher 0CDN9710-O small subunit 18S } \\
\text { ribosomal RNA gene, partial sequence }\end{array}$ \\
\hline & KC902274 & $\begin{array}{l}\text { Dasychalina sp. 0CDN9201-L small subunit } 18 \text { S ribosomal RNA } \\
\text { gene, partial sequence }\end{array}$ \\
\hline & KX668500 & $\begin{array}{l}\text { Xestospongia deweerdtae voucher USNM: } 125464518 \mathrm{~S} \\
\text { ribosomal RNA gene, partial sequence }\end{array}$ \\
\hline & KX894471 & Niphatidae sp. NIS 18 S ribosomal RNA gene, partial sequence \\
\hline & AY621510 & Xestospongia muta $18 \mathrm{~S}$ ribosomal RNA gene, complete sequence \\
\hline & KX894458 & $\begin{array}{l}\text { Xestospongia testudinaria voucher XES.1 18S ribosomal RNA } \\
\text { gene, partial sequence }\end{array}$ \\
\hline & DQ927308 & $\begin{array}{l}\text { Cribochalina vasculum voucher NIWAKD538 } 18 \mathrm{~S} \text { ribosomal } \\
\text { RNA gene, complete sequence }\end{array}$ \\
\hline & KC901980 & $\begin{array}{l}\text { Cribrochalina vasculum voucher 0M9G1420-I small subunit } 18 \mathrm{~S} \\
\text { ribosomal RNA gene, partial sequence }\end{array}$ \\
\hline
\end{tabular}




\begin{tabular}{|c|c|c|}
\hline & AB922827 & $\begin{array}{l}\text { Petrosia sp. ARY-005 gene for 18S ribosomal RNA, partial } \\
\text { sequence }\end{array}$ \\
\hline & KC902101 & $\begin{array}{l}\text { Petrosia aff. hartmani USNM } 1204818 \text { voucher USNM_1204818 } \\
\text { small subunit } 18 \text { S ribosomal RNA gene, partial sequence }\end{array}$ \\
\hline & KC902222 & $\begin{array}{l}\text { Petrosia strongylata voucher 0CDN9767-Z small subunit 18S } \\
\text { ribosomal RNA gene, partial sequence }\end{array}$ \\
\hline & KC902173 & $\begin{array}{l}\text { Petrosia weinbergi voucher 0M9G0152-Z small subunit 18S } \\
\text { ribosomal RNA gene, partial sequence }\end{array}$ \\
\hline & DQ927322 & $\begin{array}{l}\text { Aka mucosum voucher NIWAKD535 18S ribosomal RNA gene, } \\
\text { complete sequence }\end{array}$ \\
\hline \multirow[t]{14}{*}{ Verongiida } & EU702410 & Aplysina fistularis $18 \mathrm{~S}$ ribosomal RNA gene, complete sequence \\
\hline & KC901896 & $\begin{array}{l}\text { Aplysina cauliformis voucher USNM_1204836 small subunit 18S } \\
\text { ribosomal RNA gene, partial sequence }\end{array}$ \\
\hline & KC901889 & $\begin{array}{l}\text { Aplysina sp. USNM } 1204828 \text { small subunit } 18 \mathrm{~S} \text { ribosomal RNA } \\
\text { gene, partial sequence }\end{array}$ \\
\hline & KC902200 & $\begin{array}{l}\text { Aplysina fulva voucher USNM_1153593 small subunit } 18 \mathrm{~S} \\
\text { ribosomal RNA gene, partial sequence }\end{array}$ \\
\hline & KC902406 & $\begin{array}{l}\text { Pseudoceratina arabica voucher 0CDN9812-Y small subunit } 18 \mathrm{~S} \\
\text { ribosomal RNA gene, partial sequence }\end{array}$ \\
\hline & КС902010 & $\begin{array}{l}\text { Pseudoceratina sp. P02x141 small subunit } 18 \mathrm{~S} \text { ribosomal RNA } \\
\text { gene, partial sequence }\end{array}$ \\
\hline & AB922830 & $\begin{array}{l}\text { Pseudoceratina sp. P02x141 small subunit } 18 \mathrm{~S} \text { ribosomal RNA } \\
\text { gene, partial sequence }\end{array}$ \\
\hline & AY591804 & $\begin{array}{l}\text { Verongula gigantea } 18 \mathrm{~S} \text { ribosomal RNA gene, complete } \\
\text { sequence }\end{array}$ \\
\hline & KC902024 & $\begin{array}{l}\text { Verongiida sp. 0CDN8087-Y small subunit } 18 \mathrm{~S} \text { ribosomal RNA } \\
\text { gene, partial sequence }\end{array}$ \\
\hline & KC902055 & $\begin{array}{l}\text { Pseudoceratinidae sp. BMOO-08168 small subunit } 18 \mathrm{~S} \text { ribosomal } \\
\text { RNA gene, partial sequence }\end{array}$ \\
\hline & KC902144 & $\begin{array}{l}\text { Pseudoceratina purpurea voucher 0CDN8109-X small subunit } \\
18 \text { S ribosomal RNA gene, partial sequence }\end{array}$ \\
\hline & KC902318 & $\begin{array}{l}\text { Pseudoceratina sp. USNM } 1204854 \text { small subunit } 18 \text { S ribosomal } \\
\text { RNA gene, partial sequence }\end{array}$ \\
\hline & KC901952 & $\begin{array}{l}\text { Hexadella racovitzai voucher BELUM: Mc5090 small subunit } \\
18 \text { S ribosomal RNA gene, partial sequence }\end{array}$ \\
\hline & КС902148 & $\begin{array}{l}\text { Ianthella basta voucher G02x165 small subunit } 18 \mathrm{~S} \text { ribosomal } \\
\text { RNA gene, partial sequence }\end{array}$ \\
\hline
\end{tabular}

Table 2. Sequence data from predated sponges

\begin{tabular}{|l}
\hline Ridge RA1 S4A \\
TGCAGAAGGTCCCGACTTTACGGAAGGGATGTATTTATTAGATCCAAAACCAATGCCGAGGCTT \\
TCGGTCTCGGGAAGCTGGTGATTCATGATAACTGCTCGAATCGCACGGCCTTCGCGCCGGCGAT \\
GATTCATTCAAGTTTCTGCCCTATCAACTTTCGATGGTAGGGTATTGGCCTACCATGGTCGCAAC \\
GGGTAACGGAGAATTAGGGTTCGATTCCGGAGAGGGAGCCTGAGAAACGGCTACCACATCCAA \\
GGAAGGCAGCAGGCGCGCAAATTACCCAATCCCGACTCGGGGAGGTAGTGACAATAAATAACA \\
ATGCCGGCCTCTTGAGTAGGCCGGCAATTGGAATGAGTACAATCCAAACCCTTAACGAGGAAC \\
AATTGGAGGGCAAGTCTGGTGCCAGCAGCCGCGGTAATTCCAGCTCCAATAGCGTATATTAAAG \\
TTGTTGCAGTTAAAAAGCTCGTAGTTGGATTTCGGAGCCGACCGGGCGGTCTGTCGAGAGACAC \\
GCACTGCTCGGTGGCTCTTCCTCTCGGAGGCCCTGGCTGCCCTTAACTGGAGCGGGCAGGGGAT \\
TCGGGACGTTTACTTGAAAAAATTAGAGTGTTCAAAGCAGGCCGGTGCTTGATACATTAGCA \\
TGGAATAATGGAATAGGGCTTGGGTCCTATTTTGTTGGTTTTCGGGACCGAGGTCATGGTTAAG \\
AGGGACAGTTGGGGGCATTCGTATTCAATTGTCAGAGGTGAAATTCTTGGATTTATGGAAGACG \\
AACAACTGCGAA
\end{tabular}


Ridge RA2 S2

AATCAGTTATAGTTTTATTTGATGGTGCCCCACTACATGGATAACCGTGGTAATTCTAGAGCTAA TACATGCAGAAGGTCCCGACTTTTCGGAAGGGATGTATTTATTAGATCCAAAACCAATGCCGAG GCTTCGGTCTCGGGAAGCTGGTGATTCATGGTAACTGCTCGAATCGCACGGCCTTCGCGCCGGC GATGATTCATTCAAGTTTCTGCCCTATCAACTTTCGATGGTAGGGTATTGGCCTACCATGGTCGC AACGGGTGACGGAGAATTAGGGTTCGATTCCGGAGAGGGAGCCTGAGAAACGGCTACCACATC CAAGGAAGGCAGCAGGCGCGCAAATTACCCAATCCCGACTCGGGGAGGTAGTGACAATAAATA ACAATGCCGGCCTCTTGAGTAGGCCGGCAATTGGAATGAGTACAATCCAAACCCCTTAACGAGG AACAATTGGAGGGCAAGTCTGGTGCCAGCAGCCGCGGTAATTCCAGCTCCAATAGCGTATATTA AAGTTGTTGCAGTTAAAAAGCTCGTAGTTGGATTTCGGAGCCGACCGGGCGGTCTGTCGAGAGA CACGCACTGCTCGGTGGCTCTTCCTCTCGGAGGCCCTGGCTGCCCTTGACTGGAGCGGGCAGGG GATTCGGGACGTTTACTTTGAAAAAATTAGAGTGTTCAAAGCAGGCCGGTGCTTGGATACATTA GCATGGAATAATGGAATAGGGCTTGGGTCCTATTTTGG

Ridge RA2 S10

GCTCCGGCCTCGGGAAGCTGGTGATTCATGGTAACTGCTCGAATCGCACGGCCTTCGCGCCGGC GATGATTCATTCAAGTTTCTGCCCTATCAACTTTCGATGGTAGGGTATTGGCCTACCATGGTCGC AACGGGTGACGGAGAATTAGGGTTCGATTCCGGAGAGGGAGCCTGAGAAACGGCTACCACATC CAAGGAAGGCAGCAGGCGCGCAAATTACCCAATCCCGACTCGGGGAGGTAGTGACAATAAATA ACAATGCCGGCCTCTTGAGTAGGCCGGCAATTGGAATGAGTACAATCCAAACCCCTTAACGAGG AACAATTGGAGGGCAAGTCTGGTGCCAGCAGCCGCGGTAATTCCAGCTCCAATAGCGTATATTA AAGTTGTTGCAGTTAAAAAGCTCGTAGTTGGATTTCGGAGCCGACCGGGCGGTCTGTCGAGAGA CACGCACTGCTCGGTGGCTCTTCCTCTCGGAGGCCCTGACTGCCCTTGACTGGAGCGGGCAGGG GATTCGGGACGTTTACTTTGAAAAAATTAGAGTGTTCAAAGCAGGCCGGTGCTTGGATACATTA GCATGGAATAATGGAATAGGGCTTGGGTCCTATTTTGTTGGTTTTCGGGACCGAGGTCATGGTT AAGAGGGACAGTTGGGGGCATTCGTATTCAATTGTCAGAGGTGAAATTCTTGGATTTATGGA

Ridge RA3 S1

TCATTCAAATTTCTGCCCTATCAACTTTCGATGGTACGGTAGTGGCCTACCATGGTTGCCACGGG TGACGGAGAATTAGGGTTCGATTCCGGAGAGGGAGCCTGAGAAACGGCTACCACATCCTAGGA AGGCAGCAGGCGCGCAAATTACCCAATCCCGACACGGGGAGGTAGTGACGATAAATAACAATG CCGGGCTTTCTTAGTC

Ridge RA4 B

TTATAGTTTATGTGATGGTTTCTTACTACTTGGATAACCGTGGTAATTCTAGAGCTAATACATGC AGAAAGTCCCGACTTTTTGGAAGGGATGTATTTATTAGATCCAAAACCAGTGCGAGCTTCGGCT CGGTTTCTTGGTGATTCATGATAACTGCTCGAACCGTATGGCCCTTGCGCCGACGGTGCTTCATT CAAATTTCTGCCCTATCAACTTTCGATGGTACGGTAGTGGCCTACCATGGTTGCAACGGGTGAC GGAGAATTAGGGTTCGATTCCGGAGAGGGAGCCTGAGAAACGGCTACCACTTCCAAGGAAGGC AGCAGGCGCGCAAATTACCCAATCCCGACTCGGGGAGGTAGTGACAATAAATAACAATGCCGG GCTATTGTAGTCTGGCAATTGGAATGAGTACAATCTAAACCCCTTAACGAGGAACAATTGGAGG GCAAGTCTGGTGCCAGCAGCCGCGGTAATTCCAGCTCCAATAGCGTATATTAAAGTTGTTGCAG TTAAAAAGCTCGTAGTTGGATTTCGGGGCAGCCTGCCTGGTCCGCCGCAAGGCGAGTACTGGTC AGCCGCCCTTCCTCTCGAAAGCCCCGACTGCTCTTCACTGCAGTGGTCGGGTAGTTCGGGACGTT TACTTTGAAAAAATTAGAGTGTTCAAGGCAGGCTATCGCCTGAATACATTAGCATGGAATAATG GAAGAGGACCTCGGTCCTATTTTGTTGGTTTCTAGGGCCGAAGTAATGATTAAGAGGGACAGTT GGGGGCATTCGTATTTAATTGTCAGAGGTGAAATTCTTGGATTTATGAAAGACGAACTAG

Ridge RA5

GCAAGGCCTTTGCGCGGGCGATGATTCATTCAAGTTTCTGCCCTATCAACTTTCGATGGTAGGGT ATTGGCCTACCATGGTCGCAACGGGTGACGGAGAATTAGGGTTCGATTCCGGAGAGGGAGCCT GAGAAACGGCTACCACATCCAAGGAAGGCAGCAGGCGCGCAAATTACCCAATCCCGACTCGGG GAGGTAGTGACAATAAATAACAATGCCGGCCTCTTGAGTAGGCCGGCAATGGGAATGAGTACA ATCCAAACCCCTTAACGAGGAACAATGGGAGGGCAAGTCGGGTGCCGGCGGCCGCGGTAATTC 
CAGTTCCAATAGCGTATATTAAAGTTGTTGCAGTTAAAAAGTTGGTAGTTGGATTTCGGAGCCG ACCGGGCGTTCGGTCCAAAGACACGCACTGCTCGGTGGCTTTTCCTTTGGGAGGCCCTGGCTGC CTTTCACTGGAGCGGGCAGGGGATTCGGGACGTTTACTTTGAAAAAATTAGAGTGTTCAAAGCA GGCCGGTGCTTGGATACATTAGCATGGAATAATGGAATAGGGCTTGGGTCCTATTTTGTTGGTTT TCGGGACCGAGGTC

Ridge RA6 S3

GGGATAACCGTAGTAATTCTAGAGCTAATACATGCAGAAAGTCCCGACTTCTTGGAAGGGATGT ATTTATTAGATCCAAAACCAGCGCGAGTTTCCTTCGGGGGCTCGGTTGCATGGTGATTCATGATA ACTGCTCGAATCGCATGGCCTTGCGCCGGCGATGATCCATTCAAATTTCTGCCCTATCAACTTTC GATGGCAAGGTAGTGGCTTGCCATGGTGACAACGGGTGACGGAGAATTAGGGTTCGATTCCGG AGAGGGAGCCTGAGAAACGGCTACCACATCCGAGGAAGGCAGCAGGCGCGCAAATTACCCAAT CCCGACTCGGGGAGGTAGTGACAATAAATAACAATGCTGGGCTATCGTAGTCTGGCAATTGGAA TGAGTACAATCTAAACCCCTTAACGAGGAACAATTGGAGGGCAAGTCTGGTGCCAGCAGCCGC GGTAATTCCAGCTCCAATAGCGTATATTAAAGTTGTTGCAGTTAAAAAGCTCGTAGTTGGATTTC GGGGCAGCCCGGCTGGTCCGTCGCAAGGCGAGTACTGGTCGGCCGCCCTTCCTCTCGAAAGCCC CGACTGCTCTTCACTGTAGTGGTCGGGGAGTTCGGGACGTTTACTTTGAAAAAATTAGAGTGTTC AAGGCAGGCCATCGCCTGAATACATTAGCATGGAATAATGGAAGAGGACCTCGGTCCTATTTTG TTGGTTTCTAGGGCCGAAAGTAATGATTAAGAGGGACAGTTGGGGGCATTCGTATTTAATTGTC AGAAGGTGAAAATTCT

Sampela RA2 S2

GCTACATGGATAACCGTGGTAATTCTAGAGCTAATACATGCAGAAGGTCCCGACTCTCGGAAGG GATGTATTTATTAGATCCAAGACCAATGCCGGGATCTCGGTCCCGGGAAGCTGGTGATTCATGG TAACTGCTCGAATCGCACGGCCCTCGCGCCGGCGATGATTCATTCAAGTTTCTGCCCTATCAACT TTCGATGGTAGGGTATTGGCCTACCATGGTCGCAACGGGTGACGGAGAATTAGGGTTCGATTCC GGAGAGGGAGCCTGAGAAACGGCTACCACATCCAAGGAAGGCAGCAGGCGCGCAAATTACCC AATCCCGACTCGGGGAGGTAGTGACAATAAATAACAATGCCGGCCTCTTGAGTAGGCCGGCAA TTGGAATGAGTACAATCCAAACCCCTTAACGAGGAACAATTGGAGGGCAAGTCTGGTGCCAGC AGCCGCGGTAATTCCAGCTCCAATAGCGTATATTAAAGTTGTTGCAGTTAAAAAGCTCGTAGTT GGATTTCGGAGCCGACCGGGCGGTCTGTCGAGAGACACGCACTGCTCGGTGGCTCTTCCTCTCG GAGGCCCTGGCTGCCCTTAACTGGAGCGGGCAGGGGATTCGGGACGTTTACTTTGAAAAAATTA GAGTGTTCAAAGCAGGCCGGTGCTTGGATACATTAGCATGGAATAATGGAATAGGGCTTGGGTC CTATTTTGTTGGTTTTCGGGACCGAGGTCATGGTTAAGAGGGACAGTTGGGGGCATTCGTATTCA ATTGTCAGAGGTGAAATTCTTGAATTTATGGAAGACGAACATG

Sampela RA5 S7

TCTGATGGTACCTCCTACTCGGATAACCGTGGTAATTCTAGAGCTAATACATGCAGCAAGTCCC GACTTCTGGAAGGGACGTATTTATTAGATACAAAACCAATGCAGCTTCGGCTGGTCCCTTGGTG ATTCATGATAACTGCTCGAATCGCATGGCCTTGCGCTGGCGATGGTTCATTCAAGTTTCTGCCCT ATCAACTGTCGATGGTAGGGTATTGGCCTACCATGGTTGCAACGGGTGACGGAGAATTAGGGTT CGATTCCGGAGAGGGAGCCTGAGAAACGGCTACCACATCCAAGGAAGGCAGCAGGCGCGCAA ATTACCCAATCCCGACTCGGGGAGGTAGTGACAAAAAATACTGATACCGGGCTCACAAAGTCC GGCAATCGGAATGAGAACAACTTAAACCCCTTATCGATGAACAATTGGAGGGCAAGTCTGGTG CCAGCAGCCGCGGTAATTCCAGCTCCAATAGCGTATATTAAAGTTGTTGCAGTTAAAAAGCTCG TAGTTGGATTTCGGGGCGGTCCCGTCGGTCCGTCGTGAGACTGGCACTGACGGGCCTCCCTTCCT CTCGAAGTCCCCGTCTGCTCTTCACTGCAGTGGAGTGGGGAATTCGTGACGTTTACTGTGAAAA AATTAGAGTGTTCAAAGCAGGCAGCCGCTTGAATACATTAGCATGGAATAATGGAATAGGACTT GGGTCCTATTTTGTTGGTTTCCGGGACCGAAGTAATGATTAATAGGGACAGTCGGGGGCATTCG TATTTAATTGTCAGAGGTGAAATTCTTGGATTTATGAAAGACGAACA

Sampela RA6 S1

CCCTTGGTGATTCATGATAACTGCTCGAATCTCATGGCCTTGCGCTGGCGATGGTTCATTCAAGT TTCTGCCCTATCAACTGTCGATGGTAGGGTATTGGCCTACCATGGTTGCAACGGGTGACGGAGA ATTAGGGTTCGATTCCTGAGAGGGAGCCTGAGAAACGGCTACCACATCCAAGGAAGGCAGCAG GCGCGCAAATTACCCAATCCCGACTCGGGGAGGTAGTGACGAAAAATACTGATACCGGGCTCA CAAAGTCCGGCGATCGGAATGAGAACAACTTAAACCCCTTATCCATGAACAATTGGAGGGCAA 
GTCTGGTGCCAGCAGCCGCGGTAATTCCAGCTCCAATAGCGTATATTAAAGTTGTTGCAGTTAA AAAGCTCGTAATTGGATTTCGGGGCGGTCCCGTCGGTCCC

Sampela RA6 S5

CCATGGTCGCAACGGGTGACGGAGAATTAGGGTTCGATTCCGGAGAGGGAGCCTGAGAAACGG CTACCCCATCCAAGGAAGGCAGCAGGCGCGCAAATTACCCAATCCCGACTCGGGGAGGTAGTG ACAATAAATAACAATGCCGGCCTCTTGAGTAGGCCGGCAATTGGAATGAGTACAATCCAAACCC CTTAACGAGGAACAATTGGAGGGCAAGTCTGGTGCCAGCAGCCGCGGTAATTCCAGCTCCAATA GCGTATATTAAAGTTGTTGCAGTTAAAAAGCTCGTAGTTGGATTTCGGAGCCGACCGGGCGGTC TGTCGAGAGACACGCACTGCTCGGTGGCTCTTCCTCTCGGAGGCCCTGGCTGCCCTTAACTGGA GCGGGCAGGGGATTCGGGACGTTTACTTTGAAAAAATTAGAGTGTTCAAAGCAGGCCGGTGCTT GGATACATTAGCATGGAATAATGGAATAGGGCTTGGGTCCTATTTTGTTGGTTTTTGGGACCGA GGTCATGGTTAAGAGGGACAGTTGGGGGCATTCGTAT

Sampela RA6 S6

CATAAATCAGTTATAGTTTATTTGATGGTACCTCCTACTTGGATAACCGTGGTAATTCTAGAGCT AATACATGCAGCAAGTCCCGACTTCTGGAAGGGACGTATTTATTAGATACAAAACCAATGCAGC TTCGGCTGGTCCCTTGGTGATTCATGATAACTGCTCGAATCGCATGGCCTTGCGCTGGCGATGGT TCATTCAAGTTTCTGCCCTATCAACTGTCGATGGTAGGGTATTGGCCTACCATGGTTGCAACGGG TGACGGAGAATTAGGGTTCGATTCCGGAGAGGGAGCCTGAGAAACGGCTACCACATCCAAGGA AGGCAGCAGGCGCGCAAATTACCCAATCCCGACTCGGGGAGGTAGTGACAAAAAATACTGATA CCGGGCTCACAAAGTCCGGCAATCGGAATGAGAACAACTTAAACCCCTTATCGATGAACAATTG GAGGGCAAGTCTGGTGCCAGCAGCCGCGGTAATTCCAGCTCCAATAGCGTATATTAAAGTTGTT GCAGTTAAAAAGCTCGTAGTTGGATTTCGGGGCGGTCCCGTCGGTCCGTCGTGAGACTGGCACT GACGGGCCTCCCTTCCTCTCGAAGTCCCCGTCTGCTCTTCACTGCAGTGGAGTGGGGAATTCGTG ACGTTTACTGTGAAAAAATTAGAGTGTTCAAAGCAGGCAGCCGCTTGAATACATTAGCATGGAA TAATGGAATAGGACTTGGGTCCTATTTTGTTGGTTTCCGGGACCGAAGTAATGATTAATAGGGA CAGTCGGGGGCATTCGTATTTAATTGTCAGAGGTGAAATTCTTGGATTTATGAAAGACGAACAA CTGCAA

Sampela RA7 S5

GGCTCGGTCCCTTGGTGATTCATGATAACTTCTCGAACCGTATGGCCCTTGCGCGGACGGTGCTT CATTCAGATTTCTGCCCTATCAACTTTCGATGGTACGGTAGTGGCCTCCCATGGTTGCAACGGGT GACGGAGAATTAGGGTTCGATTCGGGAGAGGGAGCCTGAGAAACGGCTACCACTTCCAAGGAA GGCAGCGGGCGCGAAAATTACCCAATCCGGACTGGGGGAGGTAGTGACAATAAATAACAACCC CGGGCTATCATGTTCGGGCAATGGGAATGAGTACAATTTAAACCCTTTAACGAGGATCAATTGG AGGGCAATTTGGGGGCCAGCAGCCGCGGTAATTCCAGTTCCAAAAGGGTATTTAAAAGTTGTGC CAGTAAAAAAGTTGGTAGTTGGATTTCGGGGCGGCCTGGCTGTTCCTCCGCAAGGTGGCTACTG GTCGCCTGCCCTTCTTTTGGAAAGCCCGGATTGTTTTTCATGCCAGTGGTCGGGGAGTTCGGGAC GTTTACTTTGAAAAAATTAGAGTGTTCAAGGCAGGCTGTCGCATGAATACATTAGCATGGAATA ATGGAAGAGGACCTCGGTCCTATTTTGTTGGTTTC

Ridge PX2 S13

CAGCAGGCGCGCAAATTACCCAATCCCGACTCGGGGAGGTAGTGACAATAAATAACAATGCTG GGCTATCGTAGTCTGGCAATTGGAATGAGAACAATCTAAACCCCTTAACGAGGAACAATTGGAG GGCAAGTCTGGTGCCAGCAGCCGCGGTAATTCCAGCTCCAATAGCGTATATTAAAGTTGTTGCA GTTAAAAAGCTCGTAGTTGGATTTCGGGGCGGCCTGACTGGTCCGCCGCGAGGCGAGCACTGGT CAGCCGCCCTTCCTCTCGAAAGCCCCGACTGCTCTTCGCTGCAGTGGTCGGGGAATTCGGGACG TTTACTTTGAAAAAATTAGAGTGTTCAAGGCAGGCTCTCGCCTGAATACATTAGCATGGAATAA TGGAAGAGGACTTCGGTCCTATTTTGTTGGTTTCTGGGACCGAAGTAATGATTAAGAGGGACAG TTGGGGGCATTCGTAT 


\section{Appendix D}

Table 1. $\delta^{13} \mathrm{C}$ and $\delta^{15} \mathrm{~N}$ signatures (mean $\pm \mathrm{SD}$ ) of sources, benthic prey items and consumers (fish) collected at two sites in the Wakatobi Marine National Park, Indonesia.

\begin{tabular}{|c|c|c|c|c|c|c|}
\hline \multirow[b]{2}{*}{$\begin{array}{l}\text { Sources and } \\
\text { benthic prey }\end{array}$} & \multicolumn{3}{|c|}{ High-quality reef system } & \multicolumn{3}{|c|}{ Sponge-dominated reef system } \\
\hline & $\delta^{15} \mathrm{~N} \pm \mathrm{SD}$ & $\delta^{13} \mathrm{C} \pm \mathrm{SD}$ & $\mathrm{N}$ & $\delta^{15} \mathrm{~N} \pm \mathrm{SD}$ & $\delta^{13} \mathrm{C} \pm \mathrm{SD}$ & $\mathrm{N}$ \\
\hline $\begin{array}{l}\text { Green turf algae } \\
\text { Dictyota sp. }\end{array}$ & $1.46 \pm 0.47$ & $-12.48 \pm 2.51$ & 3 & $\begin{array}{l}0.82 \pm 0.08 \\
3.58 \pm 0.05\end{array}$ & $\begin{array}{l}-12.23 \pm 0.06 \\
-16.33 \pm 1.63\end{array}$ & $\begin{array}{l}3 \\
3\end{array}$ \\
\hline Halimeda sp. & $3.77 \pm 0.52$ & $-22.85 \pm 0.67$ & 3 & & & \\
\hline SPOM & $4.00 \pm 0.70$ & $-26.02 \pm 0.89$ & 3 & $5.43 \pm 0.65$ & $-24.25 \pm 1.09$ & 3 \\
\hline Synaptula sp. & $6.66 \pm 0.31$ & $-18.35 \pm 0.65$ & 5 & $6.11 \pm 0.28$ & $-16.86 \pm 0.34$ & 5 \\
\hline Pavona varians & $4.29 \pm 0.42$ & $-16.51 \pm 0.51$ & 3 & $4.25 \pm 0.33$ & $-14.04 \pm 0.64$ & 3 \\
\hline $\begin{array}{l}\text { Pocillopora } \\
\text { verrucosa }\end{array}$ & $4.62 \pm 0.43$ & $-15.57 \pm 0.79$ & 3 & $4.39 \pm 0.14$ & $-16.05 \pm 0.96$ & 3 \\
\hline Porites lutea & $5.3 \pm 0.23$ & $-12.7 \pm 1.61$ & 3 & $4.15 \pm 0.87$ & $-13.68 \pm 0.68$ & 3 \\
\hline Xestospongia sp. & $6.97 \pm 1.11$ & $-19.38 \pm 0.46$ & 3 & $6.35 \pm 0.15$ & $-18.67 \pm 0.47$ & 3 \\
\hline Hyrtios eretcus & $3.31 \pm 1.73$ & $-18.18 \pm 0.19$ & 3 & $4.27 \pm 0.72$ & $-16.98 \pm 0.48$ & 3 \\
\hline Clathria sp. & $6.78 \pm 0.28$ & $-20.74 \pm 0.16$ & 3 & $5.84 \pm 0.09$ & $-19.16 \pm 0.21$ & 3 \\
\hline $\begin{array}{l}\text { Lamellodysedia } \\
\text { herbacea }\end{array}$ & $4.94 \pm 0.48$ & $-26.06 \pm 0.6$ & 3 & $5.19 \pm 0.43$ & $-24.73 \pm 0.73$ & 3 \\
\hline \multicolumn{7}{|l|}{ Consumers } \\
\hline Zanclus cornutus & $9.83 \pm 0.29$ & $-16.93 \pm 0.59$ & 7 & $8.51 \pm 0.41$ & $-15.83 \pm 0.89$ & 8 \\
\hline $\begin{array}{l}\text { Pygoplites } \\
\text { diacanthus }\end{array}$ & $10.31 \pm 0.2$ & $-16.41 \pm 0.35$ & 6 & $9.59 \pm 0.43$ & $-14.93 \pm 0.24$ & 7 \\
\hline $\begin{array}{l}\text { Forcipiger } \\
\text { flavissimus }\end{array}$ & $11.38 \pm 0.22$ & $-15.04 \pm 0.42$ & 6 & $10.44 \pm 0.41$ & $-13.61 \pm 0.7$ & 5 \\
\hline $\begin{array}{l}\text { Ctenochaetus } \\
\text { binotatus }\end{array}$ & $8.61 \pm 0.5$ & $-13.5 \pm 0.27$ & 5 & $7.75 \pm 0.13$ & $-12.29 \pm 0.35$ & 5 \\
\hline Chaetodon kleinii & $10.81 \pm 0.19$ & $-16.52 \pm 0.35$ & 7 & $10.4 \pm 0.16$ & $-14.98 \pm 0.26$ & 6 \\
\hline $\begin{array}{l}\text { Chaetodon } \\
\text { lunulatus }\end{array}$ & $9.27 \pm 0.33$ & $-10.22 \pm 0.37$ & 5 & $8.51 \pm 0.38$ & $-10.78 \pm 1.36$ & 6 \\
\hline $\begin{array}{l}\text { Neoglyphidodon } \\
\text { nigroris }\end{array}$ & $9.73 \pm 0.21$ & $-17.93 \pm 0.12$ & 5 & $9.32 \pm 0.2$ & $-16.85 \pm 0.16$ & 5 \\
\hline
\end{tabular}


Table 2. One-way ANOVA to test for differences in fish size (TL mm) between sites.

\begin{tabular}{lll}
\hline Species & F & Sig. \\
\hline Z. cornutus & 26.78 & $<0.001$ \\
P. diacanthus & 0.587 & 0.46 \\
F. flavissimus & 0 & 0.984 \\
C. binotatus & 2.103 & 0.185 \\
C. kleinii & 2.577 & 0.137 \\
C. lunulatus & 2.577 & 0.143 \\
N. nigroris & 0.071 & 0.797 \\
\hline
\end{tabular}

Table 3. Parametric paired-samples t test and non-parametric Wilcox rank sum on the effect of acidification on $\delta^{15} \mathrm{~N}$ values on sponges and algae collected in the Wakatobi Marine National Park, Indonesia.

\begin{tabular}{|c|c|c|c|c|c|c|}
\hline & Taxa & $\mathrm{n}$ & Acidified & $\begin{array}{l}\text { Non- } \\
\text { Acidified }\end{array}$ & $\mathrm{T}$ & $\mathrm{P}$ \\
\hline \multicolumn{7}{|c|}{ Parametric paired samples $\mathbf{T}$ test } \\
\hline \multirow[t]{3}{*}{ Sponge } & L. herbacea & 6 & $5.19 \pm 0.28$ & $5.07 \pm 0.43$ & 0.62944 & 0.56 \\
\hline & $\begin{array}{l}\text { Xestospongia } \\
\text { sp. }\end{array}$ & 6 & $6.8 \pm 0.62$ & $6.66 \pm 0.79$ & 0.92193 & 0.40 \\
\hline & Clathria sp. & 6 & $6.25 \pm 0.35$ & $6.31 \pm 0.55$ & $-\overline{0.53573}$ & 0.62 \\
\hline Algae & $\begin{array}{l}\text { Green turf } \\
\text { algae }\end{array}$ & 6 & $1.19 \pm 0.47$ & $1.14 \pm 0.46$ & 0.25959 & 0.81 \\
\hline \multicolumn{5}{|c|}{$\begin{array}{l}\text { Wilcox rank sum test } \\
\mathrm{p}\end{array}$} & \multicolumn{2}{|l|}{$\mathrm{V}$} \\
\hline Sponge & Hyrtios eretca & 6 & $3.96 \pm 1.37$ & $3.74 \pm 1.24$ & 19 & 0.094 \\
\hline
\end{tabular}

Table 4. PERMANOVA (main test) of the effect of size (total length), site and species on the trophic position of fish collected in the Wakatobi Marine National Park, Indonesia.

\begin{tabular}{lllllll}
\hline Source & df & SS & MS & Pseudo-F & P(perm) & $\begin{array}{l}\text { Unique } \\
\text { perms }\end{array}$ \\
\hline Length & 1 & $6.2032 \mathrm{E}-2$ & $6.2032 \mathrm{E}-2$ & 11.641 & 0.002 & 996 \\
Site & 1 & 0.22363 & 0.22363 & 41.968 & 0.001 & 997 \\
Species & 6 & 4.0343 & 0.67239 & 126.18 & 0.001 & 999 \\
Si x Sp & 6 & $6.5726 \mathrm{E}-2$ & $1.0954 \mathrm{E}-2$ & 2.0558 & 0.078 & 997 \\
& 68 & 0.36234 & $5.3286 \mathrm{E}-3$ & & & \\
& 82 & 4.748 & & & & \\
\hline
\end{tabular}

PERMDISP on factor 'Site' F: $0.24749 \mathrm{df} 1: 1 \mathrm{df} 2: 81 \mathrm{P}(\mathrm{perm})=0.634$

PERMDISP on factor 'Species' F: 3.4128 df1: 6 df2: $76 \mathrm{P}($ perm $)=0.09$ 
Table 5. PERMANOVA (main test) of the effect of size (total length), site and species on the $\delta^{13} \mathrm{C}$ values of fish collected in the Wakatobi Marine National Park, Indonesia.

\begin{tabular}{lllllll}
\hline Source & df & SS & MS & Pseudo-F & P(perm) & $\begin{array}{l}\text { Unique } \\
\text { perms }\end{array}$ \\
\hline Length & 1 & 0.4642 & 0.4642 & 1.4761 & 0.239 & 998 \\
Site & 1 & 25.581 & 25.581 & 81.345 & 0.001 & 997 \\
Species & 6 & 60.41 & 60.41 & 192.1 & 0.001 & 999 \\
& 6 & 1.516 & 1.516 & 4.8209 & 0.003 & 998 \\
& 68 & 0.3144 & 0.3144 & & & \\
\hline
\end{tabular}

PERMDISP on factor 'Site' F: 0.36872 df1: 1 df2: 81 P(perm): 0.65

PERMDISP on factor 'Species' F: 0.55889 df1: 6 df2: 76 P(perm): 0.801

Table 6. Interspecific comparisons of Trophic Position (TP) of seven reef fish species collected at two sites in the Wakatobi Marine National Park, Indonesia.

\begin{tabular}{|c|c|c|c|c|c|c|}
\hline \multirow[b]{2}{*}{ Pairwise comparisons } & \multicolumn{2}{|c|}{ HQ reef system } & \multicolumn{4}{|c|}{ Sponge reef system } \\
\hline & $\mathrm{t}$ & $p($ perm $)$ & perms & $\mathrm{t}$ & $\mathrm{p}($ perm $)$ & perms \\
\hline Z. cornutus, $P$. diacanthus & 3.5107 & 0.002 & 1249 & 5.0343 & 0.001 & 5024 \\
\hline Z. cornutus, F. flavissimus & 11.074 & $<0.001$ & 1699 & 8.4111 & 0.001 & 1279 \\
\hline Z. cornutus, C. binotatus & 5.4148 & 0.002 & 788 & 3.9372 & 0.006 & 1282 \\
\hline Z. cornutus, C. kleinii & 7.7287 & $<0.001$ & 1698 & 11.36 & $<0.001$ & 2157 \\
\hline Z. cornutus, C. lunulatus & 3.1059 & 0.011 & 579 & $1.45 \mathrm{E}-02$ & 0.989 & 2891 \\
\hline Z. cornutus, $N$. nigroris & 0.6492 & 0.522 & 582 & 4.2213 & 0.002 & 1285 \\
\hline$P$. diacanthus, $F$. flavissimus & 8.7702 & 0.002 & 460 & 3.4578 & 0.003 & 792 \\
\hline P. diacanthus, $C$. binotatus & 7.9266 & 0.001 & 462 & 8.6398 & 0.001 & 791 \\
\hline P. diacanthus, C. kleinii & 4.6164 & 0.002 & 1707 & 4.4145 & 0.001 & 1251 \\
\hline P. diacanthus, C. lunulatus & 6.5186 & 0.003 & 336 & 4.6651 & 0.003 & 1706 \\
\hline P. diacanthus, $N$. nigroris & 4.7296 & 0.002 & 462 & 1.3186 & 0.224 & 787 \\
\hline F. flavissimus, $C$. binotatus & 12.949 & 0.002 & 462 & 12.552 & 0.008 & 126 \\
\hline F. flavissimus, C. kleinii & 5.068 & 0.002 & 1699 & 0.28167 & 0.854 & 245 \\
\hline F. flavissimus, C. lunulatus & 12.882 & 0.003 & 336 & 7.8839 & 0.003 & 462 \\
\hline F. flavissimus, $N$. nigroris & 12.55 & 0.002 & 462 & 5.2856 & 0.007 & 126 \\
\hline C. binotatus, C. kleinii & 11.235 & 0.002 & 789 & 28.083 & 0.002 & 336 \\
\hline C. binotatus, C. lunulatus & 2.464 & 0.044 & 91 & 4.0567 & 0.005 & 462 \\
\hline C. binotatus, $N$. nigroris & 4.7118 & 0.007 & 126 & 14.463 & 0.009 & 126 \\
\hline C. kleinii, C. lunulatus & 10.458 & 0.002 & 581 & 11.429 & 0.002 & 336 \\
\hline C. kleinii, $N$. nigroris & 9.3723 & 0.001 & 791 & 9.9145 & 0.003 & 336 \\
\hline C. lunulatus, N. nigroris & 2.6401 & 0.030 & 91 & 4.2279 & 0.009 & 461 \\
\hline
\end{tabular}


Table 7. Interspecific comparisons of pairwise comparisons of $\delta^{13} \mathrm{C}$ values of seven reef fish species collected at two sites in the Wakatobi Marine National Park, Indonesia. Non-significant pairwise tests in bold font.

\begin{tabular}{|c|c|c|c|c|c|c|}
\hline \multirow[b]{2}{*}{ Pairwise comparisons } & \multicolumn{2}{|c|}{ HQ reef system } & \multirow[b]{2}{*}{ perms } & \multicolumn{3}{|c|}{ Sponge reef system } \\
\hline & $\mathrm{t}$ & $\mathrm{p}($ perm $)$ & & $\mathrm{t}$ & $\mathrm{p}($ perm $)$ & perms \\
\hline Z. cornutus, $P$. diacanthus & 2.0066 & 0.066 & 332 & 2.5716 & 0.026 & 423 \\
\hline Z. cornutus, F. flavissimus & 6.5734 & 0.001 & 474 & 4.6999 & 0.001 & 506 \\
\hline Z. cornutus, C. binotatus & 12.089 & 0.002 & 469 & 8.377 & 0.002 & 507 \\
\hline Z. cornutus, C. kleinii & 1.5922 & 0.149 & 206 & 2.2342 & 0.048 & 292 \\
\hline Z. cornutus, C. lunulatus & 22.462 & 0.002 & 447 & 8.4296 & 0.001 & 698 \\
\hline Z. cornutus, $N$. nigroris & 3.7355 & 0.003 & 302 & 2.4949 & 0.033 & 289 \\
\hline P. diacanthus, $F$. flavissimus & 7.0139 & 0.003 & 219 & 4.6758 & 0.006 & 339 \\
\hline P. diacanthus, C. binotatus & 19.086 & 0.004 & 294 & 15.648 & 0.002 & 337 \\
\hline P. diacanthus, C. kleinii & 0.6172 & 0.561 & 218 & 0.37343 & 0.734 & 188 \\
\hline P. diacanthus, C. lunulatus & 33.783 & 0.003 & 322 & 8.0094 & 0.001 & 601 \\
\hline P. diacanthus, $N$. nigroris & 13.03 & 0.004 & 258 & 15.506 & 0.003 & 382 \\
\hline F. flavissimus, $C$. binotatus & 7.11 & 0.002 & 280 & 3.7626 & 0.009 & 112 \\
\hline F. flavissimus, C. kleinii & 6.953 & 0.003 & 451 & 4.4714 & 0.01 & 272 \\
\hline F. flavissimus, C. lunulatus & 20.105 & 0.004 & 310 & 4.1939 & 0.008 & 328 \\
\hline F. flavissimus, $N$. nigroris & 14.915 & 0.005 & 303 & 10.041 & 0.011 & 87 \\
\hline C. binotatus, C. kleinii & 16.104 & 0.001 & 397 & 14.768 & 0.003 & 327 \\
\hline C. binotatus, C. lunulatus & 15.986 & 0.016 & 113 & 2.4034 & 0.055 & 319 \\
\hline C. binotatus, $N$. nigroris & 33.579 & 0.014 & 96 & 26.702 & 0.006 & 111 \\
\hline C. kleinii, C. lunulatus & 30.086 & 0.003 & 436 & 7.4562 & 0.005 & 319 \\
\hline C. kleinii, N. nigroris & 8.6154 & 0.001 & 213 & 14.078 & 0.001 & 235 \\
\hline C. lunulatus, N. nigroris & 44.499 & 0.004 & 109 & 9.8582 & 0.004 & 375 \\
\hline
\end{tabular}

Table 8. Intraspecific comparisons of trophic position (TP) and $\delta^{13} \mathrm{C}$ values for seven reef fish species collected at two sites in the Wakatobi Marine National Park, Indonesia.

\begin{tabular}{lllllll}
\hline & \multicolumn{2}{c}{ Trophic Position } & & $\boldsymbol{\delta}^{\mathbf{1 3}} \mathbf{C}$ & & \\
$\mathbf{t}$ & & $\mathbf{P}(\mathbf{p e r m})$ & perms & $\mathbf{t}$ & $\mathbf{P}($ perm) & perms \\
\hline Z. cornutus & 4.38 & $0.001^{*}$ & 5031 & 2.772 & 0.191 & 468 \\
P. diacanthus & 1.57 & 0.149 & 1706 & 11.161 & $0.002^{*}$ & 564 \\
F. flavissimus & 2.83 & $0.028^{*}$ & 461 & 4.207 & $0.008^{*}$ & 244 \\
C. binotatus & 1.57 & 0.208 & 126 & 6.13 & $0.009^{*}$ & 98 \\
C. kleinii & 0.19 & 0.917 & 1246 & 8.866 & $0.001^{*}$ & 626 \\
C. lunulatus & 1.36 & 0.189 & 336 & 0.88 & 0.414 & 338 \\
N. nigroris & 0.19 & 0.862 & 126 & 12.359 & $0.008^{*}$ & 72 \\
\hline
\end{tabular}


Table 9. Intraspecific comparisons of Bayesian standard ellipse area $\left(\mathrm{SEA}_{\mathrm{B}}\right)$.

\begin{tabular}{lrr}
\hline $\begin{array}{l}\text { SEAc larger at the } \\
\text { low-quality site }\end{array}$ & Probability & Sig (p) \\
\hline Zanclus cornutus & 92.6 & 0.071 \\
Pygoplites diacanthus & 92.3 & 0.078 \\
Forcipiger flavissimus & 92.8 & 0.071 \\
Chaetodon lunulatus & 97.5 & $0.025^{*}$ \\
$\begin{array}{l}\text { Neoglyphidodon } \\
\text { nigroris }\end{array}$ & 74.1 & 0.250 \\
\hline SEAc smaller at the low-quality site & \\
\hline Ctenochaetus binotatus & 96.3 & $0.037^{*}$ \\
Chaetodon kleinii & 74.1 & 0.250 \\
\hline
\end{tabular}

Table 10. PERMANOVA (main test) of the effect of site and source of stable isotope ratios of carbon sources and potential prey collected from two sites in the Wakatobi Marine National Park, Indonesia.

\begin{tabular}{lllllll}
\hline Source & df & SS & MS & Pseudo-F & P(perm) & $\begin{array}{l}\text { Unique } \\
\text { perms }\end{array}$ \\
\hline Site & 1 & 13.943 & 13.943 & 12.074 & 0.002 & 999 \\
Source & 11 & 1279.3 & 116.3 & 100.71 & 0.001 & 999 \\
Si x So & 9 & 24.962 & 2.7736 & 2.4018 & 0.005 & 998 \\
Res & 48 & 55.43 & 1.1548 & & & \\
Total & 69 & 1396.2 & & & \\
\hline PERMDISP on factor 'Site' F: 1.7987 df1: 1 df2: 68 P(perm $)=0.222$ \\
PERMDISP on factor 'Source' F: 0.65746 df1: 11 df2: 58 P(perm) $=0.902$ \\
\hline
\end{tabular}

Table 11. Between source comparisons of stable isotope ratios of carbon sources and potential prey collected from the high-quality site in the Wakatobi Marine National Park, Indonesia. Bold font indicates isotopic niche overlap between groups.

\begin{tabular}{lllcl}
\hline Groups & $\mathrm{t}$ & $\mathrm{P}(\mathrm{perm})$ & perms & $\mathrm{P}(\mathrm{MC})$ \\
\hline Turf, Halimeda sp. & 6.8413 & 0.087 & 10 & 0.004 \\
Turf, SPOM & 8.5363 & 0.104 & 10 & 0.001 \\
Turf, Pavona & 3.2406 & 0.107 & 10 & 0.019 \\
Turf, Pocillopora & 2.8291 & 0.106 & 10 & 0.033 \\
Turf, Porites & 2.2007 & 0.116 & 10 & $\mathbf{0 . 0 5 2}$ \\
Turf, Detritus+1TP & 6.7631 & 0.022 & 56 & 0.001 \\
Turf, Xestospongia & 5.4139 & 0.104 & 10 & 0.006 \\
Turf, Clathria & 6.6109 & 0.092 & 10 & 0.003 \\
Turf, Hyrtios & 3.3572 & 0.092 & 10 & 0.023 \\
Turf, L dysedia & 9.1054 & 0.094 & 10 & 0.001 \\
Halimeda sp., SPOM & 3.894 & 0.082 & 10 & 0.009 \\
Halimeda sp., Pavona & 10.299 & 0.101 & 10 & 0.002 \\
Halimeda sp., Pocillopora & 10.311 & 0.087 & 10 & 0.001 \\
Halimeda sp., Porites & 9.7378 & 0.098 & 10 & 0.002 \\
Halimeda sp., Detritus+1TP & 9.5866 & 0.022 & 56 & 0.001 \\
Halimeda sp., Xestospongia & 5.5534 & 0.107 & 10 & 0.004
\end{tabular}


Halimeda sp., Clathria

Halimeda sp., Hyrtios

Halimeda sp., L. dysedia

SPOM, Pavona

SPOM, Pocillopora

SPOM, Porites

SPOM, Detritus+1TP

SPOM, Xestospongia

SPOM, Pavona

SPOM, Hyrtios

SPOM, L. dysedia

Pavona, Pocillopora

Pavona, Porites

Pavona, Detritus+1TP

Pavona, Xestospongia

Pavona, Clathria

Pavona, Hyrtios

Pavona, L. dysedia

Pocillopora, Porites

Pocillopora, Detritus+1TP

Pocillopora, Xestospongia

Pocillopora, Clathria

Pocillopora, Hyrtios

Pocillopora, L. dysedia

Porites, Detritus+1TP

Porites, Xestospongia

Porites, Clathria

Porites, Hyrtios

Porites, L. dysedia

Detritus+1TP, Xestospongia

Detritus+1TP, Clathria

Detritus+1TP, Hyrtios

Detritus+1TP, L. dysedia

Xestospongia, Clathria

Xestospongia, Hyrtios

Xestospongia, L. dysedia

Clathria, Hyrtios

Clathria, L. dysedia

Hyrtios, L. dysedia

$\begin{array}{lccc}7.0483 & 0.086 & 10 & 0.003 \\ 4.1898 & 0.1 & 10 & 0.006 \\ 5.1974 & 0.094 & 10 & 0.002 \\ 12.554 & 0.115 & 10 & 0.001 \\ 12.529 & 0.091 & 10 & 0.001 \\ 11.72 & 0.111 & 10 & 0.002 \\ 12.616 & 0.023 & 56 & 0.001 \\ 7.6016 & 0.109 & 10 & 0.002 \\ 8.7506 & 0.092 & 10 & 0.001 \\ 6.5436 & 0.093 & 10 & 0.003 \\ 1.1901 & 0.404 & 10 & \mathbf{0 . 2 8 8} \\ 1.5606 & 0.192 & 10 & \mathbf{0 . 2 0 2} \\ 3.9145 & 0.087 & 10 & 0.012 \\ 5.8521 & 0.025 & 56 & 0.001 \\ 4.9375 & 0.088 & 10 & 0.002 \\ 11.594 & 0.097 & 10 & 0.001 \\ 1.7929 & 0.107 & 10 & \mathbf{0 . 1 0 0} \\ 16.42 & 0.088 & 10 & 0.001 \\ 2.7617 & 0.099 & 10 & 0.045 \\ 6.0192 & 0.015 & 56 & 0.001 \\ 5.1519 & 0.116 & 10 & 0.004 \\ 10.176 & 0.103 & 10 & 0.001 \\ 2.576 & 0.101 & 10 & 0.037 \\ 15.409 & 0.105 & 10 & 0.001 \\ 7.2041 & 0.022 & 56 & 0.001 \\ 5.9039 & 0.095 & 10 & 0.002 \\ 8.5768 & 0.106 & 10 & 0.001 \\ 4.2413 & 0.101 & 10 & 0.006 \\ 12.921 & 0.086 & 10 & 0.001 \\ 1.6132 & 0.143 & 56 & \mathbf{0 . 1 1 1} \\ 5.3086 & 0.018 & 56 & 0.003 \\ 3.9311 & 0.016 & 56 & 0.007 \\ 14.69 & 0.021 & 56 & 0.001 \\ 1.9067 & 0.186 & 10 & \mathbf{0 . 0 9 2} \\ 3.1417 & 0.101 & 10 & 0.027 \\ 8.4556 & 0.104 & 10 & 0.001 \\ 4.204 & 0.1 & 10 & 0.009 \\ 11.719 & 0.095 & 10 & 0.001 \\ 7.308 & 0.109 & 10 & 0.001 \\ & & & \\ & & & \end{array}$

Table 12 Between source comparisons of stable isotope ratios of carbon sources and potential prey collected from the low-quality site in the Wakatobi Marine National Park, Indonesia.

\begin{tabular}{lcccc}
\hline Groups & $\mathrm{t}$ & $\mathrm{P}($ perm $)$ & perms & $\mathrm{P}(\mathrm{MC})$ \\
\hline Turf, SPOM & 17.537 & 0.093 & 10 & 0.001 \\
Turf, Pavona & 9.2721 & 0.092 & 10 & 0.002 \\
Turf, Pocillopora & 9.3153 & 0.096 & 10 & 0.001 \\
Turf, Porites & 5.6712 & 0.105 & 10 & 0.003 \\
Turf, Detritus+1TP & 26.492 & 0.014 & 56 & 0.001 \\
Turf, Xestospongia & 29.127 & 0.113 & 10 & 0.001 \\
Turf, Clathria & 59.307 & 0.083 & 10 & 0.001 \\
Turf, Hyrtios & 11.696 & 0.105 & 10 & 0.001 \\
Turf, L. dysedia & 26.732 & 0.088 & 10 & 0.001
\end{tabular}




\begin{tabular}{|c|c|c|c|c|}
\hline Turf, Dictyota & 5.2335 & 0.11 & 10 & 0.006 \\
\hline SPOM, Pavona & 12.235 & 0.107 & 10 & 0.001 \\
\hline SPOM, Pocillopora & 8.9887 & 0.104 & 10 & 0.001 \\
\hline SPOM, Porites & 10.982 & 0.111 & 10 & 0.001 \\
\hline SPOM, Detritus+1TP & 12.476 & 0.015 & 56 & 0.001 \\
\hline SPOM, Xestospongia & 7.1958 & 0.105 & 10 & 0.003 \\
\hline SPOM, Clathria & 6.8681 & 0.085 & 10 & 0.005 \\
\hline SPOM, Hyrtios & 8.3238 & 0.095 & 10 & 0.001 \\
\hline SPOM, L. dysedia & 0.60008 & 0.575 & 10 & 0.696 \\
\hline SPOM, Dictyota & 6.8272 & 0.099 & 10 & 0.003 \\
\hline Pavona, Pocillopora & 2.9028 & 0.1 & 10 & 0.032 \\
\hline Pavona, Porites & 0.49404 & 0.934 & 10 & 0.778 \\
\hline Pavona, Detritus+1TP & 8.466 & 0.028 & 56 & 0.001 \\
\hline Pavona, Xestospongia & 10.139 & 0.113 & 10 & 0.001 \\
\hline Pavona, Clathria & 12.369 & 0.095 & 10 & 0.001 \\
\hline Pavona, Hyrtios & 4.5365 & 0.104 & 10 & 0.002 \\
\hline Pavona, L. dysedia & 16.702 & 0.097 & 10 & 0.001 \\
\hline Pavona, Dictyota & 2.3152 & 0.094 & 10 & 0.071 \\
\hline Pocillopora, Porites & 2.817 & 0.11 & 10 & 0.041 \\
\hline Pocillopora, Detritus+1TP & 3.9358 & 0.018 & 56 & 0.002 \\
\hline Pocillopora, Xestospongia & 5.2358 & 0.105 & 10 & 0.003 \\
\hline Pocillopora, Clathria & 5.9942 & 0.096 & 10 & 0.008 \\
\hline Pocillopora, Hyrtios & 1.2482 & 0.295 & 10 & 0.267 \\
\hline Pocillopora, L. dysedia & 11.718 & 0.108 & 10 & 0.002 \\
\hline Pocillopora, Dictyota & 0.77916 & 0.514 & 10 & 0.500 \\
\hline Porites, Detritus+1TP & 7.0044 & 0.019 & 56 & 0.001 \\
\hline Porites, Xestospongia & 7.8262 & 0.097 & 10 & 0.001 \\
\hline Porites, Clathria & 8.8248 & 0.117 & 10 & 0.001 \\
\hline Porites, Hyrtios & 4.0831 & 0.094 & 10 & 0.010 \\
\hline Porites, L. dysedia & 13.792 & 0.094 & 10 & 0.001 \\
\hline Porites, Dictyota & 2.3842 & 0.087 & 10 & 0.054 \\
\hline Detritus+1TP, Xestospongia & 5.4725 & 0.02 & 56 & 0.001 \\
\hline Detritus+1TP, Clathria & 8.31 & 0.022 & 56 & 0.001 \\
\hline Detritus+1TP, Hyrtios & 4.1091 & 0.02 & 56 & 0.006 \\
\hline Detritus+1TP, L. dysedia & 17.819 & 0.017 & 56 & 0.001 \\
\hline Detritus+1TP, Dictyota & 3.5161 & 0.017 & 56 & 0.003 \\
\hline Xestospongia, Clathria & 2.247 & 0.08 & 10 & 0.078 \\
\hline Xestospongia, Hyrtios & 4.6765 & 0.105 & 10 & 0.004 \\
\hline Xestospongia, L. dysedia & 10.832 & 0.089 & 10 & 0.001 \\
\hline Xestospongia, Dictyota & 3.6938 & 0.103 & 10 & 0.007 \\
\hline Clathria, Hyrtios & 5.2179 & 0.099 & 10 & 0.002 \\
\hline Clathria, L. dysedia & 11 & 0.096 & 10 & 0.001 \\
\hline Clathria, Dictyota & 3.8141 & 0.097 & 10 & 0.019 \\
\hline Hyrtios, L. dysedia & 11.147 & 0.11 & 10 & 0.001 \\
\hline Hyrtios, Dictyota & 0.89201 & 0.603 & 10 & 0.458 \\
\hline L. dysedia, Dictyota & 8.0507 & 0.09 & 10 & 0.002 \\
\hline
\end{tabular}


Table 13. PERMANOVA (main test) of the effect of site and taxa type on stable isotope ratios of sources grouped into sponges, corals, algae and SPOM collected from two sites in the Wakatobi Marine National Park, Indonesia.

\begin{tabular}{lllllll}
\hline Source & df & SS & MS & Pseudo-F & P(perm) & $\begin{array}{l}\text { Unique } \\
\text { perms }\end{array}$ \\
\hline Site & 1 & 12.612 & 12.612 & 5.499 & 0.014 & 999 \\
Taxa & 4 & 803.52 & 200.88 & 87.584 & 0.001 & 999 \\
Site x Taxa & 4 & 10.456 & 12.614 & 1.1397 & 0.337 & 999 \\
Res & 47 & 107.8 & 2.2936 & & & \\
Total & 56 & 934.85 & & & \\
\hline PERMDISP on factor 'Site' F: 0.89517 df1: 1 df2: 55 P(perm) $)=0.387$ & & \\
PERMDISP on factor 'Taxa' F: 1.0145 df1: 4 df2: 52 P(perm) $=0.481$ & & \\
\hline
\end{tabular}

Table 14. Between source comparisons of stable isotope ratios of sources grouped into sponges, corals, algae and SPOM collected from two sites in the Wakatobi Marine National Park, Indonesia.

\begin{tabular}{lclll}
\hline Groups & $\mathrm{t}$ & $\mathrm{P}(\mathrm{perm})$ & Unique perms & $\mathrm{P}(\mathrm{MC})$ \\
\hline Algae, SPOM & 14.973 & 0.005 & 984 & 0.001 \\
Algae, Corals & 5.0027 & 0.001 & 998 & 0.001 \\
Algae, Detritus & 12.476 & 0.002 & 997 & 0.001 \\
Algae, Sponges & 10.42 & 0.001 & 999 & 0.001 \\
SPOM, Corals & 13.396 & 0.001 & 998 & 0.001 \\
SPOM, Detritus & 17.603 & 0.001 & 995 & 0.001 \\
SPOM, Sponges & 8.7556 & 0.001 & 999 & 0.001 \\
Corals, Detritus & 5.9336 & 0.001 & 998 & 0.001 \\
Corals, Sponges & 7.7954 & 0.001 & 996 & 0.001 \\
Detritus, Sponges & 2.7029 & 0.003 & 999 & 0.003 \\
\hline
\end{tabular}

Table 15. Spatial variation in the stable isotope ratios of sources (sponges, corals, algae and SPOM) collected from two sites in the Wakatobi Marine National Park, Indonesia.

\begin{tabular}{lllll}
\hline Source & $\mathrm{t}$ & $\mathrm{P}($ perm $)$ & Unique perms & $\mathrm{P}(\mathrm{MC})$ \\
\hline Algae & 0.46 & 1 & 10 & 0.72 \\
SPOM & 2.31 & 0.128 & 10 & 0.08 \\
Corals & 0.71 & 0.53 & 961 & 0.51 \\
Sponges & 1.98 & 0.04 & 970 & 0.04 \\
Detritus & 4.20 & 0.01 & 126 & $>0.01$ \\
\hline
\end{tabular}


Table 16. Input parameters for dual-isotope mixing models to estimate the proportional contribution of pelagic and benthic carbon to secondary production at two sites in the Wakatobi Marine National Park, Indonesia. NB Pelagic carbon corrected for $+2 \mathrm{TP}$ and benthic carbon corrected for $+1 \mathrm{TP}$.

\begin{tabular}{|l|l|l|l|l|}
\hline Site & $\begin{array}{l}\text { Pelagic carbon } \\
\text { Mean } \pm \text { SD }\end{array}$ & $\begin{array}{l}\text { Pelagic TEF } \\
\text { Mean } \pm \text { SD }\end{array}$ & $\begin{array}{l}\text { Benthic carbon } \\
\text { Mean } \pm \text { SD }\end{array}$ & $\begin{array}{l}\text { Benthic TEF } \\
\text { Mean } \pm \text { SD }\end{array}$ \\
\hline $\begin{array}{l}\text { High- } \\
\text { quality }\end{array}$ & $\delta^{13} \mathrm{C}-25.13 \pm 1.31$ & $0.78 \pm 1.3\left(\Delta^{13} \mathrm{C}\right)$ & $\delta^{13} \mathrm{C}-16.15 \pm 2.32$ & $0.39 \pm 1.3\left(\Delta^{13} \mathrm{C}\right)$ \\
$\delta^{15} \mathrm{~N} 4.71 \pm 0.99$ & $6.8 \pm 0.98\left(\Delta^{15} \mathrm{~N}\right)$ & $\delta^{15} \mathrm{~N} 5.42 \pm 1.06$ & $3.4 \pm 0.98\left(\Delta^{15} \mathrm{~N}\right)$ \\
\hline $\begin{array}{l}\text { Sponge- } \\
\text { dominated }\end{array}$ & $\delta^{13} \mathrm{C}-25.13 \pm 1.31$ & $0.78 \pm 1.3\left(\Delta^{13} \mathrm{C}\right)$ & $\delta^{13} \mathrm{C}-15.40 \pm 1.53$ & $0.39 \pm 1.3\left(\Delta^{13} \mathrm{C}\right)$ \\
$\delta^{15} \mathrm{~N} 4.71 \pm 0.99$ & $6.8 \pm 0.98\left(\Delta^{15} \mathrm{~N}\right)$ & $\delta^{15} \mathrm{~N} 4.92 \pm 1.01$ & $3.4 \pm 0.98\left(\Delta^{15} \mathrm{~N}\right)$ \\
\hline
\end{tabular}

Table 17. Chaetodon lunulatus and obligate corallivores densities (fish per $250 \mathrm{~m}^{2}$ ) recorded by stereovideo on $6 \times 50 \mathrm{~m}$ transects as part of a local monitoring program at a sponge-dominated site and higher quality reef site.

\begin{tabular}{lll}
\hline Site & Chaetodon lunulatus & Obligate corallivores \\
\hline Sponge-dominated & $0.7 \pm 0.3$ & $1.0 \pm 0.4$ \\
High-quality & $0.3 \pm 0.3$ & $1.2 \pm 0.5$ \\
\hline
\end{tabular}




\section{Appendix E}

Table 1. $\delta^{13} \mathrm{C}$ and $\delta^{15} \mathrm{~N}$ values (mean $\pm \mathrm{SD}$ ) of sponges collected at two sites and two depths in Doubtful Sound, Fiordland.

\begin{tabular}{lrllllll}
\hline & \multicolumn{3}{c}{ Inner Fiord } & \multicolumn{5}{c}{ Outer Fiord } \\
Species & Depth & $\delta^{15} \mathrm{~N} \pm \mathrm{SD}$ & $\delta 13 \mathrm{C} \pm \mathrm{SD}$ & $\mathrm{N}$ & $\delta^{15} \mathrm{~N} \pm \mathrm{SD}$ & $\delta 13 \mathrm{C} \pm \mathrm{SD}$ & $\mathrm{N}$ \\
\hline Raspailia & 10 & $9.92 \pm 0.15$ & $-23.31 \pm 0.91$ & 5 & & & \\
topsenti & 30 & $10.43 \pm 0.16$ & $-23.35 \pm 0.53$ & 5 & $9.71 \pm 0.81$ & $-22.80 \pm 0.75$ & 5 \\
Cymbastela & 10 & $8.75 \pm 0.13$ & $-22.36 \pm 1.01$ & 4 & $7.10 \pm 0.68$ & $-21.31 \pm 1.33$ & 5 \\
tricalyciformis & 30 & $9.18 \pm 0.14$ & $-19.65 \pm 0.84$ & 3 & $8.46 \pm 0.67$ & $-21.56 \pm 1.24$ & 5 \\
Axinella & 10 & $11.19 \pm 0.33$ & $-23.64 \pm 0.38$ & 5 & $11.19 \pm 0.48$ & $-23.03 \pm 0.48$ & 5 \\
richardsoni & 30 & $11.73 \pm 0.33$ & $-23.69 \pm 0.36$ & 5 & $11.01 \pm 0.30$ & $-22.84 \pm 1.46$ & 5 \\
Tethya sp. & 10 & $8.45 \pm 0.80$ & $-23.47 \pm 0.40$ & 5 & $9.27 \pm 0.47$ & $-24.34 \pm 0.81$ & 5 \\
& 30 & $9.24 \pm 0.48$ & $-22.87 \pm 0.66$ & 5 & $9.23 \pm 0.36$ & $-23.61 \pm 1.13$ & 5 \\
Latrunculia & 10 & $8.64 \pm 1.21$ & $-23.19 \pm 1.55$ & 3 & $7.72 \pm 0.20$ & $-22.70 \pm 0.35$ & 5 \\
fiordensis & 30 & & & & $8.03 \pm 0.14$ & $-22.63 \pm 0.41$ & 5 \\
\hline
\end{tabular}

Table 2. $\delta^{13} \mathrm{C}$ and $\delta^{15} \mathrm{~N}$ values (mean $\pm \mathrm{SD}$ ) of organic matter sources collected at three sites in Doubtful Sound, Fiordland.

\begin{tabular}{|c|c|c|c|c|c|c|c|c|c|c|c|}
\hline \multirow{2}{*}{\multicolumn{2}{|c|}{$\begin{array}{l}\text { Organic matter } \\
\text { sources }\end{array}$}} & \multicolumn{4}{|c|}{ Inner Fiord } & \multicolumn{3}{|c|}{ Outer Fiord } & \multicolumn{3}{|c|}{ Bradshaw Sound } \\
\hline & & Depth & $\begin{array}{l}\delta^{15} \mathrm{~N} \pm \\
\mathrm{SD}\end{array}$ & $\begin{array}{l}\delta 13 \mathrm{C} \pm \\
\mathrm{SD}\end{array}$ & $\mathrm{N}$ & $\begin{array}{l}\delta^{15} \mathrm{~N} \pm \\
\mathrm{SD}\end{array}$ & $\begin{array}{l}\delta 13 \mathrm{C} \\
\pm \mathrm{SD}\end{array}$ & $\mathrm{N}$ & $\begin{array}{l}\delta^{15} \mathrm{~N} \pm \\
\mathrm{SD}\end{array}$ & $\begin{array}{l}\delta 13 \mathrm{C} \\
\pm \mathrm{SD}\end{array}$ & $\mathrm{N}$ \\
\hline \multirow[t]{4}{*}{$\begin{array}{l}\text { Marine } \\
\text { pelagic }\end{array}$} & \multirow[t]{2}{*}{$2-200$} & 10 & $\begin{array}{l}7.15 \pm \\
1.39\end{array}$ & $\begin{array}{l}-25.50 \pm \\
0.88\end{array}$ & 5 & $\begin{array}{l}7.87 \pm \\
0.24\end{array}$ & $\begin{array}{l}-24.09 \\
\pm 0.22\end{array}$ & 5 & & & \\
\hline & & 30 & $\begin{array}{l}7.06 \pm \\
1.17\end{array}$ & $\begin{array}{l}-24.79 \pm \\
0.43\end{array}$ & $3 / 5$ & $\begin{array}{l}6.15 \pm \\
0.36\end{array}$ & $\begin{array}{l}-24.10 \\
\pm 0.22\end{array}$ & $3 / 5$ & & & \\
\hline & \multirow{2}{*}{$\begin{array}{l}\text { Pico } \\
\text { plankton }\end{array}$} & 10 & $\begin{array}{l}5.47 \pm \\
1.54\end{array}$ & $\begin{array}{l}-30.30 \pm \\
1.44\end{array}$ & 5 & $\begin{array}{l}6.30 \pm \\
0.55\end{array}$ & $\begin{array}{l}-30.60 \\
\pm 0.77\end{array}$ & 5 & & & \\
\hline & & 30 & $\begin{array}{l}5.72 \pm \\
1.21\end{array}$ & $\begin{array}{l}-32.26 \pm \\
1.64\end{array}$ & $3 / 5$ & $\begin{array}{l}5.04 \pm \\
1.44\end{array}$ & $\begin{array}{l}-30.67 \\
\pm 0.67\end{array}$ & 5 & & & \\
\hline \multirow[t]{3}{*}{$\begin{array}{l}\text { Marine } \\
\text { benthic }\end{array}$} & \multicolumn{2}{|l|}{ Ulva sp. } & $\begin{array}{l}2.26 \pm \\
0.22\end{array}$ & $\begin{array}{l}-15.43 \pm \\
0.96\end{array}$ & 5 & & & & $\begin{array}{l}3.59 \pm \\
0.86\end{array}$ & $\begin{array}{l}-17.37 \\
\pm 0.54\end{array}$ & 5 \\
\hline & \multicolumn{2}{|c|}{ Codium sp. } & & & & $\begin{array}{l}5.24 \pm \\
0.27\end{array}$ & $\begin{array}{l}-22.05 \\
\pm 0.68\end{array}$ & 5 & $\begin{array}{l}5.66 \pm \\
0.36\end{array}$ & $\begin{array}{l}-19.91 \\
\pm 1.39\end{array}$ & 5 \\
\hline & \multicolumn{2}{|c|}{ Ecklonia radiata } & & & & $\begin{array}{l}7.50 \pm \\
0.40\end{array}$ & $\begin{array}{l}-19.46 \\
\pm 0.86\end{array}$ & 5 & $\begin{array}{l}5.75 \pm \\
0.35\end{array}$ & $\begin{array}{l}-21.07 \\
\pm 0.75\end{array}$ & 5 \\
\hline $\begin{array}{l}\text { Terrestrial } \\
\text { detritus }\end{array}$ & TOM & & $\begin{array}{l}-3.36 \\
\pm 0.40\end{array}$ & $\begin{array}{l}-30.85 \pm \\
1.15\end{array}$ & 3 & $\begin{array}{l}-1.20 \\
\pm 0.52\end{array}$ & $\begin{array}{l}-29.17 \\
\pm 0.97\end{array}$ & 3 & $\begin{array}{l}-3.51 \\
\pm 0.75\end{array}$ & $\begin{array}{l}-30.35 \\
\pm 0.87\end{array}$ & 4 \\
\hline
\end{tabular}


Table 3. PERMANOVA results of $\delta^{15} \mathrm{~N}$ and $\delta^{13} \mathrm{C}$ values of sponges collected from two depths (10 and $30 \mathrm{~m}$ ) at two sites (Inner Fiord and Outer Fiord) in Doubtful Sound, Fiordland.

\begin{tabular}{|c|c|c|c|c|c|c|}
\hline Factor & df & SS & MS & $\begin{array}{l}\text { Pseudo- } \\
\text { F }\end{array}$ & $\mathrm{P}($ perm $)$ & $\begin{array}{l}\text { Unique } \\
\text { perms }\end{array}$ \\
\hline Site & 1 & 14.77 & 14.77 & 4.52 & 0.015 & 999 \\
\hline Depth & 1 & 10.54 & 10.54 & 3.23 & 0.046 & 999 \\
\hline $\mathrm{Si} \times \mathrm{De}$ & 1 & 1.19 & 1.19 & 0.36 & 0.66 & 999 \\
\hline Res & 81 & 264.24 & 3.26 & & & \\
\hline Total & 84 & 288.73 & & & & \\
\hline
\end{tabular}

PERMDISP on group factor 'Site', $\mathrm{F}=1.43, \mathrm{p}=0.29$

PERMDISP on group factor 'Depth', $F=0.22, \mathrm{p}=0.66$

Table 4. Permutational ANOVA results for $\delta^{15} \mathrm{~N}$ values of sponges collected from two depths (10 and $30 \mathrm{~m}$ ) at two sites (Inner Fiord and Outer Fiord) in Doubtful Sound, Fiordland.

\begin{tabular}{|c|c|c|c|c|c|c|c|}
\hline Factor & $\mathrm{df}$ & & SS & MS & $\begin{array}{l}\text { Pseudo- } \\
\text { F }\end{array}$ & $\mathrm{P}($ perm $)$ & $\begin{array}{l}\text { Unique } \\
\text { perms }\end{array}$ \\
\hline Site & & 1 & 13.942 & 13.942 & 8.053 & 0.005 & 997 \\
\hline Depth & & 1 & 8.0372 & 8.0372 & 4.6425 & 0.039 & 999 \\
\hline $\mathrm{Si} \times \mathrm{De}$ & & 1 & 0.4594 & 0.4594 & 0.2653 & 0.62 & 995 \\
\hline Res & & 81 & 140.23 & 1.7312 & & & \\
\hline Total & & 84 & 160.49 & & & & \\
\hline
\end{tabular}

PERMDISP on group factor 'Site', $F=0.99, \mathrm{p}=0.334$

PERMDISP on group factor 'Depth', $F=2.25, \mathrm{p}=0.136$

Table 5. Permutational ANOVA results for $\delta^{13} \mathrm{C}$ values of sponges collected from two depths (10 and $30 \mathrm{~m}$ ) at two sites (Inner Fiord and Outer Fiord) in Doubtful Sound, Fiordland.

\begin{tabular}{|c|c|c|c|c|c|c|c|}
\hline Factor & $\mathrm{df}$ & & SS & MS & $\begin{array}{l}\text { Pseudo- } \\
\text { F }\end{array}$ & $\mathrm{P}($ perm $)$ & $\begin{array}{l}\text { Unique } \\
\text { perms }\end{array}$ \\
\hline Site & & 1 & 0.823 & 0.823 & 0.53758 & 0.491 & 999 \\
\hline Depth & & 1 & 2.4985 & 2.4985 & 1.632 & 0.227 & 993 \\
\hline $\mathrm{Si} \times \mathrm{De}$ & & 1 & 0.730 & 0.730 & 0.47685 & 0.504 & 996 \\
\hline Res & & 81 & 124.01 & 1.5309 & & & \\
\hline Total & & 84 & 128.25 & & & & \\
\hline
\end{tabular}

PERMDISP on group factor 'Site', $F=0.1115, \mathrm{p}=0.783$.

PERMDISP on group factor 'Depth', $F=1.3518, \mathrm{p}=0.29$. 
Table 6. PERMANOVA results of $\delta^{15} \mathrm{~N}$ and $\delta^{13} \mathrm{C}$ values of the 2-200 fraction of the water column collected from two depths (10 and $30 \mathrm{~m}$ ) at two sites (Inner Fiord and Outer Fiord) in Doubtful Sound, Fiordland.

\begin{tabular}{|c|c|c|c|c|c|c|}
\hline Factor & df & SS & MS & $\begin{array}{l}\text { Pseudo- } \\
\text { F }\end{array}$ & $\mathrm{P}($ perm $)$ & $\begin{array}{l}\text { Unique } \\
\text { perms }\end{array}$ \\
\hline Site & 1 & 6.19 & 6.19 & 5.88 & 0.007 & 999 \\
\hline Depth & 1 & 3.68 & 3.68 & 3.49 & 0.048 & 999 \\
\hline $\mathrm{Si} \times \mathrm{De}$ & 1 & 3.05 & 3.05 & 2.89 & 0.06 & 999 \\
\hline Res & 14 & 14.74 & 1.05 & & & \\
\hline Total & 17 & 29.47 & & & & \\
\hline
\end{tabular}

PERMDISP on group factor 'Site', $\mathrm{F}=2.57, \mathrm{p}=0.11$.

PERMDISP on group factor 'Depth', $F=1.74, \mathrm{p}=0.29$.

Table 7. PERMANOVA results of $\delta^{15} \mathrm{~N}$ and $\delta^{13} \mathrm{C}$ values of picoplankton collected from two depths $(10$ and $30 \mathrm{~m})$ at two sites (Inner Fiord and Outer Fiord) in Doubtful Sound, Fiordland.

\begin{tabular}{|c|c|c|c|c|c|c|}
\hline Factor & $\mathrm{df}$ & SS & MS & $\begin{array}{l}\text { Pseudo- } \\
\text { F }\end{array}$ & $\mathrm{P}($ perm $)$ & $\begin{array}{l}\text { Unique } \\
\text { perms }\end{array}$ \\
\hline Site & 1 & 0.106 & 0.106 & 0.01 & 0.96 & 999 \\
\hline Depth & 1 & 2.69 & 2.69 & 0.93 & 0.39 & 998 \\
\hline Si $x$ De & 1 & 2.92 & 2.92 & 1.01 & 0.39 & 999 \\
\hline Res & 12 & 34.60 & 2.88 & & & \\
\hline Total & 15 & 40.50 & & & & \\
\hline
\end{tabular}

PERMDISP on group factor 'Site', $\mathrm{F}=3.49, \mathrm{p}=0.14$

PERMDISP on group factor 'Depth', $F=0.01, p=0.98$

Table 8. PERMANOVA pairwise comparisons of sponge species collected from $10 \mathrm{~m}$ at the Inner Fiord in Doubtful Sound, Fiordland.

\begin{tabular}{lccc}
\hline Groups & $\mathrm{t}$ & $\mathrm{P}(\mathrm{perm})$ & Unique perms \\
\hline Raspailia topsenti vs Cymbastela tricalyciformis & 2.1426 & $0.048^{*}$ & 125 \\
Raspailia topsenti vs Latrunculia fiordensis & 1.2612 & 0.225 & 56 \\
Raspailia topsenti vs Axinella richardsoni & 2.667 & $0.010^{*}$ & 126 \\
Raspailia topsenti vs Tethya sp. & 2.4675 & $0.012^{*}$ & 126 \\
Cymbastela tricalyciformis vs Latrunculia fiordensis & 0.7259 & 0.601 & 35 \\
Cymbastela tricalyciformis vs Axinella richardsoni & 4.9537 & $0.012^{*}$ & 126 \\
Cymbastela tricalyciformis vs Tethya sp. & 1.7022 & 0.087 & 126 \\
Latrunculia fiordensis vs Axinella richardsoni & 2.9376 & $0.019^{*}$ & 56 \\
Latrunculia fiordensis vs Tethya sp. & 0.33515 & 0.883 & 56 \\
Axinella richardsoni vs Tethya sp. & 5.9475 & $0.016^{*}$ & 126 \\
\hline
\end{tabular}


Table 9. PERMANOVA pairwise comparisons of sponge species collected from $30 \mathrm{~m}$ at the Inner Fiord in Doubtful Sound, Fiordland.

\begin{tabular}{lccc}
\hline Groups & $\mathrm{t}$ & $\mathrm{P}(\mathrm{perm})$ & Unique perms \\
\hline Raspailia topsenti vs Cymbastela tricalyciformis & 7.50 & $0.019^{*}$ & 56 \\
Raspailia topsenti vs Axinella richardsoni & 3.81 & $0.01^{*}$ & 126 \\
Raspailia topsenti vs Tethya sp. & 2.78 & $0.021^{*}$ & 124 \\
Cymbastela tricalyciformis vs Axinella richardsoni & 10.32 & $0.025^{*}$ & 56 \\
Cymbastela tricalyciformis vs Tethya sp. & 5.32 & $0.019^{*}$ & 56 \\
Axinella richardsoni vs Tethya sp. & 6.19 & $0.01^{*}$ & 126 \\
\hline
\end{tabular}

Table 10. PERMANOVA pairwise comparisons of sponge species collected from $10 \mathrm{~m}$ at the Outer Fiord site Doubtful Sound, Fiordland.

\begin{tabular}{lrcc}
\hline Groups & $\mathrm{t}$ & $\mathrm{P}(\mathrm{perm})$ & Unique perms \\
\hline Cymbastela tricalyciformis vs Latrunculia fiordensis & 2.20 & $0.041^{*}$ & 126 \\
Cymbastela tricalyciformis vs Axinella richardsoni & 6.04 & $0.008^{*}$ & 126 \\
Cymbastela tricalyciformis vs Tethya sp. & 4.72 & $0.013^{*}$ & 125 \\
Latrunculia fiordensis vs Axinella richardsoni & 9.82 & $0.004^{*}$ & 126 \\
Latrunculia fiordensis vs Tethya sp. & 4.94 & $0.013^{*}$ & 126 \\
Axinella richardsoni vs Tethya sp. & 4.47 & $0.006^{*}$ & 126 \\
\hline
\end{tabular}

Table 11. PERMANOVA pairwise comparisons of sponge species collected from $30 \mathrm{~m}$ at the Outer Fiord in Doubtful Sound, Fiordland.

\begin{tabular}{lrcc}
\hline Groups & $\mathrm{t}$ & $\mathrm{P}(\mathrm{perm})$ & Unique perms \\
\hline Raspailia topsenti vs Cymbastela tricalyciformis & 2.21 & $0.023^{*}$ & 126 \\
Raspailia topsenti vs Latrunculia fiordensis & 3.19 & $0.008^{*}$ & 126 \\
Raspailia topsenti vs Axinella richardsoni & 1.56 & 0.110 & 126 \\
Raspailia topsenti vs Tethy a sp. & 1.30 & 0.205 & 126 \\
Cymbastela tricalyciformis vs Latrunculia fiordensis & 1.75 & 0.123 & 125 \\
Cymbastela tricalyciformis vs Axinella richardsoni & 3.11 & $0.006^{*}$ & 126 \\
Cymbastela tricalyciformis vs Tethya sp. & 2.67 & $0.029^{*}$ & 126 \\
Latrunculia fiordensis vs Axinella richardsoni & 4.30 & $0.014^{*}$ & 126 \\
Latrunculia fiordensis vs Tethya sp. & 2.75 & $0.031^{*}$ & 126 \\
Axinella richardsoni vs Tethya sp. & 2.27 & $0.035^{*}$ & 126 \\
\hline
\end{tabular}


Table 12. Henze-Zirkler's Multivariate Normality Test results for each group.

\begin{tabular}{llllllll}
\hline \multirow{2}{*}{ Species } & \multicolumn{3}{c}{ Inner site } & \multicolumn{5}{c}{ Outer site } \\
& Depth & $\mathrm{N}$ & $\mathrm{HZ}$ & $\mathrm{P}$-value & $\mathrm{N}$ & $\mathrm{H}$ & P-value \\
\hline Raspailia topsenti & 10 & 5 & 0.39 & 0.15 & 0 & & \\
& 30 & 5 & 0.25 & 0.49 & 5 & 0.27 & 0.42 \\
Cymbastela tricalyciformis & Both & 10 & 0.41 & 0.26 & 5 & & \\
& 30 & 3 & 0.25 & 0.42 & 5 & 0.19 & 0.71 \\
& Both & 7 & N/A & & 5 & 0.32 & 0.29 \\
Axinella richardsoni & 10 & 5 & 0.29 & 0.47 & 10 & 0.27 & 0.62 \\
& 30 & 5 & 0.16 & 0.82 & & 0.30 & 0.32 \\
Tethya sp. & Both & 10 & 0.25 & 0.10 & & 0.21 & 0.63 \\
& 10 & 5 & 0.13 & 0.92 & & 0.34 & 0.41 \\
Latrunculia fiordensis & 30 & 5 & 0.26 & 0.46 & & 0.28 & 0.39 \\
& Both & 10 & 0.32 & 0.47 & 10 & 0.32 & 0.29 \\
& 10 & 3 & N/A & & & 0.25 & 0.41 \\
& 30 & 0 & & & & 0.11 & 0.96 \\
& Both & 3 & N/A & & 10 & 0.29 & 0.55 \\
\hline
\end{tabular}

Table 13. Estimates of corrected standard ellipse area $\left(\mathrm{SEA}_{\mathrm{C}}\right)$ and the Bayesian ellipse area $\left(\mathrm{SEA}_{\mathrm{B}}\right)$ (mode and 95\% credible intervals) of sponges sampled at two sites in Doubtful Sound, Fiordland.

\begin{tabular}{|c|c|c|c|c|c|c|c|}
\hline & \multicolumn{3}{|c|}{ Inner Fiord } & \multicolumn{3}{|c|}{ Outer Fiord } & \multirow[b]{2}{*}{$\mathrm{n}$} \\
\hline & Depth & $\begin{array}{c}\text { SEA } \\
\mathrm{c}\end{array}$ & SEAB & $\mathrm{n}$ & $\begin{array}{c}\text { SEA } \\
\mathrm{c}\end{array}$ & SEAB & \\
\hline \multirow[t]{5}{*}{ Raspailia topsenti } & 10 & 1.38 & 0.91 & 5 & & & \\
\hline & & & {$[0.37-2.72]$} & & & & \\
\hline & 30 & 0.59 & 0.42 & 5 & 1.89 & 1.37 & 5 \\
\hline & & & {$[0.17-1.26]$} & & & {$[0.56-4.11]$} & \\
\hline & Both & 1.01 & $\begin{array}{c}0.826 \\
{[0.453-1.71]}\end{array}$ & 10 & & & \\
\hline \multirow[t]{4}{*}{$\begin{array}{l}\text { Cymbastela } \\
\text { tricalyciformis }\end{array}$} & 10 & 2.37 & 1.29 & & 3.54 & 2.29 & 5 \\
\hline & & & {$[0.47-4.68]$} & & & {$[0.95-7.04]$} & \\
\hline & 30 & 0.69 & $\begin{array}{c}0.28 \\
{[0.07-1.34]}\end{array}$ & & 2.77 & $\begin{array}{c}1.91 \\
{[0.80-5.86]}\end{array}$ & 5 \\
\hline & Both & 2.45 & $\begin{array}{c}1.81 \\
{[0.894-4.53]}\end{array}$ & 7 & 4.02 & $\begin{array}{c}3.35 \\
{[1.81-6.81]}\end{array}$ & 10 \\
\hline \multirow[t]{3}{*}{ Axinella richardsoni } & 10 & 0.42 & $\begin{array}{c}0.29 \\
{[0.12-0.89]}\end{array}$ & 5 & 0.79 & $\begin{array}{c}0.53 \\
{[0.23-1.66]}\end{array}$ & 5 \\
\hline & 30 & 0.45 & $\begin{array}{c}0.29 \\
{[0.12-0.89]}\end{array}$ & 5 & 1.71 & $\begin{array}{c}1.13 \\
{[0.46-3.36]}\end{array}$ & 5 \\
\hline & Both & 0.47 & $\begin{array}{c}0.391 \\
{[0.214-0.81]}\end{array}$ & 10 & 1.43 & $\begin{array}{c}1.17 \\
{[0.637-2.38]}\end{array}$ & 10 \\
\hline \multirow[t]{3}{*}{ Tethya sp. } & 10 & 1.15 & $\begin{array}{c}0.82 \\
{[0.32-2.35]}\end{array}$ & 5 & 0.67 & $\begin{array}{c}0.69 \\
{[0.29-2.11]}\end{array}$ & 5 \\
\hline & 30 & 1.17 & $\begin{array}{c}0.77 \\
{[0.32-2.35]}\end{array}$ & 5 & 1.66 & $\begin{array}{c}1.07 \\
{[0.44-3.27]}\end{array}$ & 5 \\
\hline & Both & 1.6 & 1.32 & 10 & 1.21 & 1.03 & 10 \\
\hline
\end{tabular}




\begin{tabular}{|c|c|c|c|c|c|c|c|}
\hline & & & [0.71 - 2.65] & & & {$[0.558-2.09]$} & \\
\hline \multirow[t]{3}{*}{ Latrunculia fiordensis } & 10 & 6.02 & $\begin{array}{c}3.96 \\
{[0.95-17.5]}\end{array}$ & 3 & 0.23 & $\begin{array}{c}0.16 \\
{[0.07-0.50]}\end{array}$ & 5 \\
\hline & 30 & & & & 0.25 & $\begin{array}{c}0.16 \\
{[0.06-0.48]}\end{array}$ & 5 \\
\hline & Both & & & & 0.28 & $\begin{array}{c}0.228 \\
{[0.126-0.477]}\end{array}$ & 10 \\
\hline
\end{tabular}

Table 14. Pairwise tests estimating differences in isotopic niche size (SEA $)$ between $10 \mathrm{~m}$ and $30 \mathrm{~m}$ at two sites in Doubtful Sound, Fiordland.

\begin{tabular}{lcc}
\hline Inner Fiord site & $\begin{array}{l}\text { Probability } \\
(\%)\end{array}$ & Significance \\
\hline Raspailia topsenti $(30 \mathrm{~m}<10 \mathrm{~m})$ & 88.0 & 0.120 \\
Cymbastela tricalyciformis $(30 \mathrm{~m}<10 \mathrm{~m})$ & 95.5 & 0.045 \\
Axinella cf. richardsoni $(30 \mathrm{~m}<10 \mathrm{~m})$ & 50.0 & 0.500 \\
Tethya $\mathrm{sp} .(30 \mathrm{~m}<10 \mathrm{~m})$ & 50.4 & 0.496 \\
& & \\
\hline Outer Fiord site & & \\
Cymbastela tricalyciformis $(30 \mathrm{~m}>10 \mathrm{~m})$ & 50.4 & 0.496 \\
Axinella cf. richardsoni $(30 \mathrm{~m}>10 \mathrm{~m})$ & 86.5 & 0.135 \\
Tethya sp. $(30 \mathrm{~m}>10 \mathrm{~m})$ & 73.7 & 0.263 \\
Latrunculia fiordensis $(30 \mathrm{~m}>10 \mathrm{~m})$ & 48.6 & 0.514 \\
\hline
\end{tabular}

Table 15. Pairwise tests estimating differences in standard ellipse area $\left(\mathrm{SEA}_{\mathrm{C}}\right)$ between the Inner Fiord and the Outer Fiord for four sponge species.

\begin{tabular}{lcc}
\hline Groups & $\begin{array}{l}\text { Probability } \\
(\%)\end{array}$ & Significance \\
\hline Raspailia topsenti (Inner site < Outer site) & 86.8 & 0.132 \\
Cymbastela tricalyciformis (Inner site < Outer site) & 84.6 & 0.154 \\
Axinella cf. richardsoni (Inner site < Outer site) & 99.0 & 0.010 \\
Tethya sp. (Inner site < Outer site) & 29.6 & 0.704 \\
\hline
\end{tabular}

Table 16. PERMANOVA results for carbon sources collected from Doubtful Sound, Fiordland.

\begin{tabular}{lllllll}
\hline Factor & df & SS & MS & Pseudo-F & P(perm) & Unique perms \\
\hline Source & 5 & 2643 & 528.6 & 226.06 & 0.0001 & 9941 \\
Res & 68 & 159.01 & 2.3383 & & & \\
Total & 73 & 2802 & & & & \\
\hline PERMDISP on group factor 'Source', F: 0.27463 df1: 5 df2: 68, P(perm): 0.9387.
\end{tabular}


Table 17. PERMANOVA pairwise comparisons of carbon sources collected from Doubtful Sound, Fiordland.

\begin{tabular}{lccc}
\hline Groups & $\mathrm{t}$ & $\mathrm{P}(\mathrm{perm})$ & Unique perms \\
\hline Codium sp., Ecklonia radiata & 1.9903 & 0.0435 & 9415 \\
Codium sp., TOM & 17.098 & 0.0001 & 9374 \\
Codium sp., Ulva sp. & 7.4667 & 0.0001 & 9440 \\
Codium sp., Picoplankton & 14.922 & 0.0001 & 9893 \\
Codium sp., 2-200 & 7.2113 & 0.0001 & 9928 \\
Ecklonia radiata, TOM & 19.305 & 0.0001 & 9378 \\
Ecklonia radiata, Ulva sp. & 7.7994 & 0.0001 & 9411 \\
Ecklonia radiata, Picoplankton & 16.309 & 0.0001 & 9889 \\
Ecklonia radiata, 2-200 & 8.0693 & 0.0001 & 9936 \\
TOM, Ulva sp. & 20.766 & 0.0001 & 9363 \\
TOM, Picoplankton & 12.805 & 0.0001 & 9910 \\
TOM, 2-200 & 19.834 & 0.0001 & 9926 \\
Ulva sp., Picoplankton & 22.432 & 0.0001 & 9884 \\
Ulva sp., 2-200 & 16.665 & 0.0001 & 9918 \\
Picoplankton, 2-200 & 12.204 & 0.0001 & 9932 \\
\hline
\end{tabular}

Table 18. Input parameters for dual isotope mixing models to estimate the proportional contribution of TOM, picoplankton, the 2-200 fraction of the water column and macroalgal carbon to sponge diets at two sites in Doubtful Sound, Fiordland.

\begin{tabular}{llllll}
\hline Site & & $\begin{array}{l}\text { TOM } \\
\text { Mean } \pm \text { SD }\end{array}$ & $\begin{array}{l}\text { Picoplankton } \\
\text { Mean } \pm \text { SD }\end{array}$ & $\begin{array}{l}\text { 2-200 } \\
\text { Mean } \pm \text { SD }\end{array}$ & $\begin{array}{l}\text { Macroalgae } \\
\text { Mean } \pm \text { SD }\end{array}$ \\
\hline \multirow{2}{*}{ Inner } & $\delta^{13} \mathrm{C}$ & $-30.15 \pm 1.21$ & $-30.72 \pm 1.34$ & $-25.35 \pm 1.22$ & $-16.4 \pm 0.91$ \\
& $\delta^{15} \mathrm{~N}$ & $-2.77 \pm 0.12$ & $5.57 \pm 1.53$ & $7.12 \pm 0.7$ & $2.93 \pm 1.26$ \\
Outer & $\delta^{13} \mathrm{C}$ & $-30.15 \pm 1.21$ & $-30.68 \pm 0.65$ & $-24.10 \pm 0.22$ & $-20.62 \pm 1.36$ \\
& $\delta^{15} \mathrm{~N}$ & $-2.77 \pm 0.12$ & $5.83 \pm 1.09$ & $7.01 \pm 0.95$ & $6.04 \pm 0.94$ \\
\hline
\end{tabular}

Table 19. Percentage estimates of carbon source contributions (TOM, picoplankton 2-200 and Macroalgal OM) of four sponge species sampled at the Inner Fiord in Doubtful Sound, Fiordland.

\begin{tabular}{|c|c|c|c|c|}
\hline & $\begin{array}{l}\text { TOM } \\
\text { Mean } \pm \text { SD } \\
{[95 \% \mathrm{CI}]}\end{array}$ & $\begin{array}{l}\text { Picoplankton } \\
\text { Mean } \pm \text { SD } \\
{[95 \% \text { CI }]}\end{array}$ & $\begin{array}{l}\mathbf{2 - 2 0 0} \\
\text { Mean } \pm \mathrm{SD} \\
{[95 \% \mathrm{CI}]}\end{array}$ & $\begin{array}{l}\text { Macroalgae } \\
\text { Mean } \pm \mathrm{SD} \\
{[95 \% \mathrm{CI}]}\end{array}$ \\
\hline Raspailia & $2.9 \pm 1.8$ & $7.0 \pm 4.8$ & $70.1 \pm 8.9$ & $20.0 \pm 5.3$ \\
\hline topsenti & {$[0.6-7.5]$} & [1.1-18.7] & {$[48.7-84.4]$} & [9.5-30.8] \\
\hline Cymbastela & $4.6 \pm 2.8$ & $9.9 \pm 7.3$ & $47.7 \pm 12.1$ & $37.8 \pm 10.2$ \\
\hline tricalyciformis & {$[0.9-11.6]$} & [1.4 - 28.7] & {$[19.6-68.4]$} & [14.9-56.4] \\
\hline Axinella & $4.9 \pm 4.3$ & $11.5 \pm 9.2$ & $62.9 \pm 19.9$ & $20.7 \pm 9.6$ \\
\hline richardsoni & {$[0.6-16.4]$} & {$[1.0-34.5]$} & {$[18.4-92.7]$} & {$[0.03-39.6]$} \\
\hline \multirow[t]{2}{*}{ Tethya sp. } & $5.4 \pm 2.7$ & $13.9 \pm 7.4$ & $50.6 \pm 10.4$ & $30.1 \pm 4.8$ \\
\hline & {$[1.2-11.5]$} & {$[2.4-30.6]$} & {$[27.1-68.5]$} & [20.8-39.8] \\
\hline
\end{tabular}


Table 20. Percentage estimates of carbon source contributions (TOM, picoplankton 2-200 and Macroalgal OM) of four sponge species sampled at the Outer Fiord in Doubtful Sound, Fiordland.

\begin{tabular}{lllll}
\hline & TOM & Picoplankton & $\mathbf{2 - 2 0 0}$ & Macroalgae \\
& Mean \pm SD & $\begin{array}{l}\text { Mean } \pm \text { SD } \\
{[95 \% \text { CI }]}\end{array}$ & $\begin{array}{l}\text { Mean } \pm \text { SD } \\
{[95 \% \text { CI] }}\end{array}$ & $\begin{array}{l}\text { Mean } \pm \text { SD } \\
{[95 \% \text { CI] }}\end{array}$ \\
\hline Raspailia & $6.0 \pm 3.5$ & $10.5 \pm 6.7$ & $36.1 \pm 19.1$ & $47.5 \pm 15.8$ \\
topsenti & {$[1.1-14.4]$} & {$[1.6-26.0]$} & {$[4.2-76.2]$} & {$[12.9-74.4]$} \\
Cymbastela & $12.4 \pm 4.3$ & $4.9 \pm 3.1$ & $8.4 \pm 6.0$ & $74.4 \pm 15.8$ \\
tricalyciformis & {$[3.9-21.1]$} & {$[0.8-12.6]$} & {$[1.1-24.2]$} & {$[56.5-86.1]$} \\
Axinella & $2.6 \pm 1.8$ & $5.7 \pm 4.4$ & $62.7 \pm 18.5$ & $29.0 \pm 14.9$ \\
richardsoni & {$[0.5-7.5]$} & {$[0.6-17.8]$} & {$[17.3-91.7]$} & {$[4.1-62.6]$} \\
Tethya sp. & $7.4 \pm 3.1$ & $17.3 \pm 7.5$ & $38.5 \pm 16.7$ & $36.8 \pm 11.8$ \\
& {$[2.0-13.9]$} & {$[4.0-32.0]$} & {$[7.7-72.4]$} & {$[12.6-58.3]$} \\
Latrunculia & $16.2 \pm 3.5$ & $6.6 \pm 3.8$ & $18.6 \pm 8.8$ & $58.7 \pm 7.2$ \\
fiordensis & {$[9.1-22.9]$} & {$[1.3-15.4]$} & {$[3.6-36.7]$} & {$[44.2-72.3]$} \\
\hline
\end{tabular}

